\title{
The politics of European Union health policy-making : an actor-centred institutionalist analysis
}

Citation for published version (APA):

Boessen, A. C. M. (2008). The politics of European Union health policy-making : an actor-centred institutionalist analysis. [Doctoral Thesis, Maastricht University]. Datawyse / Universitaire Pers Maastricht. https://doi.org/10.26481/dis.20081114ab

Document status and date:

Published: 01/01/2008

DOI:

10.26481/dis.20081114ab

Document Version:

Publisher's PDF, also known as Version of record

\section{Please check the document version of this publication:}

- A submitted manuscript is the version of the article upon submission and before peer-review. There can be important differences between the submitted version and the official published version of record.

People interested in the research are advised to contact the author for the final version of the publication, or visit the DOI to the publisher's website.

- The final author version and the galley proof are versions of the publication after peer review.

- The final published version features the final layout of the paper including the volume, issue and page numbers.

Link to publication

\footnotetext{
General rights rights.

- You may freely distribute the URL identifying the publication in the public portal. please follow below link for the End User Agreement:

www.umlib.nl/taverne-license

Take down policy

If you believe that this document breaches copyright please contact us at:

repository@maastrichtuniversity.nl

providing details and we will investigate your claim.
}

Copyright and moral rights for the publications made accessible in the public portal are retained by the authors and/or other copyright owners and it is a condition of accessing publications that users recognise and abide by the legal requirements associated with these

- Users may download and print one copy of any publication from the public portal for the purpose of private study or research.

- You may not further distribute the material or use it for any profit-making activity or commercial gain

If the publication is distributed under the terms of Article $25 \mathrm{fa}$ of the Dutch Copyright Act, indicated by the "Taverne" license above, 


\section{THE POLITICS OF EUROPEAN UNION}

HEALTH POLICY-MAKING

An actor-centred institutionalist analysis 
The politics of European Union health policy-making. An actor-centred institutionalist analysis.

(C) S. Boessen, Maastricht 2008

Universitaire Pers Maastricht

ISBN 978-90-5278-728-2 


\title{
THE POLITICS OF EUROPEAN UNION HEALTH POLICY-MAKING
}

\section{An actor-centred institutionalist analysis}

\author{
Proefschrift ter verkrijging van de graad van doctor \\ aan de Universiteit Maastricht \\ op gezag van de Rector Magnificus, \\ Prof. mr. G.P.M.F. Mols \\ volgens het besluit van het College van Decanen, \\ in het openbaar te verdedigen \\ op vrijdag 14 november 2008 om 12.00 uur \\ door \\ Alexandra Cornelia Martina Boessen
}

geboren op 19 juli 1979

te Weert

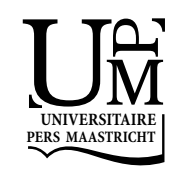




\section{Promotor}

Prof. dr. H. Maarse

\section{Co-promotor}

Dr. E. Versluis

\section{Beoordelingscommissie}

Prof. dr. A.F.A. Korsten (voorzitter)

Prof. dr. M. McKee (London School of Hygiene and Tropical Medicine, UK)

Dr. I. Mur

Dr. C. Neuhold

Prof. dr. B.F. van Waarden (Universiteit Utrecht) 
'From space, we see a small and fragile ball dominated not by human activities and edifice but by a pattern of clouds, oceans, greenery and soils' The World Commission on Environment and Development, 1987 


\section{CONTENTS}

LIST OF ABBREVIATIONS VIII

LIST OF TABLES AND FIGURES $\quad$ X

PART I INTRODUCTION

1 GENERAL INTRODUCTION 2

1.1 Health policy in the European Union 2

1.2 The Single European Market 5

1.3 Research questions 6

1.4 Relevance of the research project $\quad 7$

1.5 Methodology and case selection $\quad 8$

1.6 Outline of the book 15

2 ACTOR-CENTRED INSTITUTIONALISM 16

2.1 Explaining the framework 16

2.2 Operationalising actor-centred institutionalism 21

2.3 Scope of the research 29

PART II TOBACCO CONTROL POLICY-MAKING $\quad 31$

3 POLICY-MAKING ON THE TOBACCO ADVERTISING BAN: OVERCOMING THE DEADLOCK

3.1 Introduction 32

3.2 Explaining the deadlock 33

3.3 Regulating tobacco advertising $\quad 35$

3.4 Actors' behaviour within an institutional setting 44

3.5 Conclusion 47

4 BALANCING BETWEEN MARKET-MAKING AND MARKET-CORRECTING: THE DISCUSSION ON THE LEGAL BASIS $\quad 50$

4.1 Introduction 50

4.2 market-making versus market-correcting interventions 50

4.3 The legal basis: political interpretation $\quad 51$

4.4 The legal basis: juridical interpretation $\quad 58$

4.5 Conclusion 63

5 INTEREST REPRESENTATION ON THE TOBACCO ADVERTISING BAN 66

5.1 Introduction 66

5.2 Institutional structure and interest representation 66

5.3 The European Commission: reciprocal interest representation 68

5.4 Lobbying the Council: the national route 71

5.5 Lobbying the European Parliament: the European route 76

5.6 The European Court of Justice: litigation strategies 79

5.7 Conclusion $\quad 80$ 
6 DATA EXCLUSIVITY: MARKET PROTECTION WITHOUT KNOWN HEALTH BENEFITS 84

6.1 Introduction 84

6.2 Data exclusivity: preferences, proposals and outcomes 86

6.3 The rhetoric of innovation versus the realities of negotiation 91

6.4 Enlargement - "an appalling example of misgovernance"? 98

$\begin{array}{ll}6.5 \text { Conclusion } & 100\end{array}$

7 STRATEGIES OF THE EUROPEAN COMMISSION CONCERNING DIRECT-TOCONSUMER ADVERTISING 103

$\begin{array}{lll}7.1 & \text { Introduction } & 103\end{array}$

$\begin{array}{lll}7.2 & \text { DTCA on the European agenda } & 104\end{array}$

7.3 The pharmaceutical review: legislation on DTCA? 108

7.4 Different routes for discussion: high level groups and consultations 113

7.5 Purposeful opportunism: the Commission's role in EU policy-making 118

PART IV CONCLUSION

8 The POLITICS OF EUROPEAN UNION HEALTH POLICY-MAKING 124

8.1 Health policy-making in the European Union 124

8.2 Using actor-centred institutionalism 131

8.3 The politics of European Union health policies: the likelihood of agreement 132

8.4 Epilogue: What role for Europe in health? 146

APPENDICES

Appendix 1: interviews tobacco advertising April 2005 - March 2006

Appendix 2: interviews on pharmaceutical review October 2006 - March 2007

BIBLIOGRAPHY 150

$\begin{array}{ll}\text { Dutch summary } & 169\end{array}$

Acknowledgements $\quad 179$

$\begin{array}{ll}\text { Curriculum Vitae } & 180\end{array}$ 


\section{LIST OF ABBREVIATIONS}

ABPI Association of the British Pharmaceutical Industry

ACI actor-centred institutionalism

AESGP Association of the European Self-Medication Industry

AIM Association International de Mutualité

BASP European Bureau for Action on Smoking Prevention

CECCM Confederation of European Community Cigarette Manufacturers

Coreper Committee of Permanent Representatives

DE Data exclusivity

DG Directorate-General

DTCA Direct-to-consumer advertising

DTCI Direct-to-consumer information

EAC Europe Against Cancer

EATG European AIDS Treatment Group

ECAS European Citizen Action Service

ECJ European Court of Justice

ECL Association of European Cancer Leagues

ECSC European Coal and Steel Community

EEC European Economic Community

EFPIA European Federation of Pharmaceutical Industry's and Associations

EGA European Generic medicines Association

ELDR European Liberal, Democrat and Reform Party

EMEA European Agency for the Evaluation of Medicinal Products

ENSP European Network for Smoking Prevention

ENVI Committee on Environment, Public Health and Consumer Protection

Committee on Environment, Public Health and Food Safety

ENYPAT European Network on Young People and Tobacco

EP European Parliament

EPHA European Public Health Alliance

EPP European People's Party

EU European Union

EURATOM European Atomic Energy Community

FDA Food and Drug Administration

FTA Free Trade Agreement

GDP Gross Domestic Product

GUE/NGL European United Left/Nordic Green Left

HAI Health Action International 
ISDB International Society of Drug Bulletins

MEP Member of the European Parliament

MiEF Medicines in Europe Forum

NGO Non-governmental organisation

OTC Over the counter

PSE Party of European Socialists

SANCO Health and Consumer Protection

TABD Trans-Atlantic Business Dialogue

TAD Tobacco advertising directive

TRIPs Trade-related Aspects of Intellectual Property Rights

QMV Qualified Majority Voting

R\&D Research and Development

SEA Single European Act

SEM Single European Market

TEU Treaty on European Union

UK United Kingdom

UPE Union for Europe Group

US United States 


\section{LIST OF TABLES AND FIGURES}

TABLE 1.1 DIVERSITY OF CASES 10

TABLE 1.2 OVERVIEW TYPE OF INTERVIEWS

Figure 2.1 ACTOR-CENTRED INSTITUTIONALISM 16

TABLe 2.1 Number Of VOtES IN THE EU-15/EU-27 22

TABLE 2.2 InSTITUTIONS AND (POSSIBLE) VETO POINTS 26

TABLE 3.1 DeVelopment OF THE DiRECTIVE 98/43/EC 43

TABLE 5.1 OVERVIEW OF THE INSTITUTIONS IN RELATION TO INTEREST GROUPS' MAIN POINTS OF ACCESS

TABLE 6.1 DEVELOPMENT OF DATA EXCLUSIVITY: DIFFERENT PROPOSALS AT DIFFERENT STAGES 90

TABLE 7.1 OVERVIEW OF THE MAIN EVENTS CONCERNING DTCA 118

TABLE 8.1 DiVERSITY OF CASES

FIgURE 8.1 The POLITICAL PRAGMATIC USE OF SUBSIDIARITY CLAIMS

TABLE 8.2 OVERVIEW OF THE MAIN FINDINGS 145 


\section{PART I INTRODUCTION}




\section{GENERAL INTRODUCTION}

\subsection{HEALTH POLICY IN THE EUROPEAN UNION}

Health policy is an important instrument for shaping societies in European democracies. Citizens expect their governments to protect them against illness and disease. Thus far, the European Union ${ }^{1}(\mathrm{EU})$ has had only limited competences in the area of health. This reflects the importance member states place on the right to maintain sole competences in a policy area that is ideologically burdened and characterised by very diverse national systems that devote an $8-11 \%$ share of their gross domestic product (GDP) to healthcare expenditures (OECD, 2007). Consequently, health policy is considered a very salient issue in European societies today.

Although the EU traditionally focused on economic tasks (Greer, 2006), this did not mean that health concerns were of no interest. Under the 1951 Paris Treaty establishing the European Coal and Steel Community (ECSC), Europe was expected to promote the health and safety of workers within the coal and steel industry (article 3e).

The 1957 Treaties of Rome established the European Economic Community (EEC) and the European Atomic Energy Community (EURATOM). Member states were called upon to 'establish uniform safety standards to protect the health of workers and of the general public' (article 2b of the EURATOM). The objectives of the EEC were to promote throughout the Community, a harmonious development of economic activities, a continuous and balanced expansion, an increase in stability, an accelerated raising of the standard of living and closer relations between states belonging to it (article 2). These objectives indicated that the single market would be served by an additional commitment to social concerns. However, health policy was not mentioned as a separate area within this social agenda. The EEC included the aims of article $3 \mathrm{e}$ of the Paris Treaty, which resulted in a chapter on work health and safety. Article 118 gave the Commission the task of promoting 'close co-operation between member states in the social field'.

This state of affairs lasted until the Single European Act (SEA) of 1986 was instituted, which emphasised the importance of closer co-operation between the member states in social affairs, but only within the context of the single market. Potential public health problems caused by internal market laws were addressed by article 36 (now article 30) and article $100 \mathrm{a}(3)$ (now article 95(3)). Article 36 stated that the Treaty 'shall not preclude prohibitions or restrictions on imports, exports or goods justified on grounds of $(. .$.$) the$ protection of health and life of humans'. These measures do not constitute any

\footnotetext{
${ }^{1}$ Although the term European Union did not legally exist before the entering into force of the Treaty on European Union in 1993, the term will be used when referring to earlier periods for reasons of consistency.
} 
discrimination or restriction on trade. Article $100 \mathrm{a}(3)$ stated that the achievement of a high level of health should be considered when adopting measures 'which have as their object the establishment and functioning of the internal market'.

With support from the European Council, several programmes to protect and promote health were launched. In 1986, the 'Europe Against Cancer' (EAC) programme was developed, followed by an initiative dealing with drug abuse in 1989, and the 'Europe Against AIDS' programme in 1991. For the first time, in 1993 the Treaty on European Union (TEU) explicitly recognised a role for the EU in health. Article 3(o) (now article 3(p)) stated that the EU should 'contribute to the attainment of a high level of health protection'. The so-called public health article, article 129, mentioned that health protection should form a constituent part of other policies and gave the EU the mandate to encourage cooperation between member states and, if necessary, lend support to their actions. A high level of human health protection was to be achieved by actions 'directed towards the prevention of diseases, in particular the major health scourges, by promoting research into their causes and their transmission, as well as health information and education' (article 129(1)).

The insertion of article 129 into the Treaty established a flanking health policy (Hervey, 2002: 26). Although the protection and promotion of health was declared a prime goal of the EU and its policies, the repertory of policy instruments available to achieve this goal consisted of predominantly soft, non-binding legal instruments such as financial support and recommendations (Randall, 2000). The harmonisation of member states' legislation was explicitly excluded (see article 129(4)). Article 129 can be viewed as a compromise between those member states that did not want the EU to have any mandate in health by setting limits on the expansion of Community activities in this field, and those that wanted to go further and considered the Treaty wording as a mere formalisation for what was already taking place (Hervey, 2001a: 1423).

The Treaty of Amsterdam, renumbering article 129 as article 152, enhanced the integration element. The EU now had to ensure a high level of human health protection 'in the definition and implementation of all EC policies and activities' (article 152(1)). This implied that public health interests should be taken into account when formulating other, competing policies. At the same time, however, it was reiterated in article 152(5) that 'action in the field of health should fully respect the responsibility of the member states for the organisation and delivery of health services and medical care'.

The latest Treaty revisions resulted in the 2007 Reform Treaty following the failed ratification of the Constitutional Treaty. This is still a draft version that is expected to be ratified in June 2009 at the latest. There are some proposed additional provisions with regard to article 152: The global threat of diseases, such as SARS and the Avian flu, resulted in provisions for 'monitoring, early warning of and combating serious cross- 
border threats to health' (amended 152(1)). Furthermore, the EU may adopt 'measures setting high standards of quality and safety for medicinal products and devices for medical use' (amended article 152(4c)), as well as 'measures which have as their direct objective the protection of public health regarding tobacco and the abuse of alcohol, excluding any harmonisation of the laws and regulations of the member states' (amended article 152(5)). This is the first time tobacco and alcohol abuse are mentioned in any of the treaties. What is also remarkable, is the notion that the EU 'shall encourage cooperation between member states to improve complementarity of their health services in cross-border areas' (amended 152(2)). This can be seen in light of the recent rulings of the European Court of Justice (ECJ) on cross-border care (i.e. Molenaar (C-160/96), Kohll (C-158/96), Decker (C120-95), Geraets-Smits and Peerboom (C157/99), Müller-Fauré and Van Riet (C385/99)).

In sum, the scope of measures under article 129, as well as under article 152, remain restricted to incentive measures ${ }^{2}$ and recommendations. Thus, broad competences of the $\mathrm{EU}$ in the field of health are lacking. Member states limit possible action on issues in public and occupational health and provide the EU with weak tools to intervene (Greer, 2006). They want to preserve their sovereignty over health policies, since healthcare systems are embedded systems that are influenced by the structure and culture of the societies of which they are part (Ham, 2001). In particular, they reflect important values of the home country, such as the right to care, solidarity and equality (Ferrera, 2005). Therefore, the organisation of healthcare is based on national principles, and traditionally this has been considered to be subject to the subsidiarity principle (Thomson \& Mossialos, 2007), which states that policies should be regulated at the lowest level possible. Thus, the EU can only undertake policy activities if they have a clear added value to the existing policies of the member states.

However, this is only part of the story. In order to understand the development of European health policy, it is necessary to look beyond the notions of EU health competences as defined by the Treaty. In fact, it is the completion of the single market that allows for regulations that have an important impact on national healthcare systems. Lamping (2005: 21) is certainly correct when he says that 'health policy is a challenging example of how to make a formal non-topic one of the Union's major future policy fields - despite the Treaty'.

\footnotetext{
${ }^{2}$ It should be said that under article 152 two additional areas to adopt measures, including regulations or directives, have been added. It is possible to adopt 'measures setting high standards of quality and safety of organs and substances of human origin, blood and blood derivatives' and 'measures in the veterinary and phytosanitary fields which have as their direct objective the protection of public health'. In the Reform Treaty 'measures setting high standards of quality and safety for medicinal products and devices for medical use' and 'measures concerning monitoring, early warning of and combating serious cross-border threat to health' have been added.
} 


\subsection{THE SINGLE EUROPEAN MARKET}

Most policies should 'be understood as an intersection between health policy and other policy fields in which the EU has genuine competence' (Steffen \& Lamping, 2005a: 194). Healthcare involves people, both health care workers and patients, it involves goods, such as pharmaceuticals that have always been traded internationally, and it also involves the provision of services (McKee, Mossialos, \& Baeten, 2002). The free movement principles have resulted in a steady expansion of Community legislation and have been the driving force behind EU health policy developments, affecting several 'boundary aspects' of healthcare systems (Ferrera, 2005: 128).

'Given the cross-cutting nature of health issues and policy, it stands to reason that national governments fear the peril of too much competency being shifted to the supranational level, and of spillovers into related domestic policy fields' (Steffen \& Lamping, 2005b: 10). This is certainly true for case law judgements handed down by the ECJ. Member states were not prepared for these rulings. Take for instance the Working Time Directive, which set a maximum of 48 working hours a week, arguing that the completion of the internal market should also lead to improvements in working conditions. The ECJ defined time spent asleep while on call as working time, which had a major impact on the health service sectors. Another example is the issue of patient mobility. Rulings of the ECJ over the last decade have made it clear that free movement principles also apply to the field of health, unless there is clear evidence that these principles undermine the financing and infrastructure of healthcare in the member states (e.g. Kanavos \& McKee, 2000; Martinsen Sindbjerg, 2005; Van der Mei, 2003).

Thus, internal market legislation spilled over into case law, influencing national healthcare policies. However, the observation that health policy is ECJ-driven (Leibfried $\&$ Pierson, 2000) is only part of the picture. The role of the Commission as a policy entrepreneur (Cram, 1997; Héritier, 1999) should not be ignored. Despite the absence of substantial competences, health has emerged as a European policy field through many creative avenues (Greer, 2006: 135; Steffen, Lamping, \& Lehto, 2005: 10). Even though the member states provided the EU with narrow public health competences, explicitly excluding harmonisation of their laws, and establishing the subsidiarity principle for health services and medical care, it does have numerous responsibilities relevant to health. Separating European economic integration from national solidarity and welfare has ceased to be viable. 'The time of the patries de fraternite' (that is of self-contained islands of national social sovereignty) is long gone and cannot be resurrected' (Ferrera, 2005: 252). Doubts about the very existence of a European health policy, contrast with empirical findings demonstrating the influence exerted by the EU. It is the paradox of EU health policymaking and the role of different actors in this process, including member states opposing EU-level health regulation, that form the core of our study. 


\subsection{RESEARCH QUESTIONS}

A crucial element of health policy-making in the EU, is the balance between public health and healthcare on the one hand, and industrial policy on the other. Whereas the Treaties provided the EU with competences over trade, competition and competitiveness, healthcare policy is a relatively exclusive competence of the member states. In other words, a constitutional asymmetry (see Scharpf 2002a) exists 'between EU policies to promote market efficiency and those to promote social protection' (Permanand \& Mossialos, 2006: 689). Because health is directly related to individuals' feelings of wellbeing and security, health regulation raises complex economic and ethical issues. It is deeply embedded in, and restrained by, European and national politics, and diverse views on the appropriateness of regulatory policy, which are in part based on the nations' 'cultural heritage' (Payer, 1988). It is because of this that member states refer to the principle of subsidiarity when health interests are concerned.

The definition and priority of health interests should be placed in the context of competing policy interests. Interests can be classified in various ways. They may be seen as either national or supranational, or divided between health and other interests. Other interests (e.g. economic interests) may support, or conflict with health interests. From this perspective, policy-making may be conceptualised as the process of weighing and choosing between differing interests. In fact, policies are the result of an interactive process between many actors, all having their own - often conflicting - interests and strategies. In order to properly understand the process of EU health policy-making, it is vital to understand its dynamics.

This study concentrates on the accommodations reached between conflicting - health and other - interests of actors involved in health policy-making and conflict resolution. The overarching research question at stake is the following:

What factors influence the likelihood of agreement on EU health policy given diverging preferences, member states' claim of subsidiarity and the existence of constitutional asymmetry?

This research aims to explain health policy-making issues in light of the EU's limited competences and member states' repeated claim of subsidiarity. The focus of this study is on actors' preferences and their strategic behaviour in the policy-making process on health-related issues. Following Buse, Mays and Walt (2005: 6-7), 'health policy is synonymous with politics and deals explicitly with who influences policy-making, how they exercise that influence, and under what conditions'. The heuristic framework of actor-centred institutionalism (ACI) (Mayntz \& Scharpf, 1995: 39) (to be further elaborated upon in the next chapter), offers a conceptualisation of the role of institutions 
in public policy-making. Institutions establish different 'informal and formal rules' for politicians and interest groups seeking to enact or block policies. These rules have bearing on political struggles, affecting how much influence different actors exert by increasing or decreasing their role in the policy-making process. From this perspective, institutions are important because they intermediate between societal pressures and policy decisions, affecting the level of conflict (O'Reilly, 2005), and therefore the potential for policy change. Following this perspective, the possibility of reaching agreement, given the diverging interests in this policy domain, will be analysed using the following, more specific research questions:

- How does political decision-making on health issues take place?

- Who are the important actors in the policy-making process? What are their preferences?

- How does the institutional structure influence the strategies of actors in policy-making on health issues?

- What is the role of interest representation in policy-making on health issues?

- How do health and other interests interact in policy-making on health issues?

Three case-studies on the tobacco advertising ban, data exclusivity and direct-toconsumer advertising (DTCA) on prescription medicines should provide insight into the political game of policy-making in the field of health in order to determine what strategies actors use to come to agreements on issues where actors' preferences conflict.

\subsection{RELEVANCE OF THE RESEARCH PROJECT}

As stated, a cursory examination of the issue suggests that the EU has only limited impact on health. Although the Treaties state that the protection and promotion of health is a prime goal of the EU and its policies, the repertory of policy instruments that the EU can use to achieve this ambitious goal consist mainly of 'soft' instruments. Community action in the field of public health should fully respect the individual responsibilities of the member states. Any harmonisation of the laws and regulations on public health in the member states is explicitly excluded.

However, upon closer inspection it is apparent that the impact of the EU upon health matters is increasing (Leibfried \& Pierson, 2000), and in some areas, already substantial (Mossialos \& McKee, 2002; Steffen \& Lamping, 2005a). For instance, over the last three decades, the EU has issued a number of regulations and directives to facilitate crossborder care (Wismar \& Busse, 2002). Rulings of the ECJ underscore that health and 
healthcare are not exempt from the regulations on the free movement of persons, goods, services and capital. Restrictions on free movement are only warranted under specific conditions (Busse, Wismar, \& Berman, 2002). Furthermore, the EU launched several programs to protect and promote health (e.g. cancer, AIDS, smoking, orphan drugs, obesity). There is also a growing belief that many public health problems can only be effectively addressed by an EU-wide policy strategy (Belcher, 1999; Fischer, 1999). Finally, one should not ignore that other EU policies may have repercussions on health (e.g. agricultural policy).

The impact of EU policy-making upon health has emerged as a growing field of scientific research (Busse, Wismar, \& Berman, 2002; McKee, Mossialos, \& Baeten, 2002). Important research topics include: health and safety at work; free movement of patients and health professionals; pharmaceuticals and medical devices; the promotion of market competition in healthcare; voluntary health insurance; the internal market and the social nature of healthcare. The main purpose of most studies is to describe developments and trends in EU policy-making on health and to explore consequences for health. Many studies focus upon the content of EU regulatory programmes and seek to unravel their implications for, among others, healthcare providers and health insurers, national policymaking upon health, the pharmaceutical industry and cross-border care. However, only limited attention has been focused on the process of policy-making on health issues in an EU context. Moreover, health policy is a challenging field in which to study the tensions between economic and health interests (Mossialos \& McKee, 2002; Permanand, 2006a; Permanand \& Altenstetter, 2004; Permanand \& Mossialos, 2005; Steffen \& Lamping, 2005a; Steffen, Lamping, \& Lehto, 2005).

This study helps fill the gap that currently exists in health policy research by focusing on the policy-making process itself. Three case studies will be examined to obtain detailed insight into the interplay between different interests, and following this, there is an examination of the strategic behaviour of actors as they find agreement on policy issues touching upon health. This study is complementary to the studies listed above, and can yield important information on the factors that encourage or hinder the adoption of measures impacting upon health.

\subsection{METHODOLOGY AND CASE SELECTION}

Even though EU health policy-making is not self-evident, it has become a relevant policy field in the EU. Due to this paradox, our approach is explorative and inductive by nature.

\subsubsection{Research strategy: the case study}

Given our desire 'to understand complex social phenomena' (Yin, 2003: 2), we use the case study as a research strategy. A case study is not a methodological choice, but a choice 
of what is to be studied and features a diversity of methods to generate data. The case study strategy is preferred in situations where 'how' and 'why' questions are being posed when the researcher has no control over events because of the real-life context.

The concept of external validity (capacity for generalisation) is highly contested with regard to qualitative research. One of the criticisms of qualitative research is that it is piecemeal and therefore unrepresentative. However, Yin (2003) claims that it is important to make a distinction between statistical and analytical generalisation: 'case studies are generalisable to theoretical propositions and not to populations or universes' (Yin, 2003: 10). It is therefore meaningful to note, that case studies have an important function in building theory and generating hypotheses. The case study strategy is ideally suited to indepth exploration of issues (Hartley, 2004).

Another problem often attributed to qualitative research is replication and lack of external validity due to the fact that the researcher's interpretation of material is inevitably subjective. These critics require qualitative researchers to be 'as systematic and rigorous in their methods of empirical investigation as quantitative researchers' (see section 1.5.3 on data collection) (Devine, 2002: 205).

\subsubsection{Case selection: the concept of health policy}

The terms health and health policy can be conceptualised in a number of ways (see Lamping, 2005). In this research, health policy is considered as purposive courses of action that affect the set of institutions, actors, services and funding arrangements of the health system. We adopt a broad notion of health policy, including (access to) medical care, the organisation of the healthcare system, as well as health determinants such as tobacco and alcohol consumption.

In order to be able to study actors' strategic behaviour, the cases have to fulfil several requirements. First of all, they have to be disputed politically. Policy-making processes which do not present a certain level of conflict will most likely not provide enough insight into actors' strategies. Thus, the issues should involve diverging interests. Another prerequisite is that the policy-making processes all have a similar institutional structure, including the main actors. This allows us to concentrate on strategic behaviour. A third aspect concerns the legal basis. As discussed, EU health legislation is often based on other competences. We decided to focus our analysis on issues that are based on internal market legislation for reasons of comparability.

Duncan (2002) distinguishes three types of EU health policy-making: direct, indirect and unintentional. ECJ case law on patient mobility is considered unintentional. ${ }^{3}$ Member

\footnotetext{
3 The term 'unintentional' in this context may be disputed, because it more or less constitutes a contradictio in terminis.
} 
states are confronted with rulings they neither foresaw, nor wished for. Unintentional health policy-making is outside the purview of this study. Aware that the ECJ constitutes an important player in health politics as well, we omitted this type of policy-making, because it has already been analysed in detail elsewhere (Lamping, 2005; Greer, 2006).

Direct health policy-making concerns EU action after a health objective has been identified, either through law-making or soft measures. In the case of indirect health policy-making, the EU pursues an objective other than health, but health considerations play a major role in determining the final outcome. Another distinction is between the competing policy interests. The three case studies in our study have been selected because they represent public health, industry, and healthcare policy respectively (see table 1.1).

\begin{tabular}{|c|c|c|c|}
\hline Issues & $\begin{array}{c}\text { Type of EU health } \\
\text { policy-making }\end{array}$ & $\begin{array}{c}\text { Balance between health and } \\
\text { economic interests }\end{array}$ & Agreement \\
\hline Tobacco advertising & direct & $\begin{array}{c}\text { conflict between health and } \\
\text { economic interests; } \\
\text { public health driving force }\end{array}$ & decision \\
\hline Data exclusivity & indirect & $\begin{array}{c}\text { conflict between different } \\
\text { economic interests; } \\
\text { economics driving force }\end{array}$ & decision \\
\hline DTCA & (in)direct & $\begin{array}{c}\text { conflict between health and } \\
\text { economic interests; } \\
\text { driving force questionable }\end{array}$ & non-decision \\
\hline
\end{tabular}

Table 1.1: diversity of cases

Our first case concerns the tobacco advertising ban (Directive 98/43/EC and Directive $2003 / 33 / \mathrm{EC})$. Although the single market framework was used to make agreement possible, the main goal of a tobacco advertising ban was to improve public health and protect citizens, specifically children, who would more likely be influenced by tobacco advertisements. The tobacco advertising directive is therefore a form of direct health policy-making. The EU identified a health objective and sought to realise it through EUlevel action. A ban on tobacco advertising clashed with industry interests, specifically, the tobacco and advertising industries.

The second case concerns data exclusivity (Directive 2004/27/EC). Data exclusivity is a form of indirect health policy-making. Although regulatory policies concerning pharmaceuticals appear to 'have clear social purposes designed to limit or correct market effects, the rationale for intervening is at least as much an economic one' (Lamping, 2005: 22). The table shows that for data exclusivity, the conflict was not so much between health and economic interests, but between diverging economic interests, namely those of the research-based pharmaceutical industry, versus those of the generics pharmaceutical industry. Even more so, there was hardly any health interest representation concerned with this issue. 
Finally, the third case concerns DTCA, part of the same package proposal as data exclusivity. The Commission proposed allowing pharmaceutical companies to communicate information about medicines for HIV/AIDS, asthma and diabetes directly to the public. Lifting the existing European ban on DTCA would inevitably affect both public health and national healthcare budgets. In most European countries the amount spent on total healthcare as a percentage of GDP has been rising. Medicines, on average, account for $12-25 \%$ of health expenditures in West and East European countries (OECD, 2007), and are consistently targeted by cost control policies. Governments are under pressure to provide a business-friendly environment (Abraham, 2002), while at the same time, they have to manage their healthcare systems and give priority to health needs. DTCA is a policy issue 'at the crossroads of those competing pressures' (Mansfield et al., 2005: 6). Both the EP and the Council disagreed and cancelled the proposal, although they proposed a re-evaluation of the option to allow direct-to-consumer information (DTCI) in the future. Currently, the Commission discusses the issue of patient information in the Pharmaceutical Forum. The analytical distinction between direct and indirect health policy-making proves to be more difficult in this case. Whereas improving patient access to information should, in fact, be based on health objectives, as is the perspective of the member states and the EP (thus direct health policy-making), the Commission aimed at increasing competitiveness of the European pharmaceutical industry vis-à-vis US industry by providing it with the opportunity for DTCA (thus indirect health policy-making).

The selected policy-making processes do not directly influence the territoriality principle of healthcare systems (Ferrera, 2005). However, central to all cases is the European leaders' conundrum of 'how to reconcile the aspirations for good health services, accessible to all their citizens, with (...) economic policies that are attractive across all the electoral constituencies they must aim to satisfy' (Randall, 2000).

Restricting our analysis to three cases allows for a very detailed study. It enables a thorough insight into actors' strategic behaviour. However, it also implies that additional cases would complete the picture and enrich our understanding of EU health policymaking. One may perceive the selection of our cases as a shortcoming in that they all concentrate on binding legislation, whereas soft measures are very common with regard to EU health policy. No claim is made here that our case studies capture all types of EU policy-making. Instead, our results raise questions about the preferences of stakeholders, institutional influence and how, despite conflicting interests, policies are agreed upon. We maintain that this is not as useful in the case of soft law, since the direct impact of soft law is not comparable to regulatory policies. 


\subsubsection{Data collection}

The case study strategy often results in the collection of a huge amount of data. There are several sources of information that can be used for case studies: documents, archival records, interviews, direct and participant observation and physical artefacts. In order to increase construct validity, the use of multiple sources of evidence is essential. In fact, this aspect is one of the key characteristics of a case study.

In our research, data from both primary and secondary sources were analysed. Our data collection began with a literature review on EU policy-making in general, as well as policy-related studies to construct a generalised view of policy-making in the field of tobacco control and pharmaceuticals. We analysed EU documents such as Commission communications, speeches, minutes of the plenary meetings of the EP, questions by members of the EP to the Commission and the Council, and minutes of Council working group meetings. All documents were available via the internet, except for the Council working group minutes and several documents from the early 1990s concerning tobacco advertising that were provided through direct contact. Together with documents from the press agency 'Agence Europe', and position papers of interested parties and press releases, we were able to reconstruct the policy-making process.

For the case study on tobacco advertising, tobacco industry documents were available on the internet as a result of the 1998 Master Settlement Agreement between 46 United States (US) attorneys general and the industry. Furthermore, we gained access to the archives of the European Bureau for Action on Smoking Prevention, the Association of European Cancer Leagues and the Dutch Health Ministry through direct contacts. For the case study on data exclusivity and patient information, Scrip (the main international trade press of the pharmaceutical industry), La Revue Prescrire and the Prescrire International (publications from Association Mieux Prescrire, which is a not-for-profit organisation of health professionals providing comparative information on therapeutics, drugs and diagnostic tools) were analysed. Again, these documents were made available through direct contacts.

We combined the information collected through document analysis with the information provided by interviews. By using different sources of evidence we tried to confirm and validate (construct validity) our results. This triangulation method served mainly 'to clarify meaning by identifying different ways the phenomenon is being seen' (Stake, 1995: 97). We therefore conducted focused interviews with representatives of the key actors.

One of the issues related to representation and reliability is the sample of interviewees. Given that it is a time intensive method, a relatively small group of people were interviewed. In our case, documents provided the names of actors to contact. Then we used snowball sampling, requesting interviewees to name potential informants. One of 
the possible limitations of this method is that the selection of interviewees remains restricted to one network of interconnected people. We tried to avoid this by approaching people from several different networks. However, successful interviews depend upon people's willingness to talk. One problem in this context is limited access to the ‘seemingly secretive world of high level politics' (Devine, 2002: 200).

Unfortunately, access to some networks was limited. For instance, access to industry, both the tobacco and the pharmaceutical industry, turned out to be problematic. Between April 2005, and March 2006, we conducted in-depth interviews for the tobacco policy case. The fact that Directive 2003/33/EC was at that moment pending before the ECJ, proved a complicating factor. Several people gave this reason as justification for declining an interview. In the case of the tobacco industry, information from the industry archives fully compensated for the lack of interviews. Actually, these documents most likely provided a more accurate point of view than the information the interviews would have given us.

The interviews for the pharmaceutical policy cases were conducted from June 2006 to March 2007. Finding actors from the pharmaceutical industry willing to be interviewed also proved problematical. After several requests, the European Generic medicines Association finally granted an interview. However, the European Federation of Pharmaceutical Industries and Associations never responded to our requests, either by email or telephone.

\begin{tabular}{|c|c|c|c|c|c|}
\hline Interviews & $\begin{array}{c}\text { Member state } \\
\text { representatives }\end{array}$ & $\begin{array}{c}\text { Commission } \\
\text { and EP }\end{array}$ & $\begin{array}{c}\text { Public } \\
\text { health } \\
\text { lobbyists }\end{array}$ & $\begin{array}{c}\text { Industry } \\
\text { lobbyists }\end{array}$ & Consultant \\
\hline $\begin{array}{c}\text { Tobacco } \\
\text { advertising }\end{array}$ & 5 & 2 & 2 & - & - \\
\hline $\begin{array}{c}\text { Pharmaceutical } \\
\text { review }\end{array}$ & 6 & 3 & 4 & 1 & 2 \\
\hline
\end{tabular}

Table 1.2: overview type of interviews

We recorded and transcribed all the interviews $(n=9$ for the tobacco advertising process, all face-to-face interviews; $n=16$ for the pharmaceutical policy cases, 10 face-to-face interviews; 5 telephone interviews; and one written interview. For an overview, see appendix 1 and 2). We began each interview with a very general question: 'What was your role in the negotiating process concerning...?' This allowed the interviewees to give an open answer before specific questions related to strategic behaviour were asked. The function of the interviews in our research was to increase our insight into differing viewpoints, interpretations and perceptions of policy-making. Given the possible problems of bias, poor recall, and poor or inaccurate articulation (Yin, 2003: 92), the interviews were used to corroborate information from other sources. 
Subjective interpretation by the researcher cannot be ignored and therefore should be acknowledged in the process of collecting, analysing and interpreting data. This, however, does not mean that interpretation should simply be taken for granted. There are several ways to deal with interpretation bias. One way is to discuss the interpretation of interview material with other researchers as well as with interviewees (Hartley, 2004: 330). We sent our process description to all interviewees, asking them to comment both on their statements in the text, as well as on the analysis. However, due to time constraints experienced by most interviewees, this resulted in only a small number of (positive) responses.

\subsubsection{Methodological considerations and limitations to the study}

It is beyond the scope of this study to delineate all the actors involved in European policy-making in the field of health, assessing all their preferences and strategies on the outcome of the process. Here, institutions narrow the range of strategies, because they limit potential behaviours by 'specifying required, prohibited or permitted actions' (Scharpf, 1997: 39). Therefore, ACI provides 'a halfway position between a theoretical system that substitutes universal and standardised assumptions for empirical information on the one hand and purely descriptive studies of individual cases on the other hand' (Scharpf, 1997: 41). The decision of which actors and wider policy events are relevant in the context of the policy-making process always includes the risk of omissions. However, interviews with people involved in the policy-making processes should reduce this risk, assuming that they inform the researcher of the most important actors and events. Analysis of implementation of policy decisions falls outside the scope of this research. Furthermore, we concentrated our analysis on EU level policy-making, activities at the member state level are not included.

The core of our study is the role of different actors during policy-making. We have decided not to investigate the concept of influence, as in 'control over policy outcomes', when analysing the role of actors (Dür \& De Bièvre, 2007: 3). It is exceedingly difficult to measure influence with many actors pushing for a specific outcome. Civil servants, public opinion and political parties affect outcomes. Furthermore, the existence of several levels of interest representation regarding this issue, with voice and access strategies at the national and European level, forms a considerable obstacle to measuring influence. Therefore, we concentrated on the strategies actors used during the policy-making process. With regard to interest groups, we focused on the determinants of interest group access to policy-makers. Various factors affected the interest groups' abilities to influence outcomes. The most important factors affecting interest group access encountered in the current literature are institutions, their resources and issue-specific aspects. The latter includes public awareness and the level of technicality (Dür \& De Bièvre, 2007). 


\subsection{OUTLINE OF THE BOOK}

In this thesis we concentrate on the question of how agreement on EU health policies can be explained given the diverging preferences, member states' claim of subsidiarity and the existing constitutional asymmetry in this policy domain. We focus our research efforts on the actors, preferences, strategies and institutions that are fundamental to actor-centred institutionalism. Chapter 2 provides an explanation and operationalisation of this framework in our study.

The second part of this book consists of the empirical case study chapters on tobacco advertising. Chapter 3 describes the struggle surrounding the adoption of a tobacco advertising ban. Chapter 4 is an analysis of the discussion of one specific institution. The problem of the lack of a correct legal basis for the tobacco advertising proposal resulted in a 'framing' strategy in terms of market-making versus market-correction. Chapter 5 is an analysis of the role of interest groups in the policy-making process on tobacco advertising, focusing on the impact of the institutional structure on interest group behaviour.

The third part of this book consists of the empirical case studies on pharmaceutical policies. Chapter 6 presents the analysis of the policy-making process on data exclusivity. Here, the roles of both policy actors and the pharmaceutical industry are studied. The almost complete lack of health interest representation is assessed as well. Even though data exclusivity impacts upon healthcare budgets in European countries as well as at the global level, health interests did not seem to play a major role. Although health arguments were used to oppose lengthening data exclusivity, the major conflict was between different economic interests, namely generics and research-based pharmaceutical industries. In chapter 7 we examine the process concerning DTCA for prescription medicines. We concentrate the analysis on the role of the European Commission that strategically framed DTCA in terms of patient information once the topic was on the agenda. The legislative proposal for a pilot study that proposed to lift the ban on DTCA for three specific diseases was rejected by the EP and the Council. However, the Commission shifted the discussion to non-legislative routes, where it is still ongoing.

Whereas the cases on pharmaceutical policy-making are each described in one chapter, the case concerning tobacco advertising constitutes three chapters. There are two reasons for this. First, the policy-making process did not end with a decision, but with a judgement from the ECJ, which is considered in more detail in chapter 4. Second, the richness of data, available through tobacco industry documents and the archives of public health organisations, allowed an additional chapter on interest representation.

Finally, chapter 8 represents the fourth part of this study, offering conclusions in view of the case studies described. When comparing the different processes, we concentrated on the question of what factors influence the likelihood of agreement on health policies. 


\section{ACTOR-CENTRED INSTITUTIONALISM}

This chapter outlines the analytical framework used in our public policy analysis. This framework is based on the concept of actor-centred institutionalism (ACI). ACI is a useful tool for understanding the political manoeuvring and underlying dynamics of complex policy debates, assuming that at a certain level of conflict, the strategic capacity of actors depends on the institutional conditions facilitating conflict resolution. After describing the framework of the study, we outline the fundamental formal and informal rules of the game and the principal actors involved in EU policy-making.

\subsection{EXPLAINING THE FRAMEWORK}

Actor-centred institutionalism proceeds from the assumption that social phenomena should be explained as the outcome of interactions among intentional actors. These interactions are structured and their outcomes are shaped by the characteristics of the institutional settings in which they take place (Scharpf, 1997). Thus, actor behaviour is influenced, but not determined, by the institutional structure. The different elements of the framework of ACI will be explained below (see figure 2.1).

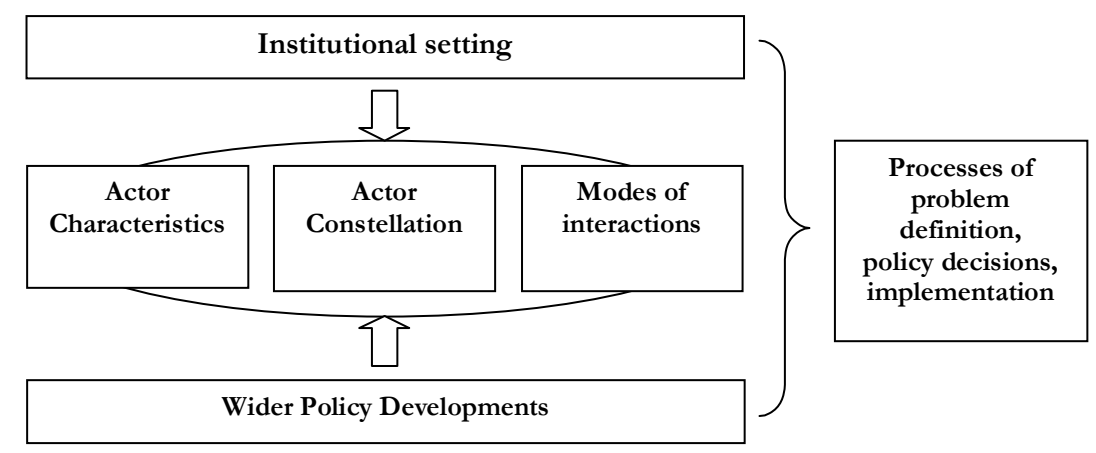

Figure 2.1: Actor-centred institutionalism based on Scharpf (1997: 44).

\subsubsection{Actor characteristics: the concept of bounded rational actors}

According to ACI, three important factors for understanding actor characteristics are actors' orientations, capabilities, and the concept of rationally bounded actors. Policy, by definition, is intentional action by actors who are most interested in achieving specific outcomes. We do not assume that actors will merely follow institutions or cultural norms (Scharpf, 1997: 36). Understanding behaviour as intentional action means that individual actors strive to maximise their individual interests. Preferences are stable, and actors 
posses all the necessary knowledge regarding possible alternatives and their consequences. However, human knowledge is limited and rationality bounded. In reaction to criticisms of the rational model of decision-making, theorists describe it as an idealised condition to which actors strive towards. A broader set of assumptions should be embraced as following a process of 'bounded rationality' (Scott, 2001; Walt, 2000), which implies that human action is not based on cognition of real world data and causal laws, but on culturally shaped and socially constructed beliefs about the real world (Scharpf, 1997: 21). This means that actors do whatever they can to maximise their interests, with a more realistic view concerning issues of complete information and utility maximisation (Scott, 2001: 66; Walt, 2000: 46-49). In this study political choice will be viewed in terms of bounded rationality. This implies a higher degree of complexity, because actor behaviours cannot be deduced from assumptions, but have to be evaluated empirically in situ (Witte, 2006: 67).

Under these constraints, policy research would be impossible if explanations had to be sought at the individual level in every case. In most instances individual self-interest alone would not be a useful predictor of role-related action (Scharpf, 1997: 61). Mayntz and Scharpf $(1995 ; 1997)$ explain why organisations intended for the purpose of policy analysis may be understood as actors. In the final analysis it is certainly true that only individuals are capable of intentional action. However, composite actors, encompassing corporate, aggregate and organisational actors, ${ }^{4}$ are often capable of coordinating the actions of their members through collectively binding decisions for which they may be held collectively responsible. Actors have assigned resources that can be used only under certain circumstances. In the political process, most relevant actors are acting 'in the interest and perspective of larger units rather than for themselves' (Scharpf, 1997: 12), such as families and other groups, and most importantly, organisations of all kinds, including firms, political parties, government ministries and the state. Therefore, a composite actor may be treated as an actor. However, in this study, analysis will occur at the individual level when necessary.

\subsubsection{Actor characteristics: orientations and capabilities}

Actors are characterised by their capabilities and orientations. Orientations refers to the desirable or undesirable nature of the status quo, the causes of a perceived problem, the efficacy and desirability of perceived courses of action, and the outcomes associated with these (Scharpf, 1997: 43). These orientations may be relatively stable, but they may also change in the course of a process through learning or persuasion. Actors' orientations are

\footnotetext{
${ }^{4}$ Composite actors are not the same as actor aggregates. Whereas composite actors involve individuals that intend to create a joint product or to achieve a common goal, actors within actor aggregates act according to their individual preferences. The aggregate effect is a result of individual choices.
} 
shaped by the specific institutional setting in which they interact (Scharpf, 1997). More importantly however, they are treated as being distinct from the institutional setting within which the interactions take place, being influenced, but not determined by the framework (Scharpf, 2000a, 770-771). Preferences and perceptions are the building blocks of actor orientations. Perceptions are the cognitive orientations of an actor, or in other words, their subjective perception of reality (Witte, 2006: 69).

Actor preferences are based upon individual or organisational interests, normative notions and interaction orientations. Organisational interests refers to 'self-interest', such as organisational survival or growth. Interests include the calculated reasoning of actors in relation to particular policy predicaments and to the cost and benefits of the available courses of action (Jupille \& Caporaso, 1999). Norm-related preferences are organisational missions as well as limitations defined by the purpose of an organisation. In this context, Scharpf mentions the concept of identity, refering to 'specific interests and norms that a particular actor chooses on the basis of 'corporate identity' or 'culture' (Witte, 2006: 70). Action within culturally and organisationally defined roles is impossible to explain without reference to the cultural and social definitions of that role, and to the institutionalised rules associated with proper performance (Scharpf, 1997: 21). Finally, interaction orientations refers to relationally defined preferences, meaning the payoffs resulting from certain behaviours vis-à-vis other actors.

The concepts related to orientations are highly complex and sophisticated. Following actors' bounded rationality, we assume that member states cannot fully control the policy agenda since they do not possess complete information regarding the responses of other actors. Therefore, it is not uncommon for actors to change their preferences during the process, stepping back from their initial position (Eising, 2000: 4). For pragmatic reasons, and because analysing all concepts would be beyond the scope of this research, we refer to preferences based on norms and interests that cannot be disentangled in practice. ${ }^{5}$

Whereas orientations are related to actors' policy positions, their capabilities determine the likelihood of realising this position. These capabilities include 'all action resources that allow an actor to influence an outcome in certain respects and to a certain degree' (Scharpf, 1997: 43), such as physical endowments, human and social capital, informational access, technological know-how, and political power as defined by the institutional structure (Schmidt, 2003). These capabilities, together with preferences and perceptions, make certain strategy options possible, and others nonviable.

\footnotetext{
${ }^{5}$ Die begriffliche Dichotomie von Normen (Werten) und Interessen verliert, da sie sich auch nicht umstandslos auf den Gegensatz vor Sollen (exogen) und Wollen (endogen) reduzieren lässt, bei näherer Betrachtung die scharfen Konturen (Mayntz \& Scharpf, 1995: 56).
} 


\subsubsection{Actor constellations and modes of interaction}

In policy-making processes, composite actors are often part of complex actor constellations. ACI tries to develop analytical categories that capture the essence of theoretically relevant aspects of actor constellations encompassing entire sectors. As a result, we cannot limit ourselves to political institutions or actors [such as the Westminster model for parliamentary democracy or German federalism], but must include all relevant actors within the respective societal institutional structures (Mayntz \& Scharpf, 1995: 44). In this manner, ACI stresses the integration of both political and nonpolitical actors in the institutional structure that characterises their behaviour.

The actor constellation represents a static picture of actors' relations, including what we know about the set of actors involved in a particular policy interaction and the degree to which their pay-off aspirations are compatible or not. It describes the possible level of conflict. The mode of interaction specifies how the conflict is going to be resolved and concerns the dynamics of actor interaction (Witte, 2006: 72). The distinction between actor constellations and modes of interaction is an analytical one, in actuality, they are intertwined.

The different modes of interaction in the context of the EU as distinguished by Scharpf (2000a; 2001), demonstrate stylistically the diverging avenues extant in conflict resolution (Witte, 2006: 72). The term 'mode' is used to characterise the rules defining rights of participation, as well as applicable decision rules (Scharpf, 2002b: 3). The modes of mutual adjustment, hierarchical direction, joint-decision and intergovernmental agreement describe 'at a highly abstract level the range of interrelationships likely among constellations of composite actors in institutional settings' (Schmidt, 2003: 324), partly related to the pillar structure of the EU. This structure has its origins in the negotations leading up to the TEU. It was desired to add powers to the Community, including security and defence policy. Following that these issues were too sensitive to national sovereignty, two additional pillars were created. The first pillar concerns European Communities, the second pillar Common Foreign and Security Policy and the third pillar Police and Judicial Cooperation in Criminal Matters.

In the context of the EU, policy-making under the mode of mutual adjustment explains actor interactions in the absence of a structure or institution. There are no obligations towards each other. The only limitations on strategic choice are actors' capabilities and physical limitations. National governments adopt their own policies, but they do so in response to, or anticipation of, policy development in other member states (Scharpf, 2001). Here, lesson-drawing, which allows the transfer of policy ideas to other places (Rose, 1991), is important. For example, to reduce growing healthcare costs, many European countries adopt cost-control policies with regard to generics and pharmaceutical pricing (Mossialos, 1998). Kümpers et al., (2002) show that, in the field of 
integrated care, the institutional and cultural characteristics of a country should be taken into consideration when determining to what extent a policy from abroad can be transferred. However, this transference is also dependent on whether member states interact while being aware of their mutual interdependence, or whether they interact in a 'compulsory negotiation system' (Scharpf, 2006: 846). There are three distinct modes of European governance: intergovernmental, joint-decision, and supranational-hierarchical.

In the intergovernmental mode, institutional conditions assure the binding force of a negotiated agreement. This agreement will only be achieved by rational actors who would not otherwise agree unless the expected outcome of the negotiations is more attractive than no agreement. This claim cannot be made for any of the other modes of interaction. The intergovernmental mode characterises Treaty revisions and policies within the second and third pillar, or those in the first pillar still requiring unanimity. Conflicts of interest strictly limit the problem-solving capacity to measures that are preferred by all governments (Scharpf, 2000b, 2002).

In the supranational-hierarchical mode, competences are centralised at supranational level without the participation of national governments and the European Parliament (EP). Policies within this mode are based on decisions made by the European Court of Justice (ECJ), or the European Commission according to the neo-liberal 'spirit' of competition law. The supranational functions of these actors 'have been most effective in policy areas where economic integration could be advanced by applying fairly explicit prohibitions in the treaties against national policies constituting barriers to the free mobility of goods, services, capital, persons or distortions of free competition' (Scharpf, 2001: 10). As explained above, hierarchical direction resulted in unexpected rulings from the ECJ, which had a direct impact upon national healthcare systems.

The mode of joint-decision combines aspects of intergovernmental negotiations and supranational centralisation. In the EU, this mode applies to most policy areas within the first pillar. Under this mode, the Commission draws up the proposal and a decision has to be made by member states in the Council and, in the case of co-decision, with the EP. This mode allows for qualified majority voting (QMV) in the Council, so an opposing minority can be overruled by a majority in favour of a policy proposal.

Our research concentrates on policies developed in the joint-decision mode, depending on resources and strategies of supranational actors as well as on the convergence or divergence of preferences among the member states. Generally, they search for consensus and try to avoid decisions that violate vital interests of one of the member states (Scharpf, 2006: 849). This means that policy proposals without a broad consensus can 'still be blocked by intergovernmental haggling over the precise content' (Scharpf, 2000b: 18-19). Therefore, the EU is vitally dependent on mechanisms to avoid deadlock, such as 
informal institutions to overcome structural inertia and to facilitate the dynamics needed to accelerate integration (Hedetoft, 2003; Héritier, 1999).

\subsubsection{The institutional setting and wider policy environment}

A narrow definition of institutions is used within the framework of ACI, ${ }^{6}$ focusing on regulation aspects. In this research, institutions will be defined as a system of formal and informal rules that structure the courses of action that actors may choose (Scharpf, 1997: 38). Formal institutions are legal-verbal procedures reflecting official 'rules of the game'. Informal institutions are non-verbal, non-official current practices developed by players during the game, including political norms, conventions and expectations.

This narrow definition has an important consequence: institutions will rarely describe a single course of action and leave considerable latitude for the strategic interaction of purposeful actors. This means institutions do not influence choices and outcomes in a deterministic sense. They form a stimulating, facilitating, but also restricting action context (Mayntz \& Scharpf, 1995: 43). In addition, actors may also ignore rules, use their powers illegitimately, or turn to informal interactions, since not every action can be regulated. Thus, explanations within the framework of ACI are based on actor behaviour as 'proximate cause' while the institutional structure constitutes the 'remote cause' (Mayntz \& Scharpf, 1995: 46). Another 'remote cause' is the wider policy environment, including political, economic, cultural, technological and other factors that influence actors and their preferences. Since it is a very broad concept, it is only through empirical analysis that we are able to assess the impact of the wider policy environment on a specific policy-making process and its outcome.

\subsection{OPERATIONALISING ACTOR-CENTRED INSTITUTIONALISM}

Actors' competences vary according to the different institutional characteristics of the EU and changes during different phases of the policy cycle. Neither the Council, the EP, or the Commission enjoy full control over the process or substance of the policy issue. In this section, the formal and informal institutions and the actors involved in regulatory policy-making in the EU will be described.

\subsubsection{Formal institutions}

Two basic formal institutional conditions for interaction in the European policy-making process are the rules concerning the interactions between the Commission, the EP, the

\footnotetext{
${ }^{6}$ A broader definition, as used in sociological institutionalism, understands institutions as 'cognitive and culturally embedded' phenomena, including 'socially constructed and culturally taken-for-granted worldviews and shared normative notions of appropriateness' (Aspinwall \& Schneider, 2000: 7).
} 
Council of Ministers and voting. The latter applies to intra-Council decision-making. There are two different voting thresholds for the adoption of legislation: unanimity and QMV. Unanimity used to be the norm for legislation under the first pillar, but after Treaty revisions QMV became the main voting rule.

The 1995 enlargement of the EU with the addition of Sweden, Finland and Austria resulted in a Council of fifteen member states with a total of 87 votes. From 1986 to 1995 a qualified majority required 54 votes cast and a blocking minority 23 votes. From 1995 the voting allotment changed and a qualified majority needed 62 votes cast and a blocking minority 26 votes. The minimum number of countries that could form a qualified majority was eight, whereas a minimum number of three countries could form a blocking minority (see table 2.1). In 2004, ten new countries joined the EU and in 2007, Romania and Bulgaria also became member states of the Community. The Treaty of Nice resulted in changes in voting weights in an extended Union as of January 2005. This was based on three conditions: each agreement should have a majority of member states in favour, have a qualified majority in the Council, and represent at least $62 \%$ of the European population (see table 2.1).

\begin{tabular}{|l|c|c|}
\hline Member states & Votes 1995-2004 & Votes 2007 \\
\hline Germany, France, UK, Italy & 10 & 29 \\
\hline Spain, (Poland) & 8 & 27 \\
\hline (Romania) & - & 14 \\
\hline Netherlands & 5 & 12 \\
\hline $\begin{array}{l}\text { Belgium, Greece, Portugal, } \\
\text { (Czech Republic, Hungary) }\end{array}$ & 5 & 10 \\
\hline Austria, Sweden (Bulgaria) & 4 & 7 \\
\hline $\begin{array}{l}\text { Denmark, Finland, Ireland } \\
\text { (Slovakia, Lithuania) }\end{array}$ & 3 & 3 \\
\hline $\begin{array}{l}\text { Luxembourg (Estonia, Latvia, } \\
\text { Slovenia, Cyprus) }\end{array}$ & 2 & 3 \\
\hline (Malta) & - & $255(73.9 \%)+62 \%$ of the EU \\
\hline Total number of votes & $62(71.26 \%)$ & \\
\hline Required votes to adopt & & \\
\hline
\end{tabular}

Table 2.1: Number of votes in the EU-15/EU-27

The Council uses its entire means to arrive at a satisfactory conclusion for those member states opposing a measure (Tsebelis \& Yataganas, 2002). Compared to national parliamentary chambers, where usually a simple majority rule is applied (more than $50 \%$ ), the threshold of a qualified majority with previously 62 votes cast $(71.26 \%)$ and currently 255 votes cast $(73.9 \%)$ is very high. In the case of unanimity, abstentions do not prevent the adoption of a proposal, whereas under QMV, abstentions are counted as votes against the passing of legislation (Selck, 2006). 
The Council can be viewed as a hierarchical pyramid. At the apex there is the Council of Ministers, followed by the Committee of Permanent Representatives (Coreper), while the base is formed by a large number of working groups. Deliberations in the Council normally begin at the working group level, where the work is prepared by examining the Commission proposal in detail and an attempt is made to reach agreement on as many issues as possible. Working groups thus form the backbone of the negotiating system. In these specialised working group meetings, national representatives operate on the basis of instructions from their respective governments, discussing Commission proposals article by article (Hayes-Renshaw, 2002). No voting takes place in the working groups. Discussion continues until consensus is possible or nothing further can be achieved. Coreper deals with unresolved issues arrising from the working group. The permanent representatives, EU ambassadors and their deputies, have a general overview of the Council's work. Whereas the representatives in the working group are experts in their fields, the permanent representatives are politicians. However, compared to the ministers, they are both policy generalists and experts in the substantive questions of a file (Lewis, 2002: 282). Only the (relatively few) items on which the working groups or permanent representatives are unable to reach agreement are sent to the Council of Ministers. All the meetings are headed by the presidency (see informal institutions) and underpinned by a Secretariat-General.

Agreement in the Council is often ascribed to package deals, issue linking, mutual exchanges, solutions based on the lowest common denominator, or to the autonomous role of the Commission (Héritier, 1999; Kingdon, 1984; Nugent, 2003; Peters, 1997). Following Eising (2000: 26-27), incremental negotiation techniques in the Council working group, clustering issues of a proposal together in order to debate compromise proposals, the role of a member state during the Council presidency and the informal role of the Commission as a policy-broker are important factors leading to agreement as well (see below for a further explanation). Although the number of votes per country is weighted, there is no enduring solidarity between larger member states. Coalitions in the Council continuously shift along lines of preferences. Both large and small member states can exert influence, by putting forward compromises and by forming coalitions with likeminded countries (Hayes-Renshaw, 2002).

For legislation to pass, in addition to the intra-Council decision-making procedure, different procedures regulate the cooperation between the Commission, the EP and the Council. The procedures that are underpinned by legal pronouncements are very important in structuring behaviour and they facilitate some policy options while hindering others (Wallace, 2000, 62-63). The first route is through administrative legislation, mainly in the form of Commission regulations or decisions. The basic work of this type of 
legislation is done within the relevant Directorate-General (DG). National officials are often able to voice their comments in a committee. Depending on the type of committee, they have the power to block administrative legislation they object to. An advisory committee gives the Commission a stronger position, whereas the management, and to a greater extent the regulatory committee, provide the member states with a stronger voice. The second route is through legislation connected with trade policies based upon agreements with third countries and therefore subject to a special decision-making procedure. The third route is through 'non-administrative' legislation achieved by consultation, assent or co-decision. ${ }^{7}$ The Treaty provision on which the proposal is based determines which procedure applies. Major differences between the various routes lie in their area of use and in the role they attribute to the different actors involved in the process. Although in each of the procedures the same 'troika' of actors is involved, the distinguishing aspect is the power of the EP (Selck, 2006).

Passing legislation is primarily covered by the co-decision procedure, which was put into effect by the Treaty on European Union (TEU) in 1993 and amended by the Treaty of Amsterdam in 1999. All deliberations are initiated by a Commission proposal. Generally, issues that are presented to governments are not fully developed and require 'framing and definition before they can be processed' (Peters, 1997: 32). This right of initiative gives the Commission an important agenda-setting role. A proposal is prepared by the responsible DG, often with outside assistance from consultants at both national and sectoral levels as well as horizontal coordination with DGs (Nugent, 2003: 123). The Commission, as a collegial body, then needs to adopt a proposal by a simple majority of the Commissioners. Consequently, individual Commissioners must build alliances within the College (Thatcher, 2001).

The most important feature of the co-decision procedure is that it provides for joint decision-making and direct negotiations between the Council and the EP and the possibility for the EP to reject draft legislation (Shackleton, 2002). The EP has a strong committee structure, with one or more committees responsible for consideration of Commission legislative proposals. It is within the committee that most amendments are proposed and the Council common position is scrutinised. A key player in this process is the rapporteur. Other committees may also draft amendments, in which case the draftsperson is the key player.

In the EP, the key agents in the aggregation of interests are the political groups. These groups share political affiliation and have demonstrated considerable evidence of collective action. This ability is necessary to influence policy (Nugent, 2002). Given the

\footnotetext{
7 The co-decision procedure replaced the cooperation procedure; the latter is now only being used in some cases related to the European Monetary Union.
} 
huge number of amendments voted upon during the plenary, the voting cues provided by those few members knowledgeable in a specific policy area from each group are essential for guiding their group members. However, within political groups significant internal divisions, both of an ideological and national nature may exist. Sometimes loyalty is related to interest groups with whom many members of the EP (MEPs) are in close contact, or to intergroups that bring together MEPs from different political parties with similar views on certain issues. ${ }^{8}$

For amendments in the first reading under co-decision, a simple majority of all members present is necessary. The Commission will incorporate those amendments that it considers an improvement of the initial proposal or that most likely will facilitate agreement. Those EP amendments that have been agreed upon by the Commission can be adopted by the Council by qualified majority. Unanimity is required if the Council wants to amend a proposal against the Commission's wishes.

There are three possible scenarios. The law can be adopted if the Council accepts the Commission proposal that has also been accepted by the EP during its first reading and if both the Commission and the Council accepted all EP amendments. In all other situations, the Council adopts a common position. To amend or reject the Council's common position in the second reading, an absolute majority is required in the EP (half of all members plus one). In a situation where the Council cannot accept second reading amendments, both actors try to negotiate an agreement in a conciliation meeting. Under the TEU, the Council could reintroduce its common position if the conciliation committee did not succeed in coming to a mutual agreement. The EP could only overturn this by an absolute majority. The Treaty of Amsterdam eliminated this possibility. Generally, conciliation increases the acceptance of second reading amendments of the EP. Since the co-decision procedure, with the EP legally, and in practice, acting as colegislator, conciliation creates a new environment where the views of the EP are considered seriously by the Council (Shackleton, 2002). Given the complexity of the conciliation meetings, an informal trialogue often replaces the formal conciliation committee (see next section).

The formal institutions mentioned above are important with regard to problem-solving. They have a strong impact upon whether an agreement can be reached. In this context, veto points (Immergut, 1992) provide different actors with opportunities to overturn a political decision at different stages of the policy-making process. Table 2.2 gives an overview of the most important veto points of policy-making processes in the EU under co-decision.

\footnotetext{
${ }^{8}$ The establishment of intergroups in the EP can be considered as an informal rule of the game.
} 


\begin{tabular}{|l|l|l|}
\hline Institutions & \multicolumn{2}{|c|}{ Veto points } \\
\hline $\begin{array}{l}\text { Simple majority in College of } \\
\text { Commissioners }\end{array}$ & If yes, no veto point & If no, then veto point \\
\hline $\begin{array}{l}\text { Qualified majority common position in the } \\
\text { Council }\end{array}$ & If yes, no veto point & If no, then veto point \\
\hline $\begin{array}{l}\text { EP absolute majority to amend common } \\
\text { position }\end{array}$ & $\begin{array}{l}\text { If yes, then possible veto } \\
\text { point }\end{array}$ & If no, no veto point \\
\hline $\begin{array}{l}\text { EP absolute majority to reject common } \\
\text { position }\end{array}$ & If yes, then veto point & If no, no veto point \\
\hline $\begin{array}{l}\text { Conciliation agreement between Council, } \\
\text { Commission and EP }\end{array}$ & If yes, no veto point & If no, then veto point \\
\hline
\end{tabular}

Table 2.2: Institutions and (possible) veto points

In theory, even more veto points exist. During the first reading, the EP has to adopt its amendments with a simple majority. The EP Rules of Procedure provide for the possibility to reject a Commission proposal during first reading, although this is not part of the Treaty provisions. If the EP is unable to reach a simple majority, the president of the EP shall ask the Commission to withdraw its proposal. This would mean the end of the legislative procedure. However, the EP can also adopt amendments that completely nullify the Commission proposal, without this being necessarily the end of the procedure. The veto points outlined in table 2.2 are the most common ones.

Yet another formal institution constitutes the repertory of policy instruments that is distinctive from the above-mentioned formal procedures. The main instruments are directives, regulations and decisions. Furthermore, recommendations and opinions are possible, but they have no binding force. Decisions are only binding on those parties to which they are directed; regulations are binding in their entirety and take up direct effect in the member states; and directives are only binding in the results to be achieved. This leaves some room for member states to accommodate the measures to national legislation. Thus, transposing directives into national law allows member states to modify them slightly to adapt them to a country's preferences, resulting in a 'legislative drift' (Steunenberg, 2006: 295), which is not true for regulations. In the case of a misfit after adoption, transposition may be delayed or a measure may not be transposed correctly (Falkner et al., 2004; Steunenberg, 2006). Even after correct transposition, lacking application or compliance may result in a 'practical drift' (Versluis, 2007). Although the process is not fully completed with the adoption of a policy measure by the Council (and the EP in the case of co-decision), because directives are still further shaped in the implementation stage, we consider policy-making and implementation to be separate from each other, with our focus on policy-making. 


\subsubsection{Informal institutions}

Informal rules have different roles in the decision-making process. On the one hand they may add dimension to the process before the institution of formal procedures, filling in gaps in formal rules or complementing them. On the other hand, they may also run counter to formal institutions by contradicting or superseding them (Stacey \& Rittberger, 2003: 858-860; Wallace, 2000: 62). It is the complexity of the formal structure that makes room for informal institutions.

The fixed occasions of the EU policy processes have to be supported by a network due to the formality of these fixed meetings. This formality makes them ill-equipped for the trade-offs, concessions and compromises that are often necessary to reach an agreement (Nugent, 2003; Peterson \& Bomberg, 1999: 57-58). In its informal role as policy-broker, the Commission can organise round tables, offer funding that could be used on a voluntary basis for research and, organise networks and mobilisation (Héritier, 1998, 2000). By facilitating the regular exchange of opinions the Commission might indirectly influence the policy direction of member states (Héritier, 1998).

When faced with an impending deadlock, the Commission often needs to act as mediator in order to have its proposal adopted. The Commission is well placed to play the role of a policy-broker since it attends all meetings in the Council and the EP and knows 'the bottom lines' of the various actors (Nugent, 2002). When the Commission is accepted by the member states as an 'honest broker' and neutral guardian of European public interests, the problem-solving capacity might increase in comparison to intergovernmental negotiations under the mode of negotiated agreement, assuming that some leeway for solutions introduced by the Commission exists (Scharpf, 2006: 851). Of course, the degree of influence exerted by the Commission can only go as far as the willingness of member states to engage in greater integration.

Not only the Commission can act as a mediator, but consensus-building and mediation are also related to intra-Council decision-making. The oldest social convention is consensus-building. There is a strong commitment to consensus in the Council, it being called a 'principle interest' in collective decision-making (Lewis, 2003: 1007). Whatever the formal institutional rule, there exists a strong tendency towards decision-making by unanimity (Wallace, 2000: 63).

As well, in the context of Council negotiations the presidency can play an important role. The presidency rotates between the member states on a six-month basis, and its main task is the arranging and chairing of the Council meetings at all levels. As the chair, it has considerable control over the number of meetings and the agenda (Nugent, 2003: 162). When negotiations are not progressing, the president might put forward a 'compromise from the chair' (Hayes-Renshaw, 2002: 58-59; Matilla, 2004: 34). 
Presidencies are expected to act as honest mediators, subject to the impartiality norm (Metcalfe, 1998: 414).

It is also the member state holding the presidency that represents the Council in a trialogue meeting. Although not formally mentioned in the treaties, the trialogue has become a regular feature of conciliation (Shackleton, 2002). Whereas a full conciliation committee can have over 100 people, a trialogue meeting is much smaller, bringing together the key EP, Council, and Commission actors to explore the possibilities for agreement.

In sum, the main informal institutions are the Commission's role as policy-broker or mediator, the establishment of EP intergroups (see previous section), the consensus norm, the role of presidencies as honest brokers given the impartiality norm, and the informal trialogue.

\subsubsection{Actors involved in European policy-making}

Actors can be defined as the players or agents in the policy-making process. In this section we describe the main actors and how their preferences, perceptions and capabilities result in a certain approach to interaction. Information about actor perceptions can be derived empirically. Generally, the data can be obtained relatively easily from public records and qualified newspaper reports as well as inside information gained through access to operative documents and confidential interviews. Following this methodological consideration, an accurate overview of actors' perceptions can be based on document analysis and interviews. The same is true for the norms and self-interests constituting actors' preferences. Moreover, as stated previously, norms and self-interests cannot be disentangled in practice. In our analysis we concentrate on the level of conflict given the diverging perceptions, preferences and capabilities.

Actor selection is rather pragmatic. The inclusion of actors in our analysis is not based on a pre-selected criterion, but on empirical evidence of their role, which is, as explained above, largely defined by the institutional setting. Therefore, the main actors under study are formal European policy actors: the Commission, the EP, the Council of Ministers and the ECJ. These formal actors always operate in a political context in which interest groups try to influence the choice of policy solutions in 'Brussels' and their behaviour in the policy-making process (Van Schendelen, 2002). There is a wide variety of interest groups in EU policy-making. They differ in size, organisation, power, strategies and relationships with formal policy-makers (Greenwood, 2003).

By facilitating some courses of action while excluding others, institutions define opportunities and constraints within which interest groups operate and assert their interests. Institutions change the rules of political engagement and hence the context in which political power is determined. As a result, the institutional setting influences the 
ability of interest groups to gain access to the policy-making process (Wiktorowicz, 2003: 618-619).

\subsection{SCOPE OF THE RESEARCH}

This research explores and adds to the understanding of the political activities in EU health policy-making. It seeks to answer the following questions: (1) Who are the important actors in the policy-making process and what are their preferences? (2) How does the institutional structure influence actors' strategies in policy-making on health issues? (3) What is the role of interest representation in policy-making on health issues? (4) How do health and other interests interact in policy-making on health issues? As explained above, ACI offers valuable tools with which to analyse 'the rationally reconstructed, institutionally-constituted strategies' of actors (Schmidt, 2003: 319) to determine what factors influence the likelihood of agreement on EU health issues. 



\section{PART II TOBACCO CONTROL POLICY-MAKING}

The second part of this book analyses the policy-making process on the tobacco advertising ban, which constitutes a public health policy. Chapter 3 describes the difficulties in reaching agreement on this issue. It concentrates on the various strategies of the formal actors, with the main question being: How was agreement possible given the deadlock? The fourth chapter specifically focuses on the ramifications of the treaty basis on the discussion concerning the ban on tobacco advertising. Since the European Court of Justice played an important role in this process, this chapter analyses the consequences of the Court's judgement for health policy. Finally, chapter 5 analyses the role of interest representation in this case from an institutionalist perspective. 


\section{POLICY-MAKING ON THE TOBACCO ADVERTISING BAN: OVERCOMING THE DEADLOCK}

\subsection{INTRODUCTION}

Since the launch of the Europe against Cancer (EAC) programme in 1987, diverse tobacco control measures have been introduced: a ban on tobacco advertising on television (89/552/EEC), tobacco labelling (89/622/EEC and 92/41/EEC), tar maximums for cigarettes $(90 / 239 / \mathrm{EEC})$ and minimum tax levels for tobacco products (92/12/EEC, 92/79/EEC and 95/59/EEC) (Duina \& Kurzer, 2004). The most contentious measure was, without any doubt, the ban on tobacco advertising. This proposal, initiated in 1989, resulted in strong counter-lobbying by the tobacco industry and its so-called third alliances, including Formula One journalists and the advertising industry (Bitton, Neuman, \& Glantz, 2002). In fact, it took almost ten years before the Council of Ministers and the European Parliament (EP) adopted Directive 98/43/EC in July 1998.

However, in 2000, the European Court of Justice (ECJ) annulled the directive, arguing that there was no legal basis for it in the treaties. The European Commission had based the tobacco advertising ban on article 100a (now article 95) concerning 'the establishment and functioning of the internal market', whereas the main reason for the ban was public health protection. After this failed policy process, a new directive regulating tobacco advertising, albeit one with a more limited scope, was adopted in 2003 (Directive 2003/33/EC). Despite its restricted scope, Germany asked the ECJ to review its validity again. However, in December 2006 the ECJ dismissed this appeal (see chapter 4 for the political and juridical discussion regarding the legal basis).

The diverging preferences of the actors involved resulted in a deadlock that lasted several years. Interestingly, however, they were eventually able to reach an agreement. How was the deadlock overcome in the end? What happened to actors' preferences? What strategies did actors pursue to resolve or maintain the deadlock? And what was the impact of the institutional setting on their roles in the policy-making process?

After explaining the different preferences concerning tobacco advertising (section 2), this chapter describes the development of the tobacco advertising ban (section 3). In order to explore the reasons for the deadlock, as well as the eventual breakthrough, we analyse the roles of the Commission, the Council and the EP in conflict resolution (section 4). Finally, we draw some conclusions on the role of actors in overcoming deadlock situations (section 5).?

\footnotetext{
${ }^{9}$ For an overview of the interviews refered to in this chapter, see appendix 1.
} 


\subsection{EXPLAINING THE DEADLOCK}

The issue of smoking has always been politicised. The diverging views regarding tobacco advertising can be structured around three themes that help to explain why the deadlock lasted as long as it did. First, member states' governments had different ideological perspectives regarding tobacco control measures. Their position was related to perceptions about state intervention in this field. Should the government opt for an interventionist role, or should it focus on individual responsibility with minimum state intrusion into the private sphere of consumption? France and Italy, for example, established traditions of state intervention in tobacco control, whereas consumer freedom was typical for the United Kingdom (UK), the Netherlands and Denmark (Duina \& Kurzer, 2004). In this context, the argument of the right to freedom of speech was also important.

The second theme is linked to the public welfare dimension. Controvery exisited regarding the health benefits of a ban (would it generate health gains?). According to advocates of the ban, advertising endorsed the idea of tobacco as a legitimate and socially acceptable product. Banning advertising would reduce the number of smokers and therefore result in fewer deaths due to smoking (Connolly, 2002). The tobacco industry consistently claimed that advertising did not affect the number of smokers, but was necessary for companies to encourage brand building among current smokers (Saffer \& Chaloupka, 2000).

The third theme is related to the distributive dimension. Some member states argued that a ban would harm the tobacco and advertisement industry and, consequently, would have a negative impact on the labour market. Therefore, member states' preferences were related to the possible economic impact of the legislation. The pressure to oppose the advertising ban did not come from the health ministries, but from the ministries responsible for trade and finance (Hayes, 1993). In 1991, Germany, the UK and the Netherlands produced $63 \%$ of all EU-manufactured cigarettes. In addition, Germany and the Netherlands were the main producers of cigars and pipe products $(67 \%)$. The cost of harmonisation would be centred on Germany, the UK and the Netherlands as the major tobacco manufacturing countries. As well, the government of Denmark obtained significant revenue from the sale of tobacco because of the high taxes imposed upon them (Duina \& Kurzer, 2004: 68; Hervey, 2001b: 108). However, those in favour of a ban further argued that because this legislation would reduce tobacco related deaths and illness, it would reduce the health and social costs of tobacco use, and thus the burden placed on the government and consequently the tax payers.

A fundamental conflict between public health and economic interests existed. Given the diverging views, it is no surprise that arriving at an agreement proved to be difficult, and the policy-making process was deadlocked for many years. In this chapter we explore 
how that deadlock was eventually overcome. Our analysis is based on an actor-centred institutionalist approach, as indicated in chapter 2 .

Negotiations on tobacco advertising took place under the co-decision procedure. Following this procedure, the Commission draws up the proposal and a decision is made by the member states in the Council and the EP. The qualified majority voting (QMV) rule in the Council implies that an opposing minority can be overruled by a majority in favour of a policy proposal. Generally, European Union (EU) governments search for consensus and try to avoid decisions that violate the vital interests of a member state (Scharpf, 2006: 849). However, in the case of a policy conflict - either because of a loss of benefits, a loss of decisional power or the costs of instrumental adjustments (Heritier, 1999: 15) - a deadlock may occur.

Under these circumstances, European action may benefit from the Commission's agenda-setting monopoly, from the expanding co-decision rights of the EP and from the good services of national representatives in the working groups (Scharpf, 2001: 13). The role of the Commission is significant in this respect. In a situation where member states have diverging preferences, or where their opinions are ambiguous, 'the Commission may pursue strategies to increase the scope of its competences' (Cram, 1997: 174).

Generally, the Commission attempts to circumvent the political impasse through various escape routes: 'policy strategies and patterns that 'make Europe work' against the odds of the given institutional conditions and the enormous diversity of interests' (Héritier, 1999: 1). It is these escape routes that smooth the way for the advancement of policy-making. To what extent was agreement possible considering the roles played by the various actors? To what extent are the rules being used creatively, 'by circumventing, reinterpreting, or combining them in such a way as to accommodate diversity' (Héritier, 1999: 97)?

This chapter analyses the roles of institutions that regulate the interplay between the EU actors: the right of initiative and honest brokering by the Commission; the codecision procedure including the EP; and the QMV rule, the neutrality norm and the consensus norm in the Council. Whereas a deadlock was to be expected given actors' preferences concerning this policy, in the end, they were able to reach a decision. After outlining the development of the policy process, we analyse the extent to which the tobacco case supports the claim that there is a strong role to be played by the Commission as agenda-setter and honest broker in circumventing a deadlock. 


\subsection{REGULATING TOBACCO ADVERTISING}

\subsubsection{Tobacco control policy on the agenda: the importance of personal circumstances}

At the 1984 European Council meeting in Fontainebleau, President Mitterrand of France and the Italian Prime Minister, Craxi, suggested creating 'a Europe of the citizens'. The Council requested a report to identify areas where the European Community could develop a new dimension closer to the concerns of European citizens. The 1984 Communication by the Commission to the Council on 'the cooperation at Community level on health related problems' (COM(84) 502 final) mentioned the fight against cancer as a possible area for action.

In 1985, the European Council called on the Commission to develop a programme against cancer. At that time, Mitterrand was suffering from cancer and not long afterwards, Delors, president of the Commission, would lose his son to cancer. Although it was kept quiet, "there was a very strong personal motivation (...) which drove the whole thing forward" (\#5, PH lobbyist). The objective of the programme was to reduce the number of cancer-related deaths by $15 \%$ by the year 2000 (Aspect Consortium, 2004: 106). "It was quite clear that if they really wanted to deal with cancer, tobacco related cancer was the biggest topic area they could target" (\#5, PH lobbyist). The Commission was authorised to set up an ad-hoc committee of cancer experts. In January 1986, the High Level Cancer Experts Committee met for the first time in Brussels. A task force was established at the Commission-level. In conjunction with the experts committee, the task force developed the first action plan.

\subsubsection{The first proposal: restricting tobacco advertising}

The first Commission initiative in 1989 concerning tobacco advertising was a proposal restricting advertising (Commission of the European Communities, 1989). Given the state of legislation in the majority of the member states, the Commission reasoned it was impossible to propose a ban. Only Italy and Portugal already banned tobacco advertising. Belgium, Ireland and Luxembourg had only banned advertising in publications directed at young people, whereas Spain, Denmark, the UK and the Netherlands had opted for partial restrictions based on legislation or voluntary agreements with the tobacco industry. In Belgium, France and Ireland, advertisements were only allowed to portray the packaging and provide certain factual information regarding the brand. In Belgium, Denmark, Germany, Ireland, the UK and the Netherlands advertisements were required to incorporate a warning.

In 1987, immediately after the Single European Act (SEA) had recognised health as a dimension of economic integration, the Commission started to work on its proposal. 
Normally the Commission works with key interest groups including industrial producers and other powerful economic stakeholders when proposing a new measure. In this case, however, the initiative was a product of Commission civil servants and the cancer expert committee. It was already clear that the tobacco industry strongly opposed any tobacco control measures, but those actors that would soon become active in promoting health at Community level were still in their infancy. In addition, the inactivity of medical and health communities at national levels was problematic (Duina \& Kurzer, 2004).

\section{The 1989 'restricting' proposal}

Advertising for tobacco products in the press and by means of bills and posters should carry health warnings. The content of the advertising message is restricted to information about the product (tar, nicotine yields etc.) and a presentation of its packaging. Advertising in publications intended for people under 18 years is not permitted. Indirect advertising is prohibited. Member states can adopt additional restrictions. Publications or the display of bills which comply with this directive cannot be prohibited.

The proposal was criticised by the parliamentary Committee on Environment, Public Health and Consumer Protection (ENVI), which claimed that it was too weak. With 23 votes in favour, 3 votes against and 6 abstentions, the committee proposed a ban on tobacco advertising. In March 1990, the EP accepted these amendments and voted in favour of a ban (170 in favour, 111 against, 17 abstentions). The parliamentary vote received huge media attention and pressured the member states in the Health Council to agree on a common position (Aspect Consortium, 2004).

The Commission considered that only an agreement on restrictions was feasible at that time. However, a coalition of opposing member states, including Germany, the UK and the Netherlands, blocked any agreement, maintaining their position of favouring voluntary agreements with the tobacco industry, while France, Italy and a number of smaller member states asked for a more ambitious directive (Duina \& Kurzer, 2004: 61).

\subsubsection{The second proposal: banning tobacco advertising}

Developments in France greatly influenced the debate at the European level. In 1990, the French government announced its plan for a ban on tobacco advertising - the Évin Law passed in January 1991. In addition, Belgium and Greece enacted stricter legislation. In response to the EP's encouragement and national developments, the Commission proposed a tobacco advertising ban in May 1991 (Commission of the European Communities, 1991), thus withdrawing its initial proposal. 


\section{The 1991 'banning' proposal}

Advertising is any form of communication, printed, written, oral, or transmitted by radio, television or in cinematic productions as well as advertising which, while not specifically mentioning the product, tries to circumvent a ban by using brand names, emblems or other distinctive features of tobacco products. Direct as well as indirect advertising for tobacco products are banned within the Community. Free distribution of tobacco products is not allowed. Tobacco sales outlets are establishments specialised in the sale of tobacco. Member states can authorise advertising within tobacco sales outlets, provided it is not visible from outside the premises. Shops with several counters for various goods are excluded from this definition. Member states have to adopt effective means to control the implementation of this directive, including provisions to ensure the possibility of legal action against advertising contrary to this directive. Finally, additional measures by the member states against tobacco advertising are allowed.

When the Commission put forward its second, more ambitious, proposal to ban tobacco advertising in 1991, the European Bureau for Action on Smoking Prevention (BASP) established by the Commission in 1990 - provided information and arguments that were used by the Commission to support its new proposal (\#2, PH lobbyist). In fact, BASP assisted advocates of the ban with all kinds of documentation. Within a few years, it became the most important target of the tobacco industry. The UK, Germany and the Netherlands strongly objected to BASP, claiming that the Commission had financed its own lobbying agency. According to The Guardian, BASP collapsed as 'furious EU officials took steps to ensure that BASP was effectively excluded from future funding' (see Neuman, Bitton, \& Glantz, 2002: 1328).

\subsubsection{The first reading of the European Parliament: only minor improvements}

In December 1991, the parliamentary ENVI Committee communicated that the proposal banning tobacco advertising met the wishes of the EP. Only minor modifications were considered necessary. The committee, with 14 votes in favour, 4 against and 5 abstentions, suggested the inclusion of a ban on tobacco sponsorship. Tobacco vending machines would not fall within the definition of tobacco sales outlets and advertising on these machines would therefore be banned. Anti-tobacco or consumer protection organisations would be explicitly mentioned as organisations allowed to initiate legal action. The committee asked for further explanation of the meaning of additional measures by the member states against tobacco advertising as proposed by the Commission, since a ban was already a stringent measure. It therefore amended this to additional stricter measures.

During the plenary debate, the legal basis of the proposal was contested. Three amendments were tabled seeking to replace article 100a by article 235 (now article 308) which allows for action in areas not covered by the treaties. Members of the EP (MEPs) were aware that such a change would require unanimity in the Council, thereby increasing the likelihood of deadlock. Despite expressions of doubt regarding the legal basis, the plenary rejected them. The EP considered the proposal for a tobacco advertising ban a delayed acceptance of its amendments on the first proposal in 1990. The plenary vote in 
February 1992 resulted in 150 votes in favour, 123 against and 12 abstentions (European parliament, 1992a). All amendments, as proposed by the parliamentary committee, were adopted. One additional amendment stated that companies could still use a brand name associated with tobacco products on the condition that the brand was first registered for other products and the turnover from tobacco products marketed under the same brand did not exceed half the turnover from other products under that brand.

The Commission regarded most of the EP amendments as repetitive wording. In its amended proposal of May 1992, the only accepted EP amendment concerned an exemption from the ban on indirect advertising for companies whose brand had already been established and whose annual turnover from tobacco products was less than $50 \%$ of the turnover of non-tobacco products.

\subsubsection{Negotiations in the Council: Breaking the deadlock}

The diverging preferences of the member states in the Council of Ministers caused a deadlock for several years. While occupying the presidency, a few member states opposing the ban deployed tactics to avoid any progress on the issue. However, despite great pressure from opposing member states and the tobacco and advertising industry, the Commission managed to keep its proposal on the agenda. It was not until an important change took place in the wider policy environment in 1997, that a concrete step towards overcoming the deadlock could be made. Elections in the UK in May 1997 resulted in a Labour government which, contrary to the position of its predecessor, supported the ban on tobacco advertising. Had the Conservatives won the election, it would have been the end for the proposal (\#2, PH lobbyist). However, this shift opened up possibilities for the negotiations to reach their final round. A common position in the Health Council was now possible because, in 1993, the Dutch government had decided to reconsider its position if such a change in the British situation occurred.

However, only a month before the decisive Health Council in December 1997, the Labour government asked for an exemption from the ban on sport sponsorship by tobacco companies. This request was the result of a large gift to the Labour party from the Formula One chairman in January 1997. The opposition in the UK called it a 'cashfor-access' affair (Cracknell, 2004). The government denied such a conflict of interest, 'claiming that up to 50,000 British jobs were at risk if Formula One racing moved to the Far East, exposing more people to tobacco advertising rather than fewer' (Warden, 1997). The UK government's position severely complicated negotiations. According to Commissioner Flynn of DG Social Affairs, it would be 'very difficult to persuade other member states to accept a derogation for Formula One, because in this case, why not take action for other sports such as cricket or snooker, which would also be particularly 
affected by such a ban. Moreover, we are running the risk of losing support of countries which are in favour of banning advertising of tobacco products' (Agence Europe, 1997a).

Prior to the Council meeting, the Dutch government expressed its intention to support the proposal for the ban in principle. The Dutch Minister of Health played a very important role in this decision (\#2, PH lobbyist). "She was a medical doctor and (...) very dedicated to health prevention policy in general and tobacco control in particular" (\#3, Dutch civil servant). The Commissioner reacted favourably to this news, although he remained sceptical of the Council's possible success on this issue (Agence Europe, 1997b), since neither the health working group nor the Committee of Permanent Representatives were able to reach an agreement.

The day before the Health Council meeting, the British and Dutch governments officially changed their positions. Furthermore, Greece declared it would abstain from voting. During the Council meeting, the Spanish delegation suddenly also announced its intention to abstain. This turnaround would have left those 'in favour' a few votes short of the 62 needed for a qualified majority (Agence Europe, 1997c). In the past, the Spanish government had always been in favour and it was clear there had been a political tradeoff. Germany had tried to prevent an agreement. There were rumours that it linked the vote on tobacco advertising to the Structural Funds. By threatening Spain with discontinuation of these funds, Germany hoped that Spain would join the opposition (interviews \#1, \#2, \#5, \#7, \#9).

Germany had always been against the proposal. It has been called a tobacco industry paradise (Poetschke Langer \& Schunk, 2001). The government's strong relationships with both the tobacco and advertising industry are an important underlying motivation for its stance. The most striking evidence for this is the contributions made by the tobacco industry to the election campaigns of all three main political parties. In addition, the industry had a serious influence over the scientific establishment, which probably impacted on scientific and public opinion in Germany (Grüning, Gilmore \& McKee, 2006). As well, it has been argued that anti-tobacco control measures during the Nazi era provoked a backlash in the post-war period. Public health programmes were rejected by political leaders as well as by the public, leading to a decline in medical interest in cancer (Duina \& Kurzer, 2004: 56-66; Simpson, 2002). However, Bachinger, McKee \& Gilmore (2008) show that the Nazi argument needs a more differentiated approach, because smoking was not a consistent element of Nazi ideology. Most policies already exisited before they came to power and even so, policies were poorly enforced and compromised by political realities.

The change in the British and Dutch attitudes encouraged the Luxembourg presidency to propose a new compromise. The compromise maintained the initial proposal in many 
ways, but allowed a two-year transition period for the phasing out of indirect advertising and sponsorship. A further extension could be granted in areas of worldwide sponsorship. In addition, advertising at the point of sale and in tobacco trade publications was permitted (Agence Europe, 1997d).

When a Council meeting is fully deadlocked, it may help to reduce the size of the delegation, since "it is best not to have too many people around when a Minister has to make concessions" (\#9, Dutch civil servant). In this case, the Luxembourg president first sent out all the lower level civil servants. At a later stage, only ministers and ambassadors were allowed to remain. Several respondents claimed that the role of the Luxembourg presidency was vital: "A small country can attain more than a large country in such a difficult situation (...). In small countries, it is less about prestige" (\#9, Dutch civil servant). Luxembourg is known for its successful presidencies (Metcalfe, 1998: 421). "There is a culture of negotiating, because of the small size of the country, which means it is used to dealing with its neighbours" (\#5, PH lobbyist).

The deal was struck around the Greek tobacco kiosks. In Greece, kiosks are surrounded by tobacco advertisements. The Greek government agreed with the tobacco advertising ban, providing there was derogation for its kiosks. The Council reached a common position, with Germany and Austria voting against and Denmark and Spain abstaining. The Luxembourg president was 'very satisfied', as was Commissioner Flynn, for whom it was 'tonight or never' (Agence Europe, 1997d).

The Council explicitly banned all forms of sponsorship, in line with a 1992 amendment from the EP. Secondly, there were some specifications with regard to the scope of the ban. Brands that existed before this directive and used for both tobacco and other products were not banned, although the brand for other products must be used in a clearly distinctive manner from that used for tobacco products. Thirdly, the ban did not apply to publications published and printed in third countries not principally intended for the Community market, communications for professionals in the tobacco trade, the presentation of tobacco products and their prices at sales outlets and advertising aimed at purchasers in establishments specialised in the sale of tobacco products and on their shop-fronts. Greek kiosks were exempted as well. Finally, member states were allowed to postpone implementation for one year in respect to the press and two years in respect to sports sponsorship. In addition, member states were allowed to continue authorising existing sponsorship organised at world level until October 2006, provided that they voluntarily reduced the visibility of advertising and decreased the sums devoted to such sponsorship. The Commission considered the Council text as an acceptable compromise. 


\subsubsection{Second reading of the European Parliament: avoiding conciliation}

After the Council had reached its common position in December 1997, the EP debated the issue in May 1998 during the second reading (European Parliament, 1998b). The Parliament was divided into two opposing groups. One group was committed to public health, whereas the other group was more concerned with ideological and distributive aspects, including the interests of the tobacco industry. The ENVI Committee delivered its opinion in April 1998 in favour of the common position without amendments (36 votes in favour, 7 against, one abstention) (European Parliament, 1998a). Even though the rapporteur considered improvement of the common position necessary, the strategy of the committee was to avoid the conciliation procedure because of the troublesome agreement in the Council. The majority of MEPs were aware that amending the common position could eventually result in a non-agreement in the Council (\#5, PH lobbyist). In May 1998, the EP voted in favour of the common position without amendments.

\subsubsection{The European Court of Justice: annulment and further policy-making}

Once the directive had been passed, Germany asked the ECJ to annul it (Case C-376/98). Previously, the ECJ had been receptive to public health arguments in favour of smoking prevention, given that it improved the functioning of the internal market. However, the German government stated that the tobacco advertising ban was not based on appropriate constitutional grounds. It argued that the directive exceeded its legal basis as an internal market measure because it represented a barrier to trade instead of facilitating it. The German government claimed that public health was the primary goal of the directive (Duina \& Kurzer, 2004: 61). Germany also enquired as to whether the fundamental right to freedom of expression, the principle of proportionality and the principle of subsidiarity had been infringed.

In its ruling, the Court agreed with the German government that the measure did not improve the functioning of the internal market, introducing rather than removing obstacles to trade and competition. 'The first indent of article 129(4) of the Treaty excludes any harmonisation of laws and regulations of the member states designed to protect and improve human health. But that provision does not mean that harmonising measures adopted on the basis of other provisions of the Treaty cannot have any impact on the protection of human health. Indeed, the third paragraph of article 129(1) provides that health requirements are to form a constituent part of the Community's other policies. Other articles of the Treaty may not, however, be used as a legal basis to circumvent the express exclusion of harmonisation laid down in article 129(4) of the Treaty' (para 77-79). The ECJ therefore annulled the directive in October 2000 (European Court of Justice, 2000). 
Remarkably, however, the Court also formulated guidelines for a legally acceptable policy. The ECJ stated that the EU could legitimately introduce a more limited ban on tobacco advertising and sponsorship with the same legal basis. This resulted in a new Commission proposal in 2001 (Commission of the European Communities, 2001a).

The '2001' proposal

Advertising for tobacco products in press and other printed publications are limited to publications intended exclusively for professionals in the tobacco trade and publications printed in third countries which are not principally for the Community market. Advertising not permitted in the press and other printed publications shall not be permitted on the internet. All forms of radio advertising and sponsorship shall be forbidden. Also other forms of sponsorship with cross-border effects shall be prohibited. Member states shall not prohibit or restrict free movement of products or services that comply with the directive.

The Council and the EP adopted the directive in 2003, which adhered strictly to the limits laid down by the Court in its judgement (Commission of the European Communities, 2003a). The scope of Directive 2003/33/EC is limited to advertising with a cross-border dimension in print media, on radio and via internet and sponsorship. Advertising in cinemas and on billboards, or using merchandising (e.g. ash trays or parasols) therefore falls outside its scope as well as sponsorship of events which are purely local, with participants coming from only one member state.

The UK government voted against the directive because of the weakness of the text. It found itself aligned with Germany, which thought the text went too far. Both countries did not manage to play a decisive role in preventing the proposal from being adopted, however. Therefore, in September 2003, the German government again asked the ECJ to review the validity of the directive. In December 2006, the ECJ dismissed the challenge by Germany against the tobacco advertising directive (European Court of Justice, 2006).

Table 3.1 presents an overview of the development of the tobacco advertising ban. It clearly shows the impact of the final round of negotiations in the Council. Several compromises were necessary to reach a common position. However, the spirit and structure of the proposal had generally been maintained. It also demonstrates that the EP did not introduce any amendments during the second reading and accepted the common position as such, in order to end the deadlock. 


\begin{tabular}{|c|c|c|c|c|c|c|c|c|c|c|c|c|c|}
\hline 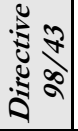 & $\stackrel{\infty}{\infty}$ & $\stackrel{\infty}{\infty}$ & $\stackrel{\infty}{\sim}$ & $\stackrel{\infty}{\infty}$ & $\stackrel{\infty}{\infty}$ & $\stackrel{\infty}{\infty}$ & $\stackrel{\infty}{\sim}$ & $\stackrel{\infty}{\infty}$ & $\stackrel{\infty}{\sim}$ & $\stackrel{\infty}{\pi}$ & $\stackrel{\infty}{\infty}$ & $\stackrel{\infty}{\infty}$ & \\
\hline$\hat{\Sigma}$ & $\stackrel{\infty}{\infty}$ & $\stackrel{\infty}{\infty}$ & $\stackrel{\infty}{\infty}$ & $\stackrel{\infty}{\infty}$ & $\stackrel{\infty}{\infty}$ & $\sum_{-\infty}^{\infty}$ & $\stackrel{\infty}{\infty}$ & $\stackrel{\infty}{\infty}$ & $\stackrel{\infty}{\infty}$ & $\stackrel{\infty}{ٍ}$ & $\stackrel{\Xi}{\nu}$ & $\stackrel{\infty}{\infty}$ & \\
\hline$\sum_{i=1}^{N}$ & $\stackrel{\infty}{\sim}$ & $\stackrel{\infty}{\infty}$ & $\stackrel{\infty}{\infty}$ & $\sum_{\nu}^{\infty}$ & $\stackrel{\infty}{\infty}$ & $\stackrel{\infty}{\infty}$ & $\stackrel{\sim}{\infty}^{\infty}$ & 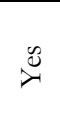 & $\stackrel{\infty}{\infty}$ & $\sum_{\nu}^{\infty}$ & $\stackrel{\infty}{\infty}$ & $\stackrel{\infty}{\infty}$ & \\
\hline 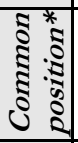 & $\stackrel{\circlearrowright}{\sim}$ & $\stackrel{\infty}{\infty}$ & $\stackrel{\infty}{\infty}$ & $\stackrel{\infty}{\infty}$ & $\stackrel{\infty}{\stackrel{\infty}{*}}$ & $\sum_{-1}^{\infty}$ & $\stackrel{\infty}{\infty}$ & $\sum_{\nu}^{\infty}$ & $\stackrel{\infty}{\infty}$ & $\stackrel{\infty}{\infty}$ & $\stackrel{\infty}{\infty}$ & $\stackrel{\infty}{\infty}$ & \\
\hline ถี & $\stackrel{\circ}{Z}$ & $\overbrace{\nu}^{\infty}$ & $\stackrel{\infty}{\infty}$ & $\stackrel{\circ}{Z}$ & $\stackrel{\circ}{Z}$ & $\stackrel{\circ}{Z}$ & $\stackrel{\circ}{Z}$ & $\stackrel{\circ}{Z}$ & $\stackrel{\infty}{\pi}$ & $\stackrel{\circ}{Z}$ & $\stackrel{\circ}{Z}$ & $\stackrel{\circ}{z}$ & \\
\hline$\sum_{i=1}$ & $\stackrel{\infty}{*}$ & $\stackrel{\circlearrowright}{\circlearrowright}$ & $\stackrel{\infty}{\infty}$ & $\stackrel{\circ}{Z}$ & $\stackrel{\circ}{Z}$ & $\stackrel{\circ}{Z}$ & $\stackrel{\circ}{Z}$ & $\stackrel{\circ}{z}$ & $\stackrel{\infty}{\infty}$ & $\stackrel{\circ}{Z}$ & $\stackrel{\circ}{z}$ & Z & \\
\hline$\sum_{i=1}^{Z}$ & $\stackrel{\infty}{\sim}$ & $\stackrel{\infty}{\infty}$ & $\stackrel{\infty}{\sim}$ & Z̊ & $\stackrel{\circ}{Z}$ & $\stackrel{\circ}{Z}$ & $\stackrel{\circ}{Z}$ & $\stackrel{\circ}{z}$ & $\overbrace{i}^{\infty}$ & $\stackrel{\circ}{Z}$ & $\stackrel{\circ}{Z}$ & $\stackrel{\circ}{Z}$ & 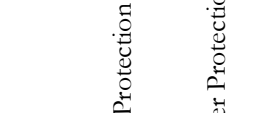 \\
\hline ปี & $\stackrel{\circ}{Z}$ & $\stackrel{\infty}{\circlearrowright}$ & $\stackrel{\infty}{\infty}$ & $\stackrel{\circ}{Z}$ & $\stackrel{\circ}{Z}$ & $\stackrel{\circ}{Z}$ & $\stackrel{\circ}{Z}$ & $\stackrel{\circ}{Z}$ & $\stackrel{\infty}{\infty}$ & $\stackrel{\circ}{Z}$ & $\stackrel{\circ}{Z}$ & $\stackrel{\circ}{Z}$ & 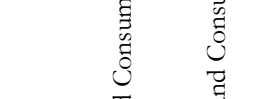 \\
\hline ปี & 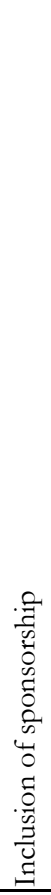 & 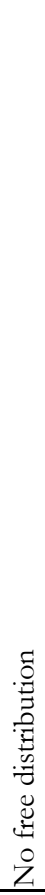 & 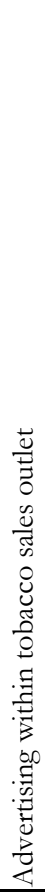 & 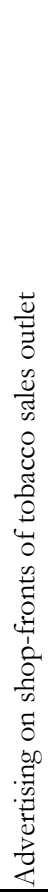 & 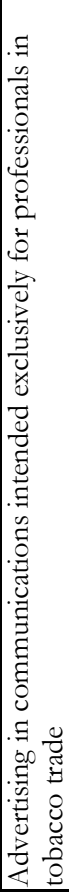 & 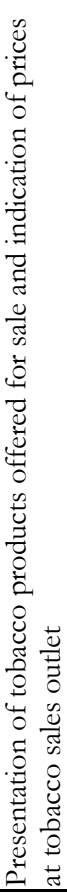 & 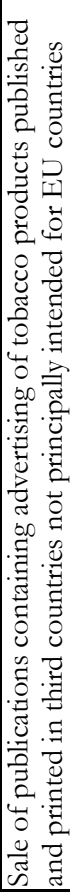 & 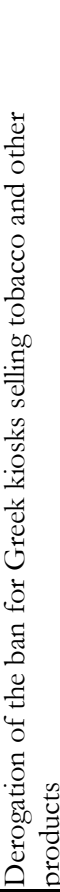 & 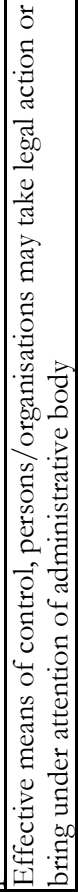 & 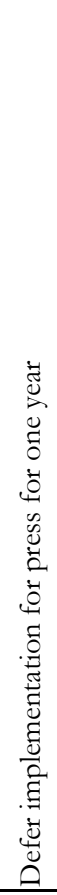 & 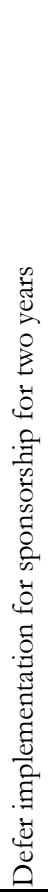 & 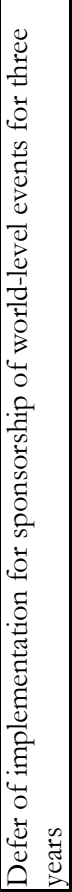 & 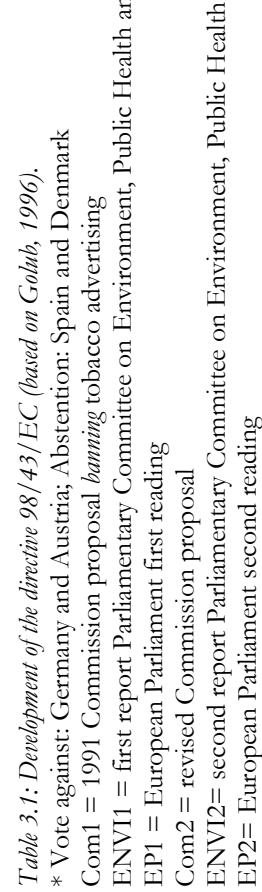 \\
\hline
\end{tabular}




\subsection{ACTORS' BEHAVIOUR WITHIN AN INSTITUTIONAL SETTING}

In this section we analyse the strategic behaviour of actors during the process of achieving agreement on tobacco advertising within a given institutional structure. The question addressed is, to what extent was agreement possible due to the roles played by the various actors. We concentrate our analysis on the main formal and informal institutions that regulate the interaction between the Commission, the EP and the Council of Ministers in European policy-making processes and the voting rules that apply to intraCouncil decision-making. One of the specific focuses of this analysis is whether the Commission used escape routes - and if so, which routes - to circumvent the deadlock situation that existed for many years.

\subsubsection{The Commission's right of initiative}

The Commission has formal agenda-setting power through its right of initiative. It is generally assumed that this right gives the Commission a substantial amount of influence on European legislation. In addition, due to its being present during the legislative process at all EP and Council meetings, the Commission often plays a mediating role (Nugent, 2002: 151-154). The process surrounding the ban on tobacco advertising illustrates that the Commission used a range of strategic options to influence the process.

An important element of the process has been the choice of legal basis for the proposal. The Commission argued that the diversity of national regulations on tobacco advertising hindered international trade. It chose article $100 \mathrm{a}$ as the legal basis for the proposal, stating that its main goal was to reinforce the functioning of the internal market. Why did the Commission choose article 100a? One possibility is that it was an attempt at regulatory expansion, with the Commission trying to increase its role in the field of public health (Duina \& Kurzer, 2004: 57). The Commission used the internal market perspective to create a legal basis for its proposals. According to article 100a(3), introduced by the SEA in 1987, the Commission should take a high level of health protection as a basis of its proposals concerning the establishment and functioning of the internal market.

At the time the Commission introduced its proposal, a public health basis did not exist in the Treaty. This was only introduced in the Treaty on European Union (TEU), although the harmonisation of national regulations concerning health was explicitly excluded. The only alternative option was article 235, providing the Commission with some leeway to act without a legal basis in special circumstances. However, the use of this article would diminish the role of the EP in consultation and require unanimity in the Council. The Commission was well aware that unanimity was problematic in this case and by linking its proposals to the single market programme, it created a situation in which the Council could decide by qualified majority (Héritier, 1999). 
Overall, the agenda-setting role of the Commission was very important during the whole policy process. First of all, the Commission decided to introduce a far-reaching proposal prohibiting tobacco advertising without much consultation. Second, its pragmatic choice for article 100a as the legal basis of the proposal influenced the process. It played the 'treaty base game' (Héritier, 2000) because the QMV rule was of great importance, as the Commission had envisaged. Even though in the end, the ECJ ruled that the directive had no legal basis and annulled it, most member states had already transposed the directive and decided to maintain the measure. As well, the already established consensus allowed for a relatively smooth adoption of Directive 2003/33/EC.

\subsubsection{The policy-brokering role of the Commission}

Convincing opposing member states to change their position was very difficult. The only option left to the Commission was to keep the issue on the agenda and wait for a 'window of opportunity' (Kingdon, 1984). In the meantime, the Commission tried to influence the landscape of pro-European health interest representation by providing resources to establish and sustain interest groups and asking them to undertake functions on behalf of the Commission, such as supplying information. Contacts with supportive interest groups could strengthen the Commission's position in relation to national governments and opposing interest groups' (Fairbrass \& Jordan, 2003: 109-110). National cancer leagues and anti-tobacco organisations were involved in spreading the message of the EAC programme (interview \#2, \#5). This strategy generated media attention, providing the Commission with a public setting to draw attention to the stalled issue of tobacco advertising, urge health ministers to adopt the proposal as soon as possible, and influence the national debate (Khanna, 2001). The discussion at European level had an effect in the member states, because it generated debate (\#3, Dutch civil servant) and resulted in an evolution towards more restrictions (\#4, Dutch civil servant). As one respondent said: "There was no way we were going to get the advertising directive approved until one of the two big governments, Germany or the UK, changed its position. (...) But you have to keep the momentum going" (\#5, PH lobbyist). While not withdrawing the tobacco advertising proposal, the Commission waited for an opportunity to make progress towards adoption of the ban. The decisive moment turned out to be in 1997, when a new government took office in the UK.

In sum, through the creation of a policy network, the Commission sought to influence member states preferences. Indeed, by generating debate on tobacco control at national level, the Commission hoped to put pressure on opposing governments. Though it is difficult to assess the final impact of these strategies on preference formation in countries, in some member states it ultimately resulted in an evolution towards more restrictions. 


\subsubsection{The role of the European Parliament under co-decision}

With the introduction of the co-decision procedure in the TEU in 1993, the power and status of the EP increased significantly. Interestingly enough, the role of the EP in this particular case was especially important in the early years of the discussion on tobacco advertising during the Commission's first proposal on restricting tobacco advertising, for which the cooperation procedure still applied. The support of the EP in 1990, for a ban on tobacco advertising was one of the reasons the Commission withdrew its proposal restricting tobacco advertising and introduced its proposal for a ban. The EP suggested only a few amendments to this proposal, which were not radical, since the proposal in general, represented the wishes of the EP.

In theory, the EP can play an important role under co-decision, with the possibility to amend or reject the Council's common position. However, in this case the EP in the second reading accepted the common position with its derogations for the Greek kiosks and prolonged timetables for implementation. Even though the ENVI Committee was not satisfied with the common position, it did not suggest amendments for improvement. The EP was afraid that an agreement was not possible under conciliation and accepted the compromise agreement of the Council over the possibility of not reaching any decision. We can thus conclude that the influence of the EP in this case was related to the fact that the Commission had proposed a ban on tobacco advertising instead of mere restriction. Its influence on the final outcome seems marginal, however. This case shows that the EP cannot play a decisive role unless it dares to risk paralysing the policy-making process (see also Golub, 1996).

\subsubsection{The Council of Ministers: qualified majority voting, the neutrality norm and the consensus norm}

The member states involved in the negotiating process had widely diverging preferences. With article $100 \mathrm{a}$ as the proposal's legal basis, a decision on tobacco advertising had to be made by qualified majority. Countries in favour of a ban actively searched for a qualified majority, whereas those against it tried to block any agreement. They disagreed with the legal basis of the proposal and tried to change it to article 235. A decision by unanimity would have been impossible. Therefore the consensus norm did not play a role. As one respondent said: "Usually we strive for consensus, but in this case it was not possible. It was either yes, or no, black or white. You could not say (...) let us ban advertising by $10 \%$ or something like that" (\#1, German civil servant).

No member state could veto the proposal, although several countries together could block it. In this case, Germany, the UK, the Netherlands, Denmark and Greece made a qualified majority impossible for many years. It was not possible for the different presidencies to find a compromise, although several opposing member states holding the 
presidency tried to stall the discussion despite the informal rule of neutrality. Yet, member states in favour actively searched for a compromise in line with their preferences, so it remains doubtful whether neutrality is possible. However, the role of the Luxembourg presidency may be described as neutral. It did actively search for consensus and tried to get all member states 'on board'.

After years without any progress, several wider policy developments resulted in changing preferences in the UK and the Netherlands. The common position clearly reflects the strategic behaviour of several member states. First, the UK decided to ask for an exemption for sports sponsorship. Germany tried to prevent a qualified majority by pressuring Spain, resulting, in the end, in Spanish abstention. Finally, Greece asked for an exemption for its kiosks, which it had the clout to ask for, since its vote in favour of the ban was necessary for a qualified majority.

\subsection{CONCLUSION}

Central to this chapter is the question of how various actors influenced agreement on a tobacco advertising ban. The institutional setting provided actors with strategic options and constraints, although institutions do not have a deterministic impact upon their behaviour. This case shows how actors' strategies depend upon their preferences related to ideological, welfare and distributive elements with regard to a tobacco advertising ban. The conflicting preferences of the member states resulted in a deadlock, with a coalition of opposing member states blocking any decision for an extended period of time. Under such circumstances, the agenda-setting and policy-brokering role of the Commission is important (Scharpf, 2006). These institutions may have a positive impact in circumventing a deadlock. To what extent does the tobacco case support this claim?

When looking at the different institutions that structure policy-making, we argue that the agenda-setting and policy-brokering role of the Commission were undeniable very important. These institutions specifically allow for considerable latitude, enabling the Commission to employ various escape routes; at the very least they seem more influential then the institutional setting surrounding the Council (QMV rule, neutrality norm and consensus norm) and the EP (co-decision procedure). Within the Council, the problems of collective action, the need for package deals, issue linking and mutual exchanges, together with negotiations being linked and continuous, which is especially relevant in a setting of 15 - and currently even 27 - member states, forms a very complex environment in which to circumvent a deadlock. The focus within the Council is far more on content, whereas the Commission has an overview of the process, including the position of the different actors involved. In addition, based on our case study we hypothesise that in a potential deadlock situation in the Council, the influence of the EP under co-decision on the final outcome is questionable, as the EP is forced to abstain from making 
amendments to the common position unless it is willing to take the risk of paralysing the policy-making process.

Compared to the EP and the Council, the role of the Commission is not as restricted and therefore provides room for strategic manoeuvring. In addition, the Commission benefits from its first-mover advantage. It chose to draft a far-reaching proposal despite the fact that several large member states were opposed to any European-level measure on tobacco advertising. It is remarkable that the Commission acted this way in a pro-tobacco climate. Some member states preferred voluntary agreements with the tobacco industry, and even though the industry was not consulted on the proposal, it managed to delay policy-making for several years by using a variety of insider and outsider (media) strategies (Boessen \& Maarse, 2008 (forthcoming); Neuman, Bitton, \& Glantz, 2002). We can identify three strategies used by the Commission to overcome the deadlock. First, the Commission played the treaty base game with its proposal of the tobacco advertising ban. Its pragmatic choice for article 100a (now article 95) allowed for QMV in the Council, and a codecision with the EP.

Second, to counterbalance industry tactics, the Commission created resistance to the pro-tobacco lobby by involving a wide range of interests. Over several years, the Commission helped to create a strong policy network at national level by subsidising national cancer leagues and anti-smoking organisations as well as organising meetings every six months. At European level, the Commission subsidised BASP and asked it to undertake functions on behalf of the Commission. While the Commission waited for a window of opportunity (Kingdon, 1984), it tried to put pressure on national governments through the building of a policy network. This resulted in an evolution at national level.

Third, the Commission knew that a window of opportunity would be decisive in this process. Several wider policy developments influenced the process to a great extent. Most importantly, there was the change of government in the UK, which resulted in a change of preferences. The role of the Dutch Minister of Health was also significant, since she managed to convince the Dutch government to vote in favour of a tobacco advertising ban. The reasons for these changes of preference were the shift of the UK and the Ministers' personal motivation, in combination with the evolutionary developments at national level towards more tobacco control measures. The Commission very consciously awaited these wider policy developments that it knew would open a window of opportunity.

Cram (1997) argued that the principal-agent relationship between the national governments and the Commission in the case of social policy did not result in the Commission playing the role ascribed to it by the member states. She characterised the Commission as a purposeful opportunist. Following Cram, while not ignoring the role of 
governments in EU policy-making, the tobacco advertising case again stresses the importance of the Commission's role in a situation where there is a clash between member states' preferences. The strategic behaviour of the Commission - and more specifically its use of specific escape routes - can play a vital role in circumventing political impasses. 


\section{BALANCING BETWEEN MARKET-MAKING AND MARKET- CORRECTING: THE DISCUSSION ON THE LEGAL BASIS}

This chapter is based on: Boessen, S., \& Maarse, H. (2008). The impact of the treaty basis on health policy legislation in the European Union: a case study on the tobacco advertising directive. BMC Health Services Research 2008, 8:77.

\section{$4.1 \quad$ INTRODUCTION}

Every piece of legislation enacted by the Community must have a legal basis in the Treaties. In this chapter, we analyse how the legal basis affected the political controversy on the ban on tobacco advertising. The Commission framed the ban as a market-making policy intervention directed at removing barriers to foster market competition and free movement. Opponents of the ban claimed that it was not a market-making, but a marketcorrecting policy intervention, for which there was no legal basis. In fact, different actors used the legal basis as a vehicle for real political controversies. In order to understand why it was so difficult to adopt a policy measure that could improve the health situation in the European Union (EU) (DiFranza et al., 2006; Harris et al., 2006; Saffer \& Chaloupka, 2000), we claim it is necessary to focus upon the political sphere (Buse, Mays, \& Walt, 2005).

In this chapter, we will show that political controversy concerning the ban on tobacco advertising, as descibed in the previous chapter, to a great extent, concentrated on the question of whether or not it had a correct legal basis. From a problem-solving perspective, this institution is important. Determining whether a decision in the Council has to be made by unanimity or qualified majority, it has a strong impact on whether or not an agreement can be reached and, therefore, on the problem-solving capacity of an institutional setting. If agreement between actors is difficult, the rule of unanimity is likely to block the policy-making process, because each actor has a veto position. Voting by qualified majority would offer a way out of this deadlock.

Although our main focus concerns the annulled Directive $98 / 43 / \mathrm{EC}$, we will also provide an analysis of the discussion on the legal basis for Directive 2003/33/EC. ${ }^{10}$ The activities within member states falls outside the scope of this chapter.

\subsection{MARKET-MAKING VERSUS MARKET-CORRECTING INTERVENTIONS}

Policy interventions with respect to the European market can be divided into two analytical categories: market-making and market-correcting interventions. Market-making interventions are directed at the removal of barriers to trade and competition, including

\footnotetext{
${ }^{10}$ For an overview of the interviews refered to in this chapter, see appendix 1.
} 
the abolishment of tariffs and other quantitative restrictions, as well as the establishment of common product standards. Another purpose of these interventions is to establish a level playing field for all market players. From the market-making perspective, all factors that distort the market process must be removed. Market-correcting interventions have a restrictive impact on competition. Policy-makers implement such interventions in order to avoid market effects they consider deviant or anomalous, such as ethical reasons or considerations related to social welfare and public health. A ban on market instruments, such as advertising, can also be interpreted as a market-correcting intervention if that intervention aims at avoiding unwanted market effects. The distinction between marketmaking and market-correcting policy interventions should be understood as an analytical one. In fact, many policies combine aspects of both and a clear-cut distinction does not always exist. Yet, it is useful for our research topic to differentiate between interventions directed at the creation of a market and interventions that pose restrictions to the market process for moral, social or other reasons.

How does the Commission's proposal for a ban on tobacco advertising fit into the distinction between market-making and market-correcting? The Commission based the tobacco advertising proposal on article $100 \mathrm{a}$, arguing that its aim was to ensure the free movement of newspapers, magazines and other publications that were hindered by differences in national regulatory regimes.

Nevertheless, the Commission's argument was artificial, because it was clearly evident that the idea of a European ban on tobacco advertising originated from the Europe against Cancer (EAC) programme (Aspect Consortium, 2004; Princen \& Rhinard, 2006). In our view, the tobacco advertising ban should be understood as a market-correcting intervention rather than a market-making one. It was not directed - or at least not primarily - at the removal of trade barriers, or the establishment of a common level playing field, but instead at the promotion of public health. What the Commission did was to frame an essentially market-correcting policy intervention as a market-making one. This observation raises important questions. Why did the Commission do so? How did the controversy about the true nature of the ban influence the strategies of the major players involved? How did the annulment of the ban by the ECJ impact upon the policymaking process? These questions will be dealt with in the next sections.

\subsection{THE LEGAL BASIS: POLITICAL INTERPRETATION}

An important institution within EU policy-making is that policy interventions must have a correct legal basis. According to the ECJ, the choice of the legal basis should be a matter of principle and not a matter of political pragmatism (Hervey, 2001a: 1430-1431). Was this indeed the case? In this section we will show that the Commission's strategic choice 
for article 100a as the proposal's legal basis generated much political controversy in the Council and the EP.

\subsubsection{The European Commission: in search for a legal basis}

When the Commission came up with its first proposal for a directive on tobacco advertising in 1989 (Commission of the European Communities, 1989), it had a limited scope. The proposal did not impose a ban, but only included restrictions to advertising. Although the proposal was clearly motivated by the ambitious goals of the EAC programme, the Commission's principal argument was that the removal of all obstacles to trade by 1992 required the harmonisation of national regulations at the European level, including those on tobacco advertising. Differences in national regulations hindered the free movement of tobacco advertising publications.

After the Commission had tabled the 1989 proposal, the EP gave its opinion during first reading under the cooperation procedure. The Committee on the Environment, Public Health and Consumer Protection (ENVI) advised the plenary to amend the proposal by asking for a total ban.

During the plenary meeting, most members of the Parliament (MEPs) emphasised the public health aspect of the Commission's proposal and regarded the suggested amendments for a total ban as an improvement for public health. The market-making argument regarding establishing an internal market for tobacco advertising hardly played a role. Only the European People's Party (EPP) argued that a ban lacked a legal basis in the Treaty and, therefore, fell outside the scope of the Community.

The Commission accepted the Parliament's principal amendment for a ban on tobacco advertising in its proposal tabled in 1991 (Commission of the European Communities, 1991). As outlined in the previous chapter, policy developments in some member states had encouraged the Commission to replace its proposal for restrictions on tobacco advertising with a ban on tobacco advertising.

The Commission's original proposal restricting advertisements (1989) and its new proposal banning tobacco advertising (1991) were both based upon article 100a. The Commission stipulated that the main goal of these proposals was to reinforce the functioning of the internal market, although it was clear right from the beginning that they also served a public health purpose.

One may argue that the Commission's market-making argument could be justified under the condition that the proposal only contained restrictions on tobacco advertising. The diversity of national regulations on tobacco advertising could indeed hinder international trade. Following this reasoning, harmonisation by means of adopting restrictions to advertising would improve the free movement of publications. However, 
when the Commission introduced a ban, its argument became seriously flawed. As one of our interviewees explained, "If [there are] advertisements for tobacco in a German cinema, what does it have to do with the internal market? What about posters in Bonn or Berlin? [They have] nothing to do with the internal market” (\#1, German civil servant). The proposal's principal purpose became combating smoking, instead of harmonising national regulations.

Why then, did the Commission choose article 100a as the legal basis for the 1991 proposal? Prior to the TEU, the Community lacked any specific authority to develop policies that had public health protection as their 'principal or sole justification'. However, 'the Single European Act (SEA) made it possible to piggy-back health considerations onto the development of the single market' (Randall, 2001: 96), because it recognised health as a dimension of economic integration. The vague language of the SEA enabled the Commission to take action in the public health sphere. The formulation of the proposal required creative wording, due to the lack of an explicit public health competence. The choice for article 100a implied that the principal objective had to be the establishment and functioning of the internal market. The Commission also referred to paragraph 3 of article 100a, which stated that the Commission should take a high level of protection of health as a basis for its proposals concerning the establishment and functioning of the internal market. However, the Commission's interpretation of this paragraph was ambiguous. It required the Commission to take health protection into account when developing policy interventions directed at the removal of obstacles to trade. It did not imply that 'a high level of protection of health' could be taken as the main objective of a policy intervention. In other words, 'a high level of protection of health' should be interpreted as a secondary policy, not as a policy objective in itself.

In fact, the Commission believed it had no real alternatives to article 100a. It took until 1993, before the Community was given a legal competence in the field of public health. Article 129 of the TEU (now article 152) gave the EU a mandate to 'encourage cooperation between member states and, if necessary, lend support to their actions'. However, article 129 excluded harmonisation of laws and regulations in member states and, therefore, could never provide a legal basis for the tobacco advertising ban. The only alternative was article 235 (now article 308), which provided the Commission with the room to act in circumstances where action by the Community was necessary, even though no legal basis existed. However, article 235 required decision-making by unanimity in the Council and decreased the role of the EP, which now only needed to be consulted. Given the diverging preferences in the Council, the Commission did not consider this feasible. Article 100a was considered to be the only option, because decisions based upon it could be taken by qualified majority voting (QMV). Thus, the choice for article 100a was a 
strategic one. It reflected the Commission's assessment that the 'article 235 route' was likely to fail, because of the impossibility of reaching political consensus on a ban.

The Commission's strategy came at a price. A key problem was that an essentially market-correcting policy intervention had to be framed in terms of market-making. This problem proved a source of fundamental tensions that played a significant role during policy-making.

\subsubsection{The Council of Ministers}

The QMV rule enabled countries opposing the ban to block agreement for many years. Germany, the UK, the Netherlands, Greece and Denmark renounced the ban "for purely economic reasons" (\#1, German civil servant). The interests of the tobacco and advertising industry apparently prevailed over public health interests.

The Commission's choice for article 100a as the legal basis of the tobacco advertising ban influenced negotiations in the Council. The Council's Legal Service ${ }^{11}$ concluded that article 100a provided an appropriate legal basis for the proposal on restricting tobacco advertising. Differences between national regulations caused a distortion in the market. Resorting to restrictions on tobacco advertising, instead of imposing a ban, would leave media free to circulate in the internal market under given conditions.

The Legal Service also examined the proposal for a ban on tobacco advertising. It concluded that the ban 'cannot be regarded as having the effect of harmonising national provisions relating to the establishment and functioning of the internal market. The provision covers purely domestic situations and is designed to protect public health'. In other words, the Legal Service held the opinion that the ban could not be based on any Treaty article.

This opinion was obviously good news for the opponents of the ban, who used it to obstruct the process. For example, the Belgian Minister of Health exploited the conclusions of the Council's Legal Service to distort the Health Council meeting undermining her role as president to facilitate the negotiating process during the second half of 1993. In fact, the Belgian government was in favour of the proposal, but the Belgian Health Minister personally did not show any commitment. The discussion in the health working group was based on an informal paper, which proposed a ban, but delayed its implementation until 1998. The Belgian Health Minister had not approved the paper and had no intention of pursuing the dossier. However, the Commission decided to reinstate the item on the Council's agenda (Philip Morris, 1993a). During the following Council meeting, the Belgian Minister cited the opinion of the legal service and returned

\footnotetext{
${ }^{11}$ The Legal Services of the Council, the Commission and the EP provide legal advice to these actors on matters of European law in order to prevent or reduce the risk of litigation.
} 
the proposal to the working group without even a 'tour de table' (Girod \& Greenberg, 1993).

Germany tabled a compromise proposal in 1994 during its presidency, limiting the scope of the original proposal to cross-border advertising. The German government held that this was the only possibility under article 100a. Indirect advertising and sponsoring were excluded, thus reducing the scope of the proposal. The UK and the Netherlands had principal objections. They maintained their earlier position that tobacco advertising regulation at the European level conflicted with article $100 \mathrm{a}$ and the principle of subsidiarity.

An important event took place in May 1997, when the new UK government rejected all the previous governments' fundamental objections to the ban. A similar development occurred in the Netherlands. In 1993, the Dutch government decided to reconsider its position in the event that its vote became decisive, which after the policy change by the UK, was indeed the case. Only a few days before the Health Council meeting in December 1997, the Dutch government decided to vote in favour of the ban. It had always used the ambiguity of the legal basis as a reason to oppose the ban, referring to the opinion of the Council's Legal Service. Yet, in the final negotiating stage, it reasoned that the Legal Service of the Commission had expressed a contradictory view. The Dutch Health Minister told the national Parliament that the issue of the legal basis was for the ECJ to sort out.

Thus, member states in favour of the ban on tobacco advertising based their position on the belief that further restrictions to tobacco advertising were required to reduce the harmful effect of smoking on public health. Member states opposing the ban gave priority to their economic interests. The controversy over the legal basis and the opinion of the Council's legal service offered them an opportunity to renounce the ban and obstruct the policy-making process without the need to refer to their economic interests. "Most legal arguments, especially those regarding competence, were just smoke screens for countries who wanted to block the ban" (\#1, German civil servant).

\subsubsection{The European Parliament}

Although the legal basis of the original proposal restricting tobacco advertising was hardly an issue in the EP, it became a major point of discussion during the debate on the proposal for the tobacco advertising ban. The ENVI Committee, which was responsible for the report, supported the proposal. The rapporteur explicitly expressed his support for the Commission's choice of article 100a as the proposals' legal basis.

In February 1992, the EP plenary gave its opinion on this issue (European Parliament, 1992a). The EPP and the Economic and Monetary Affairs and Industrial Policy Committee tabled amendments to change the legal basis, seeking to replace article 100a 
with article 235. All MEPs knew that under article 235, decisions had to be made by unanimity. The rapporteur from the ENVI Committee called this 'a deceitful attempt to sweep the text from the table' (European Parliament, 1992b). Despite expressions of doubt regarding the legal basis, the plenary rejected the motion (150 votes in favour; 123 against; and 12 abstentions). The head of the ENVI Committee stated that 'the people who wanted to change the legal basis lost. Now what we are seeing is (...) an attempt to delay the proceedings. This is plain filibustering and it is a plain abuse of the democratic process' (BASP, 1992a).

After the Council reached its common position in 1997, the EP had to give its opinion in its second reading. In a final attempt to obstruct the adoption of the ban on tobacco advertising, opponents once again focused on amending the legal basis. Many documents addressing the legal basis of the ban circulated in the EP. For example, the confederation of European Community Cigarette Manufacturers (CECCM) published a report declaring that the EP was permitted to, and should discuss and amend the legal basis (Khanna, 2001: 118). The International Union against Cancer and the Association of European Cancer Leagues framed the ban as a market-making intervention, stating that article $100 \mathrm{a}$ was correct and that differences between member states in regulation of advertising and sponsorship impeded the proper functioning of the internal market (Agence Europe, 1998).

Several (mostly German) MEPs started to raise questions about the legal basis of the Council's common position. Schleicher (EPP, Germany) suggested article 129 as the proper legal basis, since it was generally acknowledged that the directive pursued a health policy objective. In its answer, the Council said that it 'took great pains to produce a text which took into account both the efficient operation of the internal market, and the requirements of ensuring a high level of health protection. (...) The Court of Justice is competent to interpret the measures and to ensure that they comply with the Treaty'. Another example was the question to the Council issued by Jackson (EPP, UK), focusing on the opinion of the Council's Legal Service. '(...) Could the Council explain how the provisions of the current proposal are so different from the $1992 \mathrm{draft}$ as to make the Legal Service's opinion no longer applicable?' The Council responded that the Legal Service assisted the Council in its deliberations by providing independent legal advice, which was only an internal document. Finally, Florenz (EPP, Germany) asked the Commission what justified its choice for article 100a as the legal basis. The Commission answered that it considered the legal basis sufficient and appropriate.

In March 1998, the EP's Legal Service confirmed the legal basis of the common position. It did not question the Community's competence to rule on the matter. On the contrary, it felt that action at European level was necessary, but suggested that the legal basis could 
be strengthened by complementing article 100a with article 57 paragraph 2 (now article 47(2)) and article 66 (now article 55). The latter empowered the Council to adopt directives in order to facilitate the exercise of freedom of establishment, and freedom to provide services (Tridimas \& Tridimas, 2002).

The ENVI Committee delivered its opinion in April 1998 (European Parliament, 1998a). The committee had heard an oral statement from the Legal Affairs Committee, which had issued a report on its own initiative disputing the competency of the EU to adopt a ban on tobacco advertising. By a mixed view (12 votes in favour; 7 against and 3 abstentions), it concluded that the EU had no legal basis on which to act, because there was no distortion of competition, but only the abolition of an activity. However, the Parliaments' Legal Service insisted on article 100a as the correct legal basis. Considering the EP's Legal Service as a body of technical experts instead of politicians who populated the Legal Affairs Committee, the proposal based on article 100a received a go-ahead from the ENVI Committee.

In May 1998, the ban on tobacco advertising was debated in the EP plenary (see European Parliament, 1998b), which was divided in two groups. One group was committed to public health, the other to economic interests. The plenary debate again focused on the legal basis. Several MEPs argued that the directive had the correct basis. 'The Legal Services of Parliament, the Commission and the Council say that article 100a is the correct basis. It is clearly an issue of the internal market' (Kestelijn-Sierens, European Liberal, Democrat and Reform Party (ELDR), the Netherlands).

Opponents claimed that 'since Maastricht, there has been article 129 which calls on us to promote public health and the route for those who want to ban tobacco advertising is article 129 of the Treaty' (Janssen-van Raay, Union for Europe (UPE), the Netherlands). One MEP argued that 'the legal arguments being advanced by the tobacco industry through a skilfully orchestrated lobbying campaign seem intended to evade the debate on the substance of the matter by replacing it with a debate on procedure. (...) Let the Court of Justice decide on the issue of the legal basis, if it is referred to them. That is their right' (Hermange, UPE, France). The discussion on the legal basis was also called a subterfuge: 'When people say we should use article 129, they forget that, according to that article, it is not possible to adopt measures to harmonise the member states' legal and statutory provisions. So it is just a subterfuge, so much so, that we think there has been an attempt to devalue the position of the Council' (González-Álvarez, European United Left/Nordic Green Left (GUE/NGL), Spain).

Despite the discussion on the legal basis, the EP voted in favour of the Council's common position in May 1998. Directive 98/43/EC was finally adopted in July 1998. 


\subsection{THE LEGAL BASIS: JURIDICAL INTERPRETATION}

Germany had blocked the proposal for a tobacco advertising ban from the very beginning for economic reasons. After having been outvoted in the Council, it decided to appeal to the ECJ. In addition to the German government, Salamander AG (Germany), owning the Camel Boots trade mark, Una Film (Austria), distributing cinema tobacco advertising films, Alma Media Group (Greece), selling advertising space in public places, and Davidoff (Switzerland), holding the Davidoff trade mark for tobacco products as well as products outside the tobacco sector, also challenged the tobacco advertising directive before the ECJ. However, the Court of First Instance dismissed their cases, not recognising them as interested parties (European Court of First Instance, 2000).

If the directive would have been adopted by unanimity, one may assume that no government would have had an interest in challenging it. Given the fact that only interested parties, (those whose legal situation is influenced directly by the consequences of the directive and the institutions which have given birth to the directive), can bring proceedings, the list of potential plaintiffs is narrower under unanimity. Thus, QMV increases the chance of litigation before the ECJ, as member states opposing adoption may seek to enforce their point of view by judicial means. The decision of the German government to challenge Directive 98/43/EC created a new institutional setting with the ECJ as arbiter. The interaction mode thus shifted from joint decisions under QMV, to hierarchical direction, centralising competences at supranational level through an ECJ ruling (Scharpf, 2001, 2002).

\subsubsection{The European Court of Justice ruling on Directive 98/43/EC}

The debate thus continued via another route. The German government put forward several reasons why the EU was not competent to adopt the measure (European Court of Justice, 2000), basing its main argument on an inappropriate legal basis. Following its argument that tobacco advertising is essentially an activity whose effects do not extend beyond the borders of individual member states, differences in national legislation did not result in distortion of competition. In fact, a ban would allegedly counteract trade instead of facilitating it, by creating new obstacles that did not exist previously.

The Commission, the EP and the Council, joined by France, Finland and the UK, argued that cross-border trade in services and goods in tobacco advertising existed. A Community-wide measure was required because differences in national regulations could be regarded as an obstacle to free trade. They maintained that article 100a also permitted internal market regulation without a liberalising effect: 'the power conferred on the Council by that provision is not necessarily concerned with the liberalisation of trade, but rather with market regulation. That explains why it has been possible for directives containing certain prohibitions to be adopted on the basis of article 100a' (para 45). The 
Commission also argued that there was, in fact, a real distortion of competition. 'Because of existing differences in legislation, the potential profit of advertising agencies differs according to the (...) market in which they carry on business' (para 51). According to the defendants, the essential factor in assessing the choice of the legal basis was the text of the measure in question. They argued that human health was one of the directives' objectives, but not the principal one. "The emphasis on public health protection in the directive can be explained by the fact that it constituted the main (...) objective of the national measures being harmonised, but, in the context of harmonisation, it became a secondary objective' (para 56). Finally, all defendants referred to paragraph 3 of article 100a: ' $(. .$.$) a broad prohibition on tobacco advertising derives from the obligation$ imposed by article 100a(3)' (para 57).

The ECJ stated that the explicit exclusion of harmonisation in article 129 meant the directive could not be based on that particular provision. 'But that provision does not mean that harmonising measures adopted on the basis of other provisions of the Treaty cannot have any impact on the protection of human health. Indeed, the third paragraph of article 129(1) provides that health requirements are to form a constituent part of the Community's other policies. Other articles of the Treaty may not, however, be used as a legal basis in order to circumvent the express exclusion of harmonisation laid down in article 129(4) of the Treaty' (para 78-79). 'Provided that the conditions for recourse to articles 100a, 57(2) and 66 as a legal basis are fulfilled, the Community legislature cannot be prevented from relying on that legal basis on the grounds that public health protection is a decisive factor in the choices to be made' (para 88). The ECJ therefore had to examine whether the directive actually contributed to eliminating obstacles to the free movement of goods and services, and removing appreciable distortions of competition.

With regard to the elimination of obstacles to free movement, the Court ruled that the directive did not improve the functioning of the internal market. The prohibition imposed by the directive was too general because it concerned all forms of advertising. Some forms, in particular, static advertising media, were not cross-border in nature.

On what concerns elimination of distortion of competition, in examining the lawfulness of a directive adopted on the basis of article 100a of the Treaty, the Court is required to verify whether the distortion of competition, which the measure purports to eliminate is appreciable. In the absence of such a requirement, the powers of the Community legislature would be practically unlimited' (para 106). In this case, the Court argued that the distortions were not considered to be sufficiently appreciable to accept an absolute prohibition of advertising and sponsorship. Based on these findings, the ECJ annulled the directive. Traditionally, the principal means by which the Court influenced the development of the Community had been through an expansive interpretation of 
Community competences. It was the first time the ECJ ruled that the EU did not have the competence to adopt a measure (Hervey, 2001a).

\subsubsection{Directive 2003/33/EC: banning cross-border advertising and sponsorship}

Interestingly however, the Court went a step further by offering a way out. It formulated guidelines for a legally acceptable policy. The Court argued that the trend towards more restrictions on tobacco advertising in national regulations might lead to obstacles to the free movement of press products. 'In principle, therefore, a directive prohibiting the advertising of tobacco products in periodicals, magazines and newspapers could be adopted on the basis of article 100a' (para 98). A similar argument could be valid for certain forms of sponsorship. With these statements, the Court made an indirect contribution to policy-making (Tridimas \& Tridimas, 2002) which strongly influenced the further course of the process. The problem-solving intervention of the Court opened the possibility for a new proposal by the Commission, introduced a year after the annulment (Commission of the European Communities, 2001a).

This proposal had the same legal basis as the annulled Directive 98/43/EC (now, after amendment, article 95). However, the Commission made sure to emphasise the marketmaking element of the directive. Again the Commission reasoned that differences between national legislation resulted in barriers to the free movement of products and advertising related services between member states. In the case of sport sponsorship, the distortion of competition was likely to increase. As member states were heading towards increasingly stringent advertising restrictions, harmonisation could only be logically based on a ban. However, this time the scope of the proposal was limited to advertising and sponsorship with a cross-border effect. Indirect advertising, as well as those elements of advertising with no cross-border effect, fell outside the scope of the proposal.

Whereas in the previous process the ENVI Committee was responsible for the report on the proposal, in this case the Committee on Legal Affairs and the Internal Market drafted the report for the EP (European Parliament, 2002a). It took 18 months to come up with 25 amendments, which according to a member of the ENVI Committee, could 'lead to further annulment by the Court of Justice and which restrict the scope of the directive still further' (Tsatos, Party of European Socialists (PSE), Greece) (European Parliament, 2002b).

The ENVI Committee, though not the committee having prime responsibility anymore, gave its opinion on the Commission proposal: 'The new proposal is much more modest in terms of protection of public health. (...) Studies have been carried out on the effects of partial or total advertising bans on the consumption of tobacco products. They have shown that partial advertising bans have only limited effects on smoking, since the industry can easily switch to advertising in other media. On the contrary, comprehensive 
bans on the advertising and promotion of tobacco products, covering all media and all uses of brand names and logos have proved to be significantly effective in reducing smoking' (European Parliament, 2002a: 28). The ENVI Committee considered the Commission's proposal 'extremely disappointing from the point of view of health protection', but the debate did not take place in a vacuum and the EU competence to adopt legislation should be taken into account. Therefore the proposal 'goes as far as possible. (...) Any amendment seeking to introduce new elements emphasizing the public health aspects would de facto undermine the appropriateness of the legal basis' (European Parliament, 2002a: 29).

During the debate in the EP (European Parliament, 2002b), responsible Commissioner Byrne expressed his disappointment with the slow progress on the proposal: 'There have been delaying tactics, misinformation and, very often, misleading statements. It is a great pity that the Committee on Legal Affairs and the Internal Market was unable to work more quickly, in contrast to the much quicker Committee on the Environment, Public Health and Consumer Policy, whose members are the true experts in the EP. (...) I make no secret of the fact that I would have preferred to present a proposal for a complete ban (...). But, unfortunately, the legal framework does not allow us to go that far. (...) We have to recognise the legal constraints'.

In general, the discussion in the EP focused on the ECJ ruling and the question if this new proposal indeed had a Treaty basis. For example, both German MEP Lechner (EPP) and Berger (PSE) argued that most publications simply had no cross-border effect. 'I believe this question of law to be eminently political in nature (...). We should be putting down a marker, and as legislators ourselves, respecting the powers of our counterparts in the national parliament, rather than again leaving this matter to the ECJ' (Lechner). However, in November 2002, the EP passed the watered-down proposal with 309 votes in favour, 203 votes against and 39 abstentions (Watson, 2002).

Once brought to the Council, agreement was reached on 2 December 2002. Again, two member states voted against the directive: the UK and Germany. Paradoxically, the UK had just passed a ban on tobacco advertising in November 2002. After a positive vote on the annulled Directive 98/43/EC, the UK voted against Directive 2003/33/EC, claiming that the text was too weak. It remains unclear whether this was the real argument, or whether the British government wanted to please some domestic constituents, with the knowledge that the directive would be adopted anyhow (Duina \& Kurzer, 2004).

\subsubsection{The European Court of Justice ruling on Directive 2003/33/EC}

After the adoption of Directive 2003/33/EC, the German government asked the ECJ to annul article 3 and 4 (European Court of Justice, 2006), covering a ban on advertising in the press and printed publications, except those intended exclusively for professionals in 
the tobacco trade and printed in third countries not principally intended for the Community market; a ban on advertising on the internet for those advertisements that are not allowed in press and printed publications; and a ban on radio advertising and sponsorship.

The German government put forward five pleas in law in support of its action: article 95 (previously article 100a) was not the appropriate legal basis; the directive was adopted in breach of article 152(4) (previously article 129(4)). In addition, Germany also argued that there was a breach of duty to state reasons, of the rules governing the co-decision procedure, and infringement of the principle of proportionality. Whereas Directive 98/43/EC was only challenged on its legal basis, it seems that in this case, Germany searched for additional reasons to strengthen its position. However, in the light of settled case law, these grounds appeared likely to fail.

First, the German government held that none of the prohibitions laid down in article 3 and 4 of the directive contributed to eliminating obstacles to the free movement of goods, or to removing appreciable distortions of competitions. It claimed that there was hardly any cross-border trade of printed publications, consultation on the internet of printed publications from other member states was marginal and the limited range of transmitters implied that radio programmes addressed to the public in a locality or region could not be picked up elsewhere. 'The true purpose of those prohibitions is not to improve the conditions for the establishment and functioning of the internal market, but solely to protect public health' (para 24). The EP and the Council, supported by Spain, Finland, France and the Commission, disputed all these arguments.

The Court examined whether this new directive conformed to the criteria set out in the previous case on Directive 98/43/EC. The three determining factors used to decide whether the new directive was legitimately based on article 95 included the need to harmonise, a favourable internal market purpose and a favourable internal market effect. The possibility that the directive also had a public health protection goal did not matter as long as there was also a market-making element. The Court used the same wording as in the previous case (see para 88): 'Provided that the conditions for recourse to article $95 \mathrm{EC}$ as a legal basis are fulfilled, the Community legislature cannot be prevented from relying on that legal basis on the grounds that public health protection is a decisive factor in the choices to be made' (para 39).

The Court argued that disparities between national laws on tobacco advertising did indeed exist and resulted in legal obstacles to trade. The Court then examined whether article 3 and 4 were in reality designed to eliminate or prevent obstacles to the free movement of goods, the freedom to provide services or to remove distortions of competition. Given that article 8 of the directive prevents member states from prohibiting or restricting free movement of products and the freedom to provide services that 
comply with this directive, 'article 8 of the directive gives expression to the objective laid down in article 1(2) of improving the conditions for the functioning of the internal market' (para 74). Therefore article 95 was the correct legal basis of the directive and the Court dismissed this plea.

Second, Germany also maintained that article 152(4) laying down the prohibition on any harmonisation of the laws and regulations of the member states in the field of public health was circumvented, because the true purpose of the directive was public health. The Parliament and the Council argued that that the conditions for recourse to article 95 were fulfilled and that this could not prevent them from taking measures that also had an impact on the protection public health. Since the Court had already ruled that the directive had the correct legal basis and explained in paragraph 39 that this directive could have both a market-making and market-correcting effect, the second plea was dismissed as well.

Third, the German government asked for annulment, arguing that the requirement to show clearly and unequivocally the reasons for the measures adopted, as laid down in article 253 of the Treaty, were not fulfilled. However, the Court disagreed and stated that the 'recitals clearly disclose the essential objective pursued by the Community legislature' (para 114). The fourth argument concerned infringement of the co-decision procedure. Germany stated that amendments were made by the Council to article 10 and 11 of the directive without approval of the EP. However, the Court determined that 'by the present action, the applicant seeks to call into question the validity of articles 3 and 4 of the directive alone' (para 124), therefore, this plea necessarily needed to be dismissed. Finally, Germany tried to show that the prohibitions of article 3 and 4 'seriously compromise fundamental rights in the economic sectors concerned' (para 130), referring to the freedom of the press and of expression. The Council and the Parliament explained that these fundamental rights may 'be subject to certain restrictions or penalties, prescribed by law, which are necessary in a democratic society in the interests of the protection of health or morals' (para 141). The ECJ ruled that article 3 and 4 'may be regarded as measures appropriate for achieving the objective they pursue' (para 146) and therefore also dismissed this plea. Thus, Germany lost its appeal for annulment of article 3 and 4 of Directive 2003/33/EC.

\subsection{CONCLUSION}

The question of why it took so many years of negotiation before the EU adopted a policy measure that could, in fact, improve the health situation in the Community, can only be answered by focusing upon politics (Buse, Mays, \& Walt, 2005). In chapter 3 we concentrated on strategic behaviour of the policy-making actors concerning tobacco advertising. This chapter presented an analysis of the impact of the legal basis on this 
policy-making process. Following our framework of actor-centred institutionalism, actors' strategic behaviour is related to both their preferences and the institutional structure constraining or enabling them.

The policy-making process featured a high level of conflict from its initiation and throughout the process, not only because of differing views concerning the impact of the ban upon smoking behaviour, but also, and more importantly, because of distributive conflicts. At a deeper level, the political difficulties reflected a conflict between public health and economic interests. As we showed in our analysis, in the case of tobacco advertising, the discussion on the legal basis was used to circumvent debate on how to balance these interests.

When the Commission came up with its proposal for a tobacco advertising ban in 1991, it had to play the treaty base game in order to create a proper legal basis. The Treaty did not provide the Community with the legal competence to harmonise national regimes to attain a public health goal. One option was to use article 235, but this route had a serious drawback. Not only did it reduce the role of the EP to that of consultation alone, but it also required unanimity in the Council, which would be politically unfeasible given the diverging preferences of the member states. The only option left was article 100a.

The assessment of the proposals' legal basis by the member states and the EP varied with their preferences. For a long time, achieving a qualified majority in the Council was impossible, because several member states formed a blocking minority. Their main argument was that the legal basis was incorrect. They tried to reduce the scope of the proposal and suggested an alternative legal basis that they knew would never work, because of the requirement of unanimity. Thus, opposing member states within the Council tried to change the problem-solving capacity of the EU from QMV to unanimity.

In the EP, opposing MEPs tried to change the legal basis by asking the Council and the Commission questions. They also tabled amendments to change the legal basis. If the EP had indeed amended the Council's common position, a conciliation procedure between the EP and the Council would have been necessary. The actors involved were all aware that conciliation would most likely fail and result in a non-agreement. Therefore, the EP adopted the common position without amendments.

Our case also illustrates the prominent role of the ECJ, not only in legal terms, but also in terms of policy-making. Asking the ECJ to annul Directive 98/43/EC because it had no correct legal basis was obviously a clear strategic choice by Germany and a few other dedicated opponents. This implied that the institutional setting changed from the mode of joint-decision to the mode of hierarchical direction. The ruling was remarkable, because the Court did not confine itself to the conclusion that the Treaty missed a proper legal basis for the ban. The ECJ went a significant step further by suggesting a way out. The 
Commission seized the opportunity offered by the ECJ and tabled a new proposal. In 2003, a new directive with a limited scope was adopted. This directive 'survived' after the ECJ dismissed the German challenge in December 2006.

The ECJ has been relatively generous in drawing the boundaries of the internal market Treaty basis, including cases concerning the use of this basis for measures with perhaps more than an incidental health protection aim. Whereas the Court departed from this generous construction of article 100a as the legal basis in its ruling on Directive 98/43/EC (Hervey \& McHale, 2004: 94), it ruled that the article was the valid legal basis for Directive 2003/33/EC.

Our case clearly demonstrates that the Commission strategically used its right of initiative. Despite the consistent ruling of the ECJ that the choice of a legal basis should always be a matter of legal principle (Hervey, 2001a), the strategy of the Commission reflected a high degree of political pragmatism. The choice of the legal basis evolved as a strategic game in itself: it became a permanent contentious issue throughout the policymaking process. The process was characterised by the repetition of arguments that continued until the final stage. Beyond the question about the political will to adopt a ban on tobacco advertising, there was the juridical question as to whether the EU was, in fact, allowed to adopt such a measure.

The market-making versus market-correcting discussion is related to a broader question, namely the scope of EU health regulation in respect to the member states. In fact, the policy-making process on a tobacco advertising ban is related to the 'constitutional' foundations of health policy legislation in the Community.

EU health policies often have to be legitimised by Treaty articles that have no, or only an indirect link, to health and healthcare, such as the internal market Treaty basis. However, the absence of a clear cut legal basis for health policies does not imply that the EU's impact on health is negligible. The single market exposes almost all areas of economic importance to competition, including goods and services related to health(care). In many cases, market-making interventions touching upon health - including other tobacco control measures and regulations on the safety and quality of pharmaceuticals, food and medical devices - also protect consumers. These measures thus combine an internal market rationale with consumer protection and public health goals (Hervey, 2001b: 102-109). As long as the internal market, on its own, constitutes a sustainable legal basis, a health rationale can be central to internal market legislation. Thus, a marketcorrecting intervention is possible as long as it also has a market-making element. In the case of tobacco control measures, this has resulted in significant action against smoking related morbidity and mortality (Aspect Consortium, 2004: 102). So even though the EU has narrow direct competences in the field of health, European health policy is incrementally taking shape (Lamping, 2005) based on other legal bases. 


\section{INTEREST REPRESENTATION ON THE TOBACCO ADVERTISING BAN}

This chapter is based on: Boessen, S., \& Maarse, H. (2008, forthcoming). The role of interest groups in policy-making on the European ban on tobacco advertising. In: J. Richardson \& D. Coen (Eds.). Lobbying in the European Union. Oxford: Oxford University Press.

\section{$5.1 \quad$ INTRODUCTION}

Policy-making cannot be explained without analysing the role of interest representation (Greenwood, 2003). This is also certainly true in the European Union (EU). The growing importance of the EU in many policy areas has resulted in a tremendous increase of the number of interest groups in 'Brussels' all of which try to shape the policy-making process for their own benefit (Mazey \& Richardson, 2006: 248).

Interest groups at the European level include a variety of private and public companies, national interest groups and Eurogroups (Nugent, 2003), that operate as umbrella organisations as well as sector and branch associations representing business interests (Pijnenburg, 1998). They seek to affect policy-making via the European or national route (Greenwood, 2003: 31).

Much research has been done on tobacco industry strategies to influence EU tobacco control policies (see for example Bitton, Neuman, \& Glantz, 2002; Hafez \& Ling, 2005; Hiilamo, 2003; Muggli \& Hurt, 2003; Neuman, Bitton, \& Glantz, 2002; Poetschke Langer \& Schunk, 2001). We do not want to duplicate this research here, nor is it our goal to pursue an in-depth study of interest representation on the tobacco advertising ban. The main objective of this chapter is to present the results of an empirical analysis concerning the impact of formal and informal institutions on interest representation. ${ }^{12}$

Our focus is upon the relationship between institutions and the strategic behaviour of interest groups. We do not claim to have full information on all activities concerning interest representation. As one respondent said: "The advertising directive literally involved hundreds of different actors over the years and they all had their own angle on it" (\#5, PH lobbyist). Institution-based information offers us an explanation of how interest groups use the institutional structure without having to collect empirical data on all actors (Scharpf, 1997).

\subsection{INSTITUTIONAL STRUCTURE AND INTEREST REPRESENTATION}

The EU occupies a central position in many policy areas. It is therefore not surprising that interest groups arise whose goal it is to influence EU policy-making processes. We

\footnotetext{
${ }^{12}$ For an overview of the interviews refered to in this chapter, see appendix 1.
} 
distinguish among outsider (voice) and insider (access) strategies. Insider strategies concentrate on direct involvement in the political discussion, whereas outsider strategies focus on the media and the public in order to represent interests (Eising, 2005). However, interest representation is not only important for interest groups to express their ideas but also for EU actors themselves. The Commission often deliberately encourages interest group cooperation by initiating networks and providing financial support (Greenwood, 2003; Kohler-Koch, 1997). In addition, the Commission is surrounded by a more formalised structure of advisory committees, consisting of expert committees with national officials and specialists, and consultative committees composed of representatives of sectional interests without reference to the member states. These committees also provide a route for interest representation (Greenwood, 2003: 55-56).

The policy-making cycle with its shifting competences and rules of the game provides multiple chances for lobbyists to influence the process. Table 5.1 gives an overview of the main EU actors, here conceptualised as points of access for interest groups, and their relation to formal and informal institutions (see chapter 2 for a definition of formal and informal).

\begin{tabular}{|c|c|c|}
\hline \multirow{2}{*}{ Points of access } & \multicolumn{2}{|c|}{ Institutions } \\
& Formal & Informal \\
\hline Commission & Right of initiative & Network building \\
\hline Council of Ministers & Voting rules & Impartiality norm (presidency) \\
\hline European Parliament & Decision-making procedures & Intergroup creation \\
\hline European Court of Justice & Preliminary reference & - \\
\hline
\end{tabular}

Table 5.1: Overview of the institutions in relation to interest groups' main points of access

It should be noted that the EU actors are presented here as monolithic entities. We use the concept of composite actors, because in most cases individual self-interest would not be a useful predictor of role-related action. In law and in fact, individuals often act in the name of and interests of an organisation with structured responsibilities and competencies. Therefore, we assume that in the political process most relevant actors are acting in the interest and perspective of larger units rather than for themselves (Scharpf, 1997). In the following sections we analyse the impact of the formal and informal institutions on interest group behaviour. It should be noted that our focus is on strategies, not influence. 


\subsection{THE EUROPEAN COMMISSION: RECIPROCAL INTEREST REPRESENTATION}

The Commission's power to initiate and draft legislative proposals generally results in reciprocal interest representation. First, as an agenda-setter and relatively small bureaucracy, the Commission has need of information, especially in highly technical areas. In addition, interest groups can be an effective source of support (Mazey \& Richardson, 2006: 248-249). Whilst, the possibility of influencing the identification and framing of European policy problems attracts interest groups. One respondent emphasised the importance of an effective insider strategy as following: "The lobbyist job is half done if you can influence the way in which the proposal is written before it has been published. (...) So a very fundamental part of the job is trying to understand what the officials are doing, what their work programme is, what they are intending to write proposals about, what angle they are going to take, what issues they have to take into account" (\#5, PH lobbyist).

In the following section we will study how the Commission's right of initiative influenced interest representation. Although the main focus of this chapter is on how interests groups use the institutional setting, we also assess how the Commission, in its need for support and information, influenced interest representation.

\subsubsection{Tobacco advertising on the agenda: the Commission's right of initiative}

In 1984, the European Council asked the Commission to develop a new policy area closer to the concerns of European citizens. The Commission Communication on 'the cooperation at Community level on health related problems' (COM(84) 502 final) suggested the fight against cancer as such an area. In 1985, the European Council requested the Commission to launch a programme against cancer. "To get involved in an issue with which most Europeans at an individual level could identify, there was that potential political bonus (...), it was Europe doing something for European citizens and frankly it was the first time that happened" (\#5,PH lobbyist).

The Commission was authorised to set up an ad-hoc committee of cancer experts to develop the first Europe Against Cancer (EAC) programme. One of its central elements was the fight against tobacco. The first action plan (1987-1989) was a product of civil servants within the EAC programme and the cancer experts committee. Given the strength of the tobacco industry, they decided to table a series of different proposals concerning tobacco control instead of a "single all-embracing directive" (Gilmore \& McKee, 2004: 226).

The EAC group was a relatively independent unit located in Brussels and reporting directly to the Directorate-General (DG) Social Affairs in Luxembourg. It was 'free from bureaucratic restrictions (...), enjoyed a privileged position and strong staffing base' (Gilmore \& McKee, 2004: 225). The enthusiasm and dedication of the civil servants 
together with the cancer expert committee resulted in a proposal restricting tobacco advertising in 1989 (Commission of the European Communities, 1989). Developments in the European Parliament (EP) and the member states, as descibed in chapter 3 and 4, resulted in a proposal for a tobacco advertising ban in May 1991 (Commission of the European Communities, 1991).

The cancer expert committee, with a very influential president with 'frequent access to heads of government' (Gilmore \& McKee, 2004: 226) played an important role in formulating the proposals (\#2, PH lobbyist). The committee also explained the content and necessity of restrictions on tobacco advertising to the College of Commissioners (Aspect Consortium, 2004). In addition, national cancer leagues sought to influence the experts (\#2, PH lobbyist).

In order to collect information, the Commission's EAC group funded a tobacco information service in 1989. This was the European Bureau for Action on Smoking Prevention (BASP) (Aspect Consortium, 2004). When the Commission put forward its second more radical proposal to ban tobacco advertising, BASP provided information and argumentation that was used by the Commission to support its revised proposal (\#2,PH lobbyist).

The EAC programme provoked an immediate reaction from the tobacco industry, which began to set up offices in Brussels. Furthermore, the Confederation of European Community Cigarette Manufacturers (CECCM), established in the late 1980s, was provided with extra financial resources from the member firms "to give it a corporate sort of response" (\#5, PH lobbyist). Of course, this reaction was not surprising. As one interviewee explained: "It was quite clear that if you really wanted to deal with cancer, tobacco related cancer is the biggest topic area that you could target. That meant that inevitably you were going to attack the tobacco industry" (\#5, PH lobbyist).

Still, it took the industry quite some time to develop a fully functioning lobbying machine. The initial lack of response from the tobacco industry made it possible to table a proposal on tobacco advertising (Gilmore \& McKee, 2004). The tobacco industry saw itself confronted with the problem of how to target the small group of civil servants working on the proposal within the framework of the EAC programme which was not likely to take its arguments into serious account. However, the Commission's functional structure provided the industry with different points of access, being the DGs Agriculture and Industry (see Bitton, Neuman, \& Glantz, 2002: 41) with conflicting policy interests vis-à-vis the EAC programme.

Not only the tobacco industry reacted to the EAC programme. The Association of European Cancer Leagues (ECL) felt it necessary to influence EU policy-making, because "the Community actors were making proposals, the industry was lining itself up to oppose them, but there was no one who was going to give the health arguments in 
response to the industry's arguments" (\#5, PH lobbyist). For that purpose it established an office in Brussels in 1990, financed by the International Union Against Cancer and the association of European Cancer Leagues. ${ }^{13}$ The ECL became the first European public health organisation to support the Community in its anti-tobacco policy. Note that it did not play a role in drafting the tobacco advertising proposal since that had already been tabled at the moment they appointed an anti-tobacco advocate in Brussels.

\subsubsection{Creating interest representation: the informal rule of network building}

Contacts with supportive interest groups could strengthen the Commission's position 'in relation to national governments and opposing interest groups' (Fairbrass \& Jordan, 2003: 109-110). As a result, one of the measures of the first EAC action plan concerned 'information exchange in the struggle against smoking' (Aspect Consortium, 2004: 109). Resistance to tobacco control policy could be counteracted by involving a wide range of interests. However, the European health lobby still had to develop. Furthermore, in the early 1990s, medical and health communities at national level were rather inactive in their opposition against smoking (Duina \& Kurzer, 2004: 59).

The Commission, therefore, helped to develop the landscape of pro-European health interest representation by providing resources to establish and sustain interest groups and asking them to undertake functions on behalf of the Commission, such as supplying information (Greenwood, 2003). One of the first measures was providing the European Bureau for Action on Smoking Prevention with financial support. BASP assisted advocates of the ban with documents, such as a quarterly newsletter on national and international developments on tobacco control policy and thematic reports. Within a few years, it evolved as the number one target of the tobacco industry (Neuman, Bitton, \& Glantz, 2002).

The Commission also coalesced with national organisations by subsidising national cancer leagues and anti-smoking organisations. They were involved in spreading the message of the EAC programme (\#2, PH lobbyist). Cancer and anti-smoking organisations held meetings every six months. As a result "the individuals concerned got to know one another quite well, sharing good and bad practice, learning from one another. So gradually what was building was a sense of identity within the health community across the member states" (\#5, PH lobbyist). These networks were consulted regularly with regard to legislative proposals. In a tobacco industry document it was mentioned that 'the degree to which the 'antis' have penetrated the fabric of the European Community and the major international non-governmental organisations is quite remarkable. (...) The relationships

\footnotetext{
${ }^{13}$ The International Union Against Cancer is a global NGO including cancer research institutes, specialized hospitals and national cancer leagues as its member organisations. The association of European Cancer Leagues unites national organisations against cancer.
} 
between individuals and organisations are almost incestuous, but serve to consolidate a common view and strategy for smoking control throughout the region' (Philip Morris, 1993a).

In 1994, the Commission evaluated these semi-annual meetings. This resulted in the creation of two pan-European networks: the European Network for Smoking Prevention (ENSP) and the European Network on Young People and Tobacco (ENYPAT). Another consequence of the evaluation was to cease funding the European Bureau for Action on Smoking Prevention. The Commission replaced BASP with ENSP and ENYPAT, which received less financial resources and had a more restricted mandate than BASP (Bitton, Neuman, \& Glantz, 2002). The main goal was to create synergy between the member states. Lobbying was explicitly excluded from their mandate (\#2, PH lobbyist). Different explanations exist for these changes. First, Germany, the United Kingdom (UK) and the Netherlands as well as DG Agriculture pressured the EAC group within the Commission to stop financing the leading anti-tobacco lobby in Europe. Another reason mentioned was that the head of the public health unit of DG Social Affairs wanted to weaken the EAC programme, which had gained too much attention and was considered too independent. One way was to weaken the role of BASP (\#2, PH lobbyist and Doyle (1995)).

The informal rule of network building provided the Commission with the opportunity to organise interest representation and thus influence the lobby on the tobacco advertising ban. The Commission used the possibility within the EAC programme for information exchange to strengthen the public health lobby at national and European level. However, the experience with BASP suggests a limit to this informal rule. It may be one step too far when an organisation subsidised by the Commission, develops into an activist agency in a highly contentious EU policy arena.

\subsection{LOBBYING THE COUNCIL: THE NATIONAL ROUTE}

Of all EU actors, the Council is the least accessible to interest groups. It is not a forum for public debate, nor does it represent citizens directly (Beyers, 2004). Most interest groups therefore follow the national route for interest representation. Two rules of the game related to the Council's decision-making process are relevant in analysing their strategic behaviour: the voting rule and the role of the presidency. In the following section we will demonstrate how the tobacco industry used the Council's institutional structure. We will also explain why the public health lobby had more difficulties in spreading its message successfully. 


\subsubsection{The impact of qualified majority voting}

The tobacco industry's aim was to block the passage of the proposal (Bitton, Neuman, \& Glantz, 2002). Thus, Germany with ten votes in the Council was a strong ally in the industry's opposition against the ban. However, because of the qualified majority voting (QMV) rule, one member state alone could not block a decision; a blocking minority required at least 23 votes (Peterson \& Bomberg, 1999: 48). Therefore, the industry concentrated on forging alliances with national policy-makers (Bitton, Neuman, \& Glantz, 2002). In particular, it sought contact with political actors outside national Health Ministries, since they tended to support a tobacco advertising ban. Several governments opposed the ban despite the directives of their own Health Ministries. The German Chancellor Kohl and former Prime Ministers Thatcher and Major as well as the Health and later Finance Minister Clarke from the UK supported the tobacco industry's opposition. ${ }^{14}$

The level of contact can be illustrated by a correspondence between Clarke and Philip Morris' Director of Corporate Affairs in 1992. 'If the UK and Germany remain solidly opposed to the advertising and sponsorship ban, Holland and Greece will be equally solid and the blocking minority is assured. This is something I am sure you would welcome as much as we would' (Philip Morris, 1992). Clarke replied: 'I remain happily opposed to the advertising and sponsorship ban being proposed by the Commission. I will certainly do my best to ensure that our Government maintains its opposition’ (Clarke, 1992).

Both Thatcher and Major offered representatives from tobacco companies 'a seat in policy discussions across a whole range of departments' (Duina \& Kurzer, 2004: 69). Furthermore, there were contacts with high ranking officials in the Greek government (Aspect Consortium, 2004: 203; Bitton, Neuman, \& Glantz, 2002). This was quite remarkable. A respondent explained: "It is very seldom that a Prime Minister mixes into a case like this. (...) However, Prime Ministers of several member states said 'no' to the tobacco advertising ban" (\#1, German civil servant).

In the Netherlands, the industry tried to preserve Dutch opposition through its contacts within the Ministry of Economic Affairs: 'Use (...) contacts with the Economics Ministry to keep the Health Minister from undermining the Dutch position' (Philip Morris, 1993b). Officials from Finance and Economics ministries were caught repeatedly trying to silence reports which could have influenced public opinion (Bouma, 2001: 275276). Tobacco industry self-regulation was an important strategy. Infringements of the socalled voluntary code on tobacco advertising were not sanctioned. Political as well as

\footnotetext{
14 Thatcher became a consultant with Philip Morris and Clarke became deputy chairman of British American Tobacco.
} 
social support to strengthen measures against advertising hardly existed in the early 1990s. A similar situation existed in Denmark (Duina \& Kurzer, 2004: 68).

In the Council, the whole policy game was played out at different tiers. "You had 'the small administrators' level trying to get a government view with the different administrations" (\#1, German civil servant). Civil servants from national Ministries of Health discussed the tobacco advertising ban in the health working group of the Council. Negotiations in this group were “(...) incremental, mainly based on common interest. The informal atmosphere, agreeing behind the scenes normally plays quite a big role. In this case it did not have a chance. (...) The second layer was the layer of highest political people saying what they wanted” (\#1, German civil servant).

The industry also used third party alliances to promote their position clandestinely. An illustration of this strategy is a Danish coalition known as 'the Committee for Freedom of Commercial Expression' (Philip Morris, 1991). This committee - created by the tobacco industry - appeared to be an independent third party with over 50 prominent Danes. It '(positioned) itself as the voice of commercial free speech. Members of government (including the Minister of Health) (...) regularly consult(ed) with committee members, who (were) instrumental in securing the commitment and public declaration of the Minister of Health to oppose an advertising ban' (Philip Morris, 1991).

Also media and advertising groups were encouraged to raise their voices in member states and at EU level 'to fully (work) in lobbying the proposal and threats of blocking of cross-border press sales' (Burson Marsteller, 1992). One result was the launch of media campaigns in the early 1990s. A large number of European newspapers and magazines allocated space for messages against a tobacco advertising ban, warning of the potential domino-effect of the proposal; opening the door to the the tobacco advertising ban would result in subsequent bans on other products such as cars and alcohol (BASP, 1992b; Naett \& Joossens, 1992).

Finally, the tobacco industry established a programme to strengthen its relationship with journalists reporting Formula One car racing to encourage them to write against the proposal. Especially in the final stage of the policy process, the Formula One issue played an important role. The May 1997 elections in the UK resulted in a new Labour government, which, contrary to its predecessor, supported the ban on tobacco advertising. Yet, only a month before the decisive Health Council of December 1997, the $\mathrm{UK}$ asked for an exemption of sponsored sports from the ban. The background of this request was that the Labour party had accepted a large gift from Formula One chairman Ecclestone in January 1997. Opposition in the UK called it a 'cash-for-access' affair (Cracknell, 2004). According to the Commission, this complicating factor would undermine the negotiations at a very advanced stage. It would be very difficult to persuade other member states to accept such an exception (Agence Europe, 1997a). 
The tobacco industry and its alliances used all kinds of strategies to avoid a qualified majority. In one sense, it had a simpler task than the public health lobby. As Van Schendelen (2002) argues, it is easier to block a proposal, because that requires only one effective barrier, than to push a development which often requires taking more than one hurdle. The public health lobby had to take several hurdles indeed. First, public health interest groups did not have comparable financial resources. When they became more active in the early 1990s, they were already faced with massive communication campaigns organised by the opposition. They did not have the means to oppose to such campaigns. In addition, the tobacco industry could treat significant people involved in the policymaking process for lunches and dinner parties (\#5, PH lobbyist).

Second, the public health lobby still had to organise itself at European level. Organisations were not used to coordinating their strategies over twelve countries (\#5, PH lobbyist). The first notion of a European competence in public health only came with the Maastricht Intergovernmental Conference. A lobbying network based in Brussels, the European Citizen Action Service (ECAS), took the initiative and helf a conference about the EU's future public health competence. "Suddenly we had a ground swell of opinion on becoming interested in health at EU level" (\#5, PH lobbyist), which resulted in the establishment of the European Public Health Alliance (EPHA) in December 1992. EPHA had public health representatives from eleven European countries, "from the health related organisations that were already in the membership of ECAS and a whole host of new organisations that were never going to have a presence in Brussels physically but wanted somehow to connect to what was going on in the EU" (\#5, PH lobbyist). In a press release, the newly established organisation stated that 'the health consequences of smoking are well demonstrated by many epidemiological studies performed over forty years. Smoking is a common cause of death in all countries represented by EPHA. These well demonstrated facts lead us to firmly advocate a ban on all direct and indirect advertising for tobacco in countries represented by EPHA' (BASP, 1992c).

The third reason why the public health lobby was not as strong as the industry lobby was the lack of attention on European developments in national organisations. For example, the ECL tried to activate their national member organisations to influence member states opposing the ban. However, some of them questioned whether it was correct to use public money donated to cure people of cancer or to fund cancer research for a lobbying campaign. Several national member organisations - sceptical of the political character and even more so the European level - were not willing to support a lobbying campaign against tobacco advertising. In principle they supported the proposal, but in practice they believed that there were good reasons not to make too much noise

\footnotetext{
${ }^{15}$ Belgium, Denmark, Spain, Finland, UK, France, Hungary, the Netherlands, Portugal, Sweden and Switzerland.
} 
about it at home. Their broader commitment to cancer care was more important for them than their specific commitment to a ban on tobacco advertising (\#5, PH lobbyist).

The ambivalent position of national member organisations to tobacco control is well illustrated by the strategy of the Dutch Cancer Foundation, which created an 'independent' anti-smoking organisation, 'Stivoro', together with the Dutch Heart Foundation and the Asthma Fund. Receiving by no means enough money to play an important role, the balance of power between Stivoro and the tobacco industry was unequal. As Bouma (2001: 288-289) argues, Health Minister Borst, responsible for public health, did not meet with Stivoro at all during the period between 1994 and 1999.

Stivoro therefore mainly focused on outsider strategies. An example of such a strategy is a press release from Stivoro and the Medical Alliance against Smoking, created by Stivoro, in which they asked the Dutch government to support the European ban during the Health Council meeting in December 1993 as a critical step towards a qualified majority. The Medical Alliance also offered a petition to the Secretary of Health and the Parliamentary Commission on public health stating that 'the Netherlands hold the five decisive votes for a tobacco advertising ban at European level' (Dutch Ministry of Health, 1993).

In other countries too, the public health lobby used similar strategies; letters, resolutions, position papers, press releases and conferences. This focus on tobacco influenced the debate at national level (Khanna, 2001), resulting in an evolution towards more restrictions (\#4, Dutch civil servant). As one respondent said: "There was no way we were going to get the advertising directive approved until one of the two big governments, Germany or the UK, changed its position. (...) But you have to keep the momentum going" (\#1, German civil servant).

Only when a qualified majority seemed possible in the second half of 1997, did the public health lobby try to push political decision-making. The public health advocacy lobbied the Danish and Dutch government very actively, since their votes were decisive. A huge number of letters from public health organisations throughout Europe was sent to both countries in order to convince them to vote in favour of the proposal. Finally, in December 1997, a qualified majority including the Netherlands, but not Denmark accepted the ban on tobacco advertising.

The QMV rule was very important in the policy-making process on the tobacco advertising ban. Both the tobacco industry and its alliances and the public health lobby were very much aware of this. As we demonstrated, the industry tried to influence highlevel policy-makers at national level to maintain a blocking minority at European level. These insider strategies were supported by outsider strategies such as media campaigns trying to influence the public opinion. 
According to one public health lobbyist, interest representation at Council level was difficult: "That is where I think we did not do as well as the tobacco industry did. I mean, the industry quite clearly had in its fingers several key governments, Germany and the UK in particular" (\#5, PH lobbyist). Public health interest groups neither had the number of people nor the financial resources to counterbalance the industry's tactics.

\subsubsection{The presidency: searching for a compromise}

The presidency plays an important role in the context of Council negotiations. Presidencies are expected to act as honest mediators who are subject to the impartiality norm (Metcalfe, 1998: 414). When negotiations are not progressing, the president can put forward a 'compromise from the chair' (Hayes-Renshaw, 2002: 58-59; Matilla, 2004: 34). This informal norm may therefore be of interest to lobby groups as a means to influence the president.

According to a study of Neuman et al., (2002), CECCM focused on a compromise proposal based upon minimal harmonisation as an alternative to the existing Commission proposal for a ban on tobacco advertising. This compromise proposal was presented by the industry's main ally against the ban, Germany. The industry's strategy was to make optimal use of the German presidency in 1994. The compromise proposed by the German government ${ }^{16}$ was very similar to the industry proposal (Neuman, Bitton, \& Glantz, 2002).

Interest groups' awareness of the role of the presidency is illustrated by the June 1996, policy paper from the ECL asking the Irish government to keep the proposal 'on the table' and reject any movement towards a weak compromise, or even worse, a resolution during its presidency in the second half of 1996. The policy paper explicitly referred to the possible change of government in the UK in 1997: 'The likely policy switch in Britain has not been overlooked in Germany. The pressure on the German government to oppose the ban as such has not just come from the tobacco industry, but also from the advertising agencies. These sources are now pressing for German agreement to a compromise, in order to forestall a complete EU advertising ban (...)' (ECL, 1996).

\subsection{Lobbying THE European PARLIAMENT: THE European Route}

The influence the EP can exert depends on the decision-making procedure. Initially, negotiations on the tobacco advertising ban took place under the cooperation procedure which was replaced with the co-decision procedure in November 1993. The latter gave the EP an effective veto. Due to the co-decision procedure, the EP's importance for

\footnotetext{
${ }^{16}$ Minutes from the Health Working Group meeting, 7 July 1997, retrieved from the Dutch archive on tobacco advertising (doc 10657/94 SAN 96).
} 
interest representation has increased (Khanna, 2001). Interest groups provide expert knowledge trying to influence members of the EP (MEPs). In addition, they contact MEPs to get insight into policy developments (Eising, 2005).

In the following section we will study the strategic behaviour of interest groups in relation to the cooperation and co-decision procedure. The increasing importance of the EP in the policy-making process resulted in strategies to maintain contacts with MEPs throughout the process. We will therefore also focus upon the informal rule of intergroup creation.

\subsubsection{Cooperation and co-decision: lobbying the European Parliament}

The EP delivered its opinion on the first proposal restricting tobacco advertising in March 1990 in favour of a ban. This resulted in a Commission proposal for a ban on tobacco advertising in 1991. The EP gave its opinion on this proposal in February 1992 (European Parliament, 1992a).

BASP attended the EP plenary meeting of March 1990. Because it had only been created in 1989, it could not effectively lobby the EP. However, for the 1992 vote BASP provided the rapporteur of the Committee on the Environment, Public Health and Consumer Protection (ENVI) with information. Based upon what the rapporteur and other MEPs stated, representatives from BASP and the ECL knew their arguments were indeed used (\#2, PH lobbyist). The EP confirmed its vote of March 1990 in support of a ban despite a massive lobbying campaign, described in The Guardian (February 12, 1992) as 'the largest and best financed lobbying campaign ever mounted by tobacco and advertising companies. Dozens of tobacco and advertising lobbyists descended on the EP to try to persuade MEPs to change their vote'. The industry argued against the proposal based on the right to freedom of speech, the lack of a relationship between advertising and tobacco consumption, the effectiveness of voluntary agreements and claimed that advertising did not recruit new smokers. It also questioned the legal basis of the proposal. During the debate, the rapporteur of the ENVI Committee said that 'the challenge today is to stand up to the most intensive lobbying campaign that we have yet witnessed' (BASP, 1992a). In an interview, he claimed to be convinced that the tobacco lobby influenced several MEPs. When we first examined this text on advertising two years ago, there was, after all, a considerable majority in favour of a total ban. Two years later, the lobbies have done their job' (BASP, 1992a). “The enthusiasm that originally had been expressed had nearly evaporated" (\#5, PH lobbyist).

In December 1997, the Council reached its common position, again resulting in a massive lobbying campaign in the EP. Following the co-decision procedure, the EP could introduce amendments in second reading that had been proposed initially in first reading or that concerned modifications to the Commission's proposal by the Council in its 
common position. If the EP amended the common position, it would have resulted in conciliation. The public health lobby wanted to avoid this, given the narrow qualified majority (62 out of 87 votes) in the Council. For instance, the ECL published five newsletters from March to May 1998. MEPs were asked not to put forward amendments: 'any attempt to amend the directive will inevitably invoke the conciliation procedure. The German government has made quite clear that it will take the opportunity of conciliation to wreck the directive' (ECL, 1998a). The tobacco industry tried to convince MEPs to propose improvements to the common position. This led to "the situation where people pretending they were in favour of health, ran around in Parliament saying vote for amendments, and the health lobby ran around saying do not vote for the amendments. (...) The industry managed to lobby MEPs who normally were totally against a ban on tobacco advertising, who then started suggesting amendments proposing improvements to the directive" (\#5, PH lobbyist).

The rapporteur of the ENVI Committee (Cabrol, Union for Europe (UPE), France), also felt the common position had to be improved. He could not be convinced by the European lobby groups. Therefore they urged French public health organisations to convince the rapporteur not to propose amendments. The pressure from French cancer leagues as well as high level policy-makers eventually resulted in the recommendation to accept the common position as it was (\#5, PH lobbyist). According to the rapporteur, the text was 'the best possible compromise, given current national legislation, between the need to ensure a general ban on the advertising of tobacco products and the need to take account temporarily of essential economic adjustments' (European Parliament, 1998a).

Another element of discussion in the EP concerned the legal basis of the ban. Many documents on the legal basis circulated in the EP. The International Union Against Cancer and the ECL crafted a memorandum on the legality of the ban. In its newsletters, the ECL claimed that the ban had a valid legal basis. In April 1998, CECCM published a report called 'A step too far: a call to the EP to protect the integrity of the EC Treaty'. The main goal of this report was to convince the EP to reject the common position since a tobacco advertising ban had no legal basis (Khanna, 2001: 118). Furthermore, copies of the Council's Legal Service opinion of December 1993 against the legal basis circulated in the EP to create confusion (ECL, 1998b). Nonetheless, in May 1998 the EP voted in favour of the common position.

\subsubsection{The informal rule of intergroup creation}

Intergroups are groups of MEPs from different political backgrounds who share a particular interest (Gillies, 1998). Often, they are initiated and sometimes also supported by interest groups to create a platform within the EP. 
EPHA wanted to create such an intergroup. In 1994, it acquired the secretariat of the Health Forum Intergroup. It organised a whole series of meetings on health. At a critical time in the policy-making procedure, when it came to the second reading stage, EPHA planned a meeting on tobacco advertising. The tobacco industry used the Kangaroo Intergroup, concerned with breaking barriers to free trade, to oppose the ban. The industry claimed it was against the rights of freedom of expression and free trade. The Kangaroo group adopted that line, supporting the industry.

From the analysis of the lobbying strategies in the EP, we can conclude that access to rapporteurs and their committee is very important. The committee responsible for advising the plenary, in this case the ENVI Committee, was the main target for the public health lobby. Access to MEPs via intergroups was also important. Even though the tobacco advertising ban was not discussed in the EP from 1992 to 1997, these intergroups provided a platform to maintain contacts with interested MEPs.

\subsection{THE EUROPEAN COURT OF JUSTICE: LITIGATION STRATEGIES}

After lobbying strategies had failed to block the adoption of the tobacco advertising ban, the industry initiated litigation strategies. The 1963 'Van Gend en Loos' case ruling (European Court of Justice, 1963) established that Community law did not hold member states as its sole object. Private actors may also bring cases to the ECJ through the preliminary reference mechanism (Bouwen, 2004a). In September 1998, Britain's Tobacco Manufacturers Association and a group of four tobacco companies appealed to the High Court of England and Wales, asking for reference of the directive banning tobacco advertising to the ECJ.

Following Baumgartner and Jones (1991), conflict expansion to new venues can occur via the 'classic loser appeal strategy' (Baumgartner \& Jones, 1991: 1048). As early as the early 1990s, the tobacco industry had planned for legal action in case the directive was accepted (Neuman, Bitton, \& Glantz, 2002). Lobbying strategies, among others, concentrated on convincing Germany to go to Court (Aspect Consortium, 2004: 217). The industry focused on both national courts and the ECJ, respectively to demonstrate that the ban violated national laws and to question its legal basis. It was through the latter strategy that the ban was annulled by the ECJ in 2000 (European Court of Justice, 2000).

Several private actors, Salamander AG (Germany), Una Film (Austria), Alma Media Group (Greece), and Davidoff (Switzerland), also challenged the tobacco advertising directive before the ECJ (European Court of First Instance, 2000). However, the Court dismissed their cases, because it did not recognise the applicants as interested parties. Interested parties are those whose legal situation is influenced directly by the consequences of the directive and the institutions which have given birth to the directive. 
The public health lobby as an apparently neutral and independent observer, could not defend the ban. As one respondent argued: "We were not able to participate in the process at all. All we could do was to sit quietly on the sidelines and watch. Several of us, as individuals with contacts within the Commission, could say, 'well why don't you think of this argument, why don't you think of that argument' and that would be fed through to the Commission's Legal Service” (\#5, PH lobbyist).

The industry's strategic behaviour was targeted mainly at decision-making in the Commission, the Council and the EP. Litigation was the final opportunity to influence the outcome of the policy-making process. Throughout this process the industry was aware of this option and part of its strategy did indeed concentrate on what to do in case of adoption of the ban.

\subsection{CONCLUSION}

Different strands of enquiry exist concerning the study of interest groups, such as studies concentrating on the corporate-pluralism debate, the problem of collective action, and European governance and the Europeanisation of interest groups (see Woll, 2006a). Particularly the latter two strands perceive the EU as a sui generis case. Recently, more studies on EU lobbying dealt with the subject as a general political phenomenon. Taking EU lobbying as a given, and trying to understand 'the conditions that shape who lobbies where, how and to what effect' (Woll, 2006a: 460) implies identification of opportunities and constraints of the institutional structure for interest representation. There are several studies that acknowledge the importance of political opportunities for interest groups enshrined in the institutional structure. For example, authors have tried to show the power of the European Commission as a demand-side force that influences interest group activity (Mahoney, 2004), what lobbying strategy will be effective given the different phases of the EU policy-making process (Crombez, 2002; Eising, 2007), different strategies of specific and public interests (Beyers, 2004) and the logic of access of different organisational forms of business interest representation to the political actors (Bouwen, 2002, 2004a, 2004b; Eising, 2005, 2007).

This chapter shares their view that EU lobbying cannot be understood without taking into account the formal and informal institutions regarding the main actors of the policymaking process, being the Commission, the Council, the EP and the ECJ. Each of these actors is conceptualised as a point of access for interest representation. Following the actor-centred institutionalist approach, a key element of our analysis concerned the identification of a set of institutions (rules of the game) that facilitate interest representation, as shown in table 5.1 .

Whereas other studies have concentrated on the impact of formal institutions on (particular) interest groups, the focus of this chapter is on a specific policy-making 
process, describing in detail how industrial lobbyists and non-governmental organisations (NGOs) at national and European level use both formal and informal institutions. This illustrates empirically that characteristics of the political system and the structures of policy-making to a large extent influence the nature of interest representation (Greenwood, 2003: 73). In order to better prepare for eventualities (Mazey \& Richardson, 2006: 249) and given the different roles played by the Commission, the EP and the member states in the Council at different stages of the process, interest groups concentrate on more than one actor. The institutional setting creates a set of opportunities for interest groups on either side of the political spectrum. In line with Beyers (2004), our study shows that access and voice strategies are widely used and combined. The Commission's need for support resulted in better access for Europeanlevel public health lobbyists. People working for the EAC programme were not very sympathetic to the position of the tobacco industry. The industry concentrated on access via the Council. It succeeded in establishing contacts with national policy-makers having an interest in industry policy. This raises the question as to whether the functional differentiation of both the Commission and national governments influences access of different interest groups. Generally, the EP is open to all kinds of interests and access strategies were possible for both industry and public health lobbyists. They both succeeded in using the EP's rules of the game. However, it is remarkable that the public health lobby was able to persuade MEPs not to improve the common position.

This analysis shows that both NGOs and industrial lobbyists are aware of the importance of formal and informal institutions. However, for reasons explained below, there is a difference between these interest groups in the extent that they make use of the institutions. Especially for NGOs, their lack of access at national level implies that it is difficult for them to use the QMV rule to their advantage.

This can be explained by several other factors influencing the strategic behaviour of interest groups. First of all, the costs of lobbying are important. These costs relate to the organisation of interest representation, such as establishing an office in Brussels, mobilising members and the follow-up of policy-making processes. The financial resources an interest group has at its disposal determine the strategies it can use. Not surprisingly, our case study demonstrates that combined access strategies at both national and European level are easier for those interest groups which have the financial resources to do so.

Next to these organisational costs, the costs of collecting information are relevant (Broscheid \& Coen, 2007). These costs relate to the establishment of expertise and credibility. In our case, the public health lobby at EU level still had to develop its proficiency during the process on the tobacco advertising ban, whereas the tobacco 
industry had already had a significant amount of experience with regard to interest representation both in the United States as well as in the EU and at national level.

The informational cost may be reduced by the Commission. In addition to the supplyside forces that push interest groups to become active in the policy debate, there are also demand-side pressures (see Mahoney, 2004: 442). In this case, it was the Commission providing access to the public health lobby through financial incentives (national cancer and anti-tobacco organisations and BASP) and through a formal arena of debate (BASP).

The third factor that influences the strategies used by interest groups is related to these informational costs, namely credibility. The pro-tobacco lobby was perceived as being aggressive and in addition, industry did not provide honest and accurate information, whereas, especially in 'Brussels', the key to successful lobbying is information (Broscheid \& Coen, 2007). In the end, many civil servants as well as politicians did not want to be associated with the tobacco industry and were not willing to continue offering them access. Consequently, the industry adapted its strategies, concentrating on third party alliances to provide ostensible independent opinions and scientific and expert studies.

In sum, our case demonstrates the importance of an actor-centred institutionalist approach with the institutional structure resulting in multi-channel interest representation. In addition, an interests group's organisational and informational capacity influences its ability to exploit different venues according to its interests. 


\section{PART III Policy-MAKING ON PHARMACEUTICALS}

The third part of this book concentrates on pharmaceutical policy-making. Two different processes, both part of the pharmaceutical review, are analysed. Chapter 6 examines policy-making on data exclusivity, which constitutes indirect health policy-making, representing a conflict between the generics and the research-based industry. Both the strategic behaviour of formal and informal actors is examined. In chapter 7, the process of an agreement on direct-to-consumer advertising for prescription medicines is analysed. This constitutes the only process that has not as yet been decided upon. Reaching agreement on this issue is difficult, because preferences are very diverse and touch upon the healthcare systems of the member states. Whereas the Commission frames the issue in terms of patient information, both member states, the European Parliament and several patient and health organisations fear a progression towards advertising. 


\section{DATA EXCLUSIVITY: MARKET PROTECTION WITHOUT KNOWN HEALTH BENEFITS}

This chapter has been co-authored with Professor Donald W. Light (Princeton University).

\subsection{INTRODUCTION}

Since the time of Adam Smith, competition has been recognised as the principal engine of innovation. While most competitors sweat out the market pressures, the more innovative ones come up with a new feature or convenience that leads customers to chose it over others. Patent protection was applied to this fundamental reality, under the assumption that if society gave inventors temporary protection from head to head competition in return for sharing their discovery, others could build on their knowledge and accelerate innovation while the inventors could use their exclusivity to market their idea and recoup some of the research and development (R\&D) costs. A crucial feature of this system is that the period of protection comes to an end so that competitive forces spur companies to innovate further. The longer the protection, the greater the danger that companies will focus more on legal manoeuvres to lengthen market protections than on innovating (Goozner, 2004: 8).

This study concerns another legal protection from normal price competition: data exclusivity. This concept has been developed by the pharmaceutical industry as a second defense against price competition from generic manufacturers. Whereas the essence of an intellectual property system is to promote innovation, data exclusivity is not a reward for innovation, but rather protection of investment in pharmaceutical trials. Essentially, data exclusivity prohibits a regulatory authority, for a specified period of time, from using the clinical trials data submitted when a product was initially registered, to affirm the safety of a bioequivalent generic. This is based on the grounds that the initial sponsoring company paid for the trials and thus owns the data.

The central justification for data exclusivity, as with patents, is that the longer that innovator companies enjoy protection from price competition (market exclusivity), the greater their incentive to innovate. To our knowledge, no credible evidence has been provided that longer patents have produced more beneficial innovations for society. Reviews both inside the industry and outside have consistently found over the last fifty years that only 11-14 percent of new medicines are therapeutically superior to existing

ones (Barral, 1996; Prescrire International, 2007; US Senate Select Committee on Small Business, 1979).

In the United States (US), the 1984 Drug Price Competition and Patent Term Restoration Act granted a five-year period of data exclusivity to new drugs and three years for new indications of an existing medicine (Hilts, 2003). In 1987, the European 
Community introduced six or ten years of data exclusivity for new drugs (Council of the European Communities, 1987). In 2001, the European Commission submitted a proposal for harmonisation of national differences in data exclusivity up to ten years plus an additional year for new therapeutic indications as part of the pharmaceutical review ${ }^{17}$ (Commission of the European Communities, 2001b). This chapter analyses the subsequent events.

The main argument in favour of long data exclusivity periods was that in the process of completing the internal market, European Union (EU) countries could gain an edge in their struggle to win back research investments that the industry has shifted to the US. Opponents claimed that a longer period of data protection would delay the marketing of cheaper generic products, resulting in additional pharmaceutical costs to consumers and governments. The debate in the EU was framed in terms of a trade-off between greater innovation versus greater ability to control the swelling costs of medicines. It was this trade-off that required balancing. In the absence of evidence that longer data protection would result in more new drugs (especially better new drugs) and would be worth the greater cost to nations and consumers, how was the world's longest data exclusivity period made law? Why did the Commission table such an ambitious proposal? Why did member states agree, given that it would impact on national healthcare financing? Why was the European Parliament (EP) willing to compromise in the end? And what were the roles of the generics and research-based industries in this political game?

Within the review of the existing procedures that resulted in new pharmaceutical legislation in 2004, we concentrated on data exclusivity and legislation related to generics (including the Bolar provision, under which generic manufacturers may conduct tests necessary for marketing authorisation applications without infringing patents) within the package concerning medicines for human use. It is beyond the scope of this research to delineate all actors involved, assessing all their preferences and strategies. The major actors directly or indirectly involved in the process on data exclusivity are the EU and national authorities, including responsible ministries and agencies, the pharmaceutical industry and patient/consumer organisations affected by the legislation (see Feick, 2005) and, as we will show in our discussion, developing countries via the so-called free trade agreement. $^{18}$

\footnotetext{
17 The review concerned 'Council Regulation 2309/93/EEC laying down Community procedures for the authorisation and supervision of medicinal products for human and veterinary use and establishing a European agency for the Evaluation of Medicinal Products' and 'Directive 2001/83/EC of the European Parliament and the Council of the European Union on the Community code relating to medicinal products for human use'. The regulatory framework of the so-called Community code concerns licensing, manufacturing and importing, labelling/packaging requirements, wholesale distribution, advertising rules and pharmacovigilance.

${ }^{18}$ For an overview of the interviews refered to in this chapter, see appendix 2.
} 


\subsection{DATA EXCLUSIVITY: PREFERENCES, PROPOSALS AND OUTCOMES}

Initially, data exclusivity was not an issue in Europe. After marketing authorisations were required for generics beginning in 1975, no legal framework existed to prevent applicants from referring to preclinical and clinical data, although reliance on these data was considered unfair competition by the innovators who did the tests (Sanjuan Rius, 2006: 2). According to the Commission, unauthorised use of data 'seriously penalised the innovating firm which has had to meet the high cost of clinical trials and animal experiments, while its product can be copied at lower cost and sometimes within a very short period' (COM (84) 437 final in Dodds-Smith, 2000). In 1984, the Commission put forward a proposal for ten years of data exclusivity, after which a second applicant could cross-refer to the same data. A different justification for this proposal was that it would compensate for the lack of patent protection for biotechnological products in Spain and Portugal, which were to join the Community in 1986 (Perry, 2000).

Negotiations resulted in Directive $87 / 21$ /EEC providing a period of six years of data exclusivity beginning at the date of first market authorisation, and ten years for biotechnological and high-technology medicinal products. ${ }^{19}$ Member states were allowed to extend the period to ten years for all pharmaceuticals if they considered this in the interest of public health'. Belgium, France, Germany, Italy, the Netherlands, Sweden and the UK did so. Member states also had the option not to apply the six-year period beyond the date of patent expiry of the original product so that data exclusivity did not extend the 20 years of protection from free market competition. Denmark, Finland, Ireland, Luxembourg, Greece, Spain and Portugal provided six years, and the latter three countries did not offer data exclusivity beyond patent expiry (Kingham \& Castle, 2000: 214-215). Though the initial intention of the Commission was to harmonise data exclusivity periods, the final outcome did not improve the functioning of the internal market.

\subsubsection{Health care, public health and industrial policy: multiple preferences}

Only a few pharmaceuticals, which took a particularly long time to develop, benefited from the extra protection of data exclusivity beyond patent expiry (Pugatch, 2004). For most pharmaceuticals, data exclusivity usually expires before patent protection does. Even so, for the research-based industry nothing is as lucrative as stretching out monopoly rights on their profitable products. In cases where patents are not sufficient, the option to extend the privileged time of market exclusivity (Angell, 2005: 173-174) via data exclusivity explains the strong pressure exerted by the research-based pharmaceutical industry on legislators to extend data exclusivity periods. However, harmonisation of data exclusivity had a functional justification as well: unequal periods constituted an

\footnotetext{
${ }^{19}$ For an overview of high-technology medicinal products see the annex of Council Directive 87/22/EC.
} 
impediment for the single market in generics. As a result, even though the generics industry would have preferred a lower level of data protection, it 'could not be completely against harmonisation as such' (Feick, 2005: 19).

The Commission is the driving force behind harmonisation of the internal market. Supranational actors, especially the Commission, have an institutional interest in driving integration forward through high-level legislation. Within the Commission, the pharmaceutical industry has its affairs addressed by the commerce department, Directorate-General (DG) Enterprise, rather than by the health and consumer protection department, DG Sanco. Thus, the Commission uses its considerable powers to promote the growth of this high-tech industry as part of a larger effort to make Europe more attractive to research and development $(\mathrm{R} \& \mathrm{D})$ than the US, which explains the proposal to establish the longest period of data exclusivity in the world. But in this case, the products are regarded as social goods essential to healthcare systems, tempered by long national histories of how different countries treat them.

Member states' discussions on harmonisation of the pharmaceutical market reflect their different priorities in industrial and health(care) policy. The debate on data exclusivity and the Bolar provision pitted member states with six years data protection, together with the generics industry, against the Commission and member states with a strong research-based pharmaceutical industry, and the research-based industry which is interested in monopoly returns on research investments that are not diluted by generics competition. In addition, member states had an interest in containing healthcare costs by promoting the consumption of generics, creating a dilemma for those member states with strong research-based industries (Feick \& Broscheid, 2005: 19).

\subsubsection{Different positions concerning data exclusivity}

In 2001, the Commission put forward the proposal for ' $10+1$ ' year of data exclusivity, the additional year for clinically important indications authorised during the first eight years of those ten years. The Commission claimed to strive for 'an optimal balance between innovative medicinal products and generic medicines' (Commission of the European Communities, 2001b) and framed data exclusivity as an incentive to stimulate innovation, thereby promoting public health and healthcare.

The generics industry was offered a so-called 'Bolar provision', like the one that had been in place in the US since 1984. It allows a company to conduct the necessary bioequivalence studies for a generic marketing authorisation application before the key patent expires, so it is ready to be approved on the expiration date; but the more restrictive European version does not allow generics companies to start the 2-4 year process of tests to prove bioequivalence and quality manufacturing until after the data exclusivity period expires. To support its proposal, the Commission referred to the report 
'on global competitiveness in pharmaceuticals - a European perspective', which was drafted for DG Enterprise in 2000 (Gambardella, Orsenigo, \& Pammolli, 2000). According to this report, since the 1990s, European industry has been losing competitiveness compared to the US, because of its patchwork quilt of regulatory and healthcare regimes including pricing policies. According to the Commission, there should be some kind of incentive to 'further improve existing medicinal products, in particular to develop new and important therapeutic indications. Such an incentive could be an additional data protection period' (Commission of the European Communities, 2001c).

In the EP, the Committee for Environment, Public Health and Food Safety (ENVI) was responsible for drafting amendments (European Parliament, 2002a). The committee proposed to modify the Commission proposal of ' $10+1$ ' to ' $8+2+1$ ': eight years of data exclusivity plus two years of market exclusivity as part of the European version of the Bolar provision plus one additional year market protection for new indications. The ENVI Committee extended the scope of the Bolar provision: the company could also apply for, and be granted a marketing authorisation.

To allow national authorities to use test data of an originator product present in another member state, the ENVI Committee introduced the 'eurogenerics principle'. Furthermore, the committee proposed a period of three years of data exclusivity for a new indication of a well-established substance, provided that significant preclinical or clinical studies were carried out in relation to the new indication. The same period of data exclusivity was also proposed for products switching from prescription medicine to overthe-counter (OTC) status, thus providing another way to stave off price competition with generics.

In October 2002, the EP approved the amendments as suggested by its ENVI Committee. DG Enterprise changed the EP amendment for data exclusivity for a medicinal product switching from prescription-only to OTC status from three to two years and accepted the eurogenerics principle. All other amendments were rejected (see table 6.1 for an overview).

In the Council working group, the Commission's proposal on data exclusivity caused significant discussion, because half of all member states and all ten accession countries would have had to increase their exclusivity period from six to ten years. Different national governments took different positions, offering different alternatives. In the end, Council members acknowledged that ten years of market protection would be too difficult for some member states. Without going into the two alternate routes for new drugs approval (see Feick, 2002), the resulting common position of the Council was eight years of data exclusivity and two additional years of market exclusivity for authorisations 
via the mutual recognition procedure ('harmonised' national authorisation) and ' $10+1$ ' for authorisations via the centralised procedure (single Community authorisation).

With regard to the Bolar provision, the Commission opposed extending the scope of the Bolar provision beyond testing and trials; but the Council included all necessary 'practical requirements' for a generic application. Though this is a rather vague description, it most likely includes the possibility to apply for and be granted a marketing authorisation, so that a generics company can release its product on the day of expiry of a patent/data exclusivity period.

Furthermore, the Dutch government stated that the research-based industry used existing loopholes in the eurogenerics provisions time and again to block marketing authorisations of generics, especially by withdrawing the product which a generics manufacturer was making a bioequivalent competitor, so that it would be the bioequivalent of a medicine that no longer existed, while the innovator company would get a fresh patent on a slightly modified version and switch customers to it. To stop this strategy for avoiding price competition, the Dutch government proposed the 'historical reference principle', stating that companies could also develop generics of drugs that had previously been on the market (Dutch Ministry of Health, 2003). This provision was included in the Council's common position.

This common position may be accepted, rejected or amended by the EP in its second reading. To speed up this process and increase the likelihood of a compromise between the Council and the EP, informal talks were held between DG Enterprise, the rapporteurs of the EP ENVI Committee and the Italian presidency of the Council. This 'informal trialogue' resulted in agreement on ' $8+2+1$ ' both for the mutual recognition and the centralised procedure and one year of data exclusivity for new indications for wellestablished substances and for changes from prescriptive to OTC-status. The Council formally agreed in March 2004, accepting Directive 2004/27/EC. Table 6.1 provides an overview of the different proposals concerning data exclusivity that were suggested at different stages of the process.

As we will illustrate in the next section, the research-based industry's lobbyists won the battle before it began by limiting the scope of debate to variations of the same significant expansions. The central claim that additional billions in costs would be compensated by more beneficial medicines for patients was not questioned. 


\begin{tabular}{|c|c|c|c|c|c|c|c|}
\hline 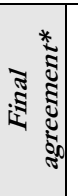 & 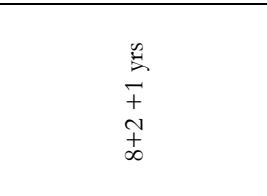 & 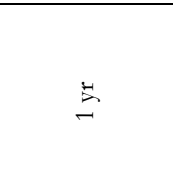 & $\stackrel{ \pm}{ \pm}$ & 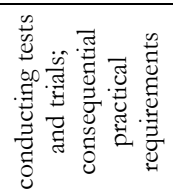 & $\cong$ & 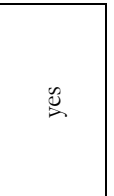 & \\
\hline$\hat{N}$ & \begin{tabular}{l}
0 \\
\multirow{2}{*}{} \\
+ \\
+ \\
+ \\
$\infty$
\end{tabular} & $\stackrel{5}{二}$ & \pm & 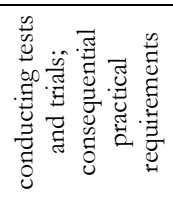 & $\mathscr{g}$ & 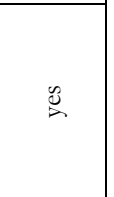 & \\
\hline$\sum_{i=1}^{N}$ & 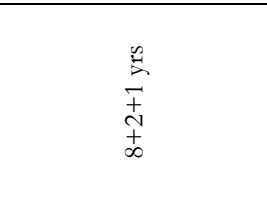 & $\stackrel{\infty}{\vec{\omega}}$ & $\stackrel{\infty}{\vec{b}}$ & 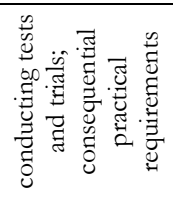 & $\cong$ & $\stackrel{\mathscr{N}}{\mathscr{n}}$ & \pm \\
\hline 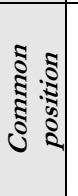 & 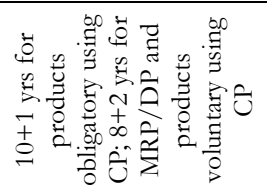 & 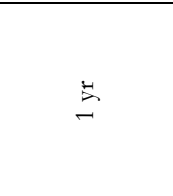 & $\stackrel{5}{\Rightarrow}$ & 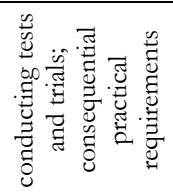 & $\stackrel{\Xi}{\mathscr{O}}$ & 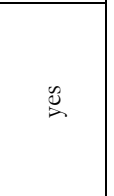 & 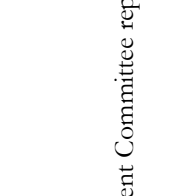 \\
\hline ถี & $\begin{array}{l}\stackrel{\infty}{E} \\
\frac{ \pm}{ \pm}\end{array}$ & $\stackrel{9}{g}$ & $\underset{⿱ 亠}{\stackrel{N}{N}}$ & 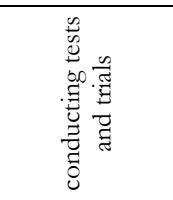 & $\mathscr{O}$ & , & 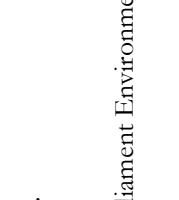 \\
\hline $\bar{I}$ & \begin{tabular}{l}
0 \\
\multirow{E}{*}{} \\
$\underset{+}{+}$ \\
+ \\
+
\end{tabular} & $\underset{\infty}{\infty}$ & 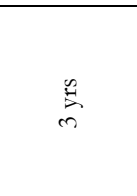 & 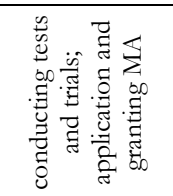 & 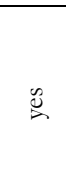 & ' & 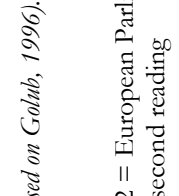 \\
\hline$\sum_{i=1}^{i}$ & 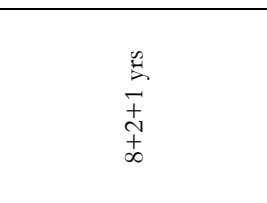 & $\underset{\infty}{\infty}$ & $\underset{\infty}{\infty}$ & 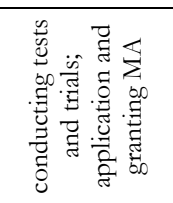 & $\ddot{g}$ & . & 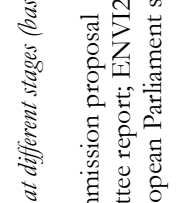 \\
\hline ปี & 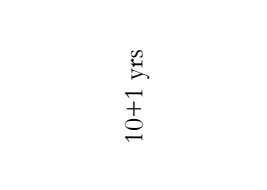 & ' & ' & 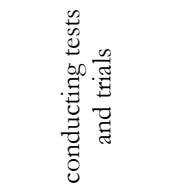 & & , & 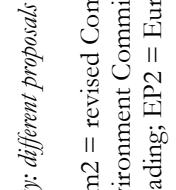 \\
\hline 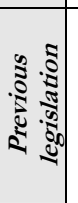 & 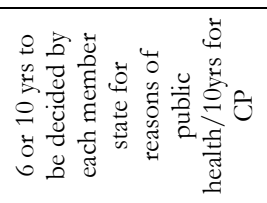 & ' & ' & ' & , & , & 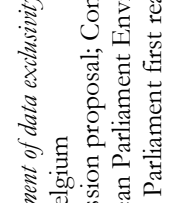 \\
\hline 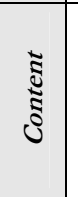 & 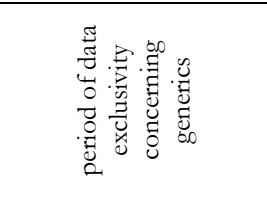 & 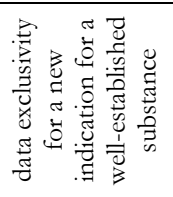 & 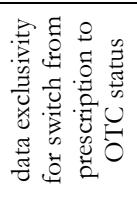 & $\begin{array}{l}a \\
.0 \\
0 \\
0 \\
0 \\
0 \\
0 \\
0 \\
\frac{a}{0} \\
0 \\
0\end{array}$ & 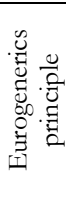 & 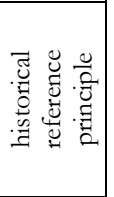 & 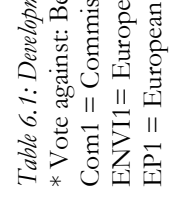 \\
\hline
\end{tabular}




\subsection{THE RHETORIC OF INNOVATION VERSUS THE REALITIES OF NEGOTIATION}

Drawing on our in-depth analysis, we explore the dynamics of negotiation with a focus on the strategies of different actors in order to understand the process by which industrial interests were translated into legal realities. The outcome of a policy-making process depends on actors' behaviour (Scharpf, 2000a), which is influenced by the institutional structure and wider policy developments. We focus on the impact of institutions that regulate the interplay between the EU actors: the right of initiative and the brokering role of the Commission; the co-decision procedure and the informal trialogue including the EP; the qualified majority voting (QMV) rule, the neutrality norm and the consensus norm in the Council.

\subsubsection{The Commission's right of initiative}

In 1984, the Commission tried to harmonise the period of data exclusivity to ten years, but did not prevail, as we have seen. Now, the huge pharmaceutical review, with more than 200 proposed changes and approximately 600 parliamentary amendments, offered a good opportunity to re-introduce it. Regulation 2309/93/EC required the Commission to evaluate the existing marketing authorisation procedures and the functioning of the European Agency for the Evaluation of Medicinal Products (EMEA) by 1999. In 2000, Cameron McKenna and Andersen Consulting conducted this evaluation, taking into account the views of national authorities, industry, patients and healthcare professionals. The report showed data exclusivity as one area justifying review, claiming that harmonisation was necessary (CMS Cameron McKenna \& Andersen Consulting, 2000: 42). However, according to several interviewees the evaluation hardly played a role. "The fact that some management consultancy firms say this, that, or the other, do I remotely think that this is an independent and necessarily honest point of view? No of course I do not. It is a game" (\#14, consumer lobbyist). In addition, according to an officer interviewed at DG Enterprise, the Commission started to develop its ideas long before the obligated evaluation (\#1, DGE). It "knew what it was going to do and was drafting the legislation at the same time that Cameron McKenna was running around collecting information" (\#6, British civil servant). Thus, several informants agreed that the Commission had its own longterm agenda to increase government protections from market competition through the data exclusivity route.

Aware that its proposal would cause controversy, the Commission presented it in terms of 'finding a balance' between stimulating innovation and competition from generics. It therefore proposed a Bolar provision to promote competition. The Commission also had an interest in doing so. Before the review, several members of the EP (MEPs) had already asked for such a provision and if it was not introduced by the Commission, the EP most likely would have tabled it anyhow. Furthermore, generics 
companies conducted their research before patent expiration in countries outside the Community, where they were allowed to do so. A 1998 study on 'policy relating to generic medicines in the OECD', on behalf of the Commission, showed that due to premarketing work done outside the EU, jobs might be permanently lost to the EU. In an extreme case, 13.000 jobs were at risk (National Economic Research Associates, 1998). To address this problem, pre-marketing work had to be permitted in Europe as well. However, application and granting of a marketing authorisation did not have to be part of the Bolar provision.

The period of ten years of data exclusivity was not based on a calculation: "How do you distribute the cost which you have in early development, and all the failures of substances? (...) In the end it is not a mathematical decision, it is a political estimation of how much incentive for innovation you need" (\#1, DGE). Yet such an estimation or 'finding a balance' between greater innovation by raising costs through protected prices, versus less innovation by reducing costs through open price competition, was done without data or evidence.

\subsubsection{Agenda-setting: lobbying the Commission}

The Commission's monopoly over what legal measures are reviewed meant that the industry was "quite naturally (...) keen to aid and abet the Commission, hoping thereby to promote its own points of view" (\#3, Danish civil servant). For this second attempt at a 10 year exclusivity, the European Federation of Pharmaceutical industries and Associations (EFPIA) already came up with a policy paper in 1999 (EFPIA, 1999). A January 2000 letter from the European Generic medicines Association (EGA) also referred to the ongoing dialogue: 'There is serious discussion to harmonise all data exclusivity provisions at national level. This is required for the proper function of the single market (...). EFPIA is calling for ten years. We have called for five years and only covering new chemical entities. The Commission has floated the idea of seven to eight years and dropping the link to patents. However, the ten year period for centralised products will remain as part of this plan' (Perry, 2000). The proposal adopted was in line with EFPIA's request.

In reaction to the Commission proposal, EFPIA said that it offered a reasonable balance between the needs of the industry, regulators and patients. It emphasised the decreasing level of innovation and stressed the need to create a proper environment in the EU for innovative medicines (Scrip, 2001). EGA argued that the proposal did not constitute a real balance at all: the period of data exclusivity increased, and the Commission failed to provide a real Bolar provision. Furthermore, EGA claimed that 'originator companies are requesting superfluous protection by means of data exclusivity for areas already protected' (EGA, 2000). EGA also questioned the causal link between data exclusivity and encouragement of innovation. In addition, the argument that clinical 
trials are very expensive and should therefore be protected was countered. According to EGA, these trials are often co-subsidised by public bodies or research foundations. It would therefore be difficult to justify that these data solely belong to the company marketing the pharmaceutical. Beyond these arguments, EGA framed the whole discussion as a choice between "public health versus private profit" (\#4, consultant).

Greenwood (2003) described the Commission's relationship with the research-based industry as 'clientilistic', with EFPIA making itself indispensable to the Commission. A Dutch civil servant (\#5) complained that "via a channel as DG Enterprise the limits of a democratic decision-making system are reached. However, one can of course not totally blame this on the pharmaceutical industry; the Commission is guilty as well". Another observed that "the Commission is very much pro-innovative industry and the generics industry is considered the underdog" (\#7, Dutch civil servant). There was constant contact between DG Enterprise and EFPIA. But according to a representative from DG Enterprise, this was completely normal: "Of course we have many direct contacts with the industry (...). They are supposed to produce the medicines. They know best in the end" (\#1, DGE). In this, as in many matters, there is a bierarchy of well-resourced expertise. At the top is an industry's trade association, richly funded and with skilled authorities on a topic, with ample time to help draft legislation or work out the specifics of a regulation. Well below them are the three or four staff members at the Commission who are responsible for drafting and knowing quite a bit about the subject area, especially from the pharmaceutical trade association experts as their mentors. Below them are the key members of parliamentary committees who have many other responsabilities. They do not really have to understand the proposal in all its technical details. They are educated by the key Commission staff as well as industry-sponsored experts. This is one dynamic of regulatory capture, the economic theory that an industry will capture the regulatory process and exploit it to keep competitors out and protect its markets (Levine \& Forrence, 1990).

Critics point out that the fact that DG Enterprise is responsible for pharmaceutical policy rather than DG Sanco makes matters worse (Garattini, Bertele, \& Li Bassi, 2003: 635); but believers of regulatory capture would predict about the same outcome were pharmaceutical affairs overseen by health rather than commerce.

Only after strong pressure to provide access to all stakeholders did the Commission organise a consultation in January 2001. However, important discussions had already taken place with industry. "In addition to the formal consultation process, the pharmaceutical industry was contacting the relevant people as early as possible" (\#12, lobbyist EGA). Whereas industry had good access to DG Enterprise, public health and consumer organisations were considered stakeholders of DG Sanco (see letter of DG 
Enterprise to Health Action International in Medawar \& Hardon, 2004: 120). In addition, these organisations were not able to concentrate on the pharmaceutical review in total. For example, Health Action International (HAI) "is doing the best it can with painfully limited resources" and given that data exclusivity "is really a quite sophisticated issue (...) you are not going to be able to get the press interested. (...) This is really for the generics industry to fight and we will hold their hand as much as we can, but you know this is not going to be our mainstream endeavour" (\#14, consumer lobbyist). The situation was similar for the European Public Health Alliance (EPHA), which at the time had 3,5 full-time employees and "had to do the entire public health agenda" (\#11, PH lobbyist). The amount and complexity of the proposals together with the lack of resources was challenging for non-governmental organisations (NGOs). In addition, there was no media attention, whereas public politicisation is a vital strategy for NGOs.

\subsubsection{The Commission's informal role as mediator}

The Commission attended all Council and EP meetings, which provided it with the opportunity to mediate a compromise. In this context, several interviewees stressed that the Commission had a monopoly on information (\#1, \#6, \#8, \#12, \#14). Others reported that the Commission official in charge of the dossier was very knowledgeable and defended its proposals in a rather aggressive way. He did not appreciate concrete amendments during the Council working group (\#5, \#7, \#9). "The more complicated, the more important it is to have somebody who completely understands the entire system. And as this is a complicated package, yes, probably the expertise inside the Commission gave it a certain influence" (\#1, DGE).

In addition, the Commission threatened the Council with a worse-case scenario if the review was not completed before May 1, 2004, when ten new member states came on board. "The first of May 2004 was a fatal date. A new Parliament, 25 member states, and the whole discussion would have started all over again. Thus, it was inescapable for the old member states to finish it before May. I think the Commission consciously anticipated it" (\#7, Dutch civil servant), being "absolutely determined to get this agreed to avoid reopening the negotiations" (\#6, British civil servant).

The Commission did not act as a mediator. Once its agenda was set and proposed legislation made, the Commission constantly pressured the member states to fall into line: it did not actively search for a compromise on data exclusivity, but insisted on adoption of the 'correct balance' it had formulated. In addition, it "was more inclined to seek and build alliances with the rapporteurs in the EP than with the various member states. (...) The EP rapporteurs and the officials from the Commission seemed to be in close contact throughout the process" (\#3, Danish civil servant). This was confirmed by a representative from DG Enterprise, as well. The influence of the Commission on the EP "depends a bit 
on the rapporteur, but we had two rapporteurs, one from the Socialists, one from the Conservative Party. Both had very close contact with the Commission" (\#1, DGE). It seems plausible that the Commission preferred to work together with the EP: first, the co-decision procedure gave the EP a strong position; and second, the Commission only needed to work with the two rapporteurs, instead of 15 member states.

\subsubsection{Co-decision and informal trialogue: the role of the European Parliament}

The influence of the EP under co-decision depends on the expertise in the committee as well as the acceptance of its amendments by both the Commission after first reading and the Council in its common position or during the (in)formal conciliation. Normally, there are no time limits during its first reading. MEPs involved 'view it as a period for discussion, for gathering expertise, laying down their respective positions, and clarifying (mainly) technical questions' (Neuhold, 2001). However, because of time constraints imposed by the upcoming enlargement, "the EP did not control the amount of issues" (\#3, Danish civil servant). Still, the issue of data exclusivity was highly politicised and therefore generated much debate.

During the EP plenary meeting in October 2002 (European Parliament, 2002c), both rapporteurs emphasised the importance of competitiveness in relation to data exclusivity. According to Grossetête (European People Party (EPP), France) 'we all know that innovation comes at a price. Industry therefore needs to guarantee the protection of this data. It is our duty to encourage research to ensure that science moves forward'. Müller (Party of European Socialists (PSE), Germany) argued that 'the harmonisation of data exclusivity is certainly a step towards increased competitiveness. (...) The ten-year-rule gives a signal to pharmaceutical companies to intensify research and market truly innovative products. However, it also gives a signal to generic drug manufacturers to use the Bolar provisions'.

Other MEPs opposed these arguments. Ainardi (European United Left (GUE), France) argued that 'the - apparently essential - aim of the proposals (...) is to strengthen the short-term competitiveness of pharmaceutical companies'. Corbey (PSE, the Netherlands) pointed out that lengthening the data exclusivity period is no guarantee for innovation. Quite the opposite in fact, there is more innovation happening in the US, which has a shorter period of protection'. After long deliberations, the EP came up with a different balance than the Commission did. Following this outcome, the Commission rejected almost all of the first reading amendments related to data exclusivity.

The Commission believed there was enough common ground between the Council and the EP to reach agreement before the second reading and it initiated an informal trialogue to iron out differences. This was of major importance, because "the formal conciliation 
procedure would not fit the time schedule" (\#8, German civil servant). As of September 2003, several informal meetings were held between the two rapporteurs, the Italian presidency and the Commission.

According to one interviewee, the trialogue is considered as an instrument to avoid unexpected steps of the EP during second reading (\#15, Belgian policy expert). However, in early December, the ENVI Committee reinstated all its amendments of the first reading regarding data exclusivity that had not been accepted by the Council. In case these amendments were adopted by the EP plenary, conciliation between the EP and the Council would be necessary. Under these circumstances, agreement before the deadline was not likely. This shows that the EP was willing to risk delaying the whole process.

Several interviewees emphasised the importance of the EP: "In very broad terms, the EP played a greater role than, at least I, had imagined from the outset" (\#3, Danish civil servant). Generally, "I think all parties, including the EP, are beginning to realise just how much power they now have. I mean, they are a true party to the discussions with this codecision procedure. And of course, they get the final word really in their second reading" (\#6, British civil servant). Indeed, the Parliament was instrumental in proposing the compromise solution.

\subsubsection{Co-decision: lobbying the European Parliament}

The role of lobbyists in the EP is an important one. They try to influence MEPs by giving them information, and MEPs regard them as a source of information for understanding key points and conflict areas. According to a representative from the Commission, "a massive package like the pharmaceutical review comes to the limits of what the legislative machine in the EU can do. Clearly, the EP is having difficulties grasping the technical details" (\#1, DGE). This was confirmed by several interviewees: the EP often does not have the necessary knowledge because of the technicality of certain issues, which increases the influence of industry lobbyists (\#9, \#10, \#13). In the case at hand, a Dutch civil servant said that representation by pharmaceutical companies and associations was phenomenal, powerful and also influenced the ENVI Committee (\#5, Dutch civil servant). A Danish civil servant confirmed this: "the influence of the industry on various MEPs was to a large degree obvious from the language of many amendments" (\#3, Danish civil servant).

In response to the industry lobby, a group of French consumer, patient and insurance organisations together with the association 'Mieux Prescrire' and the International Society of Drug Bulletins (ISDB), launched the 'Medicines in Europe Forum' (MiEF) in March 2002. According to the MiEF, the public health perspective was not adequately taken into account. It claimed that the Commission considered pharmaceuticals as normal industrial 
goods, seeking to reinforce short term competitiveness of European pharmaceutical companies by prolonging data exclusivity (Revue Prescrire, 2002).

The MiEF did not influence the process of agenda-setting on data exclusivity, because it was only created after the proposals had been tabled. Consequently, it mainly concentrated on lobbying the EP. 'We found no historical reasons and no rationale for extending the monopoly position of originator drugs, and the Commission offers no figures to support their current position. The proposed extension is clearly not intended to compensate manufacturers for time lost in administrative procedures. (...) This is quite enough: no further lengthening of the data protection period is justified' (Medicines in Europe Forum, 2003).

\subsubsection{Qualified majority voting: searching for a compromise in the Council}

With article 95 of the Treaty as the proposals' legal basis, a decision in the Council had to be achieved by qualified majority. Most member states discussed the review with their national pharmaceutical industries. This was not considered interest representation, but rather a necessity, given the review's direct impact on the industry. It was important to understand the position of the industry in order to develop policy positions on different issues (\#6, \#8, \#9). "We have had much contact with EGA, who was very active, and on the issue of data exclusivity did everything to promote the point of view of the generics industry" (\#9, Dutch civil servant). Another interviewee said that "whilst they [the pharmaceutical industry] did not drive government policy, (...) we did take account of what the industry's concerns were. (...) They did not have to lobby, they had access to us" (\#6, British civil servant).

In the Council working group, various exclusivity periods were suggested, depending on the marketing authorisation procedure used (centralised or mutual recognition procedure). Given that member states had widely diverging preferences, the informal consensus norm did not play a role. "If you want results, you must compromise. The point of unanimity was not discussed" (\#8, German civil servant). However, it took a long time before there was something of a shared vision (\#5, Dutch civil servant).

The way the Council was organised was perceived as problematic in this case. Some member states were represented by their permanent representations in Brussels. Though they understood politics, the technicality of the proposals and their involvement in many different subjects was considered a disadvantage. Those countries that were represented by technical experts were strong on content, but generally lacked insight in EU politics (\#12, \#15). In addition, these experts were responsible for marketing authorisations as such, lacking any reflex to take healthcare costs into consideration (\#15, Belgian policy expert). 
Generally, in cases where the Council acts on complex technical matters, its decisions often support the Commission's original proposal (Majone, 1996: 73). However "the negotiations were as much political as getting the framework right from a technical point of view" (\#6, British civil servant). The time pressure, though, did have an impact on the negotiations. Several interviewees claimed that member states would have preferred to discuss many items more thoroughly (\#8, \#9, \#12). When the date for accession for the ten new member states was agreed to, the Council recognised "that there were going to be significant difficulties in getting the ten member states, because of who they are and their history, to support the ten year data exclusivity period. (...) That really makes you think, 'well in that case maybe there are some concessions I can make in order to finalise this before the enlargement'" (\#6, British civil servant). At the same time, some member states kept raising problems to be able to exchange in the end for the final compromise (\#5, \#8).

Because no compromise could be found at working group level, data exclusivity needed to be discussed at ministerial level. Prior to the Council meeting in June 2003, the smaller member states with six years of data exclusivity formed a blocking minority. Finland and Denmark stated that they could not accept data exclusivity beyond eight years, whereas several other member states, including Germany, France, Italy and the UK, wanted to adopt the Commission proposal. In the end, the compromise proposal of the Greek presidency was accepted, namely ' $8+2$ ' for the mutual recognition procedure and ' $10+1$ ' for the centralised procedure. This shows that harmonisation was not the Council's priority.

The concept of data exclusivity had already been introduced in 1987, representing an irreversible path. The discussion about whether it would stimulate innovation, or not was past. The Council debate focused on how long data exclusivity should be. Opposition to ' $10+1$ ' was voiced by a coalition of member states, including accession countries, with little or no research-based industry. Their focus was on healthcare cost control. Member states with a strong research-based industry that already had ten years protection at national level were in favour. However, even those countries had to take their generics industry and healthcare costs into account. Therefore the seeming compromise of ' $8+2+1$ ' became acceptable for them in the end.

\subsection{ENLARGEMENT - “AN APPALLING EXAMPLE OF MISGOVERNANCE"?}

Even though accession countries did not ask for many exceptions with regard to the body of pharmaceutical legislation they had to adopt, the review turned out to be problematic. Prior to the new pharmaceutical legislation, accession countries had already made concessions to pharmaceutical interests, by introducing EU legislation on supplementary protection certificates and adapting their data exclusivity period. Since most of them 
provided no or shorter protection periods, they all opted for six years. However, after adoption of the review, they had to increase this period again.

The accession countries were bewildered by the fact that they had not been formally included in the review (Scrip, 2000). In 1998, the Commission recognised that 'the average per capita income in the countries of Central and Eastern Europe is considerably lower than the average in the current member states and raises therefore the question of how patients are to have access to affordable pharmaceuticals at prices which are realistic in the Single Market context' (Commission of the European Communities, 1998). Still, the Commission did not involve the accession countries when preparing its proposals for the review.

As of January 2003, the accession countries joined the Council's pharmaceutical working group. "Everybody knew they had no voice. They were listened to politely, but in the end they did not have any power to really say what they wanted" (\#5, Dutch civil servant). Some perceived the review as "the most appalling example of misgovernance, because the extension of data exclusivity was pushed through and the pharmaceutical review was fast-tracked before enlargement. (...) They [the accession countries] were totally ignored. Frankly, the interests of the industry largely based in countries like France, the UK, Germany, prevailed over the wider solidarity issue or even the general health issues" (\#11, PH lobbyist).

Health ministers of the candidate member states signed the 'Milan Declaration' in September 2003, emphasising the priority of retaining six years, since generics made up a vital share of their markets. They held that data exclusivity up to ten years would 'weaken the availability and affordability of medicines to the public, place greater burden on the national health insurance fund and have a negative impact on the fragile national pharmaceutical industry' (Ministers of Health from the Acceding Countries, 2003). But the declaration was largely a symbolic protest, because they could only participate as observers and never had the prospect of influencing the process according to their own preferences.

EGA strongly supported the declaration, claiming that data exclusivity provisions effectively block the registration of generics. According to EFPIA, joining the EU gives an opportunity to accession countries to focus more on research and the benefits that it brings for patients. Protecting local copyrights and the generics industry is not the way forward for the enlarged Europe' (Anonymous, 2004). Given the accession countries' inability to participate, MEP Corbey tabled an amendment during the second reading of the EP, which would have allowed the accession countries to maintain their negotiated six-year period. However, this was rejected.

According to a representative from the Commission, if the package had been finalised after the first of May 2004, "the final outcome would not have been eight plus two" (\#1, 
$D G E)$. This was confirmed by another interviewee: "The ten new member states could quite reasonably have said, we need, we have the right to discuss and debate every provision in this legislation" (\#6, British civil servant) which would have resulted in a different balance between more innovation and lower prices.

Prior to the accession, the ten countries could ask for transition periods on the basis of the Accession Treaty. Poland and Malta requested fifteen years of transition for implementation of data protection provisions, Hungary ten years, and Slovenia and Slovakia four years. However, the Commission issued a negative decision on these transitional periods. Only Poland and Malta have not yet transposed data exclusivity periods according to European legislation (CMS Legal Services, 2007).

\subsection{CONCLUSION}

The debate on data exclusivity in the EU has been framed in terms of an incentive to industry vis-à-vis innovation, thereby promoting public health and healthcare versus claims that it results in higher drug bills (Permanand, 2006a: 96). A key policy question is how many medicines are affected, and in what ways, by 10 years of data exclusivity? It may be only a few products that take a particularly long time to reach approval. A related question concerns the burden of this innovation tax: how much more will it cost insurers, health plans and governments, especially in the ten more economically pressed countries that were excluded from participating in the decision. In the absence of evidence that longer data protection would stimulate innovation, why did the European Commission come up with this proposal and why did member states agree? Why was the EP willing to compromise? And what was the role of the pharmaceutical industry?

This analysis shows that the industrial interests of research-based companies prevailed over the interests of others, including member states interested in controlling pharmaceutical expenditures, the generics industry, consumers and patients. A combination of factors explains this final outcome. This case makes clear how much the European Commission controls legislation at each juncture in the process and how critical is the specific Directorate-General of the Commission responsible for an area. The European agenda for pharmaceuticals is a DG Enterprise agenda, that is, high-tech economic growth. It was DG Enterprise that stressed the importance of a long data exclusivity period. Since the Commission had industrial, but no healthcare policy competences, there was a convergence between the interests of the research-based industry and the industrial policy concerns of DG Enterprise (Permanand, 2006a: 9). They had the same agenda: promotion of the research-based industry.

Our analysis also makes clear how the research-based industry lobby (EFPIA) provided the expertise and guided DG Enterprise, capitalising on a huge industry review and on the argument that ten more members joining the EU would complicate matters 
and press their case for more market protection through longer data exclusivity. EFPIA was very successful in convincing the Commission to adopt a proposal for ten years and to help push it through, although to our knowledge no evidence of greater innovation was provided. EGA tried to counterbalance this lobby, but did not have the access to the Commission as did EFPIA. Most public health and consumer organisations focused on different aspects of the review. As with the generics industry, access was far more problematic for them. The complexity of the issue of data exclusivity also resulted in public indifference. Voice strategies were therefore not possible either.

Thus, initially the Commission together with EFPIA developed the proposal on data exclusivity behind closed doors. However, the position of the EP and the member states in the Council had to be taken into account as well. Another factor that explains the outcome is the heterogeneity of actor preferences in the Council as well as the willingness of the EP to eventually paralyse the policy-making process. All actors kept emphasising their own position until the final discussion round required compromising.

A coalition of member states with strong research-based industries, the research-based industry, and the Commission were in favour of long protection periods. Opposition to the Commission proposal was voiced by the EP, the generics industry and some member states, including the accession countries, with no, or a little research-based industry and an interest in the containment of healthcare costs. Even member states 'with an innovative industry had to consider the interests of its generics producers and healthcare institutions' (Feick \& Broscheid, 2005: 19). The compromise solution was formulated by the EP. The pharmaceutical review was perceived as being very important and the EP really tried to put its mark on the final outcome.

Finally, an important contextual condition was EU expansion, which resulted in additional pressure on all actors to compromise on the review in total, including data exclusivity. Several of the accession states had comparatively short, or no periods of scientific data protection. No agreement on this issue would result in even more differences between the now greater number of member states. The legally required pharmaceutical review of the existing regulatory framework constituted the beginning, and the EU enlargement in May 2004, formed the end of a window of opportunity during which the revision of data exclusivity could take place (Feick \& Broscheid, 2005: 33).

Even if longer data exclusivity was shown to result in more research, most of it has proven to be misguided by disease models and surrogate end points that usually provide little benefit (Cuatrecasas, 2006; Horrobin, 2003). One reason is that being better than a placebo is the benchmark for approving new drugs, not being clinically superior to existing ones. It would benefit not only the health of Europeans, but also the industry if countries paid in proportion to how much better a new medicine is for patient well-being 
- the kind of value purchasing that we all do every day in our lives when we buy other products.

A growing chorus of critics inside the pharmaceutical industry and outside believe companies have become inefficient, less innovative, and more focused on lobbying governments for market protections than on discovering breakthrough drugs (Barral, 1996; Prescrire International, 2007; US Senate Select Committee on Small Business, 1979). Following the small amount of medicinal products whose data exclusivity deadline currently extends patent protection, one may conclude that the industry's victory is symbolic rather than substantial. However, as said before, for the research-based industry nothing is as lucrative as stretching out monopoly rights on their profitable products and the pharmaceutical industry quickly capitalised on this victory for longer protections from price competition in its global campaign to use data exclusivity in US Free Trade Agreements (FTAs) to prohibit trading partners from manufacturing, exporting, or importing cheap generics. "The new rules would far surpass the standard already established [for protecting IP rights of pharmaceutical companies] by the World Trade Organisation's Agreement on Trade-Related Aspects of Intellectual Property Rights (TRIPS)" (Health GAP, 2003). According to Abbott (2004), the data exclusivity and other provisions in the US FTAs force countries to give up rights they have to use generics to protect public health and promote access to medicines for all. The net effect of data exclusivity, independent of whether a medicine's patent is registered or has expired is to create a web of restrictions and uncertainties that will have a powerful chilling effect on (...) the introduction of third-party (generic) medicines that are not under patent' (Abbott, 2004).

Whether the European Community is aware of it or not, it has provided a powerful legal tool for the industry to extend high prices in poorer countries in Europe and around the world. The US will now be put under pressure to match or exceed the European length of data exclusivity as the industry plays one market off another to reach its goal of 25 years of monopoly protection from free market competition. 


\section{STRATEGIES OF THE EUROPEAN COMMISSION CONCERNING DIRECT-TO-CONSUMER ADVERTISING}

\subsection{INTRODUCTION}

Direct-to-consumer advertising (DTCA) of prescription drugs is currently only permitted in New Zealand and the United States (US). In the US, it is the third largest category of advertising, behind automobiles and fast food (Farris \& Wilkie, 2005: 3). Discussions about revising the ban on advertising are taking place in Canada, Australia and the European Union (EU). In the EU, advertising of drugs is regulated by Directive 89/552/EEC banning television advertising and Directive 92/28/EEC banning advertising of prescription-only drugs to the general public..$^{20}$ In 2001, the European Commission proposed a partial lifting of the ban by means of a 5 -year pilot study. It would give manufacturers the opportunity to inform patients on their medicinal products for HIV/AIDS, diabetes and asthma. This proposal was puzzling for several reasons.

First, DTCA for prescription medicines is highly contested. Studies on its effects show diverging - positive and negative - results and researchers conclude that more research is necessary to gain better insight (Auton, 2006; Hollon, 2005; Holmer, 2002). Scientific studies are very much polarised, and for that reason cannot form the rationale for evidence-based decisions. Therefore, a political perspective is necessary to understand the discussion that takes place in the EU.

Second, loosening the ban would influence national healthcare systems, since demand is stimulated for those medicines that are most advertised. Research indicates that DTCA drives sales of newer, more expensive drugs for conditions with enormous market potential (Hollon, 2005: 2030). In Europe, medicines on average account for 12-25\% (respectively West and East European countries) of health expenditures (OECD, 2007) and have been the object of cost containment policies everywhere. Increased consumption of prescription drugs puts further pressure on the sustainability of healthcare financing in the member states. The long-term effects of new drugs and advantages over cheaper alternatives are unknown and it is therefore questionable whether the increased cost can be justified (Mansfield et al., 2005: 6). The principle of subsidiarity, which implies that policies should be regulated at the lowest level possible, is an important justification for the member states when they fear a loss of control over issues which form an essential part of their health and social security policies (Valverde, 2005: 4). This is also true for DTCA, where authorities fear a demand explosion with a

\footnotetext{
${ }^{20}$ Directive 92/28/EEC is codified in Directive 2001/83/EC on the Community code for medicinal products. It also addresses provisions concerning advertising of over-the-counter products to the general public, advertising of all medicinal products to health professionals, sales promotion, hospitality and provision of free samples.
} 
huge impact on national healthcare budgets. Following member states' insistence on healthcare organisation and financing being a national competence, the Commission should have known that they would almost certainly block its proposal, which is exactly what happened. The Commission tabled the proposal without taking the interests of all stakeholders into account, resulting in a rejection of the pilot study by both the European Parliament (EP) and the Council in 2003.

Why did the Commission issue this contested proposal? What strategies did it use to find a way out of the political impasse and to create momentum for discussion (Cram, 1997; Héritier, 1999)? Though as yet unsuccessful, the issue has been on the agenda for more than ten years and is still under discussion. The Commission as a 'purposeful opportunist' (Cram, 1997) often succeeds in legislating on issues that do not necessarily fall within its mandate. As this chapter will demonstrate, in the case of DTCA, the Commission sought to circumvent deadlock through all kinds of escape routes defined by Héritier as 'policy strategies and patterns that 'make Europe work' against the odds of the given institutional conditions and the enormous diversity of interests' (Héritier, 1999: 1). Without unambiguous evidence of the effects of DTCA, both the Commission and the pharmaceutical industry framed the discussion in terms of direct-to-consumer information (DTCI), to emphasise that it was not about advertising. As we will demonstrate in our analysis, DTCI is a Trojan horse, used as a political instrument.

This chapter analyses the role of the Commission as a purposeful opportunist via an explorative study of the policy process regarding DTCA based on the framework of actor-centred institutionalism (Scharpf, 1997). In the following section, we reconstruct how DTCA came onto the European agenda and analyse how the Commission used various institutional routes to continue discussions and to open up room for manoeuvring. First we describe the process of the failed Commission proposal (pharmaceutical review), after which we outline the alternative routes the Commission used to ensure that the issue remained on the agenda. ${ }^{21}$ The chapter ends with an overview of the Commission's role as purposeful opportunist in the DTCA process (Cram, 1997; Héritier, 1999, 2000).

\subsection{DTCA ON THE EUROPEAN AGENDA}

In the EU, the Commission's Directorate-General (DG) Enterprise is responsible for drafting pharmaceutical legislation. According to Permanand and Mossialos (2005: 687), Commission initiatives are primarily oriented towards facilitating industrial policy objectives. There are three related processes that explain how DTCA came onto the

\footnotetext{
${ }^{21}$ For an overview of the interviews refered to in this chapter, see appendix 2.
} 
European agenda: the Bangemann Round Tables; the Transatlantic Business Dialogue; and the strong pressure exerted by the pharmaceutical industry.

\subsubsection{The 'Bangemann' Round Tables}

The Round Table discussions on completing the Single European Market (SEM) in pharmaceuticals $^{22}$ were initiated by Commissioner Bangemann, responsible for DG Enterprise, together with the European Federation of Pharmaceutical Industries and Associations (EFPIA). Discussions concentrated on price regulation and parallel imports. However, the unconventional path of a discussion forum allowed for the introduction of additional topics on the agenda (Kotzian, 2003: 180). The topic of electronic commerce was addressed at the second Round Table in December 1997. At the end of that meeting, the Commissioner concluded that one of the key issues identified for further discussion at the political level [was the] need to develop the ideas about the scope of electronic commerce' (Bangemann Round Table, 1997).

The Commission addressed the influence of electronic commerce on advertising in its Communication on the SEM in pharmaceuticals of November 1998 (Commission of the European Communities, 1998): 'The issue of direct to consumer advertising needs to be examined in greater depth. The context of such consideration, however, is unlikely to be simply that of advertising direct to the patient' (pp.16-17). This communication formed the basis of the final Round Table in December 1998, where DTCA was a central topic (Kotzian, 2003: 182). According to EFPIA, the 'Round Table has focused attention of all parties on the potential impact of new information and communication technologies. (...) The industry fully supports the objective of further developing understanding of this important area, including the potential role of direct-to-consumer information' (EFPIA, 1998). Note that the Commission excluded the possibility of DTCA in its Communication and the pharmaceutical industry explicitly refered to DTCI in its conclusions concerning the Round Table discussion.

\subsubsection{The Transatlantic Business Dialogue}

The issue of DTCA was also on the agenda of the Transatlantic Business Dialogue (TABD). ${ }^{23}$ In May 1998 it discussed the inconsistency in regulatory treatment of industry in the transatlantic marketplace (...) [which] deprives EU citizens of the right-to-know compared to their US counterparts. (...) Industry seeks the transatlantic harmonisation of its ability to communicate factual information (...) to the public' (TABD, 1998a: 25). The

\footnotetext{
${ }^{22}$ An overview of the proceedings of the three Round Tables 1996-1998 can be found on the following website: http://ec.europa.eu/enterprise/pharmaceuticals/smarket/index.htm [2008, February 14].

${ }^{23}$ The TABD is a forum for cooperation between the transatlantic business community and the governments of the EU and the US.
} 
report mentioned that DTCI is permitted under strict regulatory controls in the US. Again, explicit references to advertising were avoided. However, in the conclusions of the October 1998 TABD meeting, DTCA was refered to: 'Industry also welcomes Commission's statement that the terms of the current advertising directive may need to be revisited in the context of developments in the world around us. Industry requests that the Commission establish a working group to review DTC advertising issues' (TABD, 1998b: 11).

DG Enterprise discussed the issue of such a working group with the Pharmaceutical Committee during a meeting in April 1999. This advisory committee ${ }^{24}$, composed of representatives from member states and chaired by DG Enterprise, examines questions relating to medicinal products. The representative of DG Enterprise 'suggested that a working party should be set up to further consider the issue of information on medicinal products and the possible need to amend Directive 92/28' (Pharmaceutical Committee, 1999a). In September 1999, the Pharmaceutical Committee endorsed the plan for a 'brainstorming group' with 'no mandate to interpret the law or to give regulatory guidance' (Pharmaceutical Committee, 1999b).

At the single meeting of this working group in March 2000, it was decided to circulate a questionnaire 'on advertising and e-commerce' to stimulate wider debate. The outcome was never published and the questionnaire was removed from the EU website (Medawar \& Hardon, 2004: 118-119). However, the British public health advocacy group Social Audit made the questionnaire available on its website, ${ }^{25}$ expressing its concern 'about the poor quality of debate and deliberation so far and the undue influence of the international pharmaceutical industry in health policy-making'. Even though member states' responses were never made available, another document mentioned the 'lack of appetite' among member states for any change of law (Pharmaceutical Industry Competitiveness Task Force, 2001: 34).

\subsubsection{Industry pressure}

The pressure from the pharmaceutical industry to promote DTCA dates from the mid1990s. One example is the 'battle plan' from the Association of the British Pharmaceutical Industry (ABPI): ' $(. .$.$) the ABPI has announced that it is launching the final stages of a$ campaign before it tackles the government and the EU head on (...) It is the spearhead of a carefully thought-out campaign. The ABPI battle plan is to employ ground troops in the

\footnotetext{
${ }^{24}$ Set up by Council Decision 75/320/EEC in May 1975.

${ }^{25}$ Questionnaire on advertising and e-commerce, see www.socialaudit.org.uk/4390EU5.htm\#questionnaire. [2007, November 9]. Examples of questions show that it had a poor quality: 'Do you believe that Europe has a distinctive approach within the global environment to consider advertising/information (particularly on the internet)? If so: what are the main elements of that distinctiveness and how does that distinctiveness need to be taken forward?' Social Audit's response to questionnaire, see www.socialaudit.org.uk/5111-002.htm
} 
form of patient support groups, sympathetic medical opinion and healthcare professionals - known as 'stakeholders' - which will lead the debate on the informed patient issue. This will have the effect of weakening political, ideological and professional defences (...) Then the ABPI will follow through with high-level precision strikes on specific regulatory enclaves in both Whitehall and Brussels' (Jeffries, 2000).

In a position paper of November 2000, EFPIA addressed proposals for 'a balanced and comprehensive communication policy considering the needs of all involved parties' (EFPIA, 2000). One of the suggestions concerned a broader dialogue 'on the potential and issues associated with the use of internet (including legal aspects) in the benefit of patients'. EFPIA's annual report of 2000-2001 mentioned a public congress on the theme 'informed patients - towards new partnerships in healthcare', held in June 2001. In addition, the annual report also refered to 'an outdated European legislation regulating information to patients (Directive 92/28/EEC)' as a key factor explaining Europe's decline in the pharmaceutical field (EFPIA, 2001: 21).

As Mossialos and McKee (2002: 138) noted, 'this type of pressure, exerted by powerful national stakeholders (...) is something which the national governments, and in turn the European Commission, will not be able to ignore indefinitely. Changes to the legal environment thus appear almost inevitably if Europe is to keep pace with the US'.

In sum, discussions on DTCA in Europe seem to be directly related to the decision of the US Food and Drug Administration (FDA) to relax its rules for DTCA for prescription drugs on television after a fifteen-year moratorium in August 1997 (Medawar \& Hardon, 2004). The pressure from the pharmaceutical industry may well be the reason that Commissioner Bangemann discussed the topic during the Round Table meetings. The agendas of DG Enterprise and the pharmaceutical industry both had a strong focus on creating a competitive European pharmaceutical industry, especially vis-à-vis US industry (see Gambardella, Orsenigo, \& Pammolli, 2000). Together with the TABD, this created a window of opportunity for DG Enterprise to addres DTCA in a Communication, to discuss it in the Pharmaceutical Committee and to initiate a questionnaire.

The process showed that the discussion was blurred. Sometimes reference was made to advertising, sometimes to information. For example, during the first meeting of the TABD, factual information was emphasised, whereas at the second meeting, industry asked the Commission to review DTCA. However, both DG Enterprise and the industry tried to exclude advertising from the discussion and emphasised the importance of patient information. DG Enterprise was willing to pick up this issue and did so in a very energetic manner. The issue was on the agenda under the heading of DTCI and DG Enterprise, as we will show next, was keeping it there. 


\subsection{THE PHARMACEUTICAL REVIEW: LEGISLATION ON DTCA?}

The Round Tables were a first step towards a formal agenda (Kotzian, 2003: 184). In 2001, the Commission tabled a proposal for a 5-year pilot study (article 88) to allow DTCI to be provided by pharmaceutical companies for three chronic illnesses: HIV/AIDS, diabetes and asthma (Commission of the European Communities, 2001b: 80).

\subsubsection{The Commission's proposal: a surprise act by DG Enterprise}

In 1999, six years after the adoption of Regulation 2309/93/EC, an evaluation of the medicine control system was foreseen. In 2000, Cameron McKenna and Andersen Consulting assessed the existing pharmaceutical legislation (CMS Cameron McKenna \& Andersen Consulting, 2000), taking into account the views of all stakeholders. General satisfaction was reported with regard to the regulation of advertising: '(...) there is no clear support for consideration of any changes. Exceptions arise in relation to (...) the need to clarify the dividing line between health education and promotion of prescriptiononly medicines to the public' (pp.47). Guidelines would be sufficient in this context (pp.66).

However, several informants agreed that DG Enterprise had its own agenda (\#1, \#6, \#12, \#14). Only ten days after publication of the evaluation in October 2000, the Commission set out its own ideas in a reflection paper to the Pharmaceutical Committee, though no reference was made to DTCA (Pharmaceutical Committee, 2000). The Commission's final discussion document on the pharmaceutical review of January 2001 did not mention DTCA either (Commission of the European Communities, 2001d).

In early July, the Commission 'introduced' the subject at a special meeting of the Pharmaceutical Committee. Thus, the issue was being discussed for the first time only days before the pharmaceutical review proposals were made public. Member states expressed themselves in favour of information, however, many of them rejected DTCA (Pharmaceutical Committee, 2001).

On July 18, 2001, the Commission tabled the review proposals, including a pilot study. According to Commissioner Liikanen (DG Enterprise) it was not a matter of authorising DTCA (Commission of the European Communities, 2001e: 6). However, in the explanatory memorandum of the proposals, the Commission by mistake referred to the internet and the growing consumer demand for information as the main reasons for allowing 'public advertising of three classes of medicinal products' (Commission of the 
European Communities, 2001b: 86). ${ }^{26}$ In the same document, the Commission stated that 'information should not be equated with direct advertising' (pp.89).

In this context, it should be borne in mind that the proposals were developed by DG Enterprise. According to representatives from both DG Enterprise and DG Health and Consumer Protection (Sanco), the latter was involved in full detail. "Even if DG Enterprise has the leading responsibility, of course we always consult DG Sanco very closely" (\#1, DGE). However, DG Sanco was not able to counterbalance the industryoriented proposals of DG Enterprise. During an interview, a representative of DG Sanco explained that this was an issue where they disagreed: "The industry lobbied strongly towards DTCA in some areas. From a public health perspective, it is not clear whether there are advantages to consumers" (\#2, DGS).

Various respondents stated that DG Sanco played only a marginal role (\#5, \#9, \#10, \#11, \#14). Whereas DG Enterprise was well organised and very decisive, DG Sanco neither had the capacity, nor the knowledge to be a real partner. It was only created in 1999, with a very limited mandate and without a strong culture. During the first few years, the BSE (beef) crisis and the ban on tobacco advertising were time-consuming issues and for a small DG there was a limit as to how many battles it could take on.

\subsubsection{Interest representation: unequal access to the European Commission}

The possibility of influencing the identification and framing of European policy problems attracts interest groups. However, in this case there was hardly any public debate on DTCA during the preparation of the pharmaceutical review. 'The most recent discussions were the workshop on pharmaceutical legislation (January 26, 2001) and the advertising brainstorming meeting (March 21, 2000). At these occasions (...) AIDS, asthma and diabetes stakeholder groups did not attend' (BEUC, 2001). A representative from the European AIDS Treatment Group (EATG) also argued that, even though AIDS was one of the illnesses covered by the Commission proposal, EATG was never consulted. 'It seems that there is very little means to have input into this process. EATG believes the legislative process itself needs to become more transparent and inviting, so that stakeholders can play a real role' (HAI, 2002: 33-34).

The Commission claimed to engage the patient's perspective via a dialogue with representative groups, although it recognised a "certain misbalance in the representation. Industry is better organised" (\#1, DGE). In this context, several interviewees (\#11, \#14, \#15) criticised the financial dependence of some patient groups (see also Herxheimer, 2003): "Lobbyists of patients, I mean real ones, not those who are financed by industry,

\footnotetext{
${ }^{26}$ The English version of the document in fact used the word 'public advertising', whereas reference was made to 'information' in the other languages.
} 
are very small and they are not heard by the Commission" (\#13, PH lobbyist). Whereas industry and some patient groups had good access to DG Enterprise, public health and consumer organisations were considered stakeholders of DG Sanco. DG Enterprise explained that it had turned away from the independent consumer bodies it had traditionally consulted, since they are not able to do what we have historically looked at them to do, namely the representation of the interests of consumers as patients' (letter from DG Enterprise to Health Action International in Medawar \& Hardon, 2004: 120).

\subsubsection{No pilot study: the role of the European Parliament}

The passing of the pharmaceutical review, including the proposal for the pilot study, took place through the co-decision procedure, which provides for joint decision-making and direct negotiations between the Council and the EP and the possibility for the EP to reject draft legislation (Shackleton, 2002). After the Commission had tabled its proposal, the EP Committee for Environment, Public Health and Food Safety (ENVI) was responsible for drafting amendments. Most parliamentarians within the committee were against DTCA. 'Information on diseases or medicines coming from industry cannot be anything but promotion. (...) The proposed revision plays on smart words: information, communication, education. (...) [It] will boost healthcare expenditures and compromise rational use of drugs' (de Roo, the Netherlands and Rod, France, The Greens/European Free Alliance). Stihler (Party of European Socialists, UK) argued that 'those diagnosed with other diseases can reasonably argue that they are just as entitled to information' (European Parliament, 2002e).

The ENVI Committee suggested to delete the proposal. During the EP plenary meeting of October 2002, the Commission proposal was overwhelmingly rejected with 494 votes in favour, 42 against and 7 abstentions. Instead, the Commission was asked to present a report outlining a comprehensive consumer/patient information strategy to ensure good quality, objective, reliable and non-promotional information on medicinal products and other treatments (European Parliament, 2002d: 48).

\subsubsection{A counter-lobbying operation in the European Parliament}

Several public health and consumer organisations immediately used the EP committee deliberations to present their opinion in what was called 'a counter-lobbying operation' (Prescrire International, 2002). They had not been able to argue against the proposal during the drafting stage: they had no access to DG Enterprise and more importantly, the whole process was very secretive.

In January 2002, Health Action International (HAI) and the European Public Health Alliance (EPHA) organised a symposium on DTCA. Several patient groups attending the meeting said that they had not been consulted, nor did they support the proposal. They all 
agreed that there should be more clarity on the definitions of promotion, advertising and information (HAI, 2002: 38). Not only public health and consumer organisations expressed their opposition, but also the Pharmaceutical Group of the EU (PGEU), representing pharmacists, claimed 'that the proposals for changes to article 88 have certainly not come from physicians or pharmacists, who are very firmly against' (PGEU, 2002: 5).

Following the symposium, EPHA and HAI argued that no one claimed responsibility for the Commission's proposal: 'No one could say who exactly is driving this proposal. DG Enterprise said that this proposal was based on expectations expressed by patient groups, but it could not name a single patient group supporting this proposal. (...) EFPIA claimed that they have no position on DTCA' (HAI, 2002: 57-58). A few months later, however, EFPIA welcomed the fact that the Commission had opened the debate in the light of changes in society', though it also expressed its concerns: the proposal 'should be extended without delay to all disease categories and all patients, to be consistent with European goals of social solidarity and equity in health' (EFPIA, 2002).

The key challenge for non-governmental organisations (NGOs) was the "very strong commercial push from the pharmaceutical industry" (\#11, PH lobbyist). "I remember when going to the EP for the first time, one member of the EP (MEP) said to me, I am so happy to see a different person than a lobbyist of the pharmaceutical industry" (\#13,PH lobbyist). "Whatever the impression people get from the outside about NGO activity, the reality is that the whole thing is done on a shoestring" (\#14, consumer lobbyist).

Under such circumstances, public politicisation is vital. As one lobbyist confirmed: "I think [DG Enterprise] was probably quite surprised by the response it got on an ad hoc basis from HAI and Medicines in Europe Forum (MiEF)" (\#14, consumer lobbyist). In addition, DTCA was one of the only issues of the pharmaceutical review package picked up by the media. The parliamentary rapporteur claimed that media pressure resulted in rejection of the Commission proposal by the EP (Grossetête, 2005).

There are several possible explanations for why the EP did not just delete the proposal, but instead requested a report on patient information from the Commission. First, there was enormous pressure from the pharmaceutical industry. Second, the Commission's strategy to use the rhetoric of patient information in the context of DTCA had meant that the EP could not simply ignore the Commission's 'quest for information'. Third, several interviewees (\#1, \#3, \#5) confirmed that DG Enterprise was in close contact with the rapporteurs and tried to build alliances with them. Following the storm of criticism within the ENVI Committee concerning the proposal for a pilot study, it must have been in the interest of DG Enterprise to come up with a proposal that would be acceptable for all, without being fully defeated. The EP's request for a report allowed the Commission to 
keep the issue on the agenda. The question that arises is to what extent DG Enterprise had any impact on this. In this context, Rapporteur Grossetête (European People Party/European Democrats, France) acknowledged that she had the Commission's support for a more acceptable formulation. She was in favour of the initial Commission proposal and mentioned that it was a pity that 'emotion finally won. [However,] I could, with the support of the European Commission, introduce an amendment asking the Commission that it present, within three years, a clear text on what exists in the field of information' (Grossetête, 2005: 31).

\subsubsection{The role of the Council under time pressure}

The Commission ignored the parliamentary vote and reinstated the pilot study in its revised proposal (April 2003). Deliberations amongst the member states in the Council soon showed that most countries were against it, questioning the proposal's financial impact on their national health systems (\#5, \#11 and Weissenberg, 2005: 24). Therefore, in the end, there was hardly any debate on this issue in the Council.

Several other factors also explain the lack of discussion concerning this issue. The pharmaceutical review included more than 200 proposed changes on human medicines. Given this large number of issues, the Council had to split up negotiations. From 2002, every half year a presidency "tried to unravel part of the Gordian knot" (\#5, Dutch civil servant). In addition, the enlargement with ten new member states in May 2004 "made a difference to the speed at which we got to conclusions" (\#6, British civil servant) because "nobody really wanted to face the consequences of failure and the very arduous task of starting all over again with 25 member states" (\#3, Danish civil servant). According to DG Enterprise, there was "not enough time to dedicate discussion to information to patients; speed was too high, the package was too broad and therefore we did not succeed to get a solution there and simply postponed it" (\#1, DGE). However, it is more likely that the member states followed their preferences when deleting the proposal for a pilot study. In September 2003, the Council adopted its common position without any legislative changes concerning article 88 .

Even though the Commission made a reservation regarding the Council's removal of its pilot study and 'stayed with the Commission proposal concerning patient information' (Council of the European Communities, 2003), the topic did not cause much discussion anymore. The positions of the EP and the Council were clear, they did not want a pilot study. They agreed on article 88a of Directive 2004/27/EC that, by 2007, 'the Commission shall, following consultations with patients and consumers organisations, doctors and pharmacists organisations, member states and other interested parties, present to the European Parliament and the Council a report on current practice with regard to information provision - particularly on the internet - and its risks and benefits 
for patients. Following analysis of the above data, the Commission shall, if appropriate, put forward proposals setting out an information strategy to ensure good-quality, objective, reliable and non-promotional information on medicinal products and other treatments and shall address the question of the information sources liability' (Commission of the European Communities, 2004).

In sum, DG Enterprise clearly had its own agenda. It overruled DG Sanco, which did not have the power to block the DTCA proposal. No consultations were held with relevant stakeholders to discuss the possibility of a pilot, although DG Enterprise claimed that patient groups had asked for such a proposal. The whole issue came as a surprise act of DG Enterprise, which probably considered the pharmaceutical review a good opportunity: placing the proposal within a large package could facilitate agreement. However, in the end, the pilot study was rejected and replaced by the request for a report. Even though we do not know whether the Commission had any impact on the formulation of these amendments, Commissioner Liikanen explicitly referred to the fact that DTCI was part of the package.

\subsection{DIFFERENT ROUTES FOR DISCUSSION: HIGH LEVEL GROUPS AND CONSULTATIONS}

Although the pilot study was rejected in 2003, during and after the review process, DG Enterprise used different routes for discussion to ensure that the topic remained on the agenda.

\subsubsection{Discussions parallel to the pharmaceutical review: the G10 High Level Group}

While proposals for the pharmaceutical review were being developed, DG Enterprise established the G10 High Level Group on innovation and the provision of medicines in March 2001. The large and ineffective Bangemann Round Tables influenced the composition of the G10: a small group of people to facilitate consensus (Brown, 2007; \#3, Danish civil servant). Though initiated by DG Enterprise, it was presented as an initiative of both DG Enterprise and DG Sanco. From the member states, the Swedish Minister of Industry, together with the French, German, British and Portuguese Ministers of Health attended the meetings. EFPIA, the European Generic medicines Association (EGA) and the European Self-Medication Industry (AESGP) together with the individual firm GlaxoSmithKline represented industry. Association Internationale de la Mutualité (AIM) represented social health insurers and there was a patient representative from the Picker Institute, representing patient views as they emerged from research. There was a lot of criticism with regard to the overrepresentation of the pharmaceutical industry. "The 
composition of the group was striking. You had one patient representative and many people were defending the same interests in front of the ministers" (\#13, PH lobbyist).

Several interviewees claimed that it was a strategic choice to set up a discussion forum parallel to discussions on the review (\#1, \#13, \#14). "DG Enterprise was not getting the support it wanted for the ideas it had. This was a political move to try and orchestrate a consensus for what [it] wanted" (\#14, consumer lobbyist). According to DG Enterprise, "the G10 was a choice to stabilise certain important topics before you come up with a legislative proposal. (...) This kind of policy-shaping mind-set, sitting together in advance of preparing the legislative proposal is very important for us. (...) It helps to get ideas and consensus between the different stakeholders and therefore smoothens the further progress" (\#1, DGE).

To give as many stakeholders as possible a chance to respond to the ongoing discussion, a consultation on G10 draft recommendations was planned in September 2001 (G10 High Level Group, 2001a). Several interviewees expressed their concerns with these Commission consultations (\#13, \#14, \#15): "They cover their backs by consultation, it does not mean that it directs the initiative. They have their own direction beforehand" (\#12, lobbyist EGA).

In December 2001, a workshop was organised around the question of how to improve patient access to information on pharmaceuticals (Kotzian, 2003: 198). From the documents available, it appeared that the role of industry in patient information was not central to the workshop. Indeed, the 'programme was subsequently criticised by one health group present' (G10 High Level Group, 2001b: 2). The outcome of the workshop was not satisfactory either: 'An attempt was made to draw conclusions (...). However, in view of the short time available, and the fact that a number of delegates left early to catch flights, it proved impossible to achieve this' (pp.3).

Following the consultation and the workshop, the G10 group recommended the need for 'a workable distinction between advertising and information', though it had not been able to do so itself, or, as one interviewee claimed: "they have not been honest or smart enough to recognise that the distinction is impossible to force" (\#14,consumer lobbyist). Furthermore, 'a collaborative public-private partnership involving a range of interested parties' should be established (G10 High Level Group, 2002). Thus, the G10 group did not exclude the pharmaceutical industry in the discussion on patient information.

In July 2003, DG Enterprise adopted a Communication on the G10 initiative. 'The G10 Medicines process has been valuable in reaching consensus in areas where there has often been sterile debate. Our task now is to work with member states and the European Parliament to ensure that the process has a long-term beneficial impact' (Commission of the European Communities, 2003b). It suggested the development of a framework for the provision of pharmaceutical information through innovative solutions. In December 
2003, the Council adopted a resolution, inviting the Commission to explore the possibility of a European information system for patients and health professionals (Agence Europe, 2003a, 2003b).

In sum, G10 was successfully used as "a platform to keep issues that were not agreed upon in the review on the political agenda. And they were very successful concerning patient information. G10 jumped on it even though it was likely to be deleted from the review. So it was a safety net, which shows how well the Commission played the game. It had anticipated this. Not only content, but even more so, process was well-considered" (\#5, Dutch civil servant). Early 2004, the Commission had a request to study information provision and if necessary, propose new legislation (review result), a recommendation to establish a public-private partnership (G10) and a mandate to explore options for a European information system (Council resolution).

\subsubsection{Continuing the debate: the Pharmaceutical Forum}

To continue the discussion, DG enterprise established a High Level Pharmaceutical Forum in June 2005. ${ }^{27}$ DG Enterprise and DG Sanco co-chaired the meetings with all member states, three MEPs and ten stakeholder organisations (four pharmaceutical industry organisations, two social insurance groups and doctors, pharmacists, wholesalers and patients each represented by one organisation). The forum would meet once a year up to 2008, with its first meeting in September 2006. In addition, three working groups were set up, one of them focussing on patient information.

Again, this initiative was criticised. "Basically, (...) they are creating yet another talking shop" (\#4 public policy consultant), whereas "there is no wish in Europe for DTCA. [DG Enterprise] is finding a way of dealing with that, which of course it is doing now in the Pharmaceutical Forum initiative" (\#6, British civil servant). HAI, MiEF and the International Society of Drug Bulletins (ISDB) referred to the 'flawed methodology and the lack of transparency', questioning the legitimacy of the initiative (HAI, MiEF \& ISDB, 2007).

Within the context of the Pharmaceutical Forum, the Commission launched a consultation on quality criteria with regard to patient information and a model patient information package on diabetes from mid March to early May 2007 (Pharmaceutical Forum, 2007a). Numerous criticisms were expressed, both on the content of the information package and the process in general. EPHA doubted the added value of the consultation and called on the Commission 'to clarify how the results of the consultation

\footnotetext{
${ }^{27}$ For an overview of the Pharmaceutical Forum, see http://ec.europa.eu/enterprise/phabiocom/comp_pf_en.htm.
} 
exercise will be used'. It also criticised the Commission's approach of engaging stakeholders in the debate on patient information. The consultation did not give rise to excessive enthusiasm in the member states either. Austria expressed its doubts as to whether an approach proposing a single source of information at European level is practical. A number of heterogeneous medical approaches are pursued by various member states' (see Austrian comments on public consultation, 23 April 2007 in Pharmaceutical Forum, 2007a). Several member states as well as health and consumer organisations referred to differences at the national level in healthcare organisation and availability of treatments. They considered provision and control of patient information a national issue (European Information Service, 2007).

The report of the second meeting of the Pharmaceutical Forum of June 2007 (Pharmaceutical Forum, 2007b) showed that progress was slow and concentrated mainly on improving co-operation and sharing best practices between national authorities and other stakeholders. The working group on patient information agreed that it was not the appropriate platform to further develop the draft information package, which instead would be done by a small expert group with a strong patient involvement.

\subsubsection{Intensifying pressure: steps towards legislative activity}

Not even waiting for the end of the Pharmaceutical Forum consultation on patient information, DG Enterprise held another consultation between April and June 2007 on the 'draft report on current practices with regard to the provision of information to patients on medicinal products' (Commission of the European Communities, 2007a), as the EP and the Council had requested in the pharmaceutical review.

As a basis for this report, the Commission had conducted a survey amongst member states' medicine regulatory authorities to gain insight into their role in information provision in 2006. The result was an arbitrary totting up of different initiatives without any details on risks and benefits for patients, as requested. Following this incomplete overview, the Commission concluded that the different practices in the member states created several risks: unequal access in the Community; lack of quality standards; and lack of information which could result in uninformed choices. 'In turn, the pharmaceutical industry possesses key information on their medicines, but this information can currently not be made available to patients and healthcare professionals throughout the EU' (European Commission of the Communities, 2007: 16).

In an open letter, HAI, ISDB, MiEF and AIM claimed that the report was 'so incomplete that it casts doubts on the Commission's willingness to address the issues raised by article 88a. (...) The report's conclusions are exclusively biased in favour of allowing drug companies to communicate directly with the public' (HAI et al., 2007). Not 
surprisingly, industry regarded itself as a legitimate source of information, but opposed to DTCA (see Scrip, 2007).

The consultation showed general support for improvements in information dissemination, but overwhelming opposition to DTCA. Based on this outcome, a Communication was issued on the report on patient information in December 2007. In this Communication, DG Enterprise again emphasised the problem of unequal access to information in the various member states. It therefore announced its intention to introduce 'legal amendments to the current rules on the provision of information to patients by the end of 2008' (Commission of the European Communities, 2007b).

Not long after this announcement, a consultation was held on a forthcoming legal proposal on patient information from February to April 2008 (Commission of the European Communities, 2008). DG Enterprise's fundamental objective was to harmonise the existing situation in the member states, creating a framework for the industry to offer 'good-quality, objective, reliable and non promotional information on prescription-only medicinal products'. Again, reference was made to 'a clear distinction between advertising and non-promotional information' (pp.5). Here, 'clear criteria should distinguish the information that is allowed from the information that is not allowed' (pp.6). DG Enterprise suggested to allow dissemination of information through 'TV and radio programmes, through printed media actively distributed, through information in printed media or through audiovisual and written material provided to patients by healthcare professionals' (pp.6).

In conclusion, DG Enterprise initiated and fostered EU high level debates between experts, professionals and member state governments on patient information. The opaque approach of inviting some, but not others resulted in an overrepresentation of industrial interests. Various simultaneous routes and overlapping consultations created confusion. The content of consultation papers was biased, as were DG Enterprise's conclusions from these consultations. Whereas many stakeholders expressed their doubts concerning the process as well as the content of the consultation papers, DG Enterprise consistently claimed that there was a general interest in patient information and that no stakeholder should be excluded from this.

Another misunderstanding concerned the definition of information versus advertising. Whereas stakeholders asked for disentanglement of these concepts during the G10 process, DG Enterprise more or less created this confusion. While not asking for DTCA, it was clear that giving patients information by industry was on the agenda. Given that current law does not exclude the option of information provision, this focus may be fruitful. In this context, the quality principles for information that have been developed in the Pharmaceutical Forum explicitly mention that unbiased and objective information is 
not related to the source of information. In fact, during the different discussions, the pharmaceutical industry was never excluded.

The process showed how DG Enterprise increased pressure until, finally it once again moved from High Level discussions requiring consensus to a draft legal proposal on patient information. It is just a matter of time before the Council and the EP will again have to discuss legislative activity in this area. For an overview of the different routes of discussion over the last decade, see table 7.1.

\begin{tabular}{|c|c|}
\hline Date & Developments concerning DTCA \\
\hline December $1997 / 1998$ & Bangemann Round Tables: discussing internet and information \\
\hline May/October 1998 & Transatlantic Business dialogue \\
\hline March 2000 & First consultation on DTCA \\
\hline October 2000 & $\begin{array}{l}\text { Publication of Cameron McKenna and Andersen report: no wish for } \\
\text { legislative changes concerning DTCA }\end{array}$ \\
\hline January 2001 & $\begin{array}{l}\text { Commission organises public hearing for stakeholders: no discussion } \\
\text { concerning DTCA }\end{array}$ \\
\hline March 2001 & $\begin{array}{l}\text { Medicines High Level Group on innovation and the provision of medicines } \\
\text { (G10) }\end{array}$ \\
\hline July 2001 & European Commission adopts proposal pilot study \\
\hline May 2002 & $\begin{array}{l}\text { G10 recommendations: public-private partnership; search for workable } \\
\text { distinction advertising and information }\end{array}$ \\
\hline October 2002 & $\begin{array}{l}\text { EP first reading: rejection proposal pilot study; instead request for report on } \\
\text { patient information by the Commission }\end{array}$ \\
\hline April 2003 & $\begin{array}{l}\text { Commission adopts amended pharmaceutical review proposals, including } \\
\text { pilot study (ignoring EP vote) }\end{array}$ \\
\hline September 2003 & $\begin{array}{l}\text { Council adopts common position: rejection pilot study; no legislative changes } \\
\text { concerning DTCA }\end{array}$ \\
\hline December 2003 & Compromise between Council and EP: report on patient information \\
\hline March 2004 & Adoption of Directive 2004/27/EC including report on patient information \\
\hline June 2005 & Start High Level Pharmaceutical Forum \\
\hline September 2006 & $\begin{array}{l}\text { First meeting High Level Pharmaceutical Forum: establishment patient } \\
\text { information working group }\end{array}$ \\
\hline March-May 2007 & $\begin{array}{l}\text { Consultation Pharmaceutical Forum on patient information: quality criteria } \\
\text { and information package diabetes }\end{array}$ \\
\hline April-June 2007 & $\begin{array}{l}\text { Consultation 'draft report on current practices with regard to the provision of } \\
\text { information to patients on medicinal products' }\end{array}$ \\
\hline July-October 2007 & Consultation future of pharmaceuticals for human use in Europe \\
\hline December 2007 & Communication on current practices concerning patient information \\
\hline February-April 2008 & $\begin{array}{l}\text { Consultation legal proposal on information to patients; impact assessment on } \\
\text { the same legal proposal (by Europe Economics) }\end{array}$ \\
\hline
\end{tabular}

Table 7.1: Overview of the main events concerning DTCA

\subsection{PURPOSEFUL OPPORTUNISM: THE COMMISSION'S ROLE IN EU POLICY- MAKING}

The Commission's scope for action is limited by the decision-making power of the Council and the EP. The Commission will try and 'maximise its room to manoeuvre in the policy process while attempting to avoid direct conflict with the member states' 
(Cram, 1997: 6), for example through building a supportive network, consultations, funding related research projects, and issuing Communications. The formal and informal institutional setting leaves room for strategic behaviour.

This chapter concentrated on the question of why the Commission issued the contested proposal for a pilot study allowing DTCI for HIV/AIDS, diabetes and asthma. How did it come onto the European agenda? And what strategies did the Commission use to find a way out of the political impasse and to keep the discussion going?

In the 1990s, the results of the European pharmaceutical industry lagged behind those of US companies. When the US allowed for DTCA, DG Enterprise of the Commission felt that it could not stay behind. The pressure from the pharmaceutical industry played a major role in this. DG Enterprise skilfully used different high-level routes to open up the debate.

Commissioner Bangemann introduced the topic at the Round Table discussions. In addition to these discussions, DG Enterprise issued a Communication, initiated low level discussions in the member states' Pharmaceutical Committee, set up a working group and drew in all kind of actors through a first consultation. Meanwhile, DG Enterprise started to frame DTCA in terms of patient information (see Communication) and kept doing so throughout the process. Though the 1997 liberalisation of DTCA in the US resulted in external pressure, DG Enterprise used the language of patient information in the European context, whereas no reference was made to the argument of increasing competitiveness of the European pharmaceutical industry. These strategies can be considered 'a softening up process' (Majone in Cram, 1997: 38) to 'prepare the ground' for further measures (Kotzian, 2003: 165).

Soon after the first discussions, DG Enterprise set up the G10 High Level Group in parallel to the legislative package covering the pharmaceutical review. Patient information was dealt with during discussions in the G10 process as well as during negotiations on the review. The G10 was therefore perceived as a safety net, in case a legislative agreement would be impossible.

DG Enterprise used the large package of the pharmaceutical review to table its proposal for a pilot study. This reveals the ability of the Commission to formally set the agenda. In this process, DG Enterprise overruled DG Sanco, which appeared to be against the proposal for a pilot study. In fact, it was more or less a surprise act by DG Enterprise. No consultations preceded the proposal, although DG Enterprise claimed that patient groups had asked for such a proposal.

In the first instance, DG Enterprise failed to secure its objectives. However, even though the pharmaceutical review did not result in the outcome it had envisaged, the EP created a window of opportunity by asking the Commission to study the availability of 
information in the EU and if necessary, introduce improvements. In addition, the G10 group asked for a public-private partnership. Following these opportunities to keep the discussion going, DG Enterprise set up the Pharmaceutical Forum for high level debates between experts, professionals and member state governments on patient information.

In the time span of one year (May 2007-April 2008), four consultations were held concerning DTCI together with impact assessments on the preparation of a legal proposal. ${ }^{28}$ DG Enterprise appeared to include all stakeholders through consultations, but as we showed, the conclusions following these consultations did not represent reality. Thus, the process showed how DG Enterprise increased pressure until finally it once again moved from High Level discussions requiring consensus to a (draft) legal proposal, requiring a qualified majority in the Council and co-decision of the EP.

The situation has changed since the pilot study proposal was rejected in 2003: there is a different EP and several East-European countries became members of the EU in May 2004. In addition, the current Commissioner may want to see legislative activity taking place this year, before next year's parliamentary elections and change of Commission.

It remains to be seen whether the member states will object to the current process of 'the Commission developing itself as a focal point for a pan-European' discussion on DTCA (Randall, 2001: 134). Generally, the Commission often initiates and fosters high-level debates. These discussions should result in sharing experiences, exchanges of knowledge and the building of supporting coalitions. In this process, however, DG Enterprise managed to change the language without changing its initial objective. Our study demonstrated that it created a Trojan horse. First, it framed the whole discussion in terms of patient information, thus making a political distinction between advertising and information, aware that the concept of advertising would immediately result in opposition. Secondly, it never cleared up this problematic distinction between advertising and information. Finally, the context for discussion needs to be taken into account, which was in fact the decision to allow DTCA for prescription medicines in the US. The process showed that most stakeholders agreed with the fact that access to patient information is important and thus should be improved. In that sense, DG Enterprise managed to create commitment for this goal (see also Cram, 1997: 107-108).

\footnotetext{
${ }^{28}$ A questionnaire for the impact assessment was developed by consulting firm Europe Economics on behalf of DG Enterprise in December 2007 (with the final date of response, 31 January 2008). Respondents had to answer how certain aspects, such as $\%$ better health outcome, $\%$ sooner contacting healthcare services, $\%$ requesting particular drugs, increase or decrease in patient compliance, would be the result of a change in European legislation, with patients obtaining high quality, objective information from the pharmaceutical industry. During a phone call with Europe Economics on March 3, 2008, we were told that the impact assessment had only started very recently, and not in December 2007.
} 
Extensive consultations, considered an informal strategy of innovation employed by the Commission, are used in many other policy areas. Generally, the Commission tries to build trust through the creation of supportive and consultative networks with interest groups, or through increasing the level of transparency and accountability through full access of information (Cram, 1997; Héritier, 1999, 2000).

As we demonstrated, this did not happen in the case of DTCI, where the process showed lack of transparency with regard to the different High Level processes and the outcomes of all kind of consultations. We claim that in this case, various consultations were held simultaneously to create confusion. Though the Commission as policy entrepreneur tried to 'gradually introduce a European dimension into national policy discourses and in trans-nationalising policy debates' (Steffen \& Lamping, 2005a: 19), this strategy may turn out to be problematic, because of the delicate balance between healthcare and industrial goals. However, despite all the problems associated with DTCA, DG Enterprise seems very keen on liberalising this issue. This may be explained by the repeated complaints from European firms about their inability to compete with US companies. DTCA may therefore be regarded as a tool, not for patient empowerment, but for industry profits. However, while opponents of the Commission characterise it as 'a monstrous bureaucracy with ever lengthening tentacles, the Commission is, in fact, relatively small and is not well resourced' (Cram, 1997: 156). It is therefore unlikely that the Commission will overrule the interests of the member states. The question is thus whether they will, together with the EP, open their doors for a Trojan horse. 



\section{PART IV CONClusion}




\section{THE POLITICS OF EUROPEAN UNION HEALTH POLICY- MAKING}

\subsection{HEALTH POLICY-MAKING IN THE EUROPEAN UNION}

The process of European integration is framed in terms of market integration and liberalisation. There exists a fundamental asymmetry: policies promoting market efficiencies have become Europeanised, whereas those promoting social protection and equality remained national (Scharpf, 2002a). Community action in the field of health should fully respect the individual responsibilities of the member states and harmonisation of the laws and regulations concerning health is explicitly excluded. In this context, the repertory of policy instruments that the European Union (EU) can use to achieve the protection and promotion of health, which is one of its prime goals, consists mainly of 'soft' instruments.

The absence of a clear cut legal basis, however, does not imply that the EU's impact on health is negligible. Health policies often have to be legitimised by Treaty articles that have no, or only an indirect link, to health. The single market exposes almost all areas of economic importance to competition, including goods and services related to healthcare. As long as the internal market, on its own, constitutes a sustainable legal basis, a health rationale can be central to internal market legislation.

Notwithstanding member states' insistence that the organisation and financing of their healthcare systems is a national competence, subject to the subsidiarity principle, European health policy is gradually and incrementally taking shape based on other legal bases (Lamping, 2005). Thus, separating European economic integration from national solidarity and welfare has ceased to be viable (Ferrera, 2005: 128). While the constitutional asymmetry of economic and social policy describes the situation, it does not explain how EU health policies were, or were not agreed upon (see also Permanand \& Mossialos, 2005: 689).

If one aims to understand agreement, a balanced analytical tool that does not shy away from the complexities of European policy-making is necessary (Neyer, 2004). Here, the actor-centred institutionalist framework offers concepts for understanding the political manoeuvring and underlying dynamics of complex policy debates. Whereas substantive policy research concentrates on problems that public policy is expected to solve and the effectiveness of responses to these problems, our study is interaction-oriented. It proceeds from the assumption that social phenomena should be explained as the outcome of interactions among intentional actors. These interactions are structured and their outcomes are shaped by the characteristics of the institutional settings in which they 
take place (Scharpf, 1997). Based on our case studies, the aim of this chapter is to answer our overarching research question:

What factors influence the likelihood of agreement on EU health policy given diverging preferences, member states' claim of subsidiarity and the existence of constitutional asymmetry?

In the previous chapters, we analysed the politics of EU health policy-making, concentrating on the strategic behaviour of actors within the institutional setting, including the role of interest representation (see table 8.1).

\begin{tabular}{|c|c|c|c|}
\hline Issues & $\begin{array}{l}\text { Type of EU health } \\
\text { policy-making }\end{array}$ & $\begin{array}{l}\text { Balance between health and } \\
\text { economic interests }\end{array}$ & Agreement \\
\hline Tobacco advertising & Direct & $\begin{array}{l}\text { conflict between health and } \\
\text { economic interests; } \\
\text { public health driving force }\end{array}$ & decision \\
\hline Data exclusivity & Indirect & $\begin{array}{l}\text { conflict between different } \\
\text { economic interests; } \\
\text { economics driving force }\end{array}$ & decision \\
\hline DTCA & (in)direct & $\begin{array}{l}\text { conflict between health and } \\
\text { economic interests; } \\
\text { driving force questionable }\end{array}$ & non-decision \\
\hline
\end{tabular}

Table 8.1: diversity of cases

Of the three case studies, the first looks at the problem of agreement on the tobacco advertising ban. The second case concerns the prolongation and harmonisation of the data exclusivity period in the EU at a very high level. Finally, the third case addresses direct-to-consumer advertising (DTCA) and shows how this issue was driven forward by Directorate-General (DG) Enterprise of the European Commission. Before addressing the question of what factors influence the likelihood of agreement, we will first outline the three policy processes.

\subsubsection{The tobacco advertising ban}

Encouraged by developments in France and the European Parliament's (EP) wish for stronger regulations, the Commission replaced its 1989 proposal restricting tobacco advertising in 1991, by its proposal for a tobacco advertising ban. It hardly consulted any interested parties, whereas normally strong economic stakeholders are included at the agenda-setting stage. However, the interests of the tobacco industry were clear and a European-level health lobby did not yet exist.

When initiating its proposal, the Commission played the treaty base game. Framing the ban in market-making terms, although in fact it constituted a market-correcting policy, 
it could use article 100a (now article 95) as the legal basis of the proposal. The only other option was article 235 (now article 308), which required unanimity in the Council. Aware of the diverging preferences of member states, the qualified majority voting (QMV) rule was necessary for agreement. However, the choice of this legal basis became the most important argument against the ban in the EP and the Council. The debate focused on procedure rather than substance and a real discussion on how to balance economic and public health interests was circumvented (see chapter 4).

A blocking minority consisting of Germany, the United Kingdom (UK), the Netherlands, Denmark and Greece made agreement impossible for many years. Strong ties at a high political level with the tobacco industry influenced the position of those countries in favour of voluntary agreements. The Commission had to await a window of opportunity while keeping the issue on the agenda. It needed the support of public health, cancer and anti-tobacco organisations. The Commission therefore helped establish a prohealth network at European level. Media attention concerning tobacco control increased, which influenced the debate at national level and resulted in an evolution towards more restrictions.

After several years without any progress, the outcome of a British election resulted in a new government that expressed its wish for a ban on tobacco advertising. Following this, the Dutch government also reconsidered its position. Whereas it had always opposed a ban, the Dutch Health Minister managed to convince the government to vote in favour.

One month before the final round of discussions in the Council in December 1997, the UK had asked for an exemption of sponsored sports. It turned out that the Labour party had accepted money from Ecclestone, the Formula One leader. Only one day before the Council meeting, the UK and the Netherlands declared their intention to vote in favour, and Greece said it wanted to abstain. That would result in just enough votes for a qualified majority. However, during the Council meeting Spain announced its abstention. This was an unexpected move, since Spain had always been in favour. Though never confirmed, there were rumours that Germany had put pressure on Spain to do so.

The Luxembourg presidency managed to formulate a compromise. The common position indeed showed the need for mutual exchanges. A very important factor leading to agreement was the Greek shift from abstention to agreement. Greek kiosks were exempted from the tobacco advertising ban. In addition, member states were allowed to postpone implementation for one year in respect to the press and two years in respect to sponsorship and world level sponsorship was permitted until October 2006. Germany and Austria voted against the common position, Denmark and Spain abstained.

The second reading of the EP resulted in an enormous lobbying campaign (see chapter 5). The tobacco industry and its alliances pushed for stronger measures, claiming that there were too many compromises in the common position. The health lobby asked 
the EP to endorse the common position without amendments, because in case the EP would improve the common position, conciliation would very likely result in nonagreement. In the end, the EP aproved the Council compromise, which resulted in adoption of Directive 98/43/EC in 1998.

However, Germany did not accept the outcome and appealed to the European Court of Justice (ECJ), claiming that the primary goal of this directive was public health. In its ruling, the Court agreed with the German government that the measure did not improve the functioning of the internal market, introducing rather than removing obstacles to trade and competition. The ECJ therefore annulled the directive in October 2000.

Remarkably, however, the Court formulated guidelines for what would be legally acceptable: a ban on cross-border tobacco advertising and sponsorship. In 2001, the Commission tabled such a proposal, which was adopted by the Council and the EP in 2003. The UK and Germany voted against, the UK because of the weakness of the text, Germany because the text went too far. In September 2003, the German government again asked the ECJ to review the validity of Directive 2003/33/EC, which was dismissed in December 2006.

\subsubsection{Lengthening data exclusivity}

In 1987, agreement on Directive $87 / 21$ /EEC resulted in six years of data exclusivity, prohibiting a regulatory authority from using the clinical trials data when a product was initially registered, to affirm the safety of a bioequivalent generic. Ten years of protection was offered for biotechnological and high-technology medicinal products. Member states were allowed to extend this to all pharmaceuticals if they considered this in the interest of public health. Belgium, France, Germany, Italy, the Netherlands, Sweden and the UK did so. Member states also had the option not to apply the six-year period beyond the date of patent expiry of the original product, so that data exclusivity did not extend the twenty years of protection from free market competition. Denmark, Finland, Ireland, Luxembourg, Greece, Spain and Portugal provided six years, with the latter three countries not offering data exclusivity beyond patent expiry (Kingham \& Castle, 2000: 214-215).

In 2001, the Commission put forward a proposal to harmonise the period of data exclusivity. In addition, a proposal was tabled for a Bolar provision, under which generic manufacturers may conduct tests necessary for marketing authorisation applications without infringing patents. The Commission suggested ten years of data exclusivity plus an additional year for new therapeutic indications, which would result in the longest protection period in the world. Its main argument in favour of long data exclusivity periods was that in the process of completing the internal market, EU countries could gain an edge in their struggle to win back research investments previously shifted to the 
United States (US). However, opponents said it would delay the marketing of cheaper generic products, resulting in additional pharmaceutical cost.

Before the Commission tabled its proposal, discussions had already taken place with the pharmaceutical industry. Both the research-based and the generics industry (EGA) considered the issue of data exclusivity highly important for obvious reasons. Aware of the importance of the Commission's agenda-setting rights, they focused their information strategies on the Commission. The Commission's industrial (but no healthcare policy) competences resulted in a convergence between industry interests and the policy concerns of DG Enterprise (Permanand 2006a: 9). The outcome of an evaluation and consultations hardly played a role. In particular, the organisation representing research-based companies, the European Federation of Pharmaceutical Industries and Associations (EFPIA), had good access to DG Enterprise. Some even called the relationship clientilistic (Greenwood, 2003). DG Enterprise followed EFPIA's wish for ten years of data exclusivity even though there was no proof that data exclusivity would increase innovation. No calculations existed that showed a relation between longer data exclusivity periods and more innovation.

The research-based industry also had more resources available for lobbying the EP than the generics industry. Both sectors only used access strategies to try and influence policy-makers both at European and national level. Voice strategies were neither necessary, given that they had access at all levels, nor effective, given that the issue of data exclusivity was rather technical. There was no public attention, which made the whole topic problematic for NGOs. Thus, there was hardly any health interest representation.

In October 2002, the EP amended the Commission proposal of ' $10+1$ ' to ' $8+2+1$ ': eight years of data exclusivity plus two years of market exclusivity as part of the European version of the Bolar provision, plus one additional year of market protection for new indications. However, the Commission did not agree and in its revised proposals maintained its own formulation.

Negotiations in the Council showed highly diverging preferences along the lines of national industry interests. Generally, the Commission can play a mediating role under such circumstances. However, DG Enterprise kept emphasising a worse-case scenario after EU enlargement in May 2004. This enlargement indeed created time pressure during Council negotiations, because if they had to restart negotiations after ten new European countries joined the EU, the outcome would probably be quite different. So in fact, these countries were excluded from the process, even though they expressed their opposition to lengthening data exclusivity. Some called the pharmaceutical review an example of misgovernance, because the extension of data exclusivity was pushed through and the pharmaceutical review was fast-tracked before enlargement. 
Instead of searching for a compromise, DG Enterprise pressured the member states to fall in line with the Commission proposal. Nevertheless, ten years of market protection appeared to be too difficult for some member states. In September 2003, the Council adopted a common position with eight years of data exclusivity and two additional years of market exclusivity for authorisations via the mutual recognition procedure and ' $10+1$ ' for authorisations via the centralised procedure.

An informal trialogue was held to reach agreement before the EP's second reading. Given the tight time schedule, a formal conciliation was no option. However, in early December 2003, all amendments of the EP's first reading regarding data exclusivity were reinstated. If these amendments were adopted by the EP plenary, conciliation could not be avoided and agreement before the deadline was not likely. This shows that the EP played an important role in the final stage of the policy-making process. Indeed, the parliament was instrumental in proposing the compromise solution of ' $8+2+1$ '.

\subsubsection{Patient information or direct-to-consumer advertising of prescription medicines}

In 2001, the Commission proposed a pilot study which would allow pharmaceutical companies to communicate information about medicines for HIV/AIDS, asthma and diabetes directly to the public. This proposal came as a surprise for many stakeholders, since there was hardly any debate and no consultations were held covering this issue. In addition, DG Enterprise, responsible DG for pharmaceutical legislation, did not take the interests of DG Health and Consumer Protection (Sanco) into account. The latter was not able to counter-balance the proposal of DG Enterprise.

A few years earlier, in August 1997, the US allowed for DTCA of prescription drugs. In addition, pressure from the industry increased during the mid-1990s. Only a few weeks after the US relaxed its rules, the issue was on the agenda of Commissioner Bangemann of DG Enterprise and was being discussed during the Bangemann Round Tables in December 1997. This resulted in a Commission Communication addressing DTCA, though it was framed as direct-to-consumer information (DTCI). This strategy should be regarded in the context that lifting the existing European ban on DTCA would inevitably affect national healthcare budgets and would therefore be problematic.

In addition to the Round Table meetings, the Trans-Atlantic Business Dialogue (TABD) also focused on DTCA. Following several meetings, DG Enterprise established a working group and issued a consultation covering DTCA. Even though the results of this consultation were not made public, another document mentioned member states' 'lack of appetite' (Pharmaceutical Industry Competitiveness Task Force, March 2001: 34).

Thus, with the issue on the agenda, DG Enterprise searched for viable routes to discuss it. Loosening the ban would influence national healthcare systems, since demand 
is stimulated for those medicines that are most advertised. Member states feared a demand explosion with a huge impact on national healthcare budgets. Following their insistence that healthcare organisation and financing were a national competence, DG Enterprise should have taken this into consideration. Even though DG Enterprise claimed it was requested by some patient groups, in the end it could not name a single group. Therefore, its proposal for a pilot study is puzzling. Both the EP and the Council disagreed and cancelled the proposal.

Especially in the EP, a large counter-lobbying campaign was set up. The pharmaceutical industry was in favour of DTCI, though it regarded the Commission proposal for a pilot study not well developed. Instead, DTCI should be allowed for all diseases. The challenge for several NGOs was this strong commercial push from industry. In this context, media attention was very helpful for public health and consumer organisations.

In the Council, no changes were made to the existing law. There was quite some time pressure exerted to agree on the large package of the pharmaceutical review, of which the pilot study was part, before enlargement with ten new counties in May 2004. During an informal trialogue in December 2003 between the Council and the EP, a report on current practice with regard to patient information in 2007 was agreed upon. To what extent DG Enterprise was involved in the formulation of this amendment remains unclear, although its good relationship with the parliamentary rapporteurs may have been helpful in this matter.

DG Enterprise had developed a 'plan B' as well. Parallel to the preparation stage of the review process, it had set up the G10 High Level Group on innovation and the provision of medicines in March 2001. One of the issues discussed at G10 level was patient information. In May 2002, the G10 group recommended a public-private partnership on patient information. In addition, it asked for a clear distinction between advertising and information. Following these recommendations, the Commission adopted a Communication in July 2003, which resulted in a Council Resolution in December 2003. Here, the Council invited the Commission to explore the possibility for a European information system.

In June 2005, DG enterprise established the Pharmaceutical Forum, which again covered patient information. After the first meeting took place in September 2006, DG Enterprise increased pressure through various consultations: on quality criteria and a model information package (March-May 2007); on the requested report on patient information resulting from the pharmaceutical review (April-June 2007); on the future of pharmaceuticals in Europe (July-October 2007); and finally, on the draft legal proposal for patient information (February-April 2008). The formulation of these consultation papers clearly steered towards a role for industry and the interpretations of the results of 
these consultations were biased. Throughout the process, DG Enterprise had a clear agenda: allowing the pharmaceutical industry to communicate information to patients. However, thus far, no clear distinction has been made between advertising and information.

\subsection{USING ACTOR-CENTRED INSTITUTIONALISM}

Our analysis of the policy-making processes is based on actor-centred institutionalism (ACI) as explained and operationalised in chapter 2. The framework provided us with a descriptive language that allows for the identification of factors that influence policy outcomes and to explain variance in outcomes in different cases. Drivers of change are the attributes of actors (perceptions and capabilities) in institutional interactions (actor constellations and modes of interaction). In addition to these drivers of change, there are also background conditions to change, which are the policy problems that establish the need for change and the policy legacy (Schmidt, 2003).

The strength of the actor-centred institutionalist framework is that it cuts 'across the actors versus institutions dichotomy inherent in policy studies' (Parrish, 2003: 247) by including them both. It is a very comprehensive framework that has been described as 'one of the most methodologically fruitful approaches found in rational choice institutionalism today' (Schmidt, 2003).

The framework has been used in several studies, which all had as a starting-point for their analysis, that key actors strategically used the institutional venues to try and achieve their policy objectives (see Héritier, 1999; Parrish, 2003; Witte, 2006). For example, Parrish (2003: 247) claims to contribute 'analytically by making the case for actor-centred institutionalism in policy studies'. He reasons that in order to understand European integration in areas where policy competences did not exist previously, 'actor based approaches (such as policy networks and an advocacy coalition framework) and institutions based approaches (such as new institutionalism) have been influential'.

ACI emphasises the influence of institutions on the perceptions, preferences, and capabilities of individual and corporate actors and on the modes of interaction (Scharpf, 1997: 41). Though it is possible to make an analytical distinction between all those concepts, in practice they are intertwined. This is acknowlegded by Scharpf and Mayntz (1995) as well. For instance, actors' perceptions and preferences (including interests, norms and interaction orientations) are often simplified. In this context, Heritier (1999) refers to interests, whereas Parrish (2003) refers to actors' belief systems, including deep core beliefs, policy core beliefs and secondary aspects. In our research, we refered to preferences, which include both interests and norms.

Whereas the modes of interaction, as defined by Scharpf (1997; 2001), are rather abstract and therefore reduce the level of complexity, the concept of an actor 
constellation is very complex. An actor constellation represents what we know about the set of actors, their strategy options, their perceptions and evaluations concerning various outcomes, and the preferences of actors over these outcomes. It thus constitutes the potential level of conflict. The actual outcome can only be explained by combining an actor constellation with the mode of interaction through which the problem is solved. However, again the concepts of actor constellations and modes of interaction are intertwined in reality.

Most studies only use some concepts of the actor-centred institutionalist framework, rather than focusing on all elements. An exception is the study of Witte (2006: 495), who explains that her research is one of the few that consistently applies actor-centred institutionalism to a policy field. (...) The small number of published applications of this perspective pays testimony to the fact that developing a stylised picture of actor constellations as an explanatory tool - as aimed for by Scharpf and Mayntz - is notoriously difficult'. Most researchers thus opt for a 'reduced' actor-centred institutionalist framework. The result of the complexity of ACI is that studies using this model tend to operationalise the concepts of the framework in different ways. Therefore, making a comparison between these policy studies is not evident, though they all have in common their focus on the behaviour of actors in a particular institutional setting.

In the chapters 3 to 7, we analysed three policy-making processes in the area of health using ACI. Our focus was on actors' strategic behaviour within a given institutional setting. This setting establishes the rules of the game, which limit the number of ways a policy conflict can be played out (Immergut, 1992: 63).

\subsection{THE POLITICS OF EUROPEAN UNION HEALTH POLICIES: THE LIKELIHOOD OF AGREEMENT}

Competing explanations abound as to how legislation is made in the EU. Disagreement over fundamental issues remains despite decades of study. Central to these discussions are questions such as whether formal procedures matter more than informal norms (Bouwen, 2007; Rasmussen, 2007; Shackleton \& Raunio, 2003; Van Kersbergen \& Verbeek, 2007); whether member states engage in bargaining or problem-solving behaviour (Elgström \& Jonssön, 2000; Elgström \& Smith, 2000); whether domestic considerations tightly constrain Council meetings in Brussels (Kohler-Koch, 2003); and whether or not the Commission and the EP exercise significant influence over policy outcomes (Crombez, 2001; Garrett, 1995; Rasmussen, 2007; Stacey, 2003).

In this study, we understand the EU as a 'joint decision-making system' (Scharpf, 2001), in which the Commission, the Council and the EP are all crucial actors. None of them can unilaterally pursue their goals without obtaining the approval of all the others. Member states must coordinate their preferences with each other, in order to obtain 
sufficient votes for a qualified majority. This need for co-ordination also applies to supranational actors. The Council cannot act without a proposal on the part of the Commission.

Following our actor-centred institutionalist analysis of three EU health policy-making processes, we found several factors, that in combination (without prioritising one over another), influenced the likelihood of agreement: the preferences and strategies of member states (8.2.1); the strategic behaviour of the Commission (8.2.2); the impact of the EP (8.2.3); interests groups and their capabilities (8.2.4); and, finally, wider policy developments (8.2.5).

\subsubsection{Member states' preferences: using subsidiarity claims}

Member states have two major interests in maintaining control over health policies. First, health policies, and more concrete health services, are important sources of political legitimacy and second, the nature and scope of the social safety net affects government budgets (Gerlinger \& Urban, 2007: 134). The organisation of healthcare is based on national principles, and has traditionally been considered to be subject to the subsidiarity principle (Thomson \& Mossialos, 2007).

Member states' claim of subsidiarity in the area of health policy was taken as a starting-point for our study. However, our research demonstrates the principle's elasticity or elusiveness. Subsidiarity is not a matter of principle, but rather of political pragmatism. Van Kersbergen and Verbeek (1994; 2007) pointed to the importance of the political context of the principle, which developed as an instrument for member states to protect their national interests. Even more so, the 'Protocol on the Principle of Subsidiarity' (in the Treaty of Amsterdam) included the following formulation: 'subsidiarity is a dynamic concept and the appropriate level for action may vary according to circumstances' (see Van Kersbergen \& Verbeek, 2007: 225).

Figure 8.1 shows that the cleavage between a healthcare, a public health and an economic focus of health policy results in member states' strategic use of subsidiarity claims. In a situation where EU health policies clearly benefit national economic interests, member states' claim of subsidiarity weakens, whereas in case of negative economic consequences, member states refer to their national competences in health policy-making. EU legislation concerning more sensitive healthcare issues is hindered by member states because of 'the heterogeneity of path-dependent welfare state institutions [, which] complicate common European policies' (Haverland, 2007: 887). As Freeman and Moran (2000:36) point out, 'health policy connects national politics to international economic conditions'. Therefore, it is sometimes difficult to make a distinction between health or economics as a policy's primary intention. 


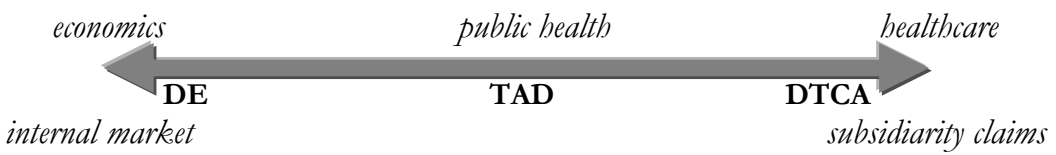

figure 8.1:The political pragmatic use of subsidarity claims

The DTCA pilot study for prescription medicines resulted in a non-agreement. DTCA has thus far been blocked by member states because of the clear impact on their healthcare system. Subsidiarity claims prevailed in the responses to the public consultation on patient information in 2007. For example, Sweden claimed that 'patient information should be provided at a national level, especially taking into account the regretfully widespread EU-scepticism'. Austria expressed its doubts as well, preferring 'an approach of mutual agreement amongst member states respecting their national specifics'. Several other countries held similar positions (see Pharmaceutical Forum, 2007a).

Opposition in the case of the tobacco advertising directive (TAD), with a clear public health focus, was based on a combination of reluctance of state intervention in the private sphere of consumption and commercial interests of the national tobacco industry. Throughout the process, opposing member states refered to the principle of subsidiarity (see chapter 4 and 5). However, after several years, public health interests prevailed over economic ones. The direct and clear relation between the use of tobacco products and the health of an individual was helpful in this context.

Finally, in the case on data exclusivity (DE), cleavages among countries were along the lines of their national industries - either generics or research-based pharmaceutical companies. Even though health and healthcare arguments were used during discussions, member states accepted the low politics of industrial policy. Therefore, no reference was made to subsidiarity in this case.

In sum, our analysis demonstrates that member states strategically used the claim of subsidiarity according to their preferences. In a situation where the organisation and financing of the national healthcare system is directly and clearly affected, as with DTCA, member states are likely to defend the status quo. Under such circumstances, subsidiarity plays an important role. However, in the case of a policy that has strong positive economic consequences, as with data exclusivity, liberalisation may be preferred. Even though this policy impacted upon member states' healthcare system, no subsidiarity claims were made. In the case of a policy that has strong negative economic consequences, as with the tobacco advertising directive, subsidiarity was again used as an argument against this measure. 


\subsubsection{The European Commission: impact of the most strategic actor}

The conventional starting point of the intergovernmentalist approach is that the Commission's autonomy vis-à-vis member states is limited. Principal-agent relations account for delegation of powers from principals (member states) to agents (the Commission). Principals may like their agents to operate in a neutral way. However, agents have preferences themselves. The result is a dual-executive system where member states' governments in EU policy-making have no monopoly over political demand (Hix, 1999). In this context, co-ordination is central to agreement.

The co-decision procedure, introduced by the Treaty on European Union (TEU), marked a fundamental change in the legislative balance between the three European actors. Most noticeably, it increased the involvement of the EP in EU legislation. Formal rational-choice institutionalists found that ' $(t)$ he result of this institutional innovation (the conciliation committee) is that the Commission's preferences need not be taken into account because it is structurally unable to affect the decisions of the Parliament and the Council' and '(f)inally, under co-decision the Commission is effectively taken out of the game before the real bargaining over policy begins' (Garrett, 1995: 303-305). The Amsterdam Treaty changes to the co-decision procedure even rendered the Commission 'irrelevant' (Crombez, 2001: 119).

However, these studies build on the assumption that formal institutions are the key factors influencing actors' behaviour (Burns, 2004; Rasmussen, 2003; Thomson \& Hosli, 2006). Yet, treaties do not tell the whole story of the kinds of behaviour that can be expected from actors (Farrell \& Heritier, 2003; Rasmussen, 2007) and as Burns (2004: 3) already showed, a 'qualitative approach can highlight aspects of decision-making overlooked by the rational-choice new institutionalist school'. Our analysis of the role of the Commission resulted in a rich picture of how it managed to affect the policy-making process. While not ignoring the role of governments in EU policy-making, our empirical results showed that several formal and informal rules of the joint-decision procedure placed the Commission at the centre of policy-making.

\section{Right of initiative}

The Commission has the right of initiative under the co-decision procedure and may benefit from this first-mover advantage. During policy-making, it may alter or withdraw its proposals when changes result in a watering-down of its initial policy goals, though in practice this is avoided (Rasmussen, 2007). Moreover, the Council requires a qualified majority for those changes which the Commission can endorse, whereas otherwise unanimity is necessary.

When initiating a legislative proposal, the Commission should 'consult widely before proposing legislation and, wherever appropriate, publish consultation documents' (point 9 of the protocol on the application of the principle of subsidiarity and proportionality, 
annexed to the Treaty of Amsterdam). It is often claimed that the position of the Commission is a 'European position' (Thomson, 2008: 189), because proposals are formulated after extensive consultation processes with stakeholders (Crossick, 2002; Neyer, 2004; Rasmussen, 2007; Thomson, 2008). Whereas Princen (2007: 23) claimed that the Commission has to consider 'the wider 'political context', in which other actors will subsequently decide on its proposals', our study clearly showed that the Commission did not necessarily search for a proposal which took those different interests into account (see also Nylander, 2001).

In the cases of the tobacco advertising ban and DTCA, the Commission conducted a solitary campaign. Consultations were not part of the preparatory stage, although the Commission knew in the case of tobacco advertising it had the support of several member states (Duina \& Kurzer, 2004: 59). With regard to DTCA, the Commission moved without a solid basis of support.

The situation was different with regard to data exclusivity, where consultants conducted an evaluation of the pharmaceutical system, taking into account the views of national authorities, industry, patients and healthcare professionals. Our study showed that this evaluation hardly played a role. The Commission had its own, long-term agenda. Agenda-setting took place behind closed doors. However, contrary to the other cases, the Commission knew it had the support of several strong stakeholders, including the large member states and the research-based pharmaceutical industry.

In sum, the Commission used the right of initiative to table very ambitious proposals, which did not reflect too much willingness of finding the middle ground. A first explanation for the formulation of the proposals may be the Commission's wish to broaden its sphere of influence. Supranational actors, especially the Commission, have an institutional interest in driving integration forward through high-level legislation (Hix, 1999). Conservative policy proposals would hardly result in a 'positive political identity' (Eichener, 1997: 599). Recognised as well by Princen \& Rhinard (2006: 1123-1124), in the case of tobacco advertising, the 1986 Single European Act (SEA) gave the Community 'some room for action in the field of health, and the European Commission was eager to develop this new policy field' (see also Duina \& Kurzer, 2004; Randall, 2001).

Second, as compromises between the EP and the member states were to be expected, the Commission may have consciously opted for a far-reaching proposal, knowing that it would be weakened during negotiations.

\section{Rhetoric strategies}

The right of initiative allows the Commission to define a problem on the political agenda. The question is, how the Commission tried to convince the other actors that it had the correct diagnosis for pressing problems and that it presented the correct solutions. Our 
study showed the importance of rhetoric, not only during the agenda-setting stage, but throughout the process (Daviter, 2007: 655).

In the case of tobacco advertising, the lack of a public health legal basis resulted in the proposal being framed in terms of an internal market initiative (see also Princen \& Rhinard, 2006: 1124). The Commission defined tobacco advertising as a problem related to the creation of the SEM. It played the treaty base game and therefore managed to influence the institutional setting of the debate. A decision in the Council had to be made by qualified majority instead of unanimity, which would have been impossible. It also allowed opponents to use legal arguments regarding (the lack of) competences as smoke screens to overshadow substantive argumentation. However, the Commission had no choice, since there were no health competences defined in the Treaty.

Data exclusivity was presented as an incentive to stimulate innovation, thereby promoting public health and healthcare. The Commission claimed to balance its proposal on data exclusivity with its proposal for a Bolar provision, thus stimulating innovation on the one hand and creating competition for generics on the other. It was presented as a trade-off. In addition, the Commission used the rhetorical threat of European industry losing competitiveness compared to the US, because of its patchwork quilt of regulatory and healthcare regimes (see also Woll, 2006b: 53), requiring incentives like data exclusivity.

In its quest for DTCA, the Commission used the rhetoric of patient information. It kept emphasising that it did not want a US-style of advertising on prescription medicines. According to the Commission, good and trustworthy information was scarce. In addition, it could no longer justify unequal access to information available through the internet. A major implication of the Commission's strategy to frame DTCA in terms of patient information, was that other actors could not simply ignore the Commission's 'quest for information'. Therefore, discussions continued.

Lamping (2005: 18) also acknowlegded the Commission's clever inventions to justify initiatives in the area of health policy. Especially in the cases of data exclusivity and DTCA, the rhetoric was in line with the framing used by the research-based industry, which shows how critical is the specific DG of the Commission responsible for an area. In that way, Commission rhetoric also accounted for a bias for action, representing issues in a way that already called for a particular decision (Anonymous, 2005).

According to Rochefort and Cobb (1994: 15), the function of problem definition 'is at once to explain, to describe, to recommend, and above all, to persuade'. The latter implies that agenda-setting is dominated by strategic representation of a situation (Farley et al., 2007), which is about the creation of an image (Princen, 2007: 30), about the strategic use of words through symbolic representation rather than reason and objective facts (Stone, 
2002). All cases showed the importance of rhetoric strategies to steer discussions, defining what counted as relevant for attention.

\section{Policy entrepreneur}

Whereas the Commission's exclusive control over the content of legislative initiatives is not difficult to show empirically, the question is (1) whether its ambitious proposals have been adopted and (2) what role the Commission played in agreement. In addition to the right of initiative, a more subtle form of influence can be exerted because the Commission is present during all Council and parliamentary negotiations, putting it in a perfect position to help forge a compromise (Burns, 2004). The Commission is often said to act as a mediator in case of impending deadlock in order to get its proposals adopted (Nugent, 2003; Scharpf, 2006). However, in the processes we analysed, the Commission did not facilitate compromising, but merely pushed for its own preferences (see also Burns, 2004).

The outcomes of the tobacco advertising directive and the directive dealing with data exclusivity both showed that the Commission secured most of its original policy objectives. It insisted on the contentious aspects of its proposals and did not abandon them throughout the process. The central position of the Commission in the policymaking process gave it many opportunities to explain its proposals and even more so, push for them. Especially in the case of data exclusivity, the Commission had an informational advantage vis-à-vis other actors because of the technicality of the issue as well as the fact that it was part of a large package of measures, which the Commission completely understood. The Commission insisted on adoption of the 'correct balance' it had formulated. Though the Commission did not manage to convince the Council and the EP on its proposal for DTCA, it ensured that the issue was kept on the agenda even after it had been defeated. The Commission opted for a non-regulatory route through the use of discussion forums. Not successful yet, since several member states express their fear of too much involvement in their national healthcare policies, it is just a matter of time to see a re-shift to the regulatory route again.

Through the creation of a policy network, the Commission sought to influence domestic interests and strengthen its own position. We found that the DG within the Commission responsible for drafting legislation, selectively offered access to stakeholders whose preferences were in line with those of the DG. During the processes on data exclusivity and DTCA, DG Enterprise offered access to pharmaceutical companies, whereas the interests of public health and consumer organisations were not taken into account at all.

With regard to tobacco advertising, the Europe Against Cancer (EAC) group of DG Social Affairs offered access to public health and consumer organisations, whereas the tobacco industry was not consulted. The sponsoring of public health lobbying 
contributed to a debate on tobacco control at national level. In some member states, this resulted in an evolution towards more restrictions. According to Princen and Rhinard (2006: 1125), 'to move an issue onto the agenda from below [through policy experts formulating specific proposals](...), it shows how the persistent build up of support and expertise at the level of specialised policy communities can help to develop EU activity in a policy field'.

Following the above, our study also touched upon the importance of differentiating between the roles of different DGs within the Commission. The DGs are quasi-ministries with each their own administrative culture, policy objectives and supporting societal groups (Hix, 1999: 54). Especially the fact that DG Enterprise controlled pharmaceutical policy instead of DG Sanco, resulted in an industry-oriented agenda. However, one may question whether DG Sanco would in fact develop different proposals. First, the EU lacks healthcare policy competences and second, the industry has a powerful lobby.

Finally, another very important strategy of the Commission is the use of wider policy developments to its advantage during negotiations. We will explain the importance of this specific factor in section 8.2.5.

In sum, the Commission pursued its own agenda without taking all interests into account. It invested in network building and forging alliances with like-minded stakeholders. It used rhetorical strategies to limit the scope of debate. Throughout the process, it did not really search for a compromise. In all cases, it rejected first reading amendments of the EP (except for the tobacco advertising ban, where preferences of the Parliament and the Commission were similar). The Commission controlled legislation at each juncture in the process (see Eichener, 1997: 600) and managed to influence policy outcomes.

Our cases showed that under the mode of joint-decision, the Commission has more space for strategic behaviour than the Council and the EP, possibly because these actors are more pluralistic than the Commission. Nevertheless, in a situation where the Council and the EP object to a policy proposal, the Commission cannot influence the outcome, despite its right of initiative and its position as policy entrepreneur (Rasmussen, 2007; Scharpf, 2006). In a situation where the member states prefer European over national policy, but do not agree on the content, the Commission can play an important role in facilitating agreement (Cram, 1997; Pollack, 1997).

Our cases also shed light on circumstances where the Commission's hands are tied. Following Cram (1997: 174), the room for strategic behaviour improves 'when national governments' opinion is ambiguous, where a range of potentially acceptable solutions exist'. During the process concerning tobacco advertising, real negotiations were barely possible. For the Commission, it was difficult to negotiate a solution in a situation that required 'uncompensated sacrifices by at least some participants' (Scharpf, 2006: 851). 
In the case of data exclusivity, which was a complex proposal, the Commission could more successfully exploit its comparative informational advantage. In addition, since it was part of a large package of measures, there were more possibilities for issue linking or package deals (Héritier, 1999). It was not a simple 'yes-or-no issue'. Therefore, when analysing a policy process - and especially the opportunities for the Commission to act as a policy-broker - it is important to take the possibilities for compromising into consideration.

\subsubsection{The impact of the European Parliament: the pragmatic choice of a suboptimal deal versus all-or-nothing}

When analysing the impact of the EP, an important variable is the choice of decisionmaking procedure. The role of the EP increased with the co-decision procedure of the TEU (amended with the Treaty of Amsterdam). It has become an increasingly powerful co-legislator (Konig, 2008), whose preferences have to be taken into account.

In the case of the tobacco advertising ban, the EP played an important role early in the process. Its support for a ban (instead of only limitations), strengthened the position of the Commission, which along with other reasons resulted in the proposal for a ban. Thus, this case showed that the EP had similar preferences as the Commission. During second reading, the rapporteur of the EP preferred to strengthen the common position, but after being pressured by several non-governmental organisations (NGOs) and its own government, the rapporteur advised the EP to accept the common position. It could have had more impact on the final outcome, but this required taking into account a risk of no legislation at all.

In the case of data exclusivity, the EP was determined to slightly modify the balance between generics competition and innovation from ' $10+1$ ' to ' $8+2+1$ '. The fact that the Commission did not accept the amendment after the EP's first reading shows that it preferred its own proposal and still aimed at adoption by the Council. However, the Council came up with its own formulation. During the informal trialogue, the EP reinstated all its first reading amendments. Given the existing time pressure, this move rendered agreement before the deadline problematic. However, the EP managed to convince the Council and the Commission to adopt its compromise proposal.

Though the final outcome seemed to be some sort of a compromise, it still implied a period of ten years of market exclusivity, as the Commission had formulated in its initial proposal. The question that needs to be asked therefore is to what extent is there a match between the interests of the EP and the Commission? The case concerning DTCA reveals a similar situation. Though it was clear that the EP in this case did not want a pilot study, after consultation with the Commission it did table an amendment that kept the issue on the agenda. 
In sum, although according to the co-decision procedure the EP as co-legislator holds an important place in decision-making, we claim that the influence on the final outcome depends on its willingness to take the risk of paralysing the policy-making process. In the case of tobacco advertising, the risk of no agreement at all was higher because of the difficulties between the member states within the Council, whereas member states' impatience to have agreement before enlargement in the case of data exclusivity may have increased the chances of the EP to forge a compromise.

\subsubsection{The impact of interest representation: differences in maturity, resources and access}

One of the factors influencing EU health policy-making is interests representation (Greenwood, 2003). Both public and specific (industrial) interests play a role that cannot be overseen in EU politics. Beyers (2004: 212) refers to two theoretical understandings of interest representation. The resource-based explanation emphasises the importance of interest groups' resources. However, following the institution-based explanation, the role of the institutional setting needs to be focused upon. This is in line with Woll (2006a: 460), who claims that in order to understand 'the conditions that shape who lobbies where, how and to what effect', one needs to identify the institutional opportunities and constraints. Our study demonstrates that a combination of both explanations offers the best insight into the impact of interest representation.

The institutional setting, with the Commission, the EP and the Council each having a specific role in the legislative process, offers interests groups several access points. However, our cases showed a difference between lobbyists to the extent that they could reach those access points or were offered access to them. In this context, the cost of lobbying (organisational and informational) are important. This is recognised by Coen (2007: 337) as well: EU lobbying is a 'multilevel process with numerous feedback loops and entry points constrained by the size of the interest group, lobbying budgets and the nature of the policy area'.

\section{Political access: organisational cost and institutional demand}

The financial resources an interest group has at its disposal to some extent determine the strategies it can use. The strong financial means of both the tobacco and the pharmaceutical industry enabled them to use all the relevant channels of lobbying at national and European levels. On the contrary, NGOs did not have the financial means to offset industry insider strategies at all levels. Therefore, these interest groups had to choose their focus: European or national level? What part of the proposal should they concentrate on?

Our study shows that public interest representation is very much related to the issue on the agenda. In this context, Princen (2007: 29) mentions the 'media' agenda, referring to 
issues covered by the media that may not necessarily overlap with the formal or public agenda. By publicising and politicising an issue, as is the case with (the fight against) DTCA and tobacco advertising, NGOs create public awareness of, and support for their cause.

During the policy-making process concerning data exclusivity, public interests hardly played a role. There are several explanations for this. We showed how the research-based pharmaceutical industry managed to capture the regulatory process. As Beyers (2004: 235) pointed out, 'when specific interests gain access to the DGs, they avoid voice'. Industry was perceived as the most relevant stakeholder whose preferences had to be taken into account, and industry offered information and argumentation on this rather technical dossier. The lack of resources made it impossible for the health lobby to focus extensively on the broad pharmaceutical review. In addition, the media showed no interest in the topic of data exclusivity.

Only in the situation where the preferences of public interest groups were similar to those of the responsible Commission DG, access to the Commission and thus insider strategies became possible. In the case of the tobacco advertising ban, the industry managed to delay an agreement by several years. The organisational costs for NGOs were reduced by the Commission (see Mahoney, 2004: 442), which supported the development of a European-level public health lobby through financial incentives and a formal arena of debate. This was not the same for DG Enterprise, which apparently had no interest in the viewpoints of the health lobby. Even consultations, which generally show the Commission's aim to build up long-term relationships with interest groups (Broscheid \& Coen, 2007), in the case of DTCA were only organised to legitimise each succeeding step in the policy process. In this context, it is interesting to note that several NGOs did not consider DG Enterprise to be a partner for doing business either. This is in line with Beyers (2004: 219), who claims that industrial interests, and not public ones, tend to approach the Commission.

\section{Expertise, credibility and reputation}

Next to the organisational costs, informational costs related to expertise is relevant as well. In the tobacco advertising case, the EU-level public health lobby still had to develop its expertise during the process, whereas the tobacco industry already had a lot of experience. Informational costs also played an important role in the cases related to pharmaceutical policy. The issue of data exclusivity was perceived as rather technical by almost all health lobbyists. Given that none of the existing organisations had EU pharmaceutical policy as their main focus, it resulted in a lack of expertise. The organisation that did focus on pharmaceutical policy from a consumer and health perspective, the Medicines in Europe Forum (MiEF), was only created during the policy-making process. The level of maturity 
certainly influenced its role, as people from this forum acknowledged they had no expertise in lobbying at that point.

Finally, interest group credibility and reputation played a role as well. The pro-tobacco lobby was perceived aggressive by those working on health issues. In addition, the industry did not provide honest and accurate information, whereas especially in 'Brussels' the key to successful lobbying is based on trust and the reputation of providing reliable information (see Bouwen, 2007; Broscheid \& Coen, 2007; Coen, 2007; Eising, 2007). Lately, the credibility of the pharmaceutical industry is also being questioned, although to our knowledge this did not have any impact on the policy-making processes we studied.

In sum, industry has a comparative advantage in terms of organisational capacity, financial resources and expertise (Coen, 2007: 335), which enables access strategies. According to Cucic (2000: 222-223) 'health interests and their promoters are being dwarfed in Brussels, to the benefit of other sectors where European actions are much further advanced'. This can be explained by the existing constitutional asymmetry. Businesses have dealt with EU politics for a long time, whereas many NGOs have only been established within the last ten years. The position of businesses is strengthened by their ability to lobby at all levels of the EU multi-level polity and by their close relationship to the Commission. Eising (2007: 395) called business interests regulatory interlocutors of the EU actors. However, our study showed that this should be nuanced, depending on which DG is responsible for drafting legislation (see also Coen, 2007). We therefore hypothesise that the functional differentiation of the Commission influences access of different interest groups and their role in the policy-making process.

\subsubsection{The impact of the wider policy environment: opening a window of opportunity}

Not surprisingly, the wider political, economic, cultural and technological context may have a major impact on the question of whether agreement is possible or not. It is especially in this context that actors are offered a window of opportunity (Kingdon, 1984). The most obvious cause for a shift in EU actors' preference heterogeneity is after every national or EP election, which may either increase or decrease the likelihood of agreement. As we have demonstrated, this aspect enabled a final decision on the tobacco advertising ban.

Another important wider policy development in this study was related to the 2004 enlargement with ten new European member states. Enlargement would result in a different balance of preferences in the Council, which especially influenced the discussion on data exclusivity. Even though one could say that this process was blocked in the Council, in the end, the member states were more eager to compromise with each other 
before the deadline of enlargement than to take into account the preferences of ten more member states, which most likely would have resulted in a different outcome. Thus, the legally required pharmaceutical review constituted the beginning, and EU enlargement in May 2004, formed the end of a window of opportunity during which the revision of data exclusivity could take place (Feick \& Broscheid, 2005).

What is remarkable in the context of these wider policy developments, is that especially the Commission used them as a strategic option for agreement. With regard to the tobacco advertising ban, the Commission kept the issue on the agenda, aware that a shift of preferences in the UK could result in a qualified majority in the Council. In the case of data exclusivity, several respondents stated that the Commission anticipated the upcoming enlargement as a means to pressure for agreement. As showed by Burns (2004: 13), impatience for legislation, such as it existed in this case, may shape the Commission's success in forging agreement.

\subsubsection{Main findings: an overview}

Existing studies on EU health policy concentrate on an overview of developments in different health-related areas, such as patient mobility, health and safety at work, pharmaceuticals and public health interests (see for example Cucic, 2000; Duncan, 2002; Greer, 2006; Martinsen Sindbjerg, 2005; Mossialos \& Permanand, 2000). These studies do not concentrate in detail on strategic behaviour of actors, but tend to portray the development of these policies over a period of time (for an exception, see Permanand, 2006a). EU policy-making on health issues can best be described as 'a self-dynamic, political (rather than simply technocratic) process that can best be understood as an inspired muddling through' (Lamping, 2005: 19). Table 8.2 provides an overview of the main findings with regard to the cases we studied. 


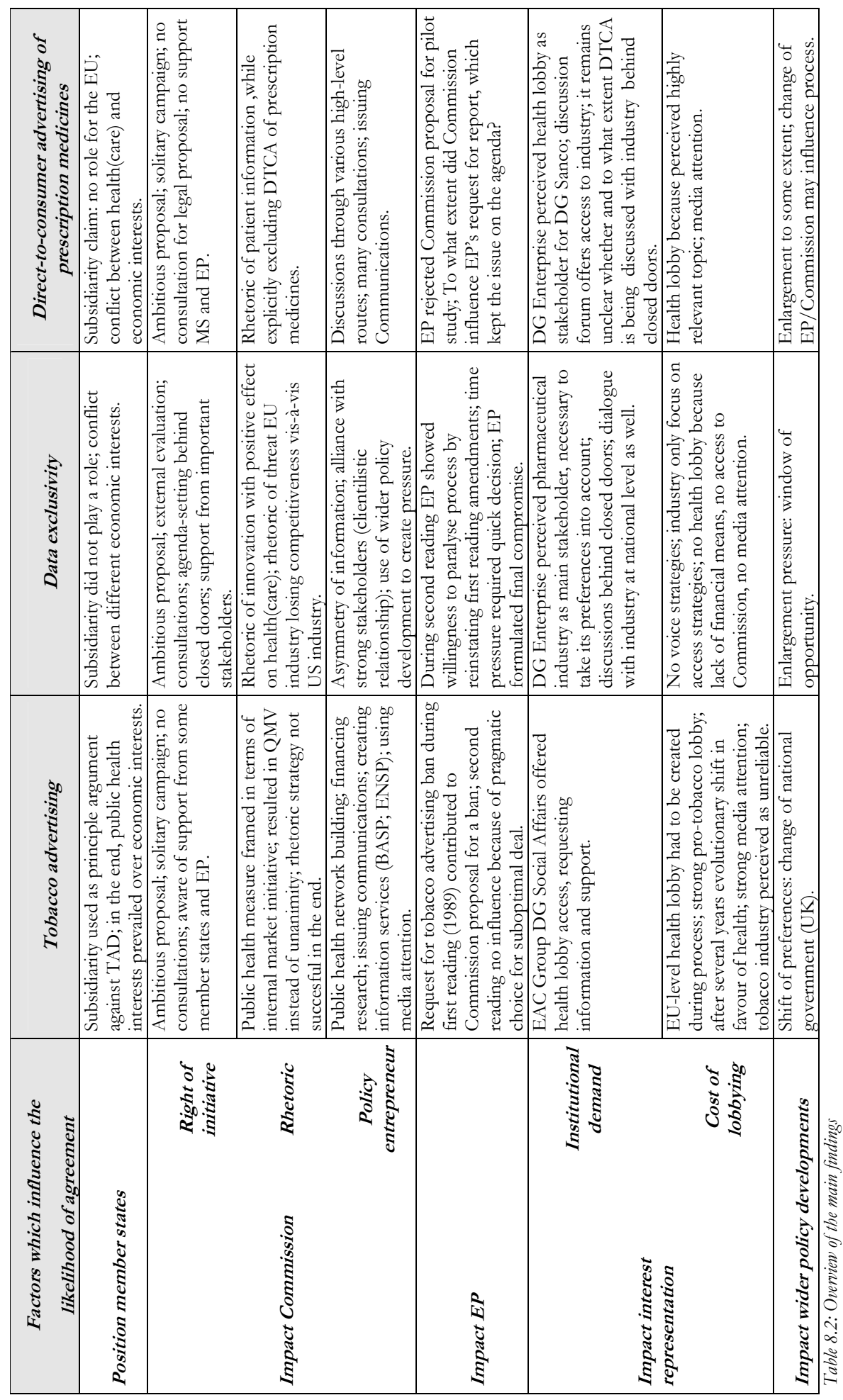


The main findings of our research are summarised below:

- The absence of a legal basis for health policy does not mean the EU has no influence on national healthcare systems. EU health policy is a divided policy area. A cleavage between a healthcare, a public health and an economic focus results in different policy-making patterns.

- Even though member states are reluctant to give up their sovereignty in the area of health, their position strongly depends on the policy focus. In the end, not health but economic interests are often decisive. Subsidiarity claims are used accordingly.

- The Commission acts as a purposeful opportunist (Cram, 1997) in health policymaking.

- The Commission's rhetoric strategies are important for steering discussions, defining what counts as relevant for attention.

- In theory, the EP, as a co-legislator, can play an important role during decisionmaking. In our cases, this is reduced to either accepting a suboptimal agreement or putting its own mark on the final outcome while risking non-agreement.

- Both NGOs and businesses recognise the importance of formal and informal institutions for lobbying. However, the extent to which they can use these institutions is determined by their level of maturity, their resources, expertise and institutional demand, especially of the Commission. During agenda-setting and negotiations, the Commission only offers access to like-minded interests groups.

- Inequality in interest representation will remain as long as citizens' representatives do not offer access to a diversity of interests. Thus far, businesses hold the better cards to play out the game according to their preferences because of the existing constitutional asymmetry.

- Wider policy developments may open up a window of opportunity. The European Commission especially, strategically uses this factor to enable agreement.

\subsection{EPILOGUE: WHAT ROLE FOR EUROPE IN HEALTH?}

Healthcare systems reflect the structure and culture of the societies of which they are part. Therefore, the organisation of healthcare is based on national principles. There is no obvious reason to harmonise those systems, although they are in fact interdependent. 'In themselves, they are exempt from European law, yet almost everything they do, and those elements that are essential for them to function, are governed by it' (see also McKee \& Mossialos, 2006: 16). Our research question addressed what factors influence the likelihood of agreement on EU health policy (in short, how to explain (non-)agreement). A related question is why EU health policies are agreed upon. Although we did not study this 
in detail, our 'how question' to a certain extent also provides an answer to this 'whyquestion'.

First, an important explanation of why EU health policies exist, is offered by the concept of spill over. The Commission's power to initiate legislative measures in the context of the SEM 'did set in motion a dynamic process of functional spill overs in the field of health legislation' (Theofilatou \& Maarse, 1998: 34). The objective was not the harmonisation of health policies as such, but rather removing obstacles to free movement principles and the creation of the SEM.

A second explanation is the political leadership of the European Commission. As Cram (1997: 6) holds, 'much of the activity of the European Commission might well be interpreted as an attempt to gradually expand the scope of its competence', for example through building a supportive network, consultations, funding related research projects, and issuing Communications. In this context, the relationship between the European Commission and the industry plays a major role as well.

Third, the case on tobacco advertising shows that also an evolutionary shift in preferences may result in European-level policies. Over the years, more and more countries favoured public health over economic interests with regard to tobacco policies. The explanation for a European public health policy may therefore be as simple as member states choosing public health. The role of the Commission should not be ignored in this specific case. As we explained, the Commission most likely saw this as an opportunity to increase its role in the area of health. The case of a European ban on tobacco advertising and broader European anti-tobacco policy is probably not representative for other public health policies in the EU.

A fourth explanation is the role of the ECJ. Current research dealing with the question of why there is something like a European health policy field, concentrates on the mode of hierarchical direction, and more specifically the role of the ECJ in this area. According to Martinsen Sindbjerg (2005: 1035-1036), European regulation concerning 'national healthcare has not occurred as an output of rational political decision-making', but rather as judicial policy-making, with an absense of political voice. Indeed, the importance of the 'four freedoms', through which a European healthcare dimension has been established via case law, should not be ignored when providing an answer as to why there is such a thing as EU-level health policy. However, as Greer (2006: 149) claims, 'once the EU legal system has expanded the role of its legal code in the health sector, the other participants government health departments, Commission DGs, lobbies - have yet more incentive to involve themselves both to defend or improve their positions, and to achieve their substantive policy goals'.

Thus, exempting health and healthcare policy from EU law has ceased to be viable, given that the boundary elements of these systems already fall within EU competences. 
'The result has been an ad hoc development of measures, and an ongoing tension between economic and social priorities in respect to the provision of healthcare' (Permanand, 2006b: 22). The question at this point is how to move forward. Whereas McKee \& Mossialos (2006) argue that there is a need for an explicit Treaty competence in relation to healthcare policy, Permanand (2006b) argues that unless a clear European agenda related to healthcare policy is formulated, it remains unclear where we are heading given member states' diverse underlying objectives related to health policy. As we demonstrated in our study, it remains unclear whether a shared agenda is possible, and if so, whether prevailing national economic interests will lead to a deviation from the European social model. 


\section{APPENDICES}

\section{APPENDIX 1: INTERVIEWS TOBACCO ADVERTISING APRIL 2005 - MARCH 2006}

\#1 Former German civil servant, 26 April 2005

\#2 Lobbyist public health organisation, 18 May 2005

\#3 Dutch civil servant, 1 June 2005

\#4 Dutch civil servant, 22 June 2005

\#5 Lobbyist public health organisation, 19 July 2005

\#6 Dutch member of the European Parliament, 3 November 2005

\#7 Former French civil servant, 23 August 2005

\#8 Former British employee of the ENVI Committee, 4 November 2005

\#9 Dutch civil servant, 8 March 2006

\section{APPENDIX 2: INTERVIEWS PHARMACEUTICAL REVIEW OCTOBER 2006 - MARCH 2007}

\#1 European Commission, DG Enterprise, 18 October 2006

\#2 European Commission, DG Sanco, 18 October 2006

\#3 Danish civil servant, 20 November 2006

\#4 Pharmaceutical policy consultant Burson-Marsteller, 4 November 2005

\#5 Dutch civil servant, 29 June 2006

\#6 British civil servant, 17 January 2007

\#7 Dutch civil servant, 31 October 2006

\#8 German civil servant, 9 January 2007

\#9 Dutch civil servant, 15 November 2006

\#10 Dutch member of the European Parliament, 23 October 2006

\#11 Lobbyist public health organisation, 9 November 2006

\#12 Lobbyist European Generic medicines Association, 9 November 2006

\#13 Lobbyist public health organisation, 16 February 2007

\#14 Lobbyist British consumer organisation, 5 December 2006

\#15 Lobbyist public health organisation, 6 December 2007

\#16 Belgian European policy consultant, 4 December 2007 


\section{BIBLIOGRAPHY}

Abbott, F.M. (2004). The DOHA Declaration on the TRIPS Agreement and Public Health: Contradictory Trend in Bilateral and Regional Free Trade Agreements. Geneva: Friends World Committee for Consultation.

Abraham, J. (2002). The pharmaceutical industry as a political player. The Lancet, 360(9344), 1498-1502.

Agence Europe (1997a). European Commissioner disappointed. No 7094: 6 November 1997.

Agence Europe (1997b). Netherlands will support 'in principle' the ban on tobacco advertising. No 7108: 27 November 1997.

Agence Europe (1997c). The ban on tobacco advertising was made problematic by Spain's announced abstention. No 7114: 5 December 1997.

Agence Europe (1997d). Discussions on ban on tobacco advertising could break deadlock. No 7113: 4 December 1997.

Agence Europe (1998). Explanations and comments on the EP Legal Affairs Committee's finding. No 7203: 18 April 1998.

Agence Europe (2003a). Parliament looks for compromise with Council on 'medicines package'. 28 November 2003.

Agence Europe (2003b). During Monday's lunch, health ministers will seek to digest vote by parliamentary committee on 'medicines package'. 28 November 2003.

Angell, M. (2005). The truth about the drug companies. How they deceive us and what to do about it. New York: Random House Trade.

Anonymous. (2004). EU pharmaceutical reform hits Hungary's generic drug industry. Business Hungary, 18(2) February 2004.

Anonymous (2005). What's in a frame? Social organization, risk perception and the sociology of knowledge. Journal of Risk Research, 8(2), 91-118.

Aspect Consortium (2004). Tobacco or health in the European Union - Past, present and future. Luxembourg: European Commission.

Aspinwall, M.D., \& Schneider, G. (2000). Same menu, separate tables: The institutionalist turn in political science and the study of European integration. European Journal of Political Research, 38(1), 1-36.

Auton, F. (2006). Direct-to-consumer advertising (DTCA) of pharmaceuticals: an updated review of literature and debate since 2003. Economic Affairs, 26(3), 24-32.

Bachinger, E., McKee, M., \& Gilmore, A.(2008). Tobacco policies in Nazi Germany: Not as simple as it seems. Public Health, 122, 497-505. 
Bangemann Round Table (1997). Conclusions second Round Table. Frankfurt, 8 December 1997. Retrieved at: http://ec.europa.eu/enterprise/pharmaceuticals/smarket/pdf/rtconcl.pdf [2007, February 14].

Barral, P.E. (1996). 20 years of pharmaceutical research results throughout the world: 1975-94. Paris: Rhone-Poulenc Rorer Foundation.

Baumgartner, F.R., \& Jones, B.D. (1991). Agenda dynamics and policy subsystems. Journal of Politics, 53(4), 1044-1074.

BASP (1992a). Newsletter No 16: The European Parliament supports a tobacco advertising ban. March 1992. pp6-8.

BASP (1992b). Newsletter No 15: Press campaign on freedom of speech in the EC. January 1992. pp3.

BASP (1992c). Newsletter No 19: Freedom of speech and the debate on the tobacco ad ban. December 1992. pp24.

Belcher, P. (1999). The role of the European Union in healthcare. Zoetermeer: RVZ.

Beyers, J. (2004). Voice and access - Political practices of European interest associations. European Union Politics, 5(2), 211-240.

BEUC (2001). BEUC comments on the G10 consultation paper 27 November 2001. Brussels: BEUC. Retrieved at: http://ec.europa.eu/enterprise/phabiocom/docs/responses/4.pdf [2007, December 17].

Bitton, A., Neuman, M., \& Glantz, S. (2002). Tobacco industry attempts to subvert European Union tobacco advertising legislation. San Francisco: Center for tobacco Control Research and Education.

Bjurulf, B., \& Elgström, O. (2004). Negotiating transparency: the role of institutions. Journal of Common Market Studies, 42(2), 249-269.

Boessen, S., \& Maarse, H. (2008 (forthcoming)). The role of interest groups in policymaking on the European ban on tobacco advertising: an institutional analysis. In J. Richardson \& D. Coen (Eds.), Lobbying in the European Union. Oxford: Oxford University Press.

Bouma, J. (2001). Het rookgordijn. De macht van de Nederlandse tabaksindustrie. L.J. Veen.

Bouwen, P. (2002). Corporate lobbying in the European Union: the logic of access. Journal of European Public Policy, 9(3), 365-390.

Bouwen, P. (2004a). The logic of access to the European Parliament: Business lobbying in the Committee on Economic and Monetary Affairs. Journal of Common Market Studies, 42(3), 473-496.

Bouwen, P. (2004b). Exchanging access goods for access: a comparative study of business lobbying in the European Union institutions. European Journal of Political Research, 43(3), 337-369. 
Bouwen, P. (2007). Competing for consultation: Civil society and conflict between the European Commission and the European Parliament. West European Politics, 30(2), 265284.

Broscheid, A., \& Coen, D. (2007). Lobbying Activity and Fora Creation in the EU: Empirically Exploring the Nature of the Policy Good. Journal of European Public Policy, 14(3), 346-365.

Brown, H. (2007). Advertising prescription drugs. Sweetening the pill. British Medical Journal, 334(7594), 664-666.

Burns, C. (2004). Codecision and the European Commission: a study of declining influence? Journal of European Public Policy, 11(1), 1-18.

Burson-Marsteller. (1992). Marketing freedoms presentation. Retrieved at: http://www.pmdocs.com/getallimg.asp?if=avpidx\&DOCID=2501343959/3986 [2005, February 4].

Buse, K., Mays, N., \& Walt, G. (2005). Making health policy. Berkshire: Open University Press.

Busse, R., Wismar, M., \& Berman, P.C. (2002). The European Union and health services: the impact of the single European market on member states. Amsterdam: IOS Press.

Clarke, K. (1992). Letter to Ian Sargeant May 1, 1992. Available: http://www.pmdocs.com/getallimg.asp?if=avpidx\&DOCID $=2501015055 \quad$ [2005, March 2].

Coen, D. (2007). Empirical and theoretical studies in EU lobbying. Journal of European Public Policy, 14(3), 333-345.

CMS Cameron McKenna, and Andersen Consulting (2000). Evaluation of the operation of Community procedures for the authorisation of medicinal products. Evaluation carried out on behalf of the European Commission. Brussels: European Commission, (DG Enterprise).

CMS Legal Services (2007). Bolar provision and regulatory data exclusivity in Europe. Retrieved at: http://www.cmslegal.com/Uploads/1367/CMS1184Bolar\%20Provision\%20in\%20EU-0831-yp.pdf [2007, December 4].

Commission of the European Communities (1989). Proposal for a Council Directive on the advertising of tobacco products in the press and by means of bills and posters (COM (89) 163 final/2 -syn 194 Luxembourg: Official Journal of the European Communities. No C124 of May 1989: pp5-6.

Commission of the European Communities (1991). Modified Proposal for a Council Directive on advertising for tobacco products Luxembourg: Official Journal of the European Communities C167 of 27 June 1991: pp3-5.

Commission of the European Communities (1998). The Single Market in Pharmaceuticals. Communication from the Commission. COM (98)588 final of 25 November 1998. Brussels. 
Commission of the European Communities (2001a). Proposal for a Directive of the European Parliament and of the Council on the approximation of the laws, regulations and administrative provisions of the Member States relating to the advertising and sponsorship of tobacco products. $\operatorname{COM}(2001) 283$ final. Brussels: Official Journal of the European Communities C270 E/13 of 20 June 2001: pp97-100.

Commission of the European Communities (2001b). Proposal for a Regulation of the European Parliament and of the Council laying down Community procedures for the authorisation and supervision of medicinal products for human and veterinary use and establishing a European Agency for the Evaluation of Medicinal Products and Proposal for a Directive of the European Parliament and of the Council amending Directive 2001/83/EC on the Community code relating to medicinal products for human use. COM (2001)0404 final. Brussels: Official Journal of the European Communities C75 E of 23 March 2002: pp189-233.

Commission of the European Communities (2001c). Report from the Commission on the experience acquired as a result of the operation of the procedures for granting marketing authorisations for medicinal products. Brussels.

Commission of the European Communities (2001d). Review of pharmaceutical legislation. Discussion document - final version. 22 January 2001. Brussels.

Commission of the European Communities (2001e). Press release 18 July 2001: Commission's proposal to review EU pharmaceutical legislation. Brussels.

Commission of the European Communities (2003a). Directive 2003/33/EC of the European Parliament and of the Council of 26 May on the approximation of the laws, regulations and administrative provisions of the Member States relating to the advertising and sponsorship of tobacco products Luxembourg: Official Journal of the European Union L152 20 June 2003: pp16-19.

Commission of the European Communities (2003b). Press release 1 July 2003: Commission pushes for a stronger European-based pharmaceutical industry for the benefit of the patient. Strasbourg. Retrieved at: http:/ / europa.eu/rapid/pressReleasesAction.do?reference $=I P / 03 / 924 \&$ format $=H T$ ML\&aged $=0$ \&language $=E N \&$ guiLanguage $=$ en $[2007,17$ November $]$.

Commission of the European Communities (2004). Directive 2004/27/EC of the European Parliament and of the Council of 31 March 2004 amending Directive 2001/83/EC on the Community code relating to medicinal products for human use. Official Journal L136 30 April 2004: pp34-57.

Commission of the European Communities (2007a). Draft report on current practice with regard to provision of information to patients on medicinal products. 19 April 2007: Brussels. Retrieved at: http:/ /ec.europa.eu/enterprise/pharmaceuticals/pharmacos/docs/doc2007/2007_04 /draft_infopatients2007_04.pdf [2007, December 17]. 
Commission of the European Communities (2007b). Communication from the Commission to the European Parliament and the Council concerning the Report on current practice with regard to provision of information to patients on medicinal products. 20 December 2007: Brussels. Retrieved at: http://ec.europa.eu/enterprise/pharmaceuticals/pharmacos/docs/doc2007/2007_12 /inf_to_patients_com_2007_862_en.pdf [2008, February 4].

Commission of the European Communities (2008). Public consultation. Legal proposal on information to patients. Brussels. Retrieved at: http://ec.europa.eu/enterprise/pharmaceuticals/pharmacos/docs/doc2008/2008_02 /info_to_patients_consult_200802.pdf [2008, March 19].

Connolly, J. (2002). The politics of tobacco advertising. Thorax BMJ, 57(Supplement II), ii64-ii68.

Council of the European Communities (1987). Council Directive 87/21/EEC of 22 December 1986 amending Directive 65/65/EEC on the approximation of provisions laid down by law, regulation or administrative action relating to proprietary medicinal products. Luxembourg: Official Journal L015, 17 January 1987.

Council of the European Communities (2003). Common position document 2001/0253 (COD), May 2003.

Cracknell, D. (2004). Ministers hit by sleaze row over 'stars for Labour'. London: The Sunday Times.

Cram, L. (1997). Policy-making in the EU. Conceptual lenses and the integration process. London: Routledge.

Crombez, C. (2001). The Treaty of Amsterdam and the Co-decision Procedure. In G. Schneider, \& M.D. Aspinwall (Eds.), The rules of integration. Institutionalist approaches to the study of Europe (pp.101-122). Manchester: Manchester United Press.

Crombez, C. (2002). Information, lobbying and the legislative process in the European Union. European Union Politics, 3(1), 7-32.

Crossick, S. (2002). Seville Summit - Creeping Council influence at Commission's expense. Brussels: European Policy Centre.

Cuatrecasas, P. (2006). Drug discovery in jeopardy. Journal of Clinical Investigation, 116(11), $2837-2842$.

Cucic, S. (2000). European Union health policy and its implications for national convergence. International journal for quality in bealth care, 12(3), 217-225.

Daviter, F. (2007). Policy framing in the European Union. Journal of European Public Policy, 14(4), 654-666.

Devine, F. (2002). Qualitative methods. In D. March \& G. Stoker (Eds.), Theory and methods in political science (pp.197-215). Basingstoke: Macmillan Press.

DiFranza, J.R., Wellman, R.J., Sargent, J.D., Weitzman, M., Hipple, B.J., \& Winickoff, J.P. (2006). Tobacco Promotion and the Initiation of Tobacco Use: Assessing the Evidence for Causality. Pediatrics, 117(6), 1237-1248. 
Dodds-Smith, I. (2000). Data protection and abridged applications for marketing authorisations in the pharmaceutical industry. In R. Goldberg \& J. Lonbay (Eds.), Pharmacentical medicine, biotechnology, and European law. Cambridge: Cambridge University Press.

Doyle, L. (1995). Brussels stubs out cash for anti-smoking group. 29 November 1995: The Guardian.

Duina, F., \& Kurzer, P. (2004). Smoke in your eyes: the struggle over tobacco control in the European Union. Journal of European public policy, 11(1), 47-77.

Duncan, B. (2002). Health policy in the European Union: how it's made and how to influence it. British Medical Journal, 324(7344), 1027-1030.

Dür, A., \& De Bièvre, D. (2007). The question of interest group influence. Journal of Public Policy, 27(1), 1-12.

Dutch Ministry of Health (1993). Internal note to the Dutch Secretary of Health of 1 December 1993 concerning the Dutch position with regard to tobacco advertising. Retrieved from the Dutch archive on tobacco advertising.

Dutch Ministry of Health (2003). Internal memo of 28 April 2003 to the Dutch Minister concerning the pharmaceutical review. Retrieved from the Dutch archive on the pharmaceutical review.

ECL (1996). UICC/ECL Submission on the continuing case for an EU Directive on tobacco advertising to Mr Michael Noonan, TD, Irish Health Minister and Mr Paidraig Flynn, European Commissioner with responsibility for Employment and Social Affairs. Brussels: June 1996.

ECL (1998a). Newsletter S.T.o.P (Stop Tobacco Promotion) issue 1. Brussels: March 1998.

ECL (1998b). Newsletter S.T.o.P (Stop Tobacco Promotion) issue 3. Brussels: April 1998.

EFPIA (1998). Development of the EU single market in pharmaceuticals. The pharmaceutical industry's agenda. June 1998. Brussels: EFPIA.

EFPIA (1999). Regulation 2000: An EFPIA perspective on the future of medicines' regulation in Europe. April 1999. Brussels: EFPIA.

EFPIA (2000). Position paper - proposals for improving regulatory communication and transparency. November 2000. Brussels: EFPIA.

EFPIA (2001). 2000-2001 The year in review. October 2001. Brussels: EFPIA.

EFPIA (2002). Position paper on the proposals for a new regulation and a new directive on the authorisation and supervision of medicinal products for human use. June 2002. Brussels: EFPIA.

Eichener, V. (1997). Effective European problem-solving: lessons from the regulation of occupational safety and environmental protection. Journal of European Public Policy, 4(4), 591-608.

Eising, R. (2000). Bounded rationality and policy learning in EU negotiations: The liberalization of the electricity supply industry. Florence: European University Institute. 
Eising, R. (2005). The access of business interests to European Union institutions: notes towards a theory. Oslo: Arena Centre for European Studies.

Eising, R. (2007). The access of business interests to EU political institutions: towards elite pluralism? Journal of European Public Policy, 14(3), 384-404.

Elgström, O., \& Jonssön, C. (2000). Negotiation in the European Union: bargaining or problem-solving? Journal of European Public Policy, 7(5), 684-704.

Elgström, O., \& Smith, M. (2000). Introduction: Negotiation and policy-making in the European Union - processes, system and order. Journal of European Public Policy, 7(5), 673-683.

Eppink, D. (2007). Life of a European Mandarin - inside the Commission. Leuven: Lannoo.

European Court of First Instance (27 June 2000). Judgement of the Court of first Instance in joined Cases T-172/98 and T-175/98 to T-177/98.

European Court of Justice (5 February 1963) Judgement of the Court in Case C-26/62.

European Court of Justice (5 October 2000). Judgement of the Court in Case C-376/98.

European Court of Justice (12 December 2006). Judgement of the Court in Case C$380 / 03$.

European Information Service (2007). European Report: 'Pharmaceutical Forum: Model for patient information gets cool welcome’, No 3326, 14 June 2007.

European Parliament (1992a). Amended proposal for a Council directive on advertising for tobacco products (COM(91) 0111-C3-0268/91 -SYN 194) Luxembourg: Office for Official Publications of the European Communities.

European Parliament (1992b). Handelingen van het Europese Parlement 16/01/1992 (nr. 3-413) Luxembourg: Office for Official Publications of the European Communities pp158-169.

European Parliament (1998a). Recommendation for second reading on the common position adopted by the Council with a view to adopting a European Parliament and Council Directive on the approximation of the laws, regulations and administrative provisions of the member States relating to the advertising and sponsorship of tobacco products - Committee on the Environment, Public Health and Consumer Protection Luxembourg: Official Journal of the European Communities of 22 April 1998.

European Parliament (1998b). Report of Proceedings: sitting of Tuesday, 12 May 1998 on advertising.

Retrieved

at: http://www.europarl.europa.eu/debats/debats?FILE=98-0512\&LANGUE=EN\&LEVEL=TOC2\&GCSELECTCHAP=6 [2006, May 14].

European Parliament (2002a). Report on the proposal for a Directive of the European Parliament and of the Council on the approximation of the laws, regulations and administrative provisions of the Member States relating to the advertising and sponsorship of tobacco products (Enhanced Hughes procedure) - Committee on Legal Affairs and the Internal Market: 9 October 2002. 
European Parliament (2002b). Plenary debate on tobacco advertising and sponsorship. Strasbourg: 18 November 2002.

European Parliament (2002c). Plenary debate on medicinal products. Strasbourg: 22 October 2002.

European Parliament (2002d). Report on the proposal for a Directive of the European Parliament and of the Council amending Directive 2001/83/EC on the Community code relating to medicinal products for human use - Committee on the Environment, Public Health and Consumer Policy: 9 October 2002..

European Parliament (2002e). European Parliament legislative Resolution on the proposal for a European Parliament and Council directive amending Directive 2001/83/EC on the Community code relating to medicinal products for human use. 22 October 2002.

Fairbrass, J., \& Jordan, A. (2003). The informal governance of EU environmental policy: the case of biodiversity. In T. Christiansen, \& S. Piattoni (Eds.), Informal governance in the European Union (pp.94-113). Cheltenham: Edward Elgar Publishing Limited.

Falkner, G., Hartlapp, M., Leiber, S., \& Treib, O. (2004). Non-compliance with EU directives in the member states: Opposition through the backdoor? West European Politics, $27(3), 452-473$.

Farley, J., Baker, D., Batker, D., Koliba, C., Matteson, R., Mills, R., \& Pittman, J. (2007). Opening the policy window for ecological economics: Katrina as a focusing event. Ecological Economics, 63(2-3), 344-354.

Farrell, H., \& Heritier, A. (2003). Formal and informal institutions under codecision: Continuous constitution-building in Europe. Governance, 16(4), 577-600.

Farris, P.W., \& Wilkie, W.L. (2005). Marketing scholars' roles in the policy arena: an opportunity for discourse on direct-to-consumer advertising. Journal of Public Policy \& Marketing, 24(1), 3-6.

Feick, J. (2002). Regulatory Europeanization, national autonomy and regulatory effectiveness: marketing authorization for pharmaceuticals. Cologne: Max-Planck-Institute for the Study of Societies.

Feick, J. (2005). Learning and interest accommodation in policy and institutional change: EC risk regulation in the pharmaceutical sector. London: Centre for analysis of risk and regulation.

Feick, J., \& Broscheid, A. (2005). A great leap ahead or an incremental step? The 20012004 Review of European pharmaceuticals authorization and regulatory Europeanization: Cologne: Max Planck Institute for the Study of Societies.

Ferrera, M. (2005). The boundaries of welfare. European integration and the new spatial politics of social protection. Oxford: Oxford University Press.

Fischer, A. (1999). A new public health policy in the European Union. Eurohealth, 5(1), 25.

Freeman, R., \& Moran, M. (2000). Reforming health care in Europe. West European Politics, 23(2), 35-58. 
G10 High Level Group (2001a). G10 Medicines Consultation Paper. Brussels: September 2001.

G10 High Level Group (2001b). Summary record of the G10 Medicines Information and Patients workshop. Luxembourg: 19 December.

G10 High Level Group (2002). Recommendations for action. Brussels: 7 May 2002.

Gambardella, A., Orsenigo, L. \& Pammolli, F. (2000). Global competitiveness in pharmaceuticals: a European perspective. Brussels: European Commission.

Garattini, S., Bertele, V., \& Li Bassi, L. ( 2003). Light and shade in proposed revision of EU drug-regulatory legislation. Lancet, 361(9358): 635-636.

Garrett, G. (1995). From the Luxembourg Compromise to Codecision: Decision Making in the European Union. Electoral Studies, 14(3), 289-308.

Gerlinger, T., \& Urban, H. (2007). From heterogeneity to harmonization? Recent trends in European health policy. Cad. Saúde Pública, 23(2), 133-142.

Gillies, D. (1998). Lobbying and European Community environmental law. European Environment, 8(6), 175-183.

Gilmore, A., \& McKee, M. (2004). Tobacco-control policy in the European Union. In E.A. Feldman, \& R. Bayer (Eds.), Unfiltered: conflicts over tobacco policy and public health. (pp.219-254). Cambridge: Harvard University Press.

Girod, L., \& Greenberg, D.I. (1993). Corporate Affairs weekly highlights, August 6, 1993. Retrieved at: http:/ /www.pmdocs.com/getallimg.asp?if=avpidx\&DOCID=2500064870/4872 [2005, February 4].

Golub, J. (1996). State power and institutional influence in European integration: Lessons from the packaging waste Directive. Journal of Common Market Studies, 34(3), 313-339.

Goozner, M. (2004). The $\$ 800$ million pill: the truth behind the cost of new drugs. Berkeley: University of California Press.

Greenwood, J. (2003). Interests representation in the European Union. Hampshire: Palgrave Macmillan.

Greer, S.L. (2006). Uninvited Europeanization: neofunctionalism and the EU in health policy. Journal of European Public Policy, 13(1), 134-152.

Grossetête, F. (2005). The European Parliament's contribution to the revision of pharmaceutical legislation and unresolved questions. In J.L. Valverde, \& P. Weissenberg (Eds.), The challenges of the new EU pharmaceutical legislation. (pp.29-32). Amsterdam: IOS Press.

Hafez, N., \& Ling, P.M. (2005). How Philip Morris built Marlboro into a global brand for young adults: implications for international tobacco control. Tobacco control, 14, 262-271.

HAI (2002). Providing prescription medicine information to consumers: is there a role for direct-to-consumer promotion? - Symposium Report.. Amsterdam: HAI.

HAI, MiEF, ISDB \& AIM (2007). Second open letter to Commissioner Verheugen and Commissioner Kypriano. Paris: 14 June 2007. 
HAI, MiEF \& ISDB (2007). Press release 'EU pharmaceutical Forum: public health is not its overriding priority'. Brussels: July 2007.

Ham, C. (2001). Commentary: Values and Health Policy: The Case of Singapore. Journal of Health Politics, Policy and Law, 26(4), 739-745.

Harris, F., MacKintosh, A.M., Anderson, S., Hastings, G., Borland, R., Fong, G.T., Hammond, D., \& Cummings, K.M. (2006). Effects of the 2003 advertising/promotion ban in the United Kingdom on awareness of tobacco marketing: findings from the International Tobacco Control (ITC) Four Country Survey. Tobacco Control, 15(suppl_3), 26-33.

Hartley, J. (2004). Case study research. In C. Cassell, \& G. Symon (Eds.), Essential guide to qualitative methods in organizational research (pp.323-334). London: Sage.

Haverland, M. (2007). When the welfare state meets the regulatory state: EU occupational pension policy. Journal of European Public Policy, 14(6), 886-904.

Hayes, A.J. (1993). European Community tobacco lobby. Tobacco control, 2(2), 170.

Hayes-Renshaw, F. (2002). The Council of Ministers. In J. Peterson, \& M. Shackleton (Eds.), The institutions of the European Union (pp.47-70). New York: Oxford University Press.

Health GAP (2003). The Central America Free Trade Agreement, access to AIDS medicines, and intellectual property. New York: Health GAP (Global Access Project).

Hedetoft, U. (2003). Cultures of states and informal governance in the EU: an exploratory study of elites, power and identity. In T. Christiansen, \& S. Piattoni (Eds.), Informal governance in the European Union (pp.36-56). Cheltenham: Edward Elgar Publishing Limited.

Héritier, A. (1998). Second-order institutionalization in Europe: how to solve collective action problems under conditions of diversity. Bonn: Max Planck Institute for research on collective Goods.

Héritier, A. (1999). Policy-making and diversity in Europe. Escape from deadlock. Cambridge: Cambridge University Press.

Héritier, A. (2000). Overt and covert institutionalization in Europe. In A. Stone Sweet, W. Sandholtz, \& N. Fligstein (Eds.), The institutionalization of Europe (pp.56-70). Oxford: Oxford University Press.

Hervey, T.K. (2001a). Community and national competence in health after tobacco advertising. Common Market Law Review, 38(6), 1421-1446.

Hervey, T.K. (2001b). Up in smoke? Community (anti)-tobacco law and policy. European Law Review, 26(2), 101-125.

Hervey, T.K. (2002). The legal basis of European Community public health policy. In M. McKee, E. Mossialos, \& R. Baeten (Eds.), The impact of EU law on health care systems (pp. 23-55). Brussels: P.I.E.-Peter Lang.

Hervey, T.K., \& McHale, J.V. (2004). Health law and the European Union. Cambridge: Cambridge University Press.

Herxheimer, A. (2003). Relationships between the pharmaceutical industry and patients' organisations. British Medical Journal, 326(31), 1208-1210. 
Hiilamo, H. (2003). Tobacco industry strategy to undermine tobacco control in Finland. Tobacco control, 12, 414-423.

Hilts, P.J. (2003). Protecting America's health: the FDA, business and one hundred years of regulation. New York: Alfred A. Knopf.

Hix, S. (1999). The political system of the European Union. Basingstoke: MacMillan Press.

Hollon, M.F. (2005). Direct-to-Consumer Advertising: A Haphazard Approach to Health Promotion. Journal of the American Medical Association, 293(16), 2030-2033.

Holmer, A.F. (2002). Direct-to-consumer advertising: Strengthening our health care system. New England Journal of Medicine, 346(7), 526-528.

Horrobin, D.F. (2003). Modern biomedical research: an internally self-consistent universe with little contact with medical reality? Nature Reviews / Drug Discovery, 2, 151-154.

Immergut, H. (1992). Health politics. Interests and institutions in Western Europe. Cambridge: Cambridge University Press.

Jeffries, M. (2000). The Mark of Zorro. Pharmacentical Marketing, May 2000, 4-5.

Jupille, J., \& Caporaso, J.A. (1999). Institutionalism and the European Union: Beyond international relations and comparative politics. Annual Review of Political Science, 2, 429 444.

Kanavos, P., \& McKee, M. (2000). Cross-border issues in the provision of health services: are we moving towards a European health care policy? Journal of Health Services Research and Policy, 5(4), 231-236.

Khanna, D. (2001). The defeat of the European Tobacco Advertising Directive: A blow for health. Yearbook of European Law, 20, 113-138.

Kingham, R.F., \& Castle, G.H. (2000). Data and market exclusivity for pharmaceuticals in the European Community. Food and Drug Law Journal, 55(2), 209-223.

Kingdon, J.W. (1984). Agenda's, alternatives and public policies. New York: HaperCollins.

Kohler-Koch, B. (1997). Organised interests in the EC and the European Parliament. European Integration online Papers (EIoP), 1(9), 1-17.

Kohler-Koch, B. (Ed.) (2003). Linking EU and national governance. Oxford: Oxford University Press.

König, T. (2008). Why do member states empower the European Parliament? Journal of European Public Policy, 15(2), 167-188.

Kotzian, P. (2003). Verhandlungen im Europäischen Arzneimittelsektor. Baden-Baden: Nomos.

Kümpers, S., Mur, I., Hardy, B., Raak, A. van, \& Maarse, H. (2006) The importance of knowledge transfer between specialist and generic services in improving health care. A cross-national study of dementia care in England and the Netherlands. The International Journal for Health Planning and Management 21(2), 151-167.

Lamping, W. (2005). European integration and health policy: a peculiar relationship. In M. Steffen (Ed.), Health Governance in Europe. Issues, challenges and theories (pp.18-48). London: Routledge. 
Leibfried, S., \& Pierson, P. (2000). Social policy. Left to courts and markets? In H. Wallace, \& W. Wallace (Eds.), Policy-making in the European Union (pp.267-292). Oxford: Oxford University Press.

Levine, M.E., \&. Forrence, J.L. (1990). Regulatory capture, public interest, and the public agenda: toward a synthesis. Journal of Law, Economics \& Organization, 6, 167-198.

Lewis, J. (2002). National Interests - COREPER. In J. Peterson, \& M. Shackleton (Eds.), The institutions of the European Union (pp. 277-298). New York: Oxford University Press.

Lewis, J. (2003). Informal integration and the supranational construction of the Council. Journal of European Public Policy, 10(6), 996-1019.

Mahoney, C. (2004). The power of institutions: State and interest group activity in the European Union. European Union Politics, 5(4), 441-466.

Majone, G. (ed.) (1996). Regulating Europe. London: Routledge.

Mansfield, P.R., Mintzes, B., Richards, D., \& Toop, L. (2005). Direct to consumer advertising is at the crossroads of competing pressures from industry and health needs. British Medical Journal, 330 (7481), 5-6.

Martinsen Sindbjerg, D. (2005). Towards an internal health market with the European Court. West European Politics, 28(5), 1035-1056.

Matilla, M. (2004). Contested decisions: Empirical analysis of voting in the European Union Council of Ministers. European Journal of Political Research, 43(1), 29-50.

Mayntz, R., \& Scharpf, F.W. (1995). Gesellschaftliche Selbstregelung und politische Stenerung. Cologne: Max Planck Institute for the Study of Societies.

Mazey, S., \& Richardson, J. (2006). Interest groups and EU policy-making: organisational logic and venue shopping. In J. Richardson (Ed.), European Union power and policy-making (pp.247-268). New York: Routledge.

McKee, M., Mossialos, E., \& Baeten, R. (2002). The implications of European law for health care. In M. McKee, E. Mossialos, \& R. Baeten (Eds.), The impact of EU law on health care systems (pp.13-22). Brussels: P.I.E.-Peter Lang.

McKee, M., \& Mossialos, E. (2006). Health policy and European law: Closing the gaps. Public Health, 120, 16-21.

Medawar, C., \& Hardon, H. (2004). Medicines out of control? Antidepressants and the Conspiracy of Goodwill. Amsterdam: Aksant Academic Publishers.

Medicines in Europe Forum (2003). 'Data protection' is protection of clinical trials results. Retrieved

at: http://www.prescrire.org/aLaUne/dossierEuropeProtectionDonneesEn.php [2007, October 6].

Metcalfe, D. (1998). Leadership in European Union negotiations: The presidency of the Council. International Negotiation, 3(3), 413-434.

Ministers of Health from the Acceding Countries (2003). The Acceding Countries Declaration signed in Milan on 5 September 2003 (Milan Declaration). Retrieved at: http://www.egagenerics.com/doc/milandec.pdf [2007, October 9]. 
Mossialos, E. (1998). Pharmaceutical pricing, financing and cost containment in the European Union member states. In R. Leidl (Ed.), Health care and its financing in the Single European market (pp.85-115). Amsterdam: IOS Press.

Mossialos, E., \& McKee, M. (2002). EU law and the social character of health care. Brussels: P.I.E.-Peter Lang.

Mossialos, E., \& Permanand, G. (2000). Public health in the European Union: Making it relevant. London: LSE Health.

Muggli, M.E., \& Hurt, R.D. (2003). Tobacco industry strategies to undermine the 8th World Conference on Tobacco or Health. Tobacco control, 12(2), 195-202.

Naett, C., \& Joossens, L. (1992). Steps towards a tobacco advertising ban in the European Community. Tobacco control, 1(1), 57-59.

National Economic Research Associates. (1998). Policy relating to generic medicines in the OECD. London: NERA.

Neuhold, C. (2001). The "legislative backbone" keeping the institution upright? The role of European Parliament Committees in the EU policy-making process. European Integration online Papers (EIoP), 5(10), 1-21.

Neuman, M., Bitton, A., \& Glantz, S. (2002). Tobacco industry strategies for influencing European Community tobacco advertising legislation. Lancet, 359(9314), 1323-1330.

Neyer, J. (2004). Explaining the unexpected: efficiency and effectiveness in European decision-making. Journal of European Public Policy, 11(1), 19-38.

Nugent, N. (2002). The Commission's Services. In J. Peterson, \& M. Shackleton (Eds.), The institutions of the European Union (pp. 141-163). Oxford: Oxford University Press.

Nugent, N. (2003). The government and politics of the European Union. New York: Palgrave Macmillan.

Nylander, J. (2001). The construction of a market. A frame analysis of the liberalization of the electricity market in the European Union. European Societies, 3(3), 289-314.

OECD (2007). OECD Health data - Frequently Requested Data. OECD, October 2007. Retrieved at: http://www.oecd.org/document/16/0,3343,en_2649_34631_2085200_1_1_1_1,00.ht $\mathrm{ml}[2007$, December 6].

O'Reilly, R.F. (2005). Veto points, veto players and international trade policy. Comparative Political Studies, 38(6), 652-675.

Parrish, R. (2003). The politics of sports regulation in the European Union. Journal of European Public Policy, 10(2), 246-262.

Payer, L. (1988). Medicine and culture: varieties of treatment in the United States, England, West Germany, and France. New York: Henry Holt and Company.

Permanand, G., \& Altenstetter, C. (2004). The politics of the EU pharmaceutical industry. In E. Mossialos, M. Mrazek, \& T. Walley (Eds.), Regulating pharmacenticals in Europe: striving for efficiency, equity and quality (pp.38-54). Maidenhead: Open University Press. 
Permanand, G., \& Mossialos, E. (2005). Constitutional asymmetry and pharmaceutical policy-making in the European Union. Journal of European Public Policy, 12(4), 687-709.

Permanand, G. (2006a). EU pharmaceutical regulation. The politics of policy-making. Manchester: Manchester University Press.

Permanand, G. (2006b). Commentary on 'Health policy and European law: Closing the gaps'. Public Health, 120, 21-22.

Perry, G. (2000). Health registration data. Letter of 27 January 2000 to essential drugs. Retrieved at: http://www.essentialdrugs.org/edrug/archive/200001/msg00094.php [2007, November 23].

Peters, B.G. (1997). Escaping the joint-decision trap: repetition and sectoral politics in the European Union. West European Politics, 20(2), 22-36.

Peterson, J., \& Bomberg, E. (1999). Decision-making in the European Union. Hampshire: Palgrave.

PGEU (2002). Proposal for a Directive of the European Parliament and of the Council amending Directive 2001/83/EC on the Community code relating to medicinal products for human use. Comments of the PGEU. Brussels: PGEU, January 2002.. Retrieved http://www.pgeu.eu/Portals/6/documents/before/02.01.11E $\% 20$ PGEU18\%20Ph\% 20Review\%20PGEU\%20Final.doc.pdf [2008, January 6].

Pharmaceutical Committee (1999a). Information on the outcome of the 47th meeting, 1516 April 1999. retrieved at: http://ec.europa.eu/enterprise/pharmaceuticals/pharmacos/docs/doc99/pc47inf.pdf [2007, November 19].

Pharmaceutical Committee (1999b). Information on the outcome of the 48th meeting, 27-28 September 1999. retrieved at: http://ec.europa.eu/enterprise/pharmaceuticals/pharmacos/docs/doc99/pc48/pc48i nf.pdf [2007, November 19].

Pharmaceutical Committee (2000). Information on the outcome of the Special Meeting on the "Review", 27 November 2000. Retrieved at: http:/ /ec.europa.eu/enterprise/pharmaceuticals/review/doc/pharcom_20001127.pdf [2007, November 19].

Pharmaceutical Committee (2001). Information on the outcome of the 2nd Special Meeting on the Review, 5 July 2001. Retrieved at: http:/ /ec.europa.eu/enterprise/pharmaceuticals/pharmacos/docs/doc2001/july/phar m_05072001.pdf [2007, November 19].

Pharmaceutical Forum (2007a). Contributions to public consultation on the Quality Principles and the Diabetes Model information Package. Retrieved at: http:/ / ec.europa.eu/health/ph_overview/other_policies/pharmaceutical/results_cons ultation_en.htm\#1 [2008, January 4].

Pharmaceutical Forum (2007b). Second Progress Report, 26 June 2007. Retrieved at: http://ec.europa.eu/enterprise/phabiocom/docs/pf_20070626_progr_report.pdf [2007, December 12]. 
Pharmaceutical Industry Competitiveness Task Force (2001). Final Report March 2001. London: PICTF.

Philip Morris. (1991). Speech by Bobby Kaplan manager of communications - PMI / CA international marketing training conference. Aug 12, 1991. Retrieved at: http:/ /www.pmdocs.com/getallimg.asp?if=avpidx\&DOCID=2500120186/0202 [2005, February 4].

Philip Morris. (1992). Letter from Ian C. Sargeant, Director Corporate Affairs, Policies \& Programmes to K. Clarke, Secretary of State for Education \& Science. 26 February 1992. Retrieved at: http://www.pmdocs.com/PDF/2501015052_5053_0.PDF [2005, March 2].

Philip Morris (1993a). History and description of Commission proposed ban October 25, 1993.

http:/ / www.pmdocs.com/getallimg.asp?if=avpidx\&DOCID=2501029018/9021 [2005, February 4].

Philip Morris (1993b). Marketing freedoms. Phillip Morris. Retrieved at: http:/ /www.pmdocs.com/getallimg.asp?if=avpidx\&DOCID=2501021740/1746 [2005, February 25].

Pijnenburg, B. (1998). EU lobbying by ad hoc coalitions: an exploratory case study. Journal of European Public Policy, 5(2), 303-321.

Poetschke Langer, M., \& Schunk, S. (2001). Germany: tobacco industry paradise. Tobacco control, 10(4), 300-303.

Pollack, M.A. (1997). Delegation, agency, and agenda setting in the European community. International Organization, 51(1), 99-135.

Prescrire International (2002). Towards a medicines policy that supports basic public health needs. Prescrire International, 11(59), 14-15.

Prescrire International (2007). A look back at pharmaceuticals in 2006: aggressive advertising cannot hide the absence of therapeutic advances. Prescrire International, 16(88), 8086.

Princen, S., \& Rhinard, M. (2006). Crashing and creeping: agenda-setting dynamics in the European Union. Journal of European Public Policy, 13(7), 1119-1132.

Princen, S. (2007). Agenda-setting in the European Union: A theoretical exploration and agenda for research. Journal of European Public Policy, 14(1), 21-38.

Pugatch, M.P. (2004). Intellectual property and pharmaceutical data exclusivity in the context of innovation and market access. Geneva: International Centre for Trade and Sustainable Development.

Randall, E. (2000). European Union health policy with and without design: serendipity, tragedy and the future of EU health policy. Policy Studies, 21(2), 133-164.

Randall, E. (2001). The European Union and health policy. Hampshire: Palgrave.

Rasmussen, A. (2003). The role of the European Commission in co-decision - a strategic facilitator operating in a situation of structural disadvantage. European Integration online Papers (EIoP), 7(10), 1-13. 
Rasmussen, A. (2007). Challenging the commission's right of initiative? Conditions for institutional change and stability. West European Politics, 30(2), 244-264.

Revue Prescrire. (2002). Editorial: A free hand. Revue Prescrire, 22(229), 401.

Rochefort, D.A., \& Cobb, R.W. (1994). The Politics of Problem Definition: Shaping the Policy Agenda. Lawrence: University Press of Kansas.

Rose, R. (1991). What is lesson drawing? Journal of Public Policy, 11(3), 3-30.

Saffer, H., \& Chaloupka, F. (2000). The effect of tobacco advertising bans on tobacco consumption. Journal of health economics, 19(6), 1117-1137.

Sanjuan Rius, J. (2006). US and EU protection of pharmaceutical test data. Geneva: Consumer Project on Technology.

Scharpf, F.W. (1997). Games real actors play: actor-centered institutionalism in policy research. Oxford: Westview Press.

Scharpf, F.W. (2000a). Institutions in comparative policy research. Comparative Political Studies, 33(6-7), 762-790.

Scharpf, F.W. (2000b). Notes towards a theory of multilevel governing in Europe. Cologne: Max Planck Institute for the Study of Societies.

Scharpf, F.W. (2001). Notes towards a theory of multilevel governing in Europe. Scandinavian Political Studies, 24, 1-16.

Scharpf, F.W. (2002a). The European Social Model: Coping with challenges of diversity. Cologne: Max Planck Institute for the Study of Societies.

Scharpf, F.W. (2002b). Legitimate diversity: the new challenge of European integration, Cahier Europeens de sciences po: Centre europeen de Sciences Po.

Scharpf, F.W. (2006). The Joint-Decision Trap Revisited. Journal of Common Market Studies, 44(4), 845-864.

Schmidt, V.A. (2003). The boundaries of 'bounded generalizations': discourse as the missing factor in actor-centred institutionalism. In R. Mayntz, \& W. Streeck (Eds.), Die Reformierbarkeit der Demokratie. Innovationen und Blockaden (pp.318-350). Frankfurt: Campus.

Scott, W.R. (2001). Institutions and organizations. London: Sage Publications.

Scrip (2000). Eastern Europe powers the EC regulatory convoy. Scrip, No 2598, 6 December 2000.

Scrip (2001). EC reforms balanced, says industry. Scrip, No 2663, 25 July 2001 .

Scrip (2007). Consultation shows no support for DTC advertising in Europe. Scrip, No 3307, 31 October 2007.

Selck, T.J. (2006). Preferences and procedures. European Union legislative decisionmaking. Groningen: Springer.

Shackleton, M. (2002). The European Parliament. In J. Peterson, \& M. Shackleton (Eds.), The institutions of the European Union (pp.95-117). Oxford: Oxford University Press.

Shackleton, M., \& Raunio, T. (2003). Codecision since Amsterdam: a laboratory for institutional innovation and change. Journal of European Public Policy, 10(2), 171-187. 
Simpson, D. (2002). Germany: bogus polls and the Euro-pain syndrome. Tobacco control, 11(2), 90.

Stacey, J. (2003). Displacement of the council via informal dynamics? Comparing the Commission and Parliament. Journal of European Public Policy, 10(6), 936-955.

Stacey, J., \& Rittberger, B. (2003). Dynamics of formal and informal institutional change in the EU. Journal of European Public Policy, 10(6), 858-883.

Stake, R.E. (1995). The art of case study research. Thousand Oaks: Sage.

Steffen, M., \& Lamping, W. (2005a). The new politics of European health policy: moving beyond the nation-state. In M. Steffen (Ed.), Health governance in Europe: Issues, challenges and theories (pp.188-200). London: Routledge.

Steffen, M., \& Lamping, W. (2005b). The European Union and Health Policy. The Dynamics of Integration. Hannover: University of Hannover, Institute for Political Science.

Steffen, M., Lamping, W., \& Lehto, J. (2005). Introduction: the Europeanization of health policies. In M. Steffen (Ed.), Health governance in Europe. Issues, challenges and theories (pp.117). London: Routledge.

Steunenberg, B. (2006). Turning swift policy-making into deadlock and delay: national policy coordination and the transposition of EU directives. European Union Politics, 7(3), 293-319.

Stone, D. (2002). The policy paradox - The art of political decision-making. New York: Norton.

TABD (1998a). Transatlantic Business Dialogue 1998 Mid-Year Scorecard Report. 54p. Retrieved at: http://static.tabd.com/manilaGems/MYM98.pdf [2007, December 6].

TABD (1998b). Transatlantic Business Dialogue Charlotte Conference: Statement of Conclusions. Retrieved at: http://static.tabd.com/manilaGems/1998CharlotteCEOReport.pdf [2007, December 6].

Thatcher, M. (2001). European regulation. In J. Richardson (Ed.), European Union power and policy-making (pp.303-320). London: Routledge.

Theofilatou, M.A. \& Maarse, H. (1998). European Community harmonization and spillovers into health regulation. In R. Leidl (Ed), Health care and its financing in the Single European Market. (pp.13-37). Amsterdam: IOS Press.

Thomson, R., \& Hosli, M. (2006). Who has power in the EU? The commission, council and parliament in legislative decision-making. Journal of Common Market Studies, 44(2), 391-417.

Thomson, R. (2008). National actors in international organizations - The case of the European Commission. Comparative Political Studies, 41(2), 169-192.

Thomson, S., \& Mossialos, E. (2007). Regulating private health insurance in the European Union: The implications of single market legislation and competition policy. Journal of European Integration, 29(1), 89-107. 
Tridimas, G., \& Tridimas, T. (2002). The European Court of Justice and the annulment of the tobacco advertisement directive: friend of national sovereignty or foe of public health? European journal of Law and Economics, 14(2), 171-183.

Tsebelis, G., \& Yataganas, X. (2002). Veto players and decision-making in the EU after Nice: Policy stability and bureaucratic/judicial discretion. Journal of Common Market Studies, 40(2), 283-307.

US Senate Select Committee on Small Business (1979). Competitive problems in the drug industry. Washington D.C.: US Government Publications Office.

Valverde, J.L. (2005). Pharmaceuticals and health policy in the context of the new EU Treaty. In J.L. Valverde, \& P. Weissenberg (Eds.), The challenges of the new EU pharmaceutical legislation (pp.3-21). Amsterdam: IOS Press.

Van Kersbergen, K., \& Verbeek, B. (1994). The politics of subsidiarity in the European Union. Journal of Common Market Studies, 32(2), 215-236.

Van Kersbergen, K., \& Verbeek, B. (2007). The politics of international norms:subsidiarity and the imperfect competence regime of the European Union. European Journal of International Relations, 13(2), 217-238.

Van der Mei, A. (2003). Cross-border access to health care within the European Union: recent developments in law and policy. European Journal of Health Law, 10(4), 369-380.

Van Schendelen, R. (2002). Machiavelli in Brussels. The art of lobbying the EU. Amsterdam: Amsterdam University Press.

Versluis, E. (2007). Even rules, uneven practices: opening the 'black box' of EU law in action. European Union Politics, 30(1), 50-67.

Wallace, H. (2000). The policy process. In H. Wallace, \& W. Wallace (Eds.), Policy-making in the European Union (pp.39-64). Oxford: Oxford University Press.

Walt, G. (2000). Health policy. An introduction to process and power. London: Zed Books.

Warden, J. (1997). UK adheres to Formula One exemption. British Medical Journal, 315(7120), 1397-1402.

Watson, R. (2002). EU Parliament votes for total ban on tobacco advertising. British Medical Journal, 325(7375), 1260-1261.

Weissenberg, P. (2005). The new pharmaceutical legislation - paving the way for a European pharmaceutical policy. In J.L. Valverde, \& P. Weissenberg (Eds.), The challenges of the new EU pharmaceutical legislation. (pp.23-27). Amsterdam: IOS Press.

Wiktorowicz, M.E. (2003). Emergent patterns in the regulation of pharmaceuticals: institutions and interests in the United States, Canada, Britain, and France. Journal of Health Politics, Policy and Law, 28(4), 615-658.

Wismar, M., \& Busse, R. (2002). Analysis of SEM legislation and jurisdiction. In R. Busse,M. Wismar, \& P. Berman (Eds.), The European Union and health services (pp.41-48). Amsterdam: IOS Press. 
Witte, J.K. (2006). Change of degrees and degrees of change: comparing adaptations of European higher education systems in the context of the Bologna process. Enschede: Center for Higher Education and Policy Studies.

Woll, C. (2006a). Lobbying in the European Union: from sui generis to a comparative perspective. Journal of European Public Policy, 13(3), 456-470.

Woll, C. (2006b). The road to external representation: the European Commission's activism in international air transport. Journal of European Public Policy, 13(1), 52-69.

Yin, R.K. (2003). Case study research: design and methods. Thousand Oaks: Sage. 


\section{DUTCH SUMmARY (SAMENVATTING)}

\section{DE POLITIEKE BESLUITVORMING RONDOM GEZONDHEIDSBELEID IN DE EUROPESE UNIE. EEN ACTOR-GECENTREERDE INSTITUTIONELE ANALYSE}

Dit boek beschrijft de uitkomsten van een exploratief onderzoek naar besluitvorming in de Europese Unie (EU) op het terrein van gezondheidsbeleid. Aanleiding voor dit onderzoek is de vraag hoe we de totstandkoming van gezondheidsbeleid kunnen verklaren. De beperkte mogelijkheden die de Verdragsteksten bieden voor dit beleid en de uiteenlopende preferenties tussen lidstaten op een terrein waarbij soevereiniteit en nationale belangen hoog in het vaandel staan, maken het namelijk niet eenvoudig besluiten te nemen op dit terrein.

De EU kent diverse beperkingen voor wetgeving met betrekking tot gezondheid(szorg). Allereerst is de verdragsbasis voor een dergelijk beleid gering. Pas sinds 1993, met het Verdrag van Maastricht, mag de EU voorstellen doen op het vlak van volksgezondheid. Echter, harmonisatie van wetgeving tussen de lidstaten is expliciet uitgesloten (artikel 152(5)). Daarom zijn voornamelijk niet-bindende maatregelen mogelijk, zoals financiële steun voor onderzoek op dit terrein en rapporten van de Commissie.

Daarnaast worden gezondheid en gezondheidssystemen gekenmerkt door culturele en structurele verschillen, waardoor afstemming tussen de lidstaten complex is. Ook het economische belang van de zorgsector vormt een belangrijke reden om een rol voor 'Brussel' op dit terrein uit te sluiten. Hierbij verwijzen lidstaten naar het subsidiariteitsbeginsel, dat bepaalt dat beleid op het meest geschikte niveau - Europees, landelijk dan wel regionaal - moet worden ontwikkeld.

Terwijl economische groei, handel en concurrentiebeleid al sinds het ontstaan van de Europese Economische Gemeenschap (EEG) in de jaren vijftig centraal staan, behoort sociaal beleid, inclusief de organisatie en financiering van de gezondheidszorg, tot de (relatief) exclusieve bevoegdheid van de lidstaten. Er bestaat dus een zogenaamde constitutionele asymmetrie tussen economisch en sociaal beleid.

Bij de totstandkoming van gezondheidsbeleid dient evenwel de bredere context in acht te worden genomen. Gezondheidsbeleid raakt aan het vrije verkeer van personen, goederen, diensten en kapitaal. Dat de expliciete verdragsbasis wellicht beperkt is, betekent niet dat er geen beleid op Europees niveau gemaakt wordt. Veel gezondheidsbeleid heeft de interne markt als verdragsbasis; daarmee kan de scheiding tussen Europese economische integratie en nationaal sociaal beleid niet langer gehandhaafd worden. Echter, deze 
constatering biedt op zich geen inzicht in de werkelijke problematiek van de totstandkoming van gezondheidsbeleid. In dit onderzoek staat de paradox van EU gezondheidsbeleid en de rol van verschillende actoren in dit besluitvormingsproces centraal.

Welke factoren beïnvloeden de kans op een overeenkomst met betrekking tot gezondheidsbeleid, gegeven de uiteenlopende preferenties, het subsidiariteitsbeginsel waar lidstaten een beroep op doen en de constitutionele asymmetrie?

Het actor-gecentreerd institutionalisme, zoals geoperationaliseerd in hoofdstuk 2, vormt de basis van dit onderzoek. Uitgangssituatie van het model is dat zowel actoren als instituties, zogenaamde formele en informele spelregels, van invloed zijn op het verloop van een besluitvormingsproces. De institutionele structuur waarbinnen een dergelijk besluit wordt genomen, beïnvloedt het strategische gedrag van actoren. Drie casussen zijn geselecteerd om inzicht te verkrijgen in het hoe en waarom van een besluit op het terrein van gezondheid(szorg) in de EU.

Het belangrijkste onderscheid tussen de casussen is dat het zwaartepunt iedere keer net iets anders ligt: bij besluitvorming omtrent een verbod op tabaksreclame is dit volksgezondheid; bij het proces rondom verlenging van de periode van data exclusiviteit is dit het bredere economische belang voor de farmaceutische industrie en bij de discussie over toestaan van geneesmiddelenreclame is dit de gezondheidszorg. Terwijl alle casussen gekenmerkt worden door politieke tegenstellingen met een botsing tussen gezondheids- en economische belangen, is de vraag welke verschillen bestaan tussen de besluitvormingsprocessen en hoe we die kunnen verklaren.

- Hoe vindt politieke besluitvorming in de EU plaats op het terrein van gezondheidsbeleid?

- Wie zijn de belangrijkste actoren in het besluitvormingsproces? Wat zijn hun preferenties?

- Op welke manier beïnvloedt de institutionele structuur het strategisch gedrag van de betrokken actoren?

- Welke rol speelt belangenbehartiging in besluitvorming omtrent gezondheidsbeleid?

- Welke interacties vinden plaats tussen gezondheids- en andere belangen in besluitvorming omtrent gezondheid? 
De eerste casus betreft een volledig verbod op tabaksreclame en sponsoring. Het belangrijkste doel van deze maatregel is de bescherming van burgers en de verbetering van de volksgezondheid door het terugdringen van het aantal rokers (direct gezondheidsbeleid). Het is duidelijk dat een verbod op tabaksreclame botst met de belangen van de tabaks- en reclame industrie.

Het tweede besluitvormingsproces heeft betrekking op een verlenging van data exclusiviteit tot $10+1$ jaar, onderdeel van een groter pakket aan maatregelen om de regelgeving rondom geneesmiddelen te vereenvoudigen en de concurrentiepositie van de Europese geneesmiddelenindustrie ten opzichte van de Verenigde Staten te versterken. Gedurende deze exclusiviteitsperiode mag niet gerefereerd worden aan de gegevens van (pre-)klinische studies aangeleverd voor het op de markt brengen van een nieuw geneesmiddel. In Europa zijn deze data voor een periode van 6 of 10 jaar niet beschikbaar voor producenten van generieke middelen. Hiermee heeft deze maatregel primair gevolgen voor de innovatieve en de generieke geneesmiddelenindustrie, resulterende in een botsing tussen uiteenlopende economische belangen (indirect gezondheidsbeleid). Echter, omdat data exclusiviteit ertoe kan leiden dat een generiek product later op de markt wordt gebracht, zijn er ook gevolgen voor de beschikbaarheid van goedkopere generieke middelen en daarmee voor de financiering van de gezondheidszorg.

Tenslotte, de derde casus betreft het toestaan van reclame voor voorgeschreven geneesmiddelen. Dit is de enige casus waar geen besluit is genomen en onderhandelingen nog steeds plaats vinden. De discussie wordt overigens niet in termen van reclame gevoerd, maar is geplaatst in het kader van patiënteninformatie. Een voorstel van de Europese Commissie om informatie toe te staan voor geneesmiddelen voor HIV/AIDS, astma en diabetes is door de lidstaten en het Europese Parlement (EP) afgewezen. Echter, daarmee is de discussie niet ten einde gekomen. Het debat wordt verder gevoerd op een ander niveau. De vraag of het hier direct of indirect beleid betreft is lastiger te duiden. Wanneer het gaat om verbetering van informatie over geneesmiddelen voor patiënten, dan zou men kunnen concluderen dat het hier zeker direct beleid betreft. Wanneer het toelaten van informatie (of reclame?) door de geneesmiddelenindustrie een manier is om de positie van de industrie te versterken, dan is het duidelijk indirect beleid. In beide gevallen heeft de maatregel duidelijk effect op financiering van de gezondheidszorg.

Om bovenstaande vragen te kunnen beantwoorden, is gekozen voor een exploratieve, inductieve casestudy benadering. De methoden van dataverzameling zijn literatuurstudie, documentenanalyse (beleidsdocumenten, persberichten, rapporten met standpunten en archiefgegevens van de tabaksindustrie) en semi-gestructureerde interviews $(n=25)$. 


\section{Een verbod op tabaksreclame}

In hoofdstuk 3, 4 en 5 wordt het besluitvormingsproces rondom het verbod op tabaksreclame geanalyseerd. In het derde hoofdstuk wordt onderzocht waarom het zolang onmogelijk was om een akkoord te vinden tussen de betrokken actoren. In hoofdstuk 4 wordt het belang van een juiste juridische basis voor een wetsvoorstel bestudeerd en de invloed van deze institutie op het onderhandelingsproces. Tenslotte wordt in het vijfde hoofdstuk bekeken hoe lobbyisten - zowel van de tabaksindustrie als van nietgouvernementele organisaties (NGOs), waaronder anti-roken organisaties en organisaties voor kankerbestrijding - gebruik maken van de institutionele structuur.

In het kader van het programma van 'Europa tegen kanker' heeft de Europese Commissie een aantal anti-rook maatregelen voorgesteld. In 1991 heeft de Commissie een verbod op tabaksreclame op de agenda geplaatst. Eerder, in 1989, was al een voorstel gedaan voor beperking van reclame. Het EP wilde echter verder gaan en stelde een totaalverbod voor. Ontwikkelingen in die richting in verschillende lidstaten (waaronder Frankrijk) motiveerden de Commissie om een ambitieuze maatregel voor te stellen. De Commissie had het voorstel in het kader van de interne markt geplaatst en beargumenteerde dat regelgeving met betrekking tot tabaksreclame in heel Europa geharmoniseerd moest worden om te voorkomen dat verschillen tussen landen tot oneerlijke concurrentie zou leiden.

Echter, diverse lidstaten waren mordicus tegen een verbod. Duitsland, Nederland, Groot-Brittannië (GB), Griekenland en Denemarken vormden een blokkerende minderheid. De onderhandelingen duurden dan ook bijna tien jaar. Het antwoord op de vraag waarom uiteindelijk toch een overeenkomst mogelijk was, hangt samen met de institutionele rol van de Commissie. De Commissie bepaalt de agenda met haar recht op initiatief en heeft gedurende de onderhandelingen in het EP en de Raad een centrale rol. Ze is bij iedere bijeenkomst vertegenwoordigd en kent daarom de posities van alle belanghebbenden. Wanneer een proces geblokkeerd is, kan de Commissie diverse strategieën aanwenden om de impasse te doorbreken.

Zoals reeds aangegeven, deed de Commissie in 1991 een vergaand wetsvoorstel. Dit is opmerkelijk gezien het feit dat anti-rook beleid nog in de kinderschoenen stond. Bovendien waren verschillende lidstaten tegen iedere rol die Europa zich toeeigende op dit terrein. Economische belangen van de tabaks- en reclame industrie leken hierbij doorslaggevend te zijn, hoewel de juridische basis van het wetsvoorstel een belangrijk argument tegen vormde.

Tot 1993 was er geen juridische basis met betrekking tot volksgezondheid en toen die later wel in het verdrag stond, werd harmonisatie explicitiet uitgesloten. Uitwijken naar de algemene rechtsbasis (artikel 308) zou betekenen dat een besluit in de Raad unanimiteit 
vereiste. Bovendien zou de rol van het EP beperkt worden. Een rechtsbasis voor het voorstel was dus problematisch en noodzakelijkerwijs gebruikte de Commissie daarom de retoriek van de interne markt. Het vraagstuk rond de juridische basis werd gedurende de onderhandelingen een middel om discussies over de echte politieke controverse te omzeilen.

Tegelijkertijd pleitte de tabaksindustrie voor vrijwillige afspraken en slaagde erin een overeenkomst met enkele jaren te vertragen. De industrie gebruikte zowel op Europees als nationaal niveau 'voice' strategieën onder andere via mediacampagnes en de inzet van Formule 1 journalisten. Echter, met name toegangsstrategieën (access) waren van belang. Directe betrekkingen tussen de industrie en beleidsmakers en politici op hoog niveau bleken zeer effectief.

De financiële middelen die de industrie beschikbaar stelde voor het lobbyen tegen het verbod op tabaksreclame maakten deze tweeledige aanpak mogelijk. Bovendien was tabaksreclame een onderwerp waar vrijwel iedereen een mening over had. De veelal agressieve manier van lobbyen heeft er echter toe geleid dat vele partijen niets meer met deze tak te maken willen hebben. De geloofwaardigheid van de industrie is in het geding gekomen. Om alsnog te kunnen lobbyen, makkt de industrie gebruik van derde schijnbaar onafhankelijke - partijen.

Begin jaren negentig, toen de tabaksindustrie al grote mediacampagnes had opgezet, moesten NGO's op het terrein van volksgezondheid op Europees niveau nog gecreëerd worden. De Europese organisatie tegen kanker (ECL) werd de eerste organisatie die de Commissie steunde in haar anti-roken beleid. Een van de strategieën van de Commissie is het ondersteunen van netwerken die haar informatie kunnen verschaffen en haar positie in de onderhandelingen kunnen versterken. Voor haar eigen ondersteuning en informatievoorziening financierde de Commissie het Europese Bureau voor Rokenpreventie (BASP). Daarnaast werden financiële middelen beschikbaar gesteld voor het opzetten van een Europees netwerk van organisaties voor kankerbestrijding en antiroken organisaties. Met name BASP werd een belangrijke pleitbezorger tegen de tabaksindustrie. Echter, in 1994 hield de financiering op omdat diverse lidstaten het te ver vonden gaan dat de Commissie subsidie verleende aan een lobbyist. Een neutralere partij werd in het leven geroepen om de Commissie van informatie te voorzien.

De toegang van NGOs tot de Commissie samen met de 'voice' strategieën resulteerden in een evolutie richting strengere maatregelen. Echter, de NGOs hadden geen toegang tot belangrijke politici in de lidstaten. Daarnaast hadden ze niet de middelen en de positie om een juridische weg te bewandelen via het Europese Hof van Justitie.

Een overeenkomst leek pas mogelijk op het moment dat Duitsland of GB voorstander zou worden van een verbod. De Commissie wist dat een nieuwe regering in GB de enige kans was op een dergelijke verandering. Dit laat zien dat de bredere beleidscontext, in dit 
geval verkiezingen in een lidstaat, een belangrijke rol speelde. De Commissie wachtte hierop terwijl ze het voorstel op de agenda hield en bouwde aan haar netwerk.

In 1997 bleek een overeenkomst mogelijk nadat Labour een nieuwe regering vormde in GB en voorstander was van een verbod op tabaksreclame. De onderhandelingen verliepen bijzonder moeizaam, maar uiteindelijk maakte Griekenland een compromis mogelijk door akkoord te gaan wanneer Griekse kiosken uitgesloten waren van het verbod. Het EP ging op verzoek van public health organisaties schoorvoetend akkoord met dit compromis en daarmee was er in 1998 een algeheel verbod op tabaksreclame en sponsoring.

Echter, de eerdere keuze om het verbod te baseren op de interne markt bleek uiteindelijk juridisch niet houdbaar. De stap van Duitsland naar het Europese Hof van Justitie (EHJ) resulteerde in het doorhalen van Richtlijn 98/43/EC.

\section{Verlenging van data exclusiviteit}

In hoofdstuk 6 wordt het onderhandelingsproces rondom data exclusiviteit genanalyseerd. In 2001 heeft de Europese Commissie een periode van 10+1 jaar data exclusiviteit voorgesteld. Het wetsvoorstel was onderdeel van een groot pakket aan maatregelen onder de noemer van de geneesmiddelenherziening. Voor de uitbreiding van de EU met tien nieuwe lidstaten in mei 2004 wilden de betrokken partijen het geneesmiddelenbeleid aanpassen en vereenvoudigen waar nodig.

Eerder, in 1987, hadden de lidstaten besloten tot een periode van tien jaar voor alle (bio)technologische geneesmiddelen en zes jaar voor de overige producten. De lidstaten konden vrijwillig deze periode van zes jaar opschroeven tot tien jaar in het kader van 'bescherming van de volksgezondheid'. Frankrijk, Duitsland, GB, Italië, Nederland, België en Zweden kozen voor deze laatste optie. Denemarken, Finland, Ierland, Luxemburg, Spanje, Portugal, en Griekenland hielden vast aan de periode van zes jaar. Hoewel de Commissie initieel had ingezet op harmonisatie van de data exclusiviteitsperiode, resulteerde de overeenkomst in diverse perioden.

De geneesmiddelenherziening bood de Commissie een nieuwe kans om harmonisatie van de periode te realiseren. Echter, diverse lidstaten samen met de generieke geneesmiddelenindustrie en de tien toetredende landen waren tegen deze zeer lange bescherming van de data. Vertraging van de introductie van van generieke middelen op de markt zou invloed hebben op de financiering van de gezondheidszorg in de afzonderlijke lidstaten. De Europese Commissie, de innovatieve industrie en een aantal lidstaten waar deze industrie sterk vertegenwoordigd is, beweerden dat de maatregel een extra stimulans voor innovatie zou zijn. Daarmee zou het uiteindelijk een positief effect hebben op de volksgezondheid en de gezondheidszorg. Echter, gedurende de onderhandelingen werd er geen enkel bewijs voor deze bewering geleverd. Om ook de generieke industrie tegemoet 
te komen, bood de Commissie de mogelijkheid tot het voorbereiden van een marktvergunning zonder dat hiermee het patent geschonden werd (Bolar maatregel). Daarmee presenteerde de Commissie het geheel als een gebalanceerd voorstel met voor ieder wat wils.

Binnen de geneesmiddelenherziening vormde data exclusiviteit een heet hangijzer. Het EP voorzag een andere balans en stelde $8+2+1$ jaar voor. De onderhandelingen in de Raad resulteerde in sterk uiteenlopende voorstellen. Uiteindelijk bleek dat harmonisatie op een niveau van het Commissievoorstel voor sommige landen te ver gaan. In het gemeenschappelijk standpunt kwam de Raad tot een bescherming van 10+1 jaar voor geneesmiddelen goedgekeurd via de centrale procedure (Europese autorisaties) en $8+2$ jaar voor de wederzijdse erkenningsprocedure (geharmoniseerde nationale autorisaties) De informele trialoog resulteerde alsnog in het voorstel van het EP.

De vraag is waarom de Commissie een dergelijk ambitieus voorstel op de agenda plaatste en hoe een overeenkomst mogelijk was gegeven de invloed op de financiering van de gezondheidszorg in de lidstaten. Een belangrijke verklaring is de interactie tussen de Commissie en de innovatieve geneesmiddelenindustrie. DG Ondernemingen was verantwoordelijk voor het wetsvoorstel en de agenda liep in dit geval parallel aan die van de innovatieve industrie. Hoewel de Commissie voorafgaand aan het voorstel een evaluatie had laten uitvoeren, speelde de uitkomsten hiervan geen rol. De Commissie had reeds achter gesloten deuren afspraken gemaakt met de industrie. Pas nadat diverse andere belanghebbenden hun onvrede hadden uitgesproken over deze gang van zaken, organiseerde de Commissie een consultatie in januari 2001. Echter, de belangrijkste gesprekken hadden toen al plaatsgevonden.

Ook tijdens de onderhandelingen hield de Commissie vast aan haar eigen voorstel en toonde zich niet bereid tot het vormen van een compromis. De Commissie hamerde daarbij steeds op de noodzaak van een overeenkomst voor de uitbreiding met tien nieuwe landen. Hoewel ze halverwege de onderhandelingen wel reeds in de Raad vertegenwoordigd waren, werden ze volledig gepasseerd in dit proces.

Een ander probleem was het gebrek aan vertegenwoordiging van consumenten/patiënten - en public health organisaties. In de EU bestond voor de geneesmiddelenherziening geen organisatie die zich specifiek richtte op geneesmiddelenbeleid. Pas in 2002 werd het medicijnen-in-Europa forum (Medicines in Europe Forum) opgericht. Aangezien de agenda toen reeds geformuleerd was en onderhandelingen al begonnen waren, richtte het forum haar pijlen op het EP. Omdat data exclusiviteit een vrij complexe kwestie was, bestond er geen aandacht vanuit de media, terwijl dat juist een belangrijke strategie is voor NGOs. 


\section{Reclame voor voorgeschreven geneesmiddelen}

De laatste casestudie heeft betrekking op het proces rondom reclame voor voorgeschreven geneesmiddelen. Dit is de enige casus waar nog geen overeenkomst gesloten is. In de Verenigde Staten (VS) is geneesmiddelenreclame toegestaan en in 2001 heeft de Europese Commissie een pilot studie voorgesteld als onderdeel van de geneesmiddelenherziening. Gedurende vijf jaar zouden geneesmiddelenfabrikanten patiënten kunnen voorzien van informatie voor producten bedoeld voor HIV/AIDS, diabetes en astma.

Het voorstel van de Commissie was om verschillende redenen verbazingwekkend. Allereerst laten de resultaten van wetenschappelijk onderzoek geen eenduidig resultaat zien met betrekking tot de effecten van geneesmiddelenreclame. Wetenschappelijk onderzoek kan daarom niet de basis vormen voor dit voorstel, dat zoals is gebleken vanuit een politiek perspectief benaderd dient te worden. Ten tweede, uit onderzoek blijkt dat geneesmiddelenreclame tot een hogere consumptie van medicijnen leidt. De lidstaten in de EU zijn daarom tegen het toestaan van reclame uit angst voor een explosieve toename en daarmee druk op de financiering van hun gezondheidszorg. Hiermee heeft een dergelijke maatregel invloed op een gezondheidszorgsysteem. De Commissie moest toch op de hoogte zijn van deze afwijzende houding van vele belanghebbenden voor haar voorstel voor een pilot studie? Lidstaten gebruikten het subsidiariteitsbeginsel als rechtvaardiging om het af te wijzen en ook een grote meerderheid in het EP stond afwijzend tegenover het Commissie voorstel.

Hoofdstuk 7 vormt een analyse van het proces rondom geneesmiddelenreclame in de EU en met name de rol van de Europese Commissie hierin. Hoewel de pilot studie in 2004 werd afgewezen, is de Commissie er namelijk in geslaagd de discussie op andere niveaus voort te zetten. Het proces laat zien dat de Commissie als doelgerichte opportunist (purposeful opprtunist) haar doel op diverse manieren nastreeft zonder hiervoor perse over een mandaat te beschikken.

De geneesmiddelenindustrie oefende druk uit op DG Ondernemingen om het op de Europese agenda te plaatsen, nadat de VS het had toegestaan. De Ronde Tafel discussies onder Commissaris Bangemann van DG Ondernemingen en de Transatlantische Bedrijven Dialoog (TABD) werden hiervoor gebruikt. DG Ondernemingen zag haar kans schoon om de kwestie op de Europese agenda te plaatsen ('window of opportunity'). Een belangrijke strategie was het omschrijven van geneesmiddelenreclame als patiënteninformatie. DG Ondernemingen en de industrie probeerden de discussie te sturen door de nadruk op informatie te leggen.

In 2001 vormde de pilot studie plotseling onderdeel van de geneesmiddelenherziening. DG Ondernemingen negeerde daarmee de eerdere disussie en de evaluatie van het geneesmiddelenbeleid door onafhankelijke consultants, waaruit bleek dat er geen interesse 
was voor geneesmiddelenreclame in de EU. Het voorstel was ook niet besproken tijdens een van de consultaties. DG Ondernemingen had sowieso reeds besloten dat public health en consumentenorganisaties niet tot de belanghebbenden behoorden, terwijl de industrie en sommige patiëntenorganisaties wel toegang hadden tot DG Ondernemingen. Het DG beschouwde deze groepen gesprekspartners van DG Gezondheid- en Consumentenbescherming. Echter, dit DG was geen sterke partij en kon niet op tegen DG Ondernemingen, dat eindverantwoordelijke is in de formulering van het geneesmiddelenbeleid.

Hoewel de public health en consumentenorganisaties waren gepaseerd door de Commissie, zochten ze de publiciteit op en presenteerden hun belangen bij het EP. Zoals hierboven reeds aangegeven, waren het EP en de lidstaten tegen het voorstel van de Commissie. Het EP stelde voor de Commissie onderzoek te laten doen naar patiënteninformatie en daarover verslag uit te brengen. Wanneer daaruit zou blijken dat een maatregel op Europees niveau nodig was om de informatievoorziening te verbeteren, behoorde dit tot de mogelijkheden.

De Commissie was zich bewust van de gevoeligheid van haar voorstel en had parallel aan de voorbereidingen voor de geneesmiddelenherziening een G10 Groep opgestart, waar discussies en consultaties leidden tot een voorstel voor een publiek-privaat partnerschap. Verder moest een onderscheid gemaakt worden tussen reclame en informatie. Voortbordurend op deze twee ingangen, het partnerschap en het rapport, kwam de Commissie met een aantal Communicaties en nog een discussiegroep in de vorm van het Pharmaceutische Forum. Nogmaals vonden diverse, deels overlappende, consultaties plaats. Opmerkelijk is dat de conclusie, ongeacht de uiteenlopende reacties, steeds neerkomt op de noodzaak de industrie te betrekken bij het bieden van informatie. Recentelijk, in van februari tot april 2008, heeft de Commissie opnieuw een consultatie gehouden over een wettelijk voorstel rondom patiënteninformatie onder andere via TV, radio en tijdschriften. En daarmee verschuiven de onderhandelingen wederom van discussies en consultaties naar wetgeving.

\section{Conclusie}

Uit de empirische analyse van de drie casestudies volgt een aantal factoren die in combinatie de kans op een overeenkomst over van EU gezondheidsbeleid kunnen verklaren, gegeven de uiteenlopende preferenties, het subsidiariteitsbeginsel en de constitutionele asymmetrie.

In het laatste hoofdstuk worden deze factoren onder de loep genomen. Allereerst spelen de preferenties van de lidstaten een belangrijke rol. Dit is op zichzelf niet zo verbazingwekkend. Wanneer voorgenomen gezondheidsbeleid echter negatieve economische gevolgen heeft, blijkt dat sommige lidstaten het subsidiariteitsbeginsel 
strategisch inzetten. De uitgangssituatie van dit onderzoek, waarbij werd aangenomen dat het subsidiariteitsbeginsel een rol speelt bij gezondheidsbeleid dient daarom genuanceerd te worden. De elasticiteit van het principe leidt tot strategisch gebruik ervan. De tweede factor is de rol van de Europese Commissie, waarbij specifiek aandacht uitgaat naar het belang van het institutionele recht van initatief, het gebruik van retoriek om de discussie te sturen en haar rol als policy entrepreneur. De Commissie lijkt de meeste speelruimte te hebben (ten opzichte van de Raad en het EP) om binnen de institutionele structuur strategieën aan te wenden die een overeenkomst mogelijk moeten maken. Opmerkelijk hierbij is dat de Commissie niet zozeer streeft naar een compromis, maar haar eigen belangen centraal plaatst.

Een andere factor van belang is de invloed die het Europese Parlement kan uitoefenen. De rol van het EP hangt sterk samen met de preferenties van de lidstaten en de kans op een overeenkomst. De rol van het EP lijkt mede bepaald te worden door pragmatisme. Wanneer de kans aanzienlijk is dat wijzigingen vanuit het EP leiden tot het stuklopen van de onderhandelingen, verkiest het EP een overeenkomst zonder verdere aanpassingen, zoals bij de tabakscasus. Een dergelijke situatie doet zich eerder voor wanneer een aantal lidstaten liever geen Europese regelgeving ziet. Wanneer alle lidstaten de voorkeur geven aan Europese regels, maar de preferenties uiteenlopen over hoe daaraan invulling te geven, dan kan het EP hier gebruik van maken en haar positie versterken.

De vierde factor is de invloed van belanghebbenden via de lobby. Zowel de beschikbare financiële middelen en de toegang (access) tot de Commissie als agendavormer, als de beschikbare expertise, geloofwaardigheid en reputatie spelen hierbij een rol. Hoewel het onderzoek gezondheidsbeleid betreft, hebben bedrijven een sterkere positie. De toegang tot de Commissie en andere actoren is afhankelijk van wie verantwoordelijk is voor het beleid. Vooral binnen de Commissie is het DirectoraatGeneraal bepalend voor toegangsstrategieën van de belanghebbenden.

Tenslotte vormt de bredere beleidscontext een belangrijke factor. Hoewel dit een relatief abstracte factor is, die per proces verschillend is, laat het onderzoek zien dat met name de Commissie strategisch gebruik van deze bredere context maakt. 


\section{ACKNOWLEDGEMENTS}

This book is the result of 4 years of research on European Union health policy-making. I would like to start with thanking my two supervisors, Prof. Hans Maarse and Dr. Esther Versluis, for the time they invested for discussion and commenting on my papers. In addition, I very much appreciate my colleague Jan van der Made, who always showed his interest in my work and whose comments were very useful as well.

I would also like to say thanks to the researchers from the Max Planck Institute for the Study of Societies in Cologne, for showing me a different research paradigm, as well as for their helpful comments on papers and presentations and the insightful discussions. Especially Dr. Jürgen Feick, who always had the patience to discuss many issues with me in German, a challenging and learning experience for me. Furthermore, I perceived it as a great opportunity to write a paper together with Professor Donald Light from Princeton University.

No research is possible without access to relevant information. I am therefore very grateful to the interviewees that were willing to share their time, experiences and insights with me. In addition, I would like to thank Dr. Pieter de Coninck of the Dutch Ministry of Health, who was very helpful in providing me access to Dutch archival data.

Sandra Boessen

April 2008 


\section{Curriculum VitaE}

Sandra Boessen was born in Weert (the Netherlands) on 19 July 1979. After finishing secondary school, she studied Health Sciences at Maastricht University, the Netherlands (1997-2001). She specialised in Health Policy and Administration (MSc). In 2002, she worked as a policy advisor at the Province of Limburg. In 2002-2003, she studied in Belgium, were she did a master International Politics at the Faculty of Social and Political Sciences, Antwerp University, with cum laude result. Her thesis 'Who is afraid for coherence? A research concerning the (in)coherence of the WTO TRIPS agreement and developing countries' access to pharmaceuticals' was awarded the price for development cooperation of the Province of Antwerp. From 2004-2008 she worked as a PhD researcher and lecturer at the Department of Health Organisation, Policy and Economics of the Faculty of Health, Medicine and Life Sciences (Maastricht University). She visited the Max Planck Institute for the Study of Societies in 2007. 